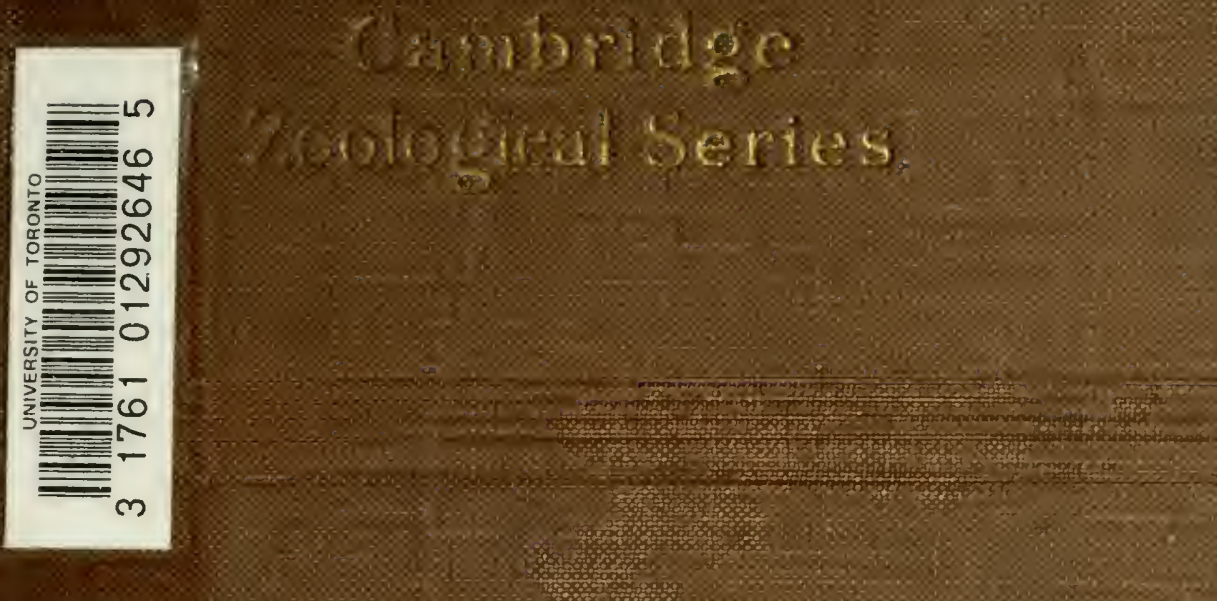

\title{
THE HOUSE-FLY
}




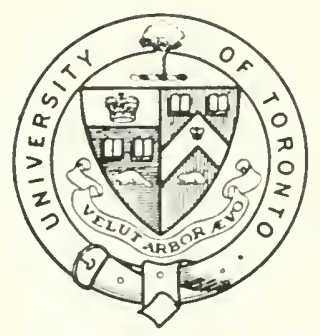

Presented to the

UNIVERSITY OF TORONTO

LIBRARY

by the

ONTARIO LEGISLATIVE

LIBRARY

1980 


CAMBRIDGE ZOOLOGICAL SERIES

THE HOUSE-FLY 


\section{CAMBRIDGE UNIVERSITY PRESS}

C. F. CLAY, MANAGER

ILOMDOn : FETTER LANE, E.C.

Eoimburgh: 100 PRINCES STREET

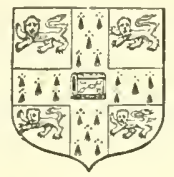

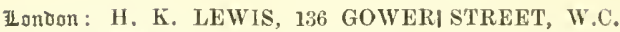

Zlondon: WILLIAM WESLEY AND SON, 28 ESSEX STREET, STRAND

feres Gork: G. P. PUTNANI'S SONS

Bomban and calcutta: MACMILLAN AND [CO., LTD.

Totonto: J. H. DENT AND SONS, LTD.

Tokgo: THE MARUZEN-KABUSHIKI-KAISHA 
Digitized by the Internet Archive in 2008 with funding from Microsoft Corporation 


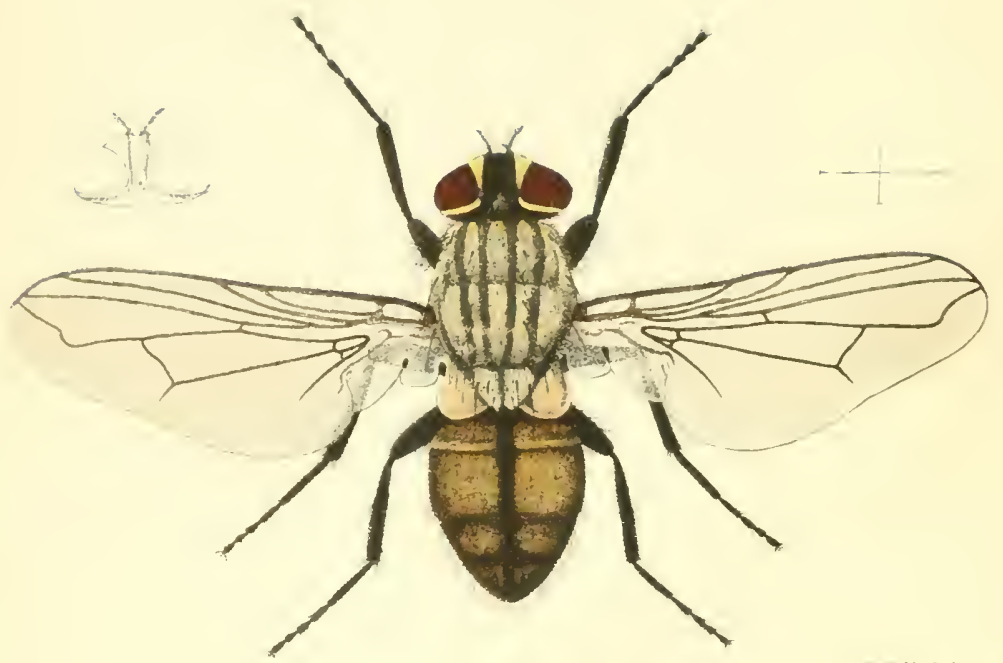

$\sin \operatorname{sic} \cos x$

Fig. 1. The House-fly, Musca domestica L. Female. Inset, head of male. 
36033

\section{THE HOUSE-FLY}

MUSCA DOMESTICA LINN.

ITS STRUCTURE, HABITS, DEVELOPMENT, RELATION TO DISEASE AND CONTROL

$$
\text { Shie }
$$

BY

\section{GORDON HEWITT \\ D.Sc., F.R.S.C.}

DOMINION ENTOMOLOGIST OF CANADA; FORMERLY LECTURER IN ECONOMIC ZOOLOG Y IN THE UNIVERSITY OF MANCHESTER

\section{Cambridge :}

at the University Press

1914 


\section{Cambrioge:}

PRINTED BY JOHX CLAY, M.A.

AT THE UNIVERSITY PRESS

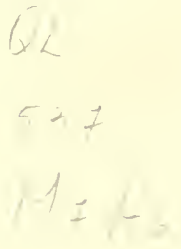


TO MY WIFE

ELIZABETH BORDEN 



\section{PREFACE}

THE world-wide interest which has been created during the last few years in the relation which the house-fly bears to the hygienic state of the individual and of the community, as a product of insanitary conditions and as a potential and not infrequent disseminator of certain eommon and preventable infectious diseases, has rendered the presentation of our knowledge of this insect, its habits and relation to disease most desirable and, indeed, necessary as a means of appreciating its significance from the entomological and medical standpoint and as a basis for further investigation.

In 1907, 1908 and 1909 respectively the three parts of my monograph on the House-fly were published in the Quarterly Journal of Microscopical Science under the title: "The Structure, Development and Bionomics of the House-fly, Musca domestica Linn." For the convenience of workers the Manchester University Press very kindly republished in volume form two hundred copies of the letterpress and plates of the monograph, which reprints Sir Ray Lankester, the Editor of the Q. J.M. S., permitted me to obtain. With a certain amount of additional matter in the form of appendices this limited edition was issued in 1910 under the title: "The House-fly, Musca domestica Linn. A Study of the Structure, Development, Bionomies and Economy." This reprint is now exhausted.

Although the present volume contains the whole of the original matter published in the Quarterly Journal of Microscopical Science, the extent of subsequent work by investigators 
in all the continents has necessitated the preparation of a completely new work. I have naturally endearoured to review whatever work relating to the house-Hy has been carried on, but it is not unlikely, in fact, with the multiplicity of scientific journals, most probable that some contributions to our knowledge may have escaped my notice and any advice in regard to such omissions woukl be most cordially appreciaterl.

The volume is not intended as a popular treatise on the subject. Such a function is filled by my small volume "HouseHies and how they Spread Disease" in the Cambridge Manuals of Science and Literature, and by Dr L. O. Howard's book "The House-fly : Disease Carrier." It is primarily intended for the use of entomologists, medical men, health officers and others similarly engaged or interested in the subject, and it is hoped that it will be of value to students.

I wish to acknowledge my indebtedness to Mr H. T. Giissow, who took the photographs illustrated in figs. 33, 72, 74, and to Mr C. T. Brues, of Harrard University, for the use of the original photograph, fig. 36. Mr F. W. L. Sladen also has kindly assisted me by taking the photographs, figs. 32, 35, 70, 97. Except where it is otherwise stated, the rest of the illustrations were drawn by me.

\section{GORDON HEWITT.}

OtTaWA, Canada, July, 1913. 


\section{CONTENTS}

\section{PART I}

THE STRLCTLRE AND HABITS OE THE HOLSE-FLY

I. IXTRODECTION

Historical, 1. Description of Musca domestica. 5. Distribution, $\because$.

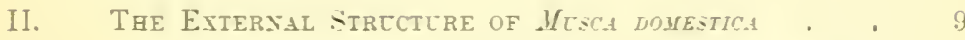

Head capsule, 9. Proboscis, 12. Thorar, 1s. Wings. 23. Legs, 26. Abdomen, 26 .

III. The Ixteryal Strectere of Mrsca domestica . . 28

Muscular s5stem, 28. Ferrous srstem, 29. Alimentary system, 34. Respiratory ststem, 41. Tascular spstem and bods carity. 4\%. Reproductive spotem, th.

IT. The Imterial Strectire of the Head atd Proboscis OF 3/TSCA DOYESTICA . . . . . . 55 Musculature of Proboscis, 5s. Oral lobes. 61.

T. The Habits axd Biosomics of the Hocse-fly . .

Local Distribution and comparatire abundauce, 6.5. Seasonal Preralence, 67. Flight or Distance trarelled by House-tlies, 67. Feeding Habits and the Influence of Food. 74 . Influence of Temperature. 83 . Influence of Light, \&3. Hibernation, \$4. Regeneration of Lost parts, \&6. Longerity, s6. 


\section{PAR'T II}

THE BREEDING HABITS; LIFE-HISTORY AND STRLCTURE OF THE LARTA

V1. ThE BREEDING Habits OF MI:SCA DOMESTICA . . .

IIistorical, 87. Materials in which $1 \%$. domestica breeds, 94. Location of Breecling Place, 95̃. Breeding season, 95. Abundance of Flies in relation to breeding Places, 96.

VII. The LrFe-History of THE House-Fly

Proportion of sexes, 98. Copmlation, 98. Oviposition, 99. Egg, 101. Larva, 102. P’upa, 105. Emergence of adult fly, 108. Summary of duration of development, 108. Factors governing development, 110. Sexual maturity, 112. Number of generations, 113.

Vili. The External Features of the Fulu-grown Larva . 115

IX. The Internal Structere of the Fuld-grown Laria.

Muscular system, 120. Nervous system, 12\%. Sensoly Organs, 132. Alimentary system, 132. Cephalo-pharyngeal sclerites, 134. Respiratory system, 140. Vascular system and body cavity, 143. Imaginal Discs, 145.

\section{PART III}

THE NATURAL ENEMIES AND PARASITES OF THE HOUSE-FL I

X. Arachnids axd Mrrtapods . . . .

Chernes nodosus, 150. Mites borne by House-flies, 154. Centipedes and Sipiders, 158.

XI. The Fuxgal Disease: Earets mesea Cohx. . . 160

Xil. Ixsect and Tertebrate Exemies . . . . . 167

Parasitic Insects, 167. Prelaceons Insects, 170. Vertebiate Enemies, 172.

XiII. Protozonl Parasites . . . . . .

Herpetomonas muscae-dompsticue, 173. Crithidia muscaedomesticue, 178. Leptomonas muscae-domesticae, 180.

Xiv. The Parasitic Neyatode: /haronem.l Mesche Carter 


\section{PART IV}

OTHER SPECIES OF FLIES FREQUENTING HOUSES CIIAPTER

XV. The Lesser House-FLY, Faxy Cancelatis L. AND the LATRINE FLY, F. SCALiRtS FAB. . . . . 186;

XVt. The Stable Fly, Stomoxy Calloitrats L. . . . 197

fVII. The Blow flues, Calliphora krithrocephalla Meit. and) C. VOMtoria L., AXD THE SHEEP MAggot OR "Greex Bottle" Flis, Licilia caesar L. . .

XVIII. The Clester Fly, Pollevta reme Fab. and Mescles STABCLASE FALL. . . . . . .

Nix. Aluied Muscid Flies and Miscellaneous Flies found IN Hocses

M. domestica sub. sp. determinatu Walker, 211. Musca enteniata Bigot, 212. Musca retustissimo Walk., 212. Root Maggot Fly, Anthomyice radicum Meigen, 213. Moth Flies, Psychoda spp., 216.

\section{PART $V$}

\section{THE RELATION OF HOUSE-FLIES TO DISEASE}

XX. The Dissemination of Pathogenic organisms by Fuies Introductory, 218. Historical, 220. Methods by which Bacteria are spread by Flies, 221. Infection from Flies bred in infected material, 224 .

XXI. The Carriag of Typhoid Fever by Flies. . . Epidemiological and circumstantial eridence, 232. Bacteriolngical evidence, 244.

XXII. The Relation of Flies to Sumber Diarrhoea of Infants

XXiti. The Dissemination of Other Diseases by Fles.

Anthrax, 266. Tuberculosis, 269. Cholera, 272. Ophthalmia, 275. Plague, 278. Small-pox, 279. Diphtheria, 279. Yaws (Framboesia), 280. Leprosy, 282. Dysentery, 281. Oriental Sore, 285. Syphilis, 287. 
xily. Miscellaneous Expermexts ox the carriage of MicroORgaNisMS bY Flies, bY bOTH YatURAL aND artiFICLAL IVFECTIOY

Natural infection, 288. Poliomyelitis, 293. Trypanosomes, 294. Surra, 294. Danysz virus, 294. Rabies, 295. Fungal spores, 295. Bacteria on Flies captured under natural conditions, 29f;. Intestinal Protozoa, 300.

XXY. The Relation of Flies to Mriasis and to the spread OF INTESTINAL WorMLS . . . . .

Myiasis, 301. Mole of Infection, 306. Miscellaneous eases of Myiasis, 307. Rinte played by Flies in the spread of Intestinal Worms, 308.

\section{PART VI}

\section{CONTROL MEASLRES}

Axti. Preventive and Remedial Measeres . . .

Prevention of Breeding, 317. Treatment and disposal of Mamure, 318. Destruction of Refuse, 324. Protection of Infants and the sick, 325. Protection of Food, 325. Destruction of Adult Flies:-Trapping, 326. Poisoning, 327.

Xxvil. Organised effort in Control Measures . . . 330

Bibliography . . . . . . . . . . 336

$\operatorname{IXDEX} . . .5 . .5 \% 3$ 


\section{LIST OF ILLUSTRATIONS}

FIGURE

1. $\mathbf{H}$ usca domestica, female

PAGE

2. Reproduction of Plate from Gleichen

Frontispiece

3. II. domesticu, vertical section of heal and proboscis . . 13

4. Structure of preudo-trachea . . . . . . . . 16

5. Pseudo-tracheal rings . . . . . . . . 16

6. M. domestica; thorax, lateral aspect. . . . . . 19

7. Wing of $\mathrm{K}$. domestica. . . . . . . . . 23

8. .. domestica, nervous system . . . . . . . 30

9. Thoracic ganglion, lateral aspect . . . . . . 32

10. Thoracic ganglion, ventral aspect . . . . . . 33

11. H. domesticu, longitudinal section of alimentary canal . . $3 \frac{1}{4}$

12. Alimentary canal, dorsal aspect. . . . . . . 35

13. Section of prorentriculus . . . . . . . . . 37

14. Posterior region of alimentary canal . . . . . 38

15. Transverse section of lingual salivary gland . . . . 40

16. Longitudinal section of rectal gland . . . . . . 40

17. M. domestica, tracheal sacs of anterior thoracic spiracle . . $4: 3$

18. Tracheal sacs of posterior thoracic spiracle . . . . 44

19. Ducts of cephalic tracheal suply . . . . . . 45

20. H. domestica, female rejroductive organs. . . . . 49

21. Female reproductive organs, accessory glands . . . . 50

22. Female abdomen and oripositor . . . . . . 51

23. M. domestica, male reproductive organs . . . . . . 53

24. Terminal abdominal segments of male . . . . . 54

25. Lateral aspect of terminal abdominal segments of male. . 55

26. Terminal segments of male and penis . . . . . . 56

27. Penis, lateral aspect . . . . . . . . . . 57

28. M. domestica, transrerse section of head capsule . . . 59

29. Transverse section of haustellum . . . . . . 61

30. Transverse section of oral lube . . . . . . 629

31. Transverse section of labial salivary glands . . . . $6: 3$ 
32. Proboscis marks of $\mathrm{H}$. domestica . . . . . . Ti

33. Proboscis marks of Museid fly . . . . . . . 7s

34. Y. domesticu regurgitating food. . . . . . . 80

35. Faecal and vomit spots of $M$. domestice . . . . . 81

36. I. domestica, mass of eggs . . . . . . . 100

37. Eggs of $\mathrm{H}$. domestica . . . . . . . . 101

38. Egrg before energence of larva . . . . . . . . 101

39. Newly-hatched larva of $M$. domestice . . . . . 102

40. I. domesticu, full-grown larra . . . . . . . 104

41. Puparium after emergence of larva . . . . . . 104

42. Nymph of .1. domestica renoved from puparium . . . 106

43. Head of nymph . . . . . . . . . 106

44. Anterior end of mature larva of $\mathbf{H}$. domestica, lateral aspect. 117

45. Ventrul aspect of pseudo-cephalon of mature larva . . . 117

46. Section of surface of oral lobe of larva . . . . . 118

47. Section of lobes of anterior spiracular process . . . . 118

4h. H. domestica, muscles of right side of larva . . to fuce 120

49. Muscles of cepbalo-pharyngeal sclerites of larva . . . 123

50. Oblique section through pharyngeal mass of litra. . . 125

51. Oblique section through pharyngeal mass of larva . . . 126

52. M. domestica, nervous system of larva . . . . . 128

53. Gaughionic complex of larva . . . . . . . . . 129

54. Visceral nervons system of larva . . . . . . 131

55. H. domesticu, alimentary system of larva . . . . . 133

56. Cephalo-pharyngeal skeleton of full-grown larva . . . 134

57. Cephalo-pharyngeal skeleton of first larval instar . . . 135

58. Longitudinal section of proventriculus of larva. . . . 137

59. H. domesticu, tracheal system of left side of larva . . . 141

60. Posterior end of second stage larva of $\boldsymbol{M}$. domesticu . . 142

61. Posterior end of full-grown larva of $M$. domestice . . . 142

62. Posterior spiracle of full-grown larva of $\mathrm{K}$. domesticu . . 142

63. W. domesticu, horizontal section of "heart" of larva . . 144

64 Inaginal dises of posterior thoracic region of larva. . . 146

65. Longitudinal section through cephalic discs of larra . . 146

66. Transverse section anterior to ganglion of larra . . . 148

67. Transverse section of ventriculus of mature larva . . . 149

68. Transverse section of salivary gland of mature larva . . 150

69. Chernes nodosus Schr. . . . . . . . 152

70. M. domestica infested with Trombidium mites. . . . 155

71. F. creniculuris infested with Ganasid mites . . . 157

72. M. domestice killed hy Empresa inuscue . . . . . 161

73. Section of abdomen of $\mathrm{H}$. domestica filled with E'mpusa. 162

74. Empuse spores devoured by flies . . . . . . 163 
FIGORE

PAGE

75. Spulangia sp., parasite of $M$. domestica . . . . . 167

76. Muscid parisite, Figites sp). . . . . . . . . 169

77. Diagram of life-cycle of Herpetomones musce-domesticue. $\quad 175$

78. Habronema muscue Carter . . . . . . . . 183

79. Lesser honse-fly, Funnia canicularis. . . . to face 186

80. Stable Fly, Stomoxys calcitrans. . . . . to fure 186

81. Leg joints of $F$. scaluris and $F$. ecenicularis . . . . 187

82. Antennae of $F$. caniculuris and $M$. domestice . . . 189

83. $H^{\top}$. cuniculuris, larva . . . . . . . . . 191

84. Anterior end of larva of $F$. cuniculuris . . . . . 192

85. Palmate dorsal appendage of larva of $F$. cuniculuris . . 192

86. Posterior spiracle of larva of $F$. cancularis . . . . 192

87. F. scaluris, larva. . . . . . . . . . 194

88. Body segment of larva of $F^{\prime}$. scclaris . . . . . 195

89. Head of Stomoxys culcitruns, lateral aspect . . . . 198

90. Posterior end of larva of $S$. culcitrans, with spiracle . . 200

91. Posterior end and spiraeles of larva of Calliphora erythocephala 201

92. Root Maggot Fly, Lnthomyia radicum Meig., female . . 214

93. A. radicum, larva . . . . . . . . 215

94. Posterior end of larva of A. radicum . . . . . 215

95. A. radicum, pupa . . . . . . . . . 215

96. Tarsal joints of M. domestica . . . . . . . . 218

97. Slope culture of micro-organisms carried by M. domestica . 247

98. Plate culture of bacteria carried by H. domestica . . . 248

99. Chart of summer diarrhoea and flies in 1904 (Manchester) . $\quad 256$

100. Chart of summer diarrhoea and flies in 1909 (Manchester) . 257

101. Mimesota Fly Trap . . . . . . . . . 326

102. Card of Instructions . . . . . . . . . . 331

103. Enkarged model of the House-fly, M. domestica . . . 333

104. Enlarged model of the larva of the Honse-fly, M. domestice . $3: 34$

Map of portion of City of Ottawa showing range of flight of marked flies 



\section{PART I}

\section{THE STRUCTURE AND HABITS OF THE HOUSE-FLY}

\section{CHAPTER I}

\section{INTRODUCTION}

Anovg the numerous and remarkable advances which have been marte in the reahn of medical science within the last two decades, nome has created so wide a public interest, nome has been fraught with consequences affecting so large and widespread a proportion of the world's inhabitants, and destined to affect the future welfine and progress of mankind to so great a degree, as the gradual discovery of the rôle which insects play in the dissemination of disease. Malaria, which has harl a far-reaching effect on the history of the world and on the immigration of the white man into new regions of the earth, and which in India alone imposes a tax of over a million human lives each year, has been shown to be conveyed by the mosquito. Plagrue, which in all ages has created terrific devastation, sweeping away millions of lives, transforming populous cities into deserted wildernesses, was found to be transmitted by the flea. The "black sickness," or Kala Azar, which has decimated districts and depopulated areas in the tropical comtries where it occurs, has been found to be due to a parasitic organism which can be transmitted by the bed-bug. Sleeping sickness, which numbers its victims by the hundred thousand, depends for its distribution upon the tse-ts fly. Lice have been shown to transmit the cansative organism o. typhus fever. The common stable-fly has been shown to be a possible disseminator of infantile paralysis 
or polionyelitis. One by one man's parasitic attendants and blood-sucking visitors have been shown to be potent vehicles of death. Of all revelations perhaps none affects so great a number of people in all comntries, both by its significance and effects, as the demonstration of the disease-carrying power of the common honse-fly. From the dark iges man has been accustomed to regard his ubiquitous companion in his wanderings over the face of the globe, not only with a marked rlegree of tolerance, but, if the rhymes of our childhood are to be believed, with some moasure of affection. The discovery, therefore, of the fact that the commonest and most widely distributed insect and the animal most closely assuclated with man was not only begotten and a fiequenter of filth, but was also a potent and common carrier of pathogenic and putrefactive organisms, excited an interest in the minds of a larger number of perple than many other discoveries of a like character in which both the insect and the disease with which it was associated were more restricted in their distribution and affected a correspondingly small number of people.

So obsessed were perople's minds with the ictea that the house-fly was of no significance in relation to man's welfare that it was not only deemed mororthy of 'serious study, but when. as a result of close study, its true character and habits were being revealed, the results of such studies were regarded with considerable smprise and scepticism. The story of the gradual revelation of the disease-carrying powers of the honse-fly is recorded in subsequent chapters. The history of the development of our knowledge of the insect itself, its structure, habits and life-history is noteworthy on account of our long contimued ignorance concerning these facts.

Naturalists of all ages have briefly referred to the habits anc. characteristies of the house-Hy. Both Réammur (1738) and De Gee. (1758-78) included short accomes of this insect in their classica memoirs, but they contributed little to our knowledge of th. structure or derelopment of the Hy.

The most comprehensive of the earlier accounts of the hou fly was written by Gleichen $(1790)^{1}$. This most interesting b.

I This is the date of the copy of this rare book which is in my possession; $1 \mathrm{k}$ may have been, however, an earlier edition in 1766 . 
of thirty-two quate pages is illustrated by four rory striking coloured plates which show the derelopment of the fly and structumal details, both external and internal, of the Hy and latrat (fig. 2). The author gives a somewhat detailed acconnt of the

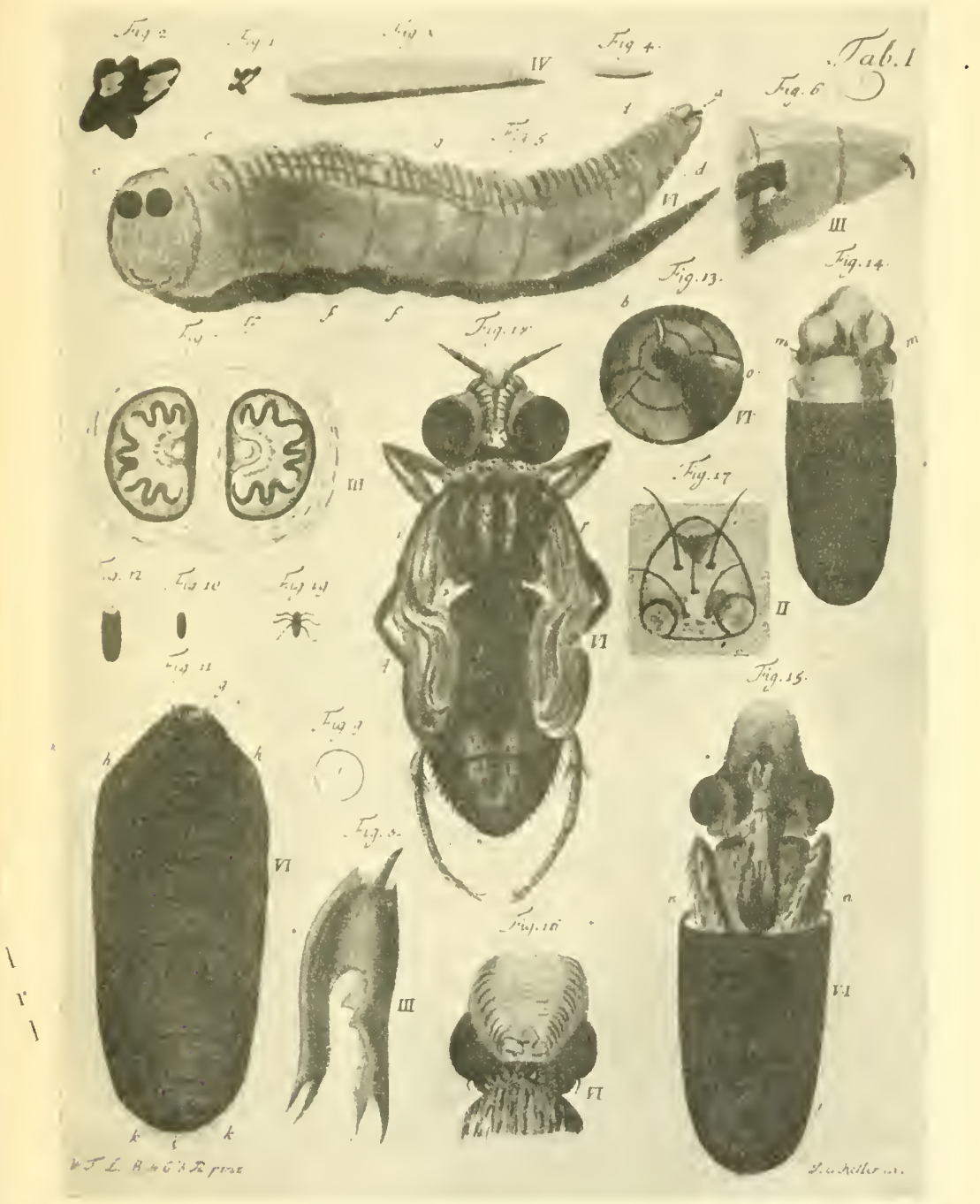

FIx. 2. Hicprorluction of Plate I of Gleichen's Geschichte der gimeinen Stubenticye, 1790. 
habits and development of the fly. It was natural that he should make some errors, such as mistaking the brown testes for the kidneys, in attempting to describe the anatomy at sin early a clate of our knowlerlge of morphology and methods of study. Notwithstanding these limitations, Gleichen's was still the most comprehensive and detailed account of the house-fly when I commenced to study the insect.

A short popular account of the house-fly was publisherl, conjointly with that of the earth-worm, by Samnelson and Hicks in 1860, in a book entitled Humble Creatures. Thongh interesting, the accomnt is very superficial and contains much that is inaccurate.

In 1874 Packard wrote a fairly complete accomnt of the developmental history of the honse-fly as observed in Massachusetts, U.S.A., and in 1880 Taschenberg gare a good popular account of the insect and its breeding habits in his Prolitische Inselitenliunde.

Howad gave a short accomnt of the life-histmy of the honsefly in a bulletin on homsehold insects, published in 1896 by the United Stater Department of Agriculture, and he gare a further accomnt in 1900 , in a valuable paper on the insect fauma of human excrement. Newstearl, in 1907, gave a preliminary report of his stmly of the development and hreeding-places of the house-fly in the city of Liverpool, and a second repont wats published in 1909 .

Space forbick the enumeration of the countless papers and accomnts of the honse-fly which have been written during the past two or three years. Some of these contain original information, the majority of them do not. Of recent publications, Howard's popular book on the house-fly (1911) should be mentionerl, not only as being a complete account of the insect and its clisease-carrying powers, but becanse it contains many original observations. "Special reference shonld be made to the valuable. series of papers published in connection with an inquiry carried ont by the Lueal Goremment Board on Hies as carriers of infection.

1 Since the above lines were written Graham-Smith bas given an excellent account of the disease-carrying powers of the non-blood-sucking flies in his flies and Disease (1913); see Bibliography. 
"This investigation has been the most complete organiserl sturly of the Hy als a vector of micro-organisms that has yet borm made, and in the subsequent pages I have made full nsse of the contents of the fire reports which have appeared up to the time of writing ${ }^{2}$.

My own studies were begun in 1905, at which time no conplete study of the anatomy or development of the house-fly harl been made, and the gradual realisation of the ecomomic status of the fly marle such a study not only desirable but necessary in view of om profomel ignoraner on the subject. A preliminary account of the life-history was published in 1906. In the following rear (1907) a detailed account of the anatomy of the Hy was published, this being the first part of a monograph an the structure, development and bionomics of Musce domesticu. The secomel part of this monograph was publisherl in 1908 and gave an account of the hreeding-habits, development and bionomics of the larva. The concluding part of the work was published in 1909, and in it were described the bionomics of thr. homse-Hy, its allies and parasites and its relation to human diseast.

In ardition to the investigations which I have contimuer since that date, other investigators have arded to on knowledge of the bionomics of the homse-fly with the result that, althongh our knowledge of the insect cannot be said to be conplete, we have decreasert onr previons unfortmate ignorance of the commonest insect to a markerd degree and have furnisherl a solid hasis for further studies along particular lines, and information necessary to a consideration of the means of control and prevention.

\section{Description OF MeSCA DOMESTICA.}

Musca domestica was first described in 1758 by Linnaeus in his Systema Vaturae: his description is as follows:

"Antemnis plumatis pilosa nigra, thorace lineis 5 olsoletis abdomine nitidulo tessellato: minor. Habitat in Europe domibus, etiam Americae. Larvae in simo equinae. Pupae parallele cubantes."

It was more fully described by Fabricius in his Genera Insectorum.

1 A Further Report, No. 6, has appeared since the above was written. 
The house-fly, together with the blow-fly and the bliwrlsucking Hies stomoxys and Glossine, belongs to the family Muscidae, which is characterised by having the terminal joint of the antenna, the arista, always combed or pluned, and by the absence of large bristles or macrochaetae on the abdomen. The Inscidae, together with the Inthomyidae and Tachiniclae, comstitute the group Muscidue calypteratae, which are characterised ly the possession of squamate, small lobes at the bases of the wings which cover the halters. In the acalyptrate momsids the sifuamate are absent or rudimentary. These two groups belong to the sub-order Cyclorrhapha, one of the two primary divisions: of the Diptera. The Cyclorrhapha have coarctate pupae, the pupal case being formed by the hardening of the lant larval skin, and the Hies escaping through a circular orifice former by the Hy pushing off the end of the pupa by means of an inflated sac-like organ-the ptilinum or frontal sac-which is afterwards withdrawn into the head, its presence being marked by a frontal crescentic opening-the limule. The other sul-order, the Orthorrhapha, have obtected pupae.

The most complete specific description of Musca domestica has been given by Schiner (186t), of which the following is a free translation:

"Frons of male occupying a fourth part of the breadth of the head. Frontal stripe of female narrow in fiont, so broad behind that it entirely fills up the wirlth of the frons. The rlursal region of the thorax clusty grey in colonr, with fomr equally broad longitudinal stripes. Scutellum grey, with black sides. 'The light regions of the abdomen yellowish, transparent, the larkest parts at least at the base of the rentral side yellow. The last segment and a dorsal line blackish brown. Seen from behind and against the light the whole abdomen shimmering yellow, and only on each sirle of the dorsal line on each segment a clull transwerse band. The lower part of the face silky rellow, shot with blackish brown. Median stripe velvety black. Antemna. brown. Palpi black. Legs blackish brown. Wings tinged with pale grey, with yellowish base. The female has a broal velvety black, often reddishly shimmering frontal stripe. which is not broacker at the anterior end than the bases of the antennace. but 
becomes so rery much broader aborr that the light dustines: of the sides is entirely obliterated. The abdomen grarlually becoming darker. The shimmering areals on the separate segments generally brownish. All the wher parts are the same as in the male."

The mature insects neasure firon 6 to $7 \mathrm{~mm}$. in length and from 13 to $15 \mathrm{~mm}$. across the wings. Frecpently dwarfed specimens may be found, normal in every respect but size. 'This is due, as my breeding experiments demonstrated, to adverse conditions dluring the larval stage; starration especially tends to produce undersized indiriduals.

\section{Distribltion OF MLSGA DOILESTOA.}

Musca domestica is undonbtedly the most widely distributed insect to be found: the animal most commonly associated with inan, whom it appears to have followed orer the entire globe. It extends from the sub-polar regions, where Linnaeus refers to its occurrence in Lapland and Fimmark as "rara avis in Lapponili, at in Finmarchia Norwegiae integras domos fere replet," to the tropics, where it occurs in enomous numbers. Referring to its abundance in a house near Para in equatorial Brazil, Austen (1904) says: "At the mid-day meal they swarmed on the table in almost inconceivable numbers," and other travellers in clifferent tropical countries have related similar experiences to me, how they swarm round each piece of food as it is carried to the mouth.

In the civilised and populated regions of the world it occurs commonly, and the British Musem (Natural History) collection and my own contain specimens from the following localities (certain of the localities have, in addition, been obtained from lists of insect famnas):

Asia. Aden: North-West Provinces (India): Calcutta : Madras; Bombay (it probably occurs orer the whole of India): Ceylon; Central China; Hong-Kong; Shanghai: Straits Settlements; Japan.

Africa. Port Said: Suez, Egypt; Somaliland; Nyassaland; Uganda; British E. Africa: Rhodesia; Transraal: Natal: Cape 
Colony: Marlagascar: Northern and Southern Nigeria: St Helena; Mirrleinar.

America. Distributed orer North America; Brazil: Monte Viden (Uruguay): Argentine: Vialparaiso: West Indies.

Anstralia and New Zealand.

Europe and the isles of the Mediterranean: it is especially common in Cyprus.

Not only is the world-wide distribution of the house-fly of interest but its local abundance, which will be considererl in a subsequent chapter ( $)$. 65), is noteworthy: 


\section{CHAP'TER II}

THE EXTERNAL STRUCTLRE (IF MUSCA DOMLETICA

Previoes to this sturly the only complete aceonnt which has been published on Muscid anatomy was Lowne's comprehensive monograph (1895) on the blow-tly, Calliphora erythrocephala, which is an elaboration of his smaller and earlier memoir (1870). Not only are many of Lowne's conclusions untenialble, but the value of his work as a compatrative study would increaste with confirmation.

\section{The Head Capsule.}

The head capsule of $M$. domestica presents great modifications when compared with the typical insect head. Considerable? difficulty is experienced in explaining its structure in the morphological terms employed in the simpler orders of insects. Lowne did not lessen the difficulty in describing the head of the blow-fly by the invention of new terms of little morphological value. The head of the fly is strongly convex in frout, the posterior surfice being almost flat and slightly conical. For the sake of clearness the composition of the head capsule will be described from behind forwards. The occipital foramen occupies a median slightly ventral position on the posterior surface. It is surrounded by the occipital ring, the inner margin of which projects into the cavity of the head. From the sides of the inner margin of the occipital ring two short chitinous bars bend inwards and approach each other internally, forming a support-the jugum-for the tentorial membrane. On each side of the occipital ring below the jugum : small cavity occurs, into which a corresponding process fiom the prothorax fits, forming a support for the head. 
The occipital ring is surommded by the four plates, which make up the sides and back of the head capsule. On the ventral side, between the occipital ring and the aperture from which the proboscis depends, a median basal plate, the gulomental plate, represents the fused gula and basial portions of the greatly modified second maxillare. The occipital segment is bounded laterally by the genate (Lowne's paracephala) and dorsally by the epicranium. These parts have been divided by systematists into so many regions that a somewhat detailed description will be necessary to make their boundaries clear.

The genae bear the large compound eyes which wecupy almost the whole of the antero-lateral region of the head. On the posterior flattened surface of the head the genae are flat, and extend from the gulo-mental plate to the epicranial plate, the sutures of the latter being vertical. On the dorsal side each sends a narrow strip between the inner margin of the eye and the epicranimm; this strip surrounds the eye and meets the ventral portion of the gena; it is of a silver to golden metallic hustre. On the ventral side below the eye each gena bounds the proboscis aperture laterally: a number of stout bristles arise from this margin and also from its antero-lateral region, which is often spoken of as the "jowl." In the anterior region, where the genae are in contact with the clypens, there are two prominent ridges bearing strong setae; these are usually known as the "facialia." Berlese (1909) regards the facialia as reprosenting a portion of the fourth (mandibular) segment. They are certainly distinct from the genae, as may be seen in the head of the newly formed nymph (fig. 43). Strictly speaking they are both facialia and peristomatia, facio-peristomial sclerites in fict.

The epicranimm (epicephaton of Lowne) on the posterin surface of the hear is Hat. On the anterion surface it is convex, and divider into a number of regions. On the top of the head between the cyes it is called the vertex. This contains the three ocelli situated on a slightly raised ocellar triangle, which is surrounded by a second triangle, the vertical triangle. The median region in front of and below the rertex is the froms. In the middle of this there is a black frontal stripe. The froms appears 
to be composed of two sclerites for which 'Townsend, in it letter. to me, suggests the term "frontalia." In the male the eves an. only namowly separated by the frontal stripe. In the female the frontal stripe widens ont on the vertex. This chancter proviles a ready means of distinguishing the male from the female, as the result of it is that in the male the eyes are close tugether on the dorsal side, being separatexl by alout one-fifth of the wilth of the hearl, whereas in the female the space between the eyes is abont one-third the wilth of the head. 'The edges of the genae bordering on the frons bealr anch a row of stout setre-the fronter-orbital bristles.

The antennate are situaterl below the lower elge of the firms. Each antemin consists of three joints and the arista. The two proximal joints are short and compose the "seape" and arise firm a strip representing the antennal segment, situited between the frons and the prefrons. The third joint, the flagellum, is longer, and hangs vertically in front of the clypens. It is covered with sensory setae, and contains two pits of sensory finction (olfactory, I believe). From the npper side the plumose arista arises. This probably represents the terminal three joints of the antemna. The lower edge of the frons represents the anterior margin of the epicranim. It is of interest here to note that, whereas the arista of $M$. domestica is plumose, that is, it bears fine bristles on the upper and lower sides, the arista of the stable-fly, Stomoxys calcitrans, bears bristles on the upper side only, and the arista of the lesser house-Hy, Fannia canicularis, is apparently devoid of bristles, in reality it is minutely pilose.

The rest of the facial region is composed of the clypous or, as it is usually called, the face, a convenient term, but one which hides its true morphology. The face is depressed, and is covered by the flagella of the antemae. Between the upper and lateral edges of the face and the lower edge of the epicranium a crescentic opening, the lumule, marks the invagination of the ptilinum. The epistominm is a narrow strip below the face bounding the anterior edge of the proboscis aperture. 


\section{The Skeletoy of the Proboscis.}

An account of the probuseis of $M$. domestica was published by Macloskie in 1880 . The proboscis of the blow-fly, which is rery similar in many respects to that of the honse-fly, has been described by Anthony (1874), Kratedin (1880) and Lowne (t.c.). The results of these authors differ in many letails. My study of the proboscis of $M$. domestica confirms Kraepelin's results, ant as Lowne's is the only eomplete account of the muscis hearl, a full description of the anatomy, both internal and external, of the head of $\boldsymbol{M}$. domestica will be given. Recently (iraham-Sinith (1912) has makle a very careful study of the anatomy and function of the oral suckers of the blow-fly, Calliphora erythrocephala. His observations are confirmatory of $m y$ own study of the oral lobes of $M$. domestica which I made in 1906 , but which was not described in great detail in the first part of my monograph (1907).

Lowne regards the greater part of the proboscis as being developed from the first maxillae and not from the labium or fused second pair of maxillae. The latter is the usually accepted view, and one which I smpport on morphological grounds. On account of the very exceptional nature of his conclusion, he refuterl the commonly accepted terms of the various parts of the proboscis and invented new ones, an nnfortunate habit to which he was addicted. For the sake of descriptive clearness it will be necessary to refrain from constant reference to Lowne's terms or any discussion as to their merits.

The proboscis consists of two chief parts: a proximal membranous conical portion, the rostrum, and a rlistal portion which bears the oral lobes and which has been termed the haustellum. The term haustellum has also been used by some authors to designate the distal portion of the proboscis minus the oral lobes.

The Rostrum (fig. 3). This proximal membranous portion of the proboscis is attached to the edges of the proboscis aperture, that is to the epistomium, genae and the gulo-mental plate. It has the shape of a truncated cone and bears on the anterior side a pair of palps which bear sensury setae of two sizes. 


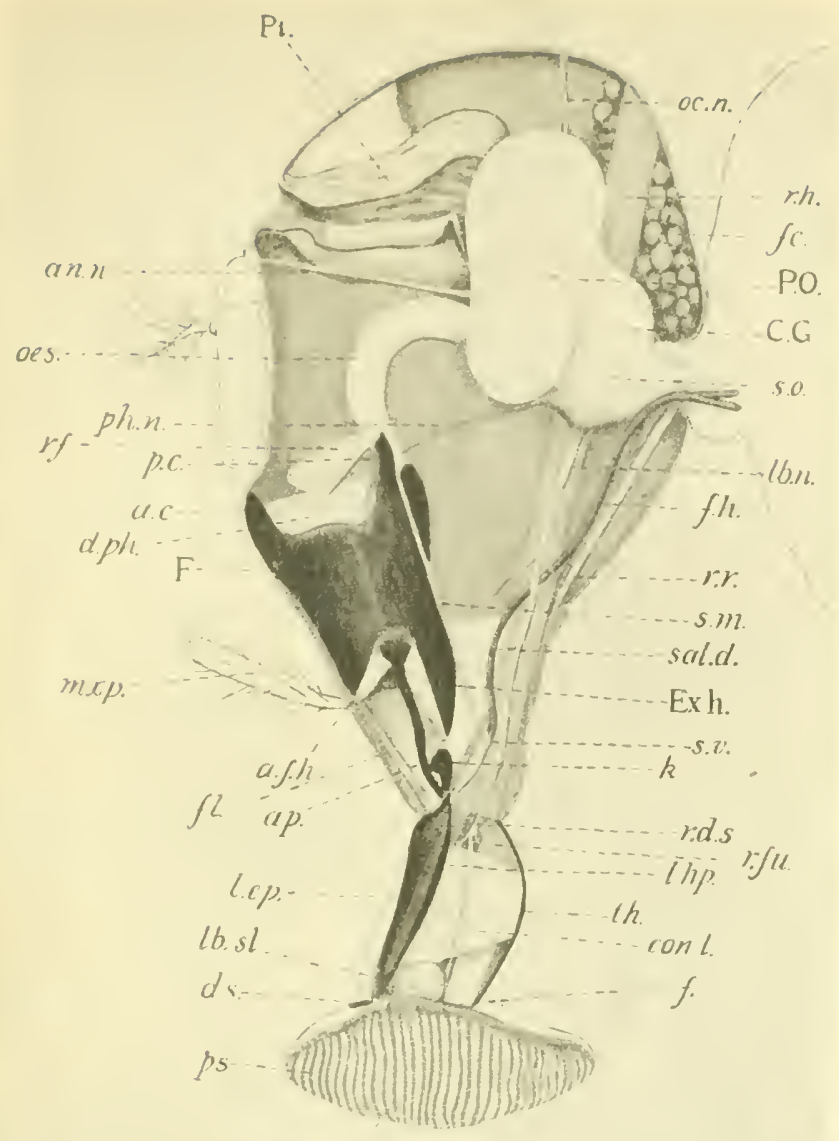

gp.

F1g. 3. Interior of the head of $u$. domestica. In this figure the left side of the heal capsule and of the proboscis have been removed and the compound ert of the same side, leaving the optic ganglion (periopticon). All the tracheal structures have been omitted.

11.c. Anterior cornu of fulcrum. a.f.h. Accessory flexor muscles of haustellum. ap. Apodeme of labrum. an.n. Antennal nerve. C.G. Cephalic ganglion. con.l. Dilator muscles of labium-hypopharynx. d.ph. Dilator muscles of pharynx. d.s. Discal sclerite. Ex.h. Extensor muscle of haustellum. $F$. Fulcrum. $f$. Furca. f.c. Fat celis. $f . h$. Flexor muscle of haustellum. f.l. Flexor muscle of labrum-epipharynx. I.p. Gustatory papillae of oral lobes. $k$. Hyoid sclerite of phargnx. lb.n. Labial nerve. $l b . \mathrm{k} l$. Labial salivary gland. l.hp. Labium-hypopharynx. l.ep. Labrum-epipharynx. mxp. Maxillary palp. oes. Oesophagus. oc.n. Ocellar nerve. ph.n. Pharyngeal nerve. p.c. posterior cornu of fulcrum. P.O. Periopticon. ps. Pseudotrachea. Pt. Ptilinum. r.d.s. Retractor muscles of discal sclerites. $r . f$. Petractor muscle of fulcrum. $r . f u$. Retractor muscle of furca. r.h. Retractor muscle of haustellum. $r . r$. Retractor muscle of rostrum. s.». Suboesophageal ganglion. sul.d. Common duct of the lingual salivary glands. $s . x$. Valve of common salivary duct. s.m. Huscle controlling valve of salivary duct. th. Theca. 
The Huustellum. This forms the ristal portion of the proboseis and is attached to the rostrum. Its distal portion, which comprises the oral lobes, will be described separately. The posterior side of the proximal portion is formed by a strongly convex heart-shaped sclerite, the theca (figs. 3 and 29), which morphologically represents a portion of the labium. The lower angle of the theca is incised by a semicircular sinus. By means of this the thea rests on a trirarliate continuous sclerite, the furca, which consists of a median, slightly convex rol (fig. 3, f.), from the anterior end of which two arms diverge and form the chief sketetal structures of the oral lobes. The lower end of the theca rides on the structure, the bottom of the sinus resting on the median rod, and the two pointer lateral terminations of the theca rest on the arms. In this manner these processes, in a state of repuse, keep the arms of the furca closely approximated. The result of this arrangement will be seen later in studying the musculature of the proboscis.

The sides of the haustellum are membranons. On its anterior face, in a grove formed by the overlapping membranous sides, lie the labmun-epipharynx and labiun-hypopharynx. The labrum(pipharynx (fig. 3, l.ep.) is attached at its proximal end to the membranons rostrum, but is incapable of a labral-like movement on accomt of its close connection with the labimm-hypopharynx. Two slightly-curved, hammer-shaped aporlemes (fig. 3, ap.) are attached to the proximal end of the labrum-epipharynx. They assist in folding the probuscis during retraction, as will be shown later: The labmu-epipharynx is shaped like a blunt arrow-head: the external surface is somewhat flattened. It is composed of two pairs of selerites, an outer pair enclosing an inner pair, which form the pharyngeal channel. The erlges of the inner tube are comnected by a groove with the hypopharyngeal portion of the labiun-hypopharynx, as shown. The labium-hypopharynx (fig. 3, l.lip.) represents the finsion of the hypopharynx with the greatly nurlified and fused second maxillae or labium. It consists of a sclerite, curved in section, having the chitinous hypopharyngeal tube (fig. $29, h_{p}$.) fuserl to it along the upper half of its length. The alges of the hypopharyngeal tube engage with those of the inmer pair of sclerites of the labrum-epipharyx, as mentioned 
before. Distally, the hypopharyngeal tube beeones free from the labium, as shown in fig. 29, and rnds in a point where the lingmal salivary duct opens.

Down each side of the labimm-hypopharyngeal sclerite a rod-like thickening rums. Distally, these thickened margins (paraphyses of Lowne) articulate with the discal sclerites. 'The discal sclerites (fig. 3, ds.) are united at the posterior and to form, when the oral lobes are expanded, a $U$-shaped structure, with the limbs constricted in the middle where the ends of the thickened margins of the labinn-hypopharynx articulate. They are smok in deeply between the two mal lobes at the base of thr mal pit with the fiere encts of the $U$ anterior, these being spatulate and curved anteriorly.

The Orul Lobes. Normally the two oral lobes or labella are comnected by a kelicate attachment along the inner anterior edges to form an wal sucking organ, but under pressure this delicate connection is serered and the oral dise presents a heart-shaped insteal of the normal appearance. On the upper or onter aboral surfices the oral lobes bear sensory setae, the larger marginal setac being different in structure from the rest, as will be described later in the account of the internal structure of the oral lobes (p. 61). On the lower and, when the proboscis is withrluwn, the imes oral surface a large number of chammels, called the psendotracheae (fig. 3, ps.), from their fancied resemblance to th. anmular tracheae, rum from the edges of the oral lobes to the internal margins. These channels are alnost circular or oral in section, being incomplete on one side and thereby communicating with the surface of the oral lobe. The chamnels are kept open by means of small incomplete chitinnus rings which give the psendo-tracheae their anmular appearance. Each of these inconplete chitinous rings is bifurcated at one end but single at the wther end (fig. 4). The rings are so arranged that the bifid andis alternate with the single ends. The psendo-tracheal chammel communicates with the external surface of the oral lobes through the opening through the bifid extrentitics of each ring, as is shown in the accompanying figure (fig. 5). From the outer. edge of the oral lobe the psendo-tracheate gradually increase in size as they approach the inner margin of the lobe. The number 
of psendo-tracheae traversing each oral lobe is thirty-six, and they are grouped in three sets. One anterior set if twelve psencto-tracheac run into a single large pseudo-tracheal channel running along the anterior inner margin of the oral lobe, and " posterior set of twenty or twenty-one all run into is common

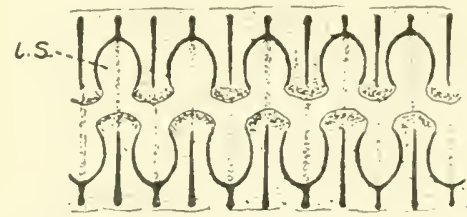

Fig. 4. Oral aspect of a pseudo-tracheat showing interbifid spaces (i...) between bifid ends of the pseudo. tracheal rings.

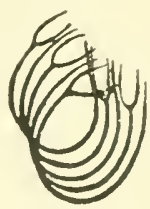

Fic. 5. Chitinous psemlo-tracheal rings.

channel rumning along the posterior inner margin of the lobe: between these two sets a median set of three or four pseurlotracheate run direct ints the oral aperture.

Grahan-Sinith (l.c.) has marle comparative measurencents of the psendo-tracheae of several species of non-biting flics and of the interbifid spaces, as he terms the area enclosed between the bifid extremities of the chitinoms rings of the psemtotracheale. The aremge measmements of the various parts are as follows:

\section{Pseudo-trachene Interbifid spunss}

Diameter Diameter Diameter near Diameter near at at distal the proximal the distal ends proximal end ends of the of the pseudoenil psendo- tracheare trachere

\begin{tabular}{|c|c|c|c|c|}
\hline Culliphora erythocepleala & 02 & $\cdot 01$ & .006 & .00411111. \\
\hline Sarcophagu carneria & 02 & .01 & $\bullet 05$ & $\cdot 004$ \\
\hline Lucilia cuesur & $\cdot 02$ & .01 & $\cdot 006$ & $\cdot 004$ \\
\hline Fannia canicularis & $\cdot 016$ & $00 s$ & .006 & $\cdot 904$ \\
\hline ophyou antherat & 016 & .008 & .006 & 0.4 \\
\hline Musere domestica & .016 & $\cdot(1) \cos$ & .0014 & .0033 \\
\hline
\end{tabular}

The companatively small size of the interbific spaces of the homse-tly should be noted, ats this has some bearing on the feeding habits of the fly. 
The Oral Aperture lies at the base of the small oral pit, which is a space kept open betweren the onal lobes by means of the discal sclerites. The median psendo-trachear do not extend as far as the discal sclerites, but on entering the oral pit the chitinous rings cease and are replacerl by nanow $\Lambda$-shaped sclerites for a short distance, while the sirles of the oral pit are bordered by a row of teeth, which have been termed the prestomial teeth and which lic at the sides of the openings of the psendo-tracheal chamuels. Between the psendo-tracheac the membranous surface of each oral lobe is thrown, probably in the relaxed state only, into longitudinal sinuous ridges; there appear to be two such ridges between adjacent pseudo-trachear. Projecting from the bottom of the furrows are several papillare, generally four or five to each interpseudo-tracheal area, of a gustatory nature, the gustatory papillae (fig. 3, gp.).

In certain text-books and treatises in which the proboscis of the honse-fly is describerl a misconception of the character and consequent function of the pseurlo-tracheae is frequently repeaterl. The psendo-trachear are described as horny "rasp-like" ridges which, by a "rasping" action, remove small particles, of sugar, for" example, which the Hy can swallow. A careful sturly of the nature of the psendo-tracheate and the method of feeding of the house-fly would convince anyone who attempted to verify the above idea of the mistaken interpretation and description.

'The Fulcrum. This chitinous portion of the pharynx (fig. 3, F.) hes on the lower part of the head and in the rostrum. Kraepelin describes it as being shaped like a Spanish stirup iron. Its structure will be best nnderstond by referring to the figures. It consists of an outer portion, which is $U$-shaped in section; the basal portion, which is posterior and forms the How of the pharynx (which Lowne, unfortunately, terms the hypopharynx), is vertical when the proboscis is extended. This basal portion is evenly rounded at both ends, and at the sides of the upper end there is a pair of processes-the posterior cornua (fig. 3, p.c.) which serve for the attachment of muscles. The sides of the fulcrum are somewhat triangular in shape; their upper anterior portions are produced to form the anterior cormua (u.c.): here the sides bend inwarls at right angles, and neet beliw the epistomium, upon which the

H. II.-F. 
fincrum is hinged. The fulcrum is therefore quadrilateral in section at the upper proximal end, and trilateral at the lower distal (nud. The basal portion (fig. 28, b.p.) forms the floor of the pharynx : the roof of the pharynx is formed by another chitinous piece $(r \cdot p$.) with a median thickenerl raphe. This roof lies parallel with the basal piece, and is fused with the sides of the fulcrum. On the nembranous wall of the pharynx, between the labium-hypopharynx and the fulcrum, a small chitinous sclerite (fig. 3, $k$.) is derelopect, which Lowne terms the hyoid sclerite. It is $U$-shaped in section, and serves to keep the lumen of the pharynx in this region listended.

\section{The Thorax (fig. 6).}

As in all Diptera the possession of a single pair of wings has resulted in the great development of the mesothorax at the expense of the other thoracic segments, consequently the thorax is chiefly made up of the sclerites composing the mesothorax. The prothorax and mietathorax compose very small portions on the anterior and posterior faces respectively. Seen from above the thorax is oriform with the blunt end anterior and slightly flattened. Three transverse sntures on the dorsal side mark the limits of the prescutmin, scutum and scutellum of the mesothoracic segment; the mesothoracic scutellum forms the pointed posterior end, and slightly werhangs the anterior end of the abdomen.

The Prothorax. The prothoracic segment has been reduced to such an extent that it is hopeless to attempt to homologise all the separate sclerites with those of a typical thoracic segment. To obtain a complete riew of the prothorax it is necessary to examine it from the anterior end after the removal of the head. The following sclerites can then be recognised. The prosternum is a median ventral plate quadrilateral in shape, having the anterior end rounded and broader than the posterior end. It does not ocenpy the whole of the prosternal area, but is bounded by the prosternal nombrane. Internally, a ridge runs to the posterior end of the prosternum and bifurcates, each ridge ruming to the posterior corners, to which two strong processes (the hypotremata of Lowne) are attached. In firont of the prosternum there is a small saddle-shaped sclerite which, on account of 1 ts position, may be called the interclaricle 
(the sella of Lowne). 'T'wo lobes at its anterior end are covered with small processes, probably sensory in function. A pair of snall sclerites is situated in front of these lobes: these sclerites with the interclavicle no doubt belong to the prosternme. "The interclavicle is rentral to the cephalothoracic foramen. The jugnales

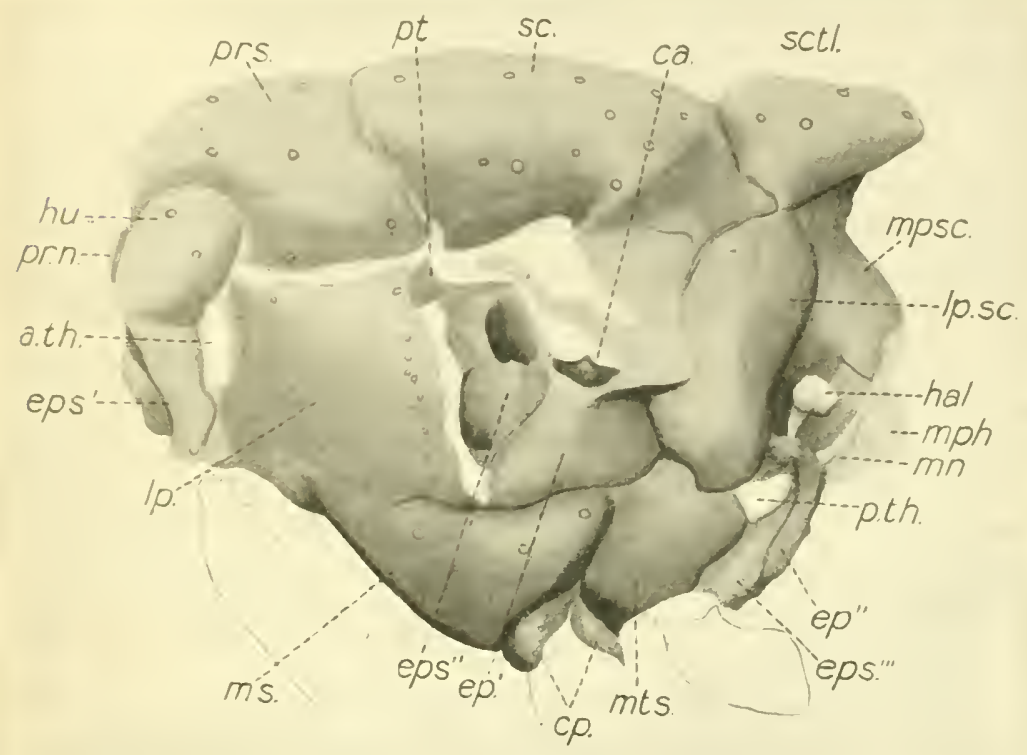

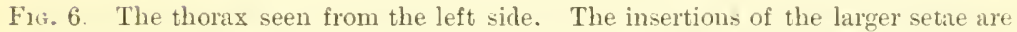
shown; for the sake of clearness the sclerites of the wing-base are omitted.

a.th. Anterior thoracic spiracle. ca. Costa. cp. Intermediate coxal plates. $e p^{\prime} ., e p^{\prime \prime}$. Epimera of the meso- and meta-thoracic segments. eps'., eps'., eps'". Epistema of the pro-, meso-, and meta-thoracic segments. hal. Haltere. hu. Humerus. lp. Lateral plate of mesosternum. lp.sc. Lateral plate of postscutellum, mph. Mesophragma, mpsc. Median plate of postscutellum. mn. Metanotum. ms. Mesosternum. mts. Metasternum. p.th. Posterior thoracic spiracle. pt. Parapteron. pr.n. Pronotum. prs. I'rescutum of mesothoras. se. Seutum. setl. Seutellum.

(3me jurgulatives of Kunckel d'Herculais) are two prominent pecket-shaped sclerites lying one on each side of the cephalothoracic foramen, and having their convex faces external. Lying immediately below each of the jugulares is a small rorl-like sclerite-the clavicle. The dorsal region of the prothorax, the pronotum (fig. 6, pr.n.), is formed by two sclerites mnited in the 
median line, their dorsal siles being eurved. From the rentral side of the pronotum a pair of chitinous apodemes project inter the thoracic cavity. The lateral regions of the pronotum are in contact with the humeri (hu.) and the prothoracic epistema. The hruneri are a pair of strongly convexed sclerites situated in the antero-lateral regiom of the thorax. They are bounded above by the presentmon of the mesothorax, internally and below by the epistema of the prothomx, and externally by the lateral plate of the mesostermum and the anterior thoracic spincle. Its inner concave surface serves for the attachment of the muscle of the prothoracic coxa. The episterna $\left(e p s^{\prime}\right.$.) (epitrochlear sclerites of Lowne) are comparatively large sclerites forming the lateral regions of the prothorax. They overhang the attachments of the prothoracic limbs. The internal skeleton of the prothorax consists of the two stout hollow apodemes-the hypotremata mentioned previonsly. They arise from the postero-lateral edges of the prostemmm, and run obliquely across the rentral edge of the anterior thoracic spiracle where the hypotseme divides, the posterior branch rums up the posterior margin of the spiracle, between the lateral plate of the mesnstemum and the peritreme (the chitinoms ring surrounding the spiracle), the anterior branch finses with the prothoracic episternum.

The Mesothorax. The notrum of the mesothorax occupies the whole of the dorsal side of the thorax. It is composed of the four sclerites to which Audouin (1824) gave the names of prescutmm, scutum, scutellum, and postscutellum. The prescutum (prs.) forms the anterior part of the florsal region of the thorax. Its anterion. portion bends down ahnost vertically to mite with the promotum. The anterior exge of the prescutum is inflecterl after the pronotal suture, and is reduced in the merlian line to a small bifurcating process. The prescutum is bomnled laterally by the humeris and a membranous strip-the dorso-plenal membane. The scutum (sc.) is the largest of the mesometal plates. It vecupies the whole of the median torsal region of the thorax. Anteriorly it is bommled by the prescutum, laterally by the alar membrame and the lateral plate of the postsentellum, and posteriorly by the senterlun. From the lateral reging of the scutum a process projects forwards amd downwards and articulates with the posterior portion of the 
wing-base (the metapterygium). The seutellum(setl.) is a triangular pocket-shaped sclerite which werhangs the postsentellum and the base of the abdomen. 'The posterione surfice of the thorax is ehietty composed of the lange postscutelhum. This is male up of three pieces, a median escutcheon-shaped plite (mpsc.) strongly enomex to the exterior, and two convex linteral plates (lp.se.). 'The lateral plates and bounded below by the metastermm and spiraceses and anteriorly by the plemal region of the mesothorax.

The mesosternum is a sclerite of comsiderable size and forms the kexl of the thorax. It consists of a motian ventral portion (ms.) which is profuced laterally to form two large lateral plates (lp.). The medion portion is lomuded in fiont by the posternum and the formmina of the anterior coxae, and behind by the median coxal foramina. A short distance behind the anterior end a depression in the mirl-ventral line extending to the posterion erlge indicates a median inflection forming the entothorax. The lateral regions of the posterior margins of the mesosternm are inflecter on each side to form the entoplema. The lateral plates of the mesosternum form the whole of the anterior portion of the plemal region: each is bounderl in front by the humerus, spiracle, and prothoracic episternum, ahove by the dorso-plemal membrane, and behind by the mesoplemal membrane. The ventral side of the lateral plate is continuous in front with the median plate of the mesosternum, and behind is mited by means of a suture. The remaining portion of the mesoplemal region is made up of the episternmm, epineron, and two small sclerites connected with the wing-base-the parapteron and eosta. The epistemum (eps".) is situated behind the mesoplemal membrane and below the alar membrane: below and behind it is bounded by the epineron. It. surface is marked by two convexities, the ampullat, the mpper of the two eorresponding to Lowne's great ampulla of the blow-fly. The dorsal side of the episternum is intimately connecterl with the sclerites' of the anterior portion of the wing-base.

'The epimeron $\left(e p^{\prime}.\right)$ is a triangular sclerite, and is lommler

1 In this account the individual sclerites which compose the wing-hase will not be described. Lowne has described them at great length for the blow-fly, and although the wing-base sclerites of $M$. domestict differ slightly in shape from those of Calliphra, Lowne's description of the relations hold good for the former insect. 
below by the mesosternum and metasternum, behind by the lateral plate of the postscutellum, and abore by the episternum and alar membrane. The parapteron ( $p t$.) is a sclerite situated at the top of the mesoplenral menbrane. The greater portion of it is internal, unly a small triangular portion can be seen externally. Internally this is continued as a cruriform sclerite to which are attached important muscles controlling the wings. The costa (ca.) is a small sclerite situated on the dorsal margin of the epimeron. The internal skeleton of the mesothorax consists of the entothorax, intopleura, mesophragma, and the inflected codges of the epistema and epinera. The entothorax is composed of a median vertical plate subtriangular in shape, on the top of which a median plate produced laterally into wing-like processes rests. On this structure the thoracic nerve-centre lies. The entoplema and the inflecterl edges of the episterna and epimera all serve for the attachment of wing muscles. The mesophragma ( $m p h$.) is a convex sclerite fused with the lower edge of the postscutellum. Its posterior edge is incised in the middle and forms the dorsal arch of the thoracoabolominal foramen.

The Metathorax. The largest sclerite of the greatly reduced metathorax is the metastermum (mts.). It is a wing-shaped sclerite with the narrow transverse portion sitnated between the coxal formina of the median posterior pairs of legs: the expanded lateral portions form the wall of the thorax above the insertion of these legs. The edges of the narrow transverse strip are inflecterl, and unite the lateral portions of the metasternum. A troughshaped longitudinal fold-the metafurea-rests on the narrow transverse portion of the metasternum. The posterior end of the metafurca bends domnards and articulates with the postcrior coxae on each sicle. The metafurca serves for the attachment of the thoraco-abdominal muscles. The pleural region of the metathorax is a narrow triangular space sitnated behind the lateral portion of the metasternm and the posterior coxac. It is composed of a nurrow triangnlar episternmm and epimeron. The former $\left(e p s^{\prime \prime \prime}\right.$.) is bonnded in front by the metastemum, the posterior thoracic spiracle and the base of the haltere, betow by the posterior coxal foramen, and behind by the epimeron. The epimeron $\left(e p^{\prime \prime}.\right)$ is also bounded below by the coxal foramen and 
behind by the narrow dorsal arch of the metathorax and the first. abdominal segment, its apex comes in contact with the base of thr. haltere. The dorsal region of the metathorax has practically. disappeared, all that can be recognised as metanotum is a namow chitinous strip $(\mathrm{mn}$.) on wach sicle between the apex of the metaplemal area and the dorsial edge of the first abdominal area.

\section{The Wrings.}

The wings are situated at the sides of the scutum on the alar membrane, to which are attached the sclerites of the wing-bas? They are covered with rery fine hairs.

In describing the neuration of the wings the nomenclature proposed by Constuck and Neerham (1898) for the wings of the whole group of insects will be employerd.

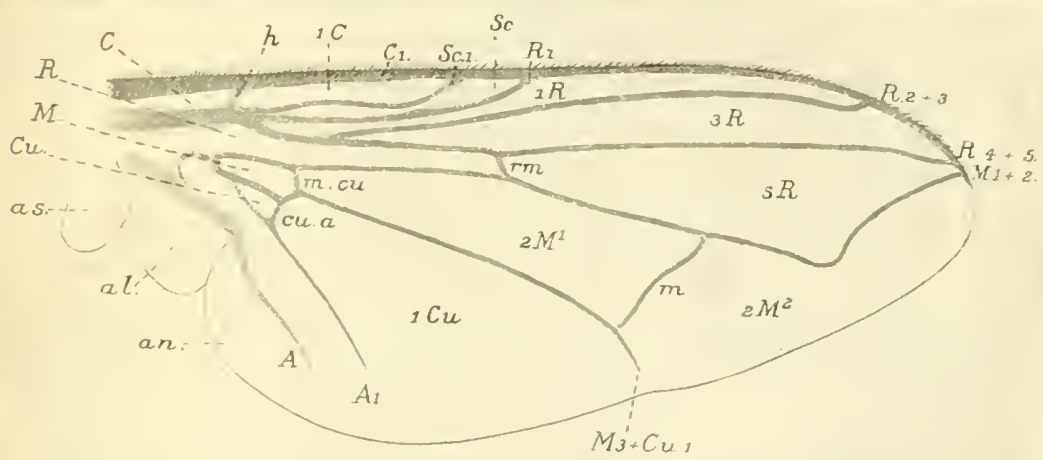

FIg. 7. Wing. The nervures are drawn slightly thicker than they naturally are.

an. Anal lobe. al. Alula. as. Antisquama. A. Anal cell. A.1. Anal nervure. Cu. Cubital cell. $1 \mathrm{Cu}$. First cubital cell. cu.a. Cubito-anal transverse nervure. C.1. Costa. C. Costal cell. 1 C. First costal cell. M. Medial cell. m.cll. Medio-cubital transverse nervure. $m$. Medial transverse nerrure. $2 H^{1}, 2 H^{2}$. First and second second medial cells. $U_{0} 1+2$. Medial longitudinal nervure. $M .3+C u$. Medio-cubital longitudinal nervure. R.Radial cell. $R .1$ to R. 4+5. Radial longitudinal nervures. Sc. Subcostal cell. Sc.1. Subcosta.

The nervures of the wing are ochraceous. The anterior edge of the wing (fig. 7) is formed by a stout nervure, the costa (C. I) which is very setose. The second longitudinal nervure, the subcostal (SC. 1) joins the costal about half way along its length. I small transverse nervure, the humeral $(h$.) divides the costal cell 
into costal (C.) and first costal (1 C.) colls. The next main morure-the radial-divides into a number of branches (in the typical insect five); some of these have coalescerl in the fly. A nervure joining the costal just past the middle is the first radial (R. 1) cutting off the sub-costal cell. The next nervure, which joins the costal on the apical curve, represents the fused socond and third malial nervures $(R \cdot 2+3)$. This cuts off the first radial coll (1 R.). The last nervure, which joins the costal almost at the apex of the wing, lepresents the fused fourth and fifth radial nervures $(R .4+5)$ and so cuts off the third radial cell (3R.). 'The fourth main longitudinal nervure is the median, which, in the typical insect, divides into three, but in the Hy the nervures have mulergone coalescence, as will be shown. The first and second median nerrures have coalesced $(M .1+2)$, and do not run direct to the margin of the wing, but bend forwarls and alnost meet R. $4+5$ on the costa. Abont half way across the wing a transrerse nervore, the radio-medial $(r m$.) mites $R .4+5$ and $M .1+2$, and cuts off the fifth radial cell $(5 R$.) from the radial $(R$.). 'The next longitudinal nervure represents the coalesced third medial and cubital nervures $(M .3+C u .1)$. It runs to the posterior margin of the wing alwut half way along the length of the latter. The nervures $M .1+2$ and $H_{.} 3+C u .1$ are mitod by two neprures: a proximal nervure, the medio-cubital (m.cu.) representing part of the original longitudinal vein $M .3$, cuts off the suall triangular merlial cell $(M)$; the distal transverse nervure $m$. cuts off the first second merlial cell ( $2 M^{1}$.) from the second second medial cell ( $2 M^{2}$.). The last longitudinal nervure, the anal (A. I), is undivided and does not reach the margin of the wing, thus incompletely soparating the first cubital $(1 C u$. ) and anal $(A$.$) cells. A small nervure, the$ cubito-anal (cu.a.) representing a portion of the original cubital vein (Cu. 2) slightly more proximal than the medio-cubital cuts off the small triangular enbital cell $(C u$. $)$ trom the first cubital cell (1 Cu.). Rumming parallel with, and posterion to, the anal longitudinal nervure, there is apparently another nervure. This, howerer, is not a true nervure but is merely a chitinised furrow giving adclitional strength to the posterior angle of the wing. 'The posterior exlge of the base of the wing is divided into a number of lobes. These are the anal lobe, and, as Sharp (1895) proposed, 
the alulia, antisquimat, and squami. The squama is thieker than the rest, and is attached posteriorly to the wingrent between the mesoscutum and the lateral plates of the postscutellum. It covers the haltere, as in all "calyptrate" Muscirlate?

The Halteres. The halteres or balancers (fig. 6 hal.) are gomerally considered to represent the rudinentary metathoracic wings. They are cowered by the squamas, amel are sitnated on the sides of the thoma above the pesterion spiracles. Each consists ol a conical base on which are a mmober of chordonotal sense-organs and on this base is momuted a slender lexl, at the end of which a small spherical knob is attached. The wall of the distal half of this sphere is thinner than the proximal half, and in preserved specimens is generally indenterl. Experiments show that the halteres are organs of a static function. They are not balancing organs in the rense that they are equivalent to the balancing pole of a ropewalker. They also have probably an auditory function. They are innersater by the largest pair of nerves in the thorax.

1 The nomenelature of Comstock and Needham has not yet been adopted by dipterologists in general, but on accomt of its morphological value, it may in course of time replace the present confused system. It may, therefore, be useful if the nomenclature employed in the foregoing description be compared with those most usually employed.

Lovgrudinal Nenveres. $C_{1}$. Costal. $S c_{1}$. Mediastinal; auxiliary. $R_{1}$. Subcostal; 1st longitudinal. R. 2+3. Radial; 2nd longitudinal. R.4+5. Cubital; 3rl longitudinal; ulnar (Lowne). $M .1+2$. Median; 4 th longitudinal; diseal (Verrall). $M .3+\mathrm{Cu}_{1}$. Submedian; 5 th longitudinal; postical (Verrall). $A_{1}$. Anal; 6th longitudinal. Pseudonervure; axillary; 7th longitudinal.

Transverse Nerveres. $h$. Humeral; 1st transverse; basal cross-vein (Verrall). rm. Discal; 2nd transverse; middle cross-rein (Verrall); medial transverse; anterior transverse (Austen). m.cu. Anterior basal transverse (Austen); lower cross-vein (Termall); postical transverse (Lowne). m. Posterior transverse (Austen); postical cross-vein (Verrall); discal transverse (Lowne). cu.u. Posterior basal transverse (Austen); anal cross-vein (Verrall); anal transverse (Lowne).

Cells. C. Costal. $1 \mathrm{C}$. Second costal. Se. Third costal (Lowne correctly calls this "sub-costal"). $1 R$. Marginal. $3 R$. Sub-marginal; cubital (Lowne). $5 R$. First posterior cell (Austen); sub-apical (Lowne and Verrall). $2 M^{2}$. Second posterior cell (Austen); apical. $1 \mathrm{Cu}$. Third posterior cell (Austen and Verrall); patagial (Lowne). $2 M^{1}$. Discal (this term is used also in Lepidoptera, Trichoptera, and Psocoptera, and in each family refers to a different cell!). R. Anterior basal cell (Austen); upper of tirst basal or radical (Verrall); prepatagial (Lowne). M. P'osterior basal cell (Austen); middle or second basal or radical (Terrall); anterior basal (Lowne). Cu. Anal cell (Austen); lower or third basal or radical (Verrall); posterior basal (Lowne). 


\section{The Legs.}

The three pains of legs are composed of the typical number of segments. Each comsists of coxa, trochanter, femmr, tibia, and tarsus. The coxae are the only segments that show any comsiderable difference in the three pairs of legs. 'The anterior' coxac are comparatively liarge and boat-shaped, the intermediate coxac are smaller and their separate sclerites more marked ; the coxal plates of the intermediate coxite are shown in fig. 6 (cp.). The coxal joints of the posterion pair of legs are almost similar to those of the intermediate pair. The anterior femora are shorter and stouter in the middle than those of the intermediate posterior pairs of legs. The anterior tibiace are also shorter than those of the snceeding legs. The anterior tibiae are covered on their inner sides with closely-set, orange coloured setae which serve as a comb by means of which the fly removes particles of dirt adhering to the setae which clothe its body; the first tarsal joints of the posterior legs are also similarly provided. The tarsi consist of five joints, the terminal joints bearing the "feet." These organs, about which so much has been written, consist of a pair of curved lateral claws or "ungues" which subtend a pair of membranous pyriform padsthe pulvilli. The pulvilli are covered on their ventral sicles with innumerable, closely-set, secreting hairs by means of which the fly is able to walk in any position on highly polished surfaces. A small sclerite lies between the bases of the pulvilli. The tarsal joints and the other segments of the legs are covered with a large number of setae.

\section{THE ABDOMEN.}

The abdomen is oviform with the broad end basal. The total number of segments which compose the abdomen is eight in the male and nime in the female. The visible portion consists of apparently four segments in the male and female, in reality there are five, as the first segment has become very much rednced, and has finsed with the second abrominal segnent forming the anterion. fiace of the base of the abdomen (see fig. 22). The segments succeeding the fifth are greatly reduced in the male, and in the 
female they form the tubular oripositor which, in repuse, is tolescoped within the abdomen. The secoml, thiml, fourth and fifth abdominal segments are well developerl and each mainly comsists of a large tergal plate, which extends laterally to the ventral side. 'The stermal plates are much redneed, and form a series of narrow plates lying on the ventral membrane along the mitl-ventral line. The spiracles are situated on the lateral margins of the tergal plates. The sclerites of the abdomen which are exposerl are strongly setuse, especially the fourth and fifth dorsal plates, but they do not bear macrochactae.

The terminal abdomimal segments of the male and temale anc described in detail in the account of their reproduction systems (see pp. 50, 5:3). 


\section{CHAP'TER III}

THE INTERNAL STRUC'TURE OF IIUSCA DOMESTICA

'The Muscular Sistem.

THE muscular system of the fly is similar to that of Volucella, described by Kunckel d'Herculais (1881), and of the blow-fly, described by Lowne and Hammond, and consequently it will be but briefly described. The muscles may be divided into the following groups: 1. Cephalic; 2. Thoracic; 3. Segmental: 4. Those controlling the thoracic appendages: and 5. Special muscles.

1. The cephalic muscles will be comsidered in the detailed description of the head (see p. 58).

2. The thoracic muscles are enormously developed and almost fill the thoracic eavity. They are arranged in two series. The clorsales (figs. 17,18 ) are six pairs of muscle-bands on each side of the median line, attached posteriorly to the postscutellum and mesophragma, and anteriorly to the prescutum and anterior region of the sentum. The stemorlorsales (st.do.) are vertical and external to the dorsales and are arranged in three bundles on each sirle. The first two pairs have their upper ends attached to the prescutum and scutum, and their lower ends inserted on the mesnsternum; the third pair is attached dorsally to the scutum and ventrally to the lateral plate of the postscutellum above the spiracle. As Hammond has shown in the blow-fly (1881), all these muscles are mesothoracic. The dorsales by contraction lowsen the alar membrane and so depress the wing, the sternodorsales have the opposite effect. 
3. The segmental muscles. These muscles, which ano so prominent in the larval, have almost disappeared in the imagon. They are represented by the cervical muscles, certain small thoracic muscles, the thoraco-abdominal muscles, and the segmentally-aranged abdomimal muscles, together with the muscles controlling the ovipositor and male gonapophyses.

4. 'The muscles controlling the thracic appendarges, the wings, legs and halteres. There is an elaborate series of musches controlling the roots of the wing, but in order to avoid too much detail they will not be described here. 'The flexor muscles of the anterior coxae have their origin on the inner surfaces of the huneri, a fact supporting the prothoracie nature of these sclerites; the flexors of the midclle parr of legs have their origin on the sides of the posterior region of the prescutum. The intemal muscles of the leg are similar to those of the blow-fly and Volucella.

5. Special muscles. These are the muscles controlling the spiracular valves, the penis, and other small muscles.

\section{The Nervous Śstem.}

The central nerrous system (fig. 8) consists of: (1) the brain or supraosophageal ganglia, which are closely mnited with the suboesophageal ganglia, the whole forming a compact mass which I propose to call the cephalic ganglion (fig. 8, C.G.), perforater by a small foramen for the passage of the narrow oesophagus, and (2) the thoracic compound ganglion, which is composed of the fused thoracic ganglia with the abdominal ganglia. The two componnd nerve centres are united by a single median ventral cord running from the suboesophageal ganglia to the anterior end of the thoracic nerve-centre.

The cephalic ganglion consists of the supraoesophageal ganglia and the suboesophageal ganglia so closely united that the commissural character of the circumoesophageal comnectives is completely lost. Externally on the dorsal side of the brain three longitudinal fissures can be seen, a median fissure and two lateral fissures marking the origin of the optic lobes. 


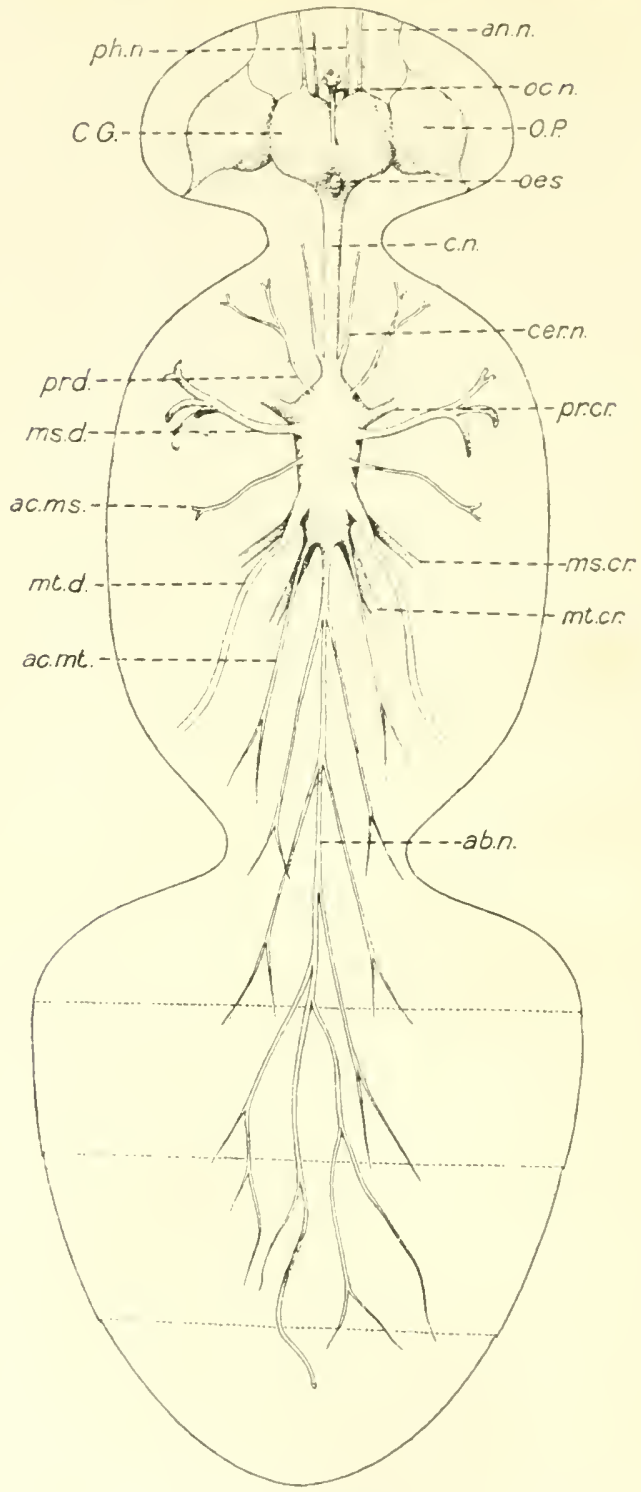

FIti. 8. Nervous system. The very fine nerve which runs along the dorsal side of the oesophagus to the proventricular ganglion (Pv.(I., fig. 20) has been purposely omitted.

ah.H. Abrlominal nerve. ac.ms. Aecessory mesothoracic dorsal nerve. ac.mt. Accessory metathoracic dorsal nerve. cer.n. Cervieal nerves. c.n. Cephalothorneic nerve cord. 1).P. Optie peduncle. mr.er., ms.cr., mt.cr. Pro-, meso-, and metathoracic crumal nerves. pr.d., ms.d., mt.d. Pro-, meso-, and meta-thoracic dorsal nerves. 
The Suprooesophageal gangliu. 'The characters of the ganglia composing the brain are hidden by the sheath of cortical cells. which fill up the spaces between the ganglia; the characters of these can be ascertained by a study of the serial sections. The median mass, the procerebrmm, is formed by the fusion of the procerebral lobes. These are mited before and behind, and enclose a central ganglionic mass - the central borly. Behind the cerebrum two pairs of fungiform boties arise. On the anterior face of the procerebrum the antennal of olfactory lobes which represent the deutucerebrum are situated laterally. Each sends a nerve (figs. 3, 8, an.n.) to the antenna. Above these and on the dorsal side is a pair of lobes, the firontal lobes which are contignoms with each other in the median line; these belong morphologically to the tritocerebrum. Posterior to these in the median dorsal line of the cerebrum a single median nerve, the ceellar nerve (figs. 3, 8, oc.n.), arises; this rums vertically to the coelli. I pair of lobes, which correspond to Lowne's thalami of the blow-thy, are situated external to and between the frontal and antennal lobes. The peduncles of the optic lobes have thein origins from the sides of the procerebrum. Each optic peduncle (fig. 8, O.P.) contains three ganglionic masses which Hickson (1885) has termed from the brain peripherally the opticon, epiopticon and periopticon (fig. 3, P.U.) respectively.

The subvesophageal ganglia (fig. 3, s.o.). The conmissures miting the supraoesophageal ganglia to the oesophageal mass cannot be recognised as such, owing to the extreme state of cephalisation of the cephalic ganglia. They are represented by the regions of the oesophageal foramen, and from the anterior side of each of them arises a pharyngeal nerve (fig. 3, ph.n.). From the ventral side of the suboesophageal ganglia a pair of nerves, the labial nerves (fig. $3, l b . n$.), arise and run down the proboscis, innervating the muscles of that organ; on reaching the oral lobes they bifurcate and branch freely, supplying the numerous sense organs in those structures. The cortical cells (Leydig's Punltsubstanz), which fill up the spaces between the ganglia and form an investing sheath round the whole ganglionic mass, are of two kinds. The smaller cells are rounded, their nuclei are large in proportion to the protoplasm, and their proto- 
plasmic fibres anastomose with each other. Among these smaller cortical cells, and also occasionally in the ganglionic substance, large ganglionic cells occur, their protoplasm taking the stain very readily. Unipolar, bipolar, and tripolar ganglion cells are fiond.

The Eyes. Each eye contains about 4000 facets. They are similar in all respects to the eyes of the blow-fly, which have been fully described by Hickson (loc. cit.), whose results my study contirms: consequently a description of their structure will not be given. It should be noted that, in spite of the fact that Hickson corrected many mistaken views held by Lowne in his memoir (1884), these are repeated in his later momograph of the blow-tly.

The cephalo-thoracic nerve cord (fig. 8, c.n.) unites the cephalic and thoracic ganglia. Near its junction with the thoracic ganglion a pair of cervical nerves (cer:n.) arise, immervating the muscles of the neck.

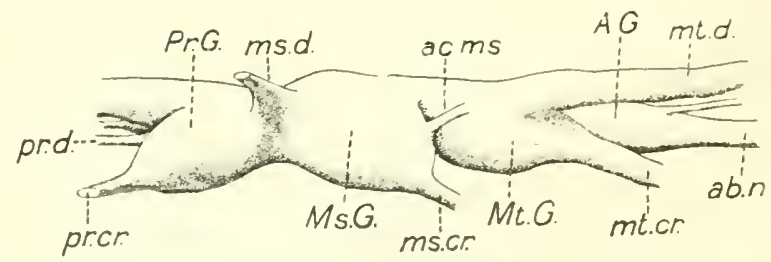

FIti, 9. Thoracic compound ganglia. Left aspect.

Lettering as in figs. 8 and 10 .

The Thoracic ganglion (figs. $8,9,10$ ) is prriform, with the broad end anterior, and rests on the antothoracic skeleton of the mesothorax. As in the cephalic ganglion, the component ganglia are ensheathed in a cortical layer, which is of the same nature as that of the cephalic gangliom. The nerves of the three pairs of legs (pr.cr., ms.cr.., mt.cr.) arise from three large ganglia, which are the prothoracic (Pr.G.), mesothoracic (Ms.G) and metathoracic (IIt.G.) ganglia. These are united by a median longituclinal band of nerve tissue, which runs florsal to them, and behind the metathoracic ganglia swells out into a ganglionic mass (A.G.) which represents the abotoninal ganglia. In this morlian forsal band there is a median forsal fissure stretching posteriorly 
from above the middle of the mesothoracic ganglia. 'The dorsal regions of the mesothoracic and metathoracic ganglia show ganglionic swellings. From the antero-dorsal sides of the prothonacio ganglia a pair of prothoracic dorsal nerves ( $p r \cdot d$.) arises and supplies the muscles of that region, including those of the anterior thoracic spiracle. The nerves supplying the mesothoracic legs (ms.cr.) arise from the postero-ventral sides of the mesothoracic ganglia. Between the mesothoracic ganglia there is a median gamglionic

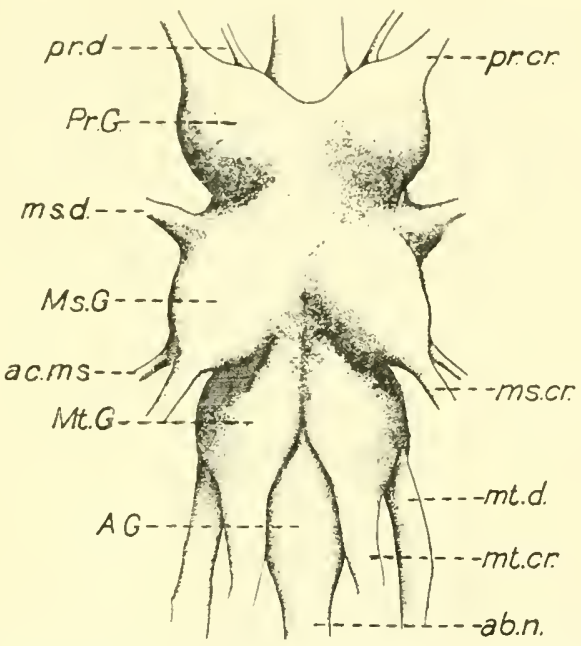

FIG. 10. Thoracic compound ganglion after the removal of the cortex. Seen from the ventral side. This and fig. 9 were drawn from models reconstructed from sections.

Pr.G., Ms.G., Mt.G. Pro-, meso-, and meta-thoracic ganglia. A.G. Abdominal ganglion. Other lettering as in fig. 8 .

mass, situated slightly dorsal, from the middle region of which the nerve fibres of the large pair of dorsal mesothoracic nerves (ms.d.) arises: Lowne, in the blow-fly, calls these prothoracic. The roots of these nerves are broad dorso-ventrally. These nerres imnervate the sterno-dorsales muscles of the middle region. In this median mesothoracic nerve centre, posterior to the origin of the dorsal mesothoracic nerves, the fibres of a pair of nerves, the accessory dorsal mesothoracic nerves (ac.ms.), have their origin; externally these appear to arise dorsal to the roots of the mesothoracic crural nerves. The dorsal metathoracic nerves 
(mt.d.), which innervate the halteres and are the largest pair of thoracic nerves, have their origin from the median dorsal band in front of the metathoracic ganglia, so that they appear to be almost menothoracic in origin. The metathorax crumal nerves (mt.cr.) arise from the posterior ventral sides of the metathoracic ganglia. Posterior to these a pair of slender nerves, the accessory dorsal metathoracic nerves, have their origin, and innervate the muscles at the posterior end of the thorax.

The dorsal band becomes much thinner posterior to the abdominal ganglion, and runs into the abrlomen as a median abdominal nerve $(a b . n$.). In the thorax two pairs of abdominal nerves arise. In the abdomen the abdominal nerves arise alternately and irregularly from the median abdominal nerve. The median abdominal nerve finally terminates in the genitalia.

\section{The Alinentary Sistem (figs. 11 and 12).}

The alimentary canal of the house-fly is shorter than that of the blow-Hy, and also than that of Glossina described by Hinchin (1905), and slightly longer than the alimentary tract

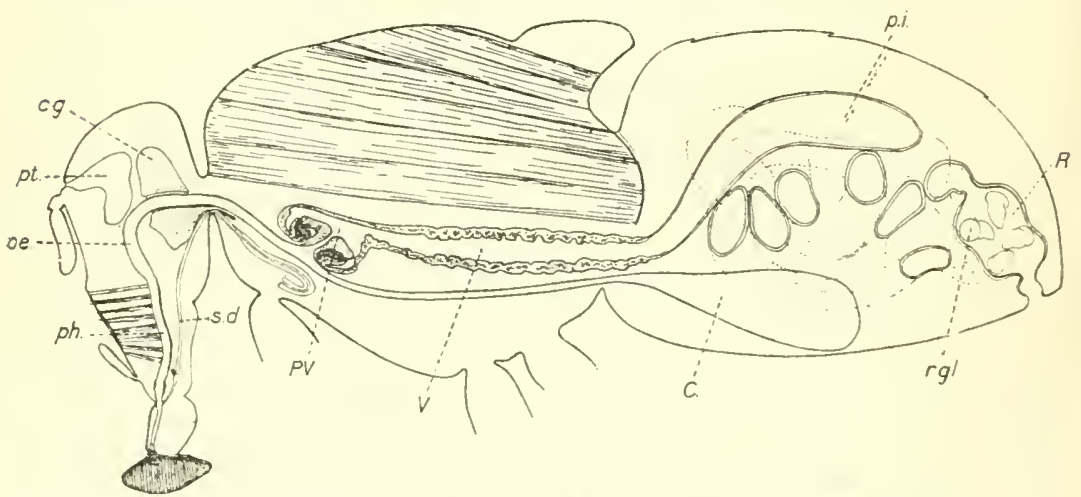

Fig. 11. Longitudinal section of the Alimentary Canal of $1 I$. domestica.

$p h$. Pharyngeal suction pump. oe. Oesophagus. pt. Ptilinum. e.g. Supra-oesophageal ganglion. s.d. Lingual salivary duct. $P J$. Proventriculus. $I$. Ventriculus. C. Crop, p.i. Proximal intestine. I. Rectum. r.gl. Rectal gland.

of Stomoxys describer by Tulloch (1906). It serres as a goorl example of the Muscid digestive canal. It is of a suctorial character, and consists of pharynx, oesophagus, crol, proventri- 


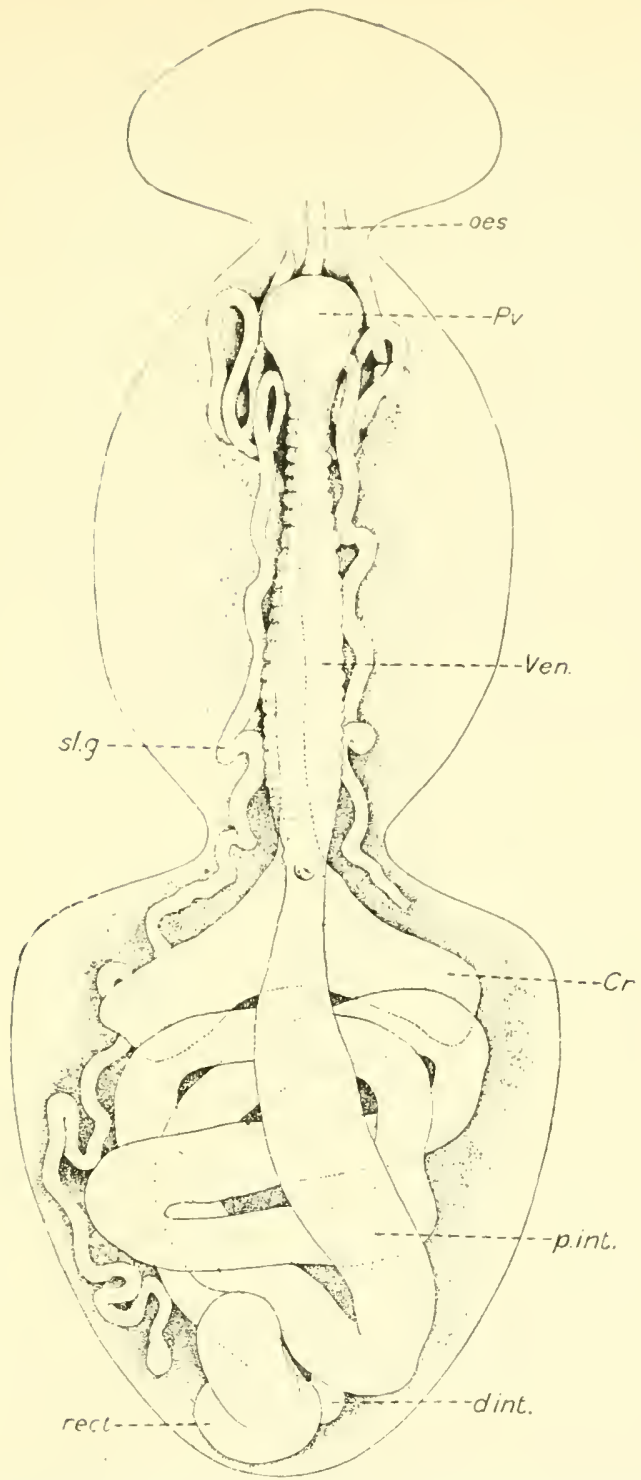

FIG. 12. The alimentary canal as it is seen on dissection from the dorsal side. The malphigian tubes have been omitted, and also the distal portion of the lingual salivary gland $(s l . g$.) of the right side. The duct of the crop $(C r$.$) is$ shown by the dotted line beneath the proventriculus $(P v)$ and ventriculus ( Ten.). p.int. Proximal intestine. d.int. Distal intestine. rect, Rectum. 
culus, ventriculus or chyle stomach, proximal and distal intestine and rectum.

The Pharynx has already been described, and will be further referred to in the detailed description of the head (1pp. 56 et seq.). At the proximal end of the fulcrum, where the oesophagus arises, there is usually a small mass of cells, which Kraepelin has described as glandular, but which I believe to be simply fiat-cells.

The Oesophagus (oes.) commences at the proxinal end of the pharynx, and describes a curve before passing through the oesophageal foramen in the cephalic ganglion, where it narrows slightly. It then passes through the cervical region into the thorax in the anterior region of which it opens into the proventriculus $(P v$. $)$ continuous with, and in the same line as the vesophagus, the duct learling to the crop (fig. 13, d.cr.) passes along the thorax dorsal to the thoracic nerve-centre, and entering the abdomen it leads into the crop, which lies on the ventral side of the abdomen. The oesophagus has a muscular wall, enclosing a layer of flat epithelial cells, and is lined by a cuticular intima, which is thrown into several folds at the anterior end.

The Crop (Cr.) is a large bilobed sac, capable of considerable distension, and when filled with the liquid food, it loses its bilobed shape and occupies a large portion of the antero-ventral region of the abdomen. Its walls exhibit museular (unstriped) fibres; the Hat epithelial cells have a very thin cuticle. The function of the crop will be more fully described later when an account of the method of feeding is given. Graham-Smith has shown (1910) that the capacity of the crop of $M$. domestica varies between 003 and 002 c.c.

The Proventriculus $(P v$. $)$ is circular and flattened dorsoventrally. Its structure will be understend by reference to fig. 13. In the midclle of the ventral side it opens into the oesophagus, and on the dorsal side the outer wall is continned as the wall of the ventriculus ( $V e n$.). The interior is alnost filled up by a thick circular plug $\left(P^{P}\left(p_{1}\right)\right.$.), the eclls of which have a fibrillar structure, and is pierced through the centre by the oesophagus. The neck of the plug is sumunded by a ling of elongate cells, external to which the wall of the proventriculus 
begins, and, enclosing the plug at the sides and above, it merges into the wall of the rentriculus. I do not agree with Lowne, who regards the proventriculus as "a gizzard and nothing mor,", but its structure suggests a pumping function and also that of a valve. This interpretation of a combined pump and valve operated at will by the fly is supporterl by the fly's mothod of feeding and regurgitating its foorl, which habits will be described later. (p. 80).

On the dorsal side of the oesophangus, at its junction with the proventriculus, a small ganglion, the proventricular ganglion

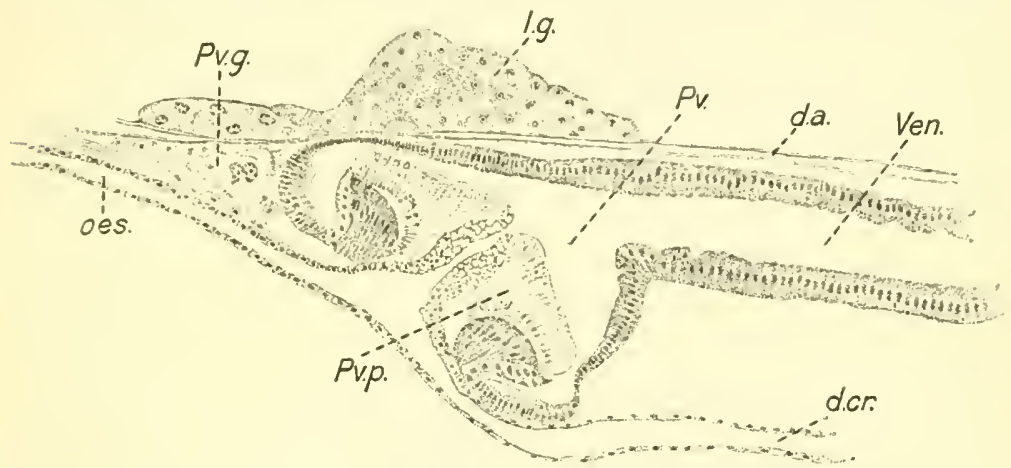

FIG. 13. Section through the proventriculus and the anterior end of the ventriculus, to show the strueture of the proventricular plug $(P c . p$.$) and the ducts of$ the oesophagus (oes.) and crop (l.cr.). (Camera lucida drawing.)

(Pv.g.) lies, communicating by means of a fine nerve with the cephalic ganglion: this forms a part of the sympathetic or visceral nerrous system.

The Ventriculus, w. Chyle Stomach (Ven.), represents the anterior region of the mesenteron, the posterior region of the latter. being formed by the proximal intestine. It is narrow in front, and widest in the posterior region of the thorax, where it again narrows in passing through the thoraco-abdominal foramen into the abdomen to become the proximal intestine. Except in the anterior and posterior regions, where colmmnar cells compose the digestive epithelium, the walls of the ventriculus are thrown into a number of transverse folds, which are again subdivided longitudinally, the result being the formation of small crypts or sacculi, which are lined by large cells. These sacculi correspond to the digestive coeca of other insects. 
The Proximal Intestine (p.int.) is the longest region of the gint. It varies in length considerably. In the normal-sized condition its conurse is as follows: Beginning at the anterior end of the abdomen, it runs dorsally beneath the heart to the posterior region, where it curves downwards, turns to the left, and runs forward for a short distance, curving to the right, where it doubles back transversely to the left. Here it doubles sharply back to the right, from whence it rums forwarl for a little way

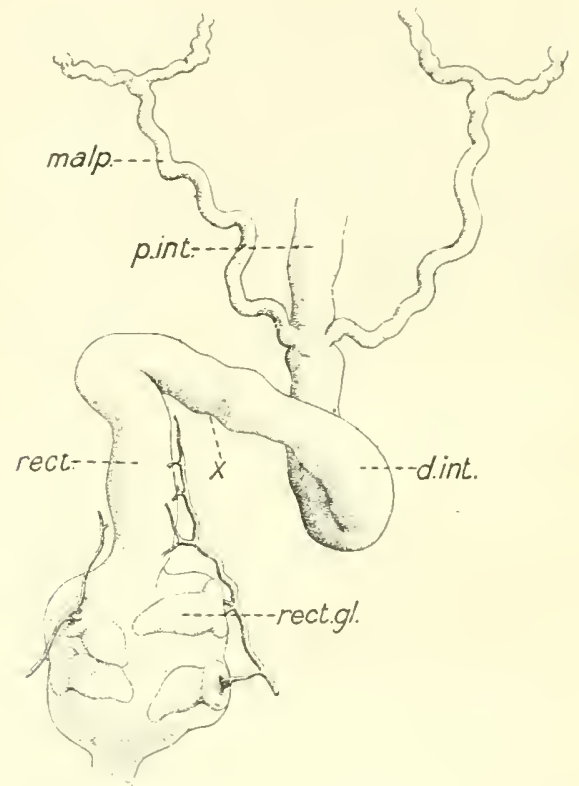

FIG. 14. The posterior region of the alimentary canal, to show the rectal glands (rect.gl.) with their tracheal supply, the origin of the malpighian tubes (malp.), and the position of the rectal valie indicated at $X$.

and crosses orer to the left. Curving, it runs posteriorly to become the distal intestine. Its walls are lined by an epithelimm of large columnar cells.

The Distal Intestine (d. int.). The junction of this with the proximal intestine is markerl by the entrance of the ducts of the nalpighian tubes. It rums posteriorly and curves dorsally and forwards to become the rectum, from which it is separated by a cone-shaped valve, the rectal valve, the position of which 
is marked externally (fig. 14, X.). The epithelinm of the distal intestine consists of small cubical cells, which project into the lumen, and are covered by a fairly thick chitinous intima. The epithelial wall of the distal intestine is thrown into usually about six longitudinal folds.

The Rectum (rect.) is composert of three parts, an interiol' region, an intermediate region which is swollen to form the rectal cavity, and a shorter region posterior to this which opens externally by the anus. The anterior region is lined by cubical cells, whose internal faces project into the lumen of the rectum, and give the chitinus intima a tuberculated structure. 'The intermediate region, which forms the rectal cavity, contains the four rectal glands (rect.gl.). Its walls are lined by a thin cuticle supported by a flattened epithelium. The posterior portion of the rectum is short, and has thick muscular walls. The cuticular intima is continuons with that of the external skeleton.

\section{Salivary glands.}

There are two sets of salivary glands-a pair of labial and a pair of lingual glands. The structure of the labial glands will be described in the accomnt of the anatony of the head (p. 63).

The Lingual Glands (fig. 12, sl.g.), though considerably longer than the total length of the body, are of the simplest tubular type. They are of uniform width thronghout their whole length, except the slightly swollen blind termination. These blind ends lie one on each side of the rentral and posterior region of the abdomen, generally embedded in the fat body. They take a sinnous course forwards through the abdomen into the thorax, where they rm alongside the ventriculus. At the sides of the proventriculus they are thrown into several folds, which appear to be quite constant in character. They pass forwards at the sides of the oesophagus, and on entering the cervical region the ducts lose their glandular character and assume a spiral thickening; before leaving the cervical region the two ducts unite below the oesophagus, and the single median duct enters the head ventral to the cephalothoracic nerve cord and runs direct to the proximal end of the hypopharynx, at the end of 
which it opens. A short distance before entering the hypopharynx the salivary duct (fig. 3, sal.d.) is provided with a small valve controlled by a pair of fine muscles $(s . m$.) which serve to

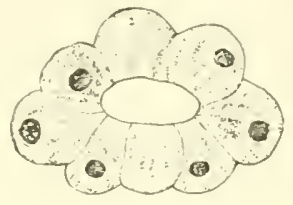

FIG. 15.

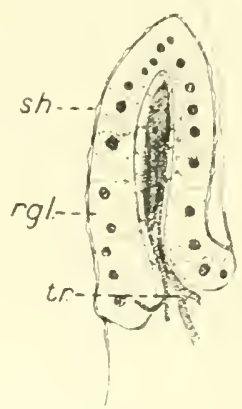

FIG. 16.

FIcr. 15. Transverse section of the lingual salivary gland, showing the fibrillar character of the gland cells. $\times 220 . \quad$ (Camera lucida drawing.)

Fig. 16. Vertical section of one of the rectal glands, to show its structure. $\times 56$. (Camera lucida drawing.)

$s h$. Perforate chitinous sheath. r.gl. Gland cell. tr. Trachea.

regulate the flow of the salivary secretion. The glands are composerl of glandular cells (fig. 15), which are convex externally and have a fibrillar appearance in. section. No vacuoles have been found in the cells.

\section{The malpighian tubes.}

A pair of malpighian tubes (fig. 14, malp.) arise at the point of junction of the proximal and distal intestines, that is, where the mesenteron joins the proctodaem. Each malpighian tube is shortly divided at an angle of $180^{\circ}$ into two malpighian tubules. The malpighian tubules are very long and convoluted, and intimately bound up with the diffuse fat body, so that it is a matter of considerable difficulty to dissect them out entire. They have a moniliform appearance and are of uniform width throughout: never more than two cells can be scen in section. They are generally yollowish in colour. As in most insects, they are unfoubtedly of an excretory nature, as the contents of the cells 
and tubules show. Lowne's view that, in the blow-Hy, they are of the nature of a hepato-pancreas is untenable on both morphological and physiological grounds.

\section{The rectal glunds.}

The four rectal glands (rect.gl.) are arranged in two pairs, two aach side of the rectal carity. Each rectal gland (tig. 16) has a conical or pyriform apex with a swollen eircular base. It is composed of a single layer of large columnal cells (r.gl.); the papilla is hollow and its carity is in communication with the general body carity. It is covered extemally by a perforate chitinous sheath (sh.), which is continuous with the intima of the rectum. A number of tracheae (tr.) enter the cavity of each gland, and fine tracheae may be found penetrating the wall. The cavity of the gland is filled with a loose tissue of branching cells. As the gland is capable of pulsation, there is no doubt a constant interchange of blook between the cavity of the gland and the body carity (which is a hatemocoel). By this means waste product: may be extracted from the blood by the large gland cells and excreted into the rectum through the pores on the external sheath of the gland. The rich supply of tracheae probably assists the cells in the process of excretion, as we find the tracheae very numerous, and intimately connected with the malpighian tubules.

\section{ThE RespiRatory SYSTEM.}

The respiratory or tracheal system is dereloped to a very great extent in the $\mathrm{fl}_{\mathrm{y}}$ and occupies more space than any other anatomical structure. Only by dissection of the freshly-killed insect can one obtain a true conception of its development and importance. It consists of tracheal sacs of varying size, having extremely thin walls and tracheae which may arise from the sacs, or, in the case of the abdominal tracheae, independently from the spiracles.

The Anterior Thoracic Spiracles (figs. 6, 17, a.th.). Each is a large rertical opening behind the humeral sclerite and above the anterior legs. It is surrounded by a chitinous ring, the 
peritreme, and the opening is guarded by a number of dendritic processes which prevent the entrance of dust and other foreign borlies. It leads into a shallow chamber or vestibule which commmicates with the rest of the spiracular system throngh a valvular aperture.

The anterior thoracic spiracles supply the whole of the head, the anterior and median regions of the thorax, the three pairs of legs, and by means of the abdominal air sacs a large part of the viscera.

Internal to the valve the tracheal system divides. The tracheal sacs springing from the posterior side are as follows: Ventrally a rather narrow tracheal duct leads into a sac-the anterior ventral thoracic sac (fig. 17, a.v.s.) - situated at the side of the thoracic ganglion which it supplies. Above the origin of this another tracheal duct leads to a rertical sac supplying the anterior sterno-dorsales muscles. Dorsally the ducts of two sacs take their origin; the smaller and more dorsal is a Hat sac closely apposed to the anterior ends of the dorsales muscles (do.) which it supplies; the more rentral of the two is one of the two most important branches of the anteriur thoracic spiracle (the other being the branch supplying the head). In the thorax it takes the form of an elongated sac lying below the dorsales muscles, and by the side of the alimentary canal. From the dorsal side of this the longitudinal thoracic sac (l.tis.) a number of branches arise which supply the lower dorsales muscles. It is constricted about the middle of its length and anterior to the constriction a branch is given off which supplies the rentral portion of the median stemo-dorsales muscles. In the posterior region of the thorax another ventral branch is given off from which branches arise, one supplying the rentral portions of the posterior sterno-dorsales muscles, the other opening into the posterior ventral thoracic sac (p.v.s.) which supplies the intermediate and posterior legs.

The longitudinal thoracic sac then narrows, and passes threngh the thoraco-abrominal opening into the abdomen. In the abromen it immediately dilates to form one of the large abdominal air-sacs (ab.s.). The pair of abdominal air-sacs in some cases occupies about half the total space of the abdomen. W'hen the 


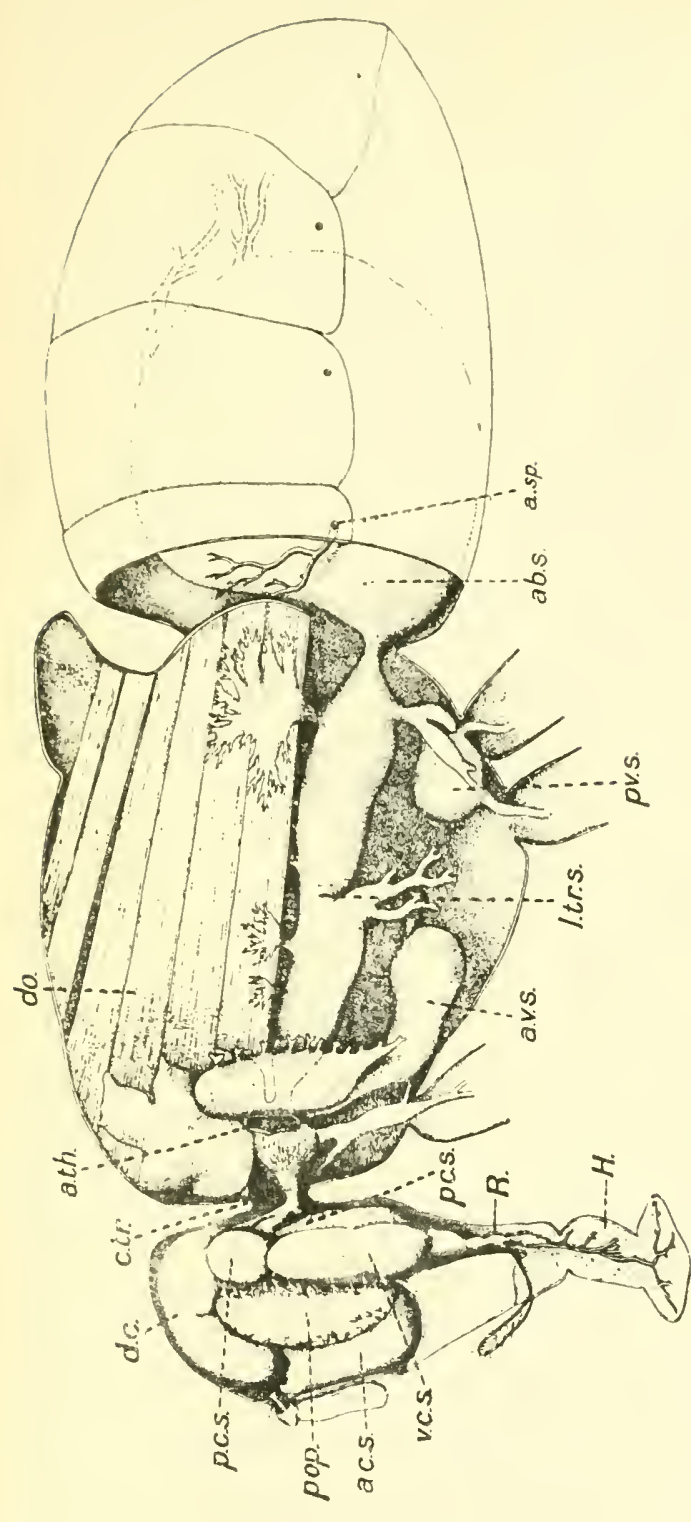

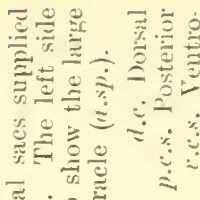

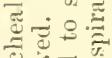

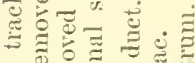

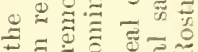

๑ี

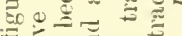

㱒

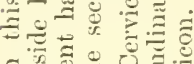

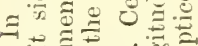

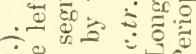

立导导

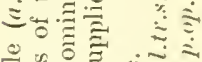

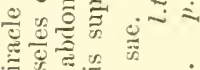

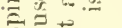

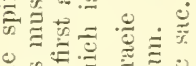

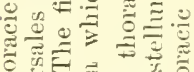

递总

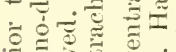

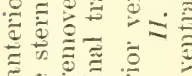

里司苛.

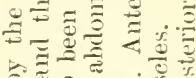

$\approx \approx 0 \approx \approx 0$

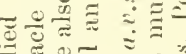

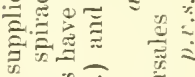

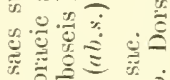

$\approx \cong$

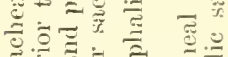

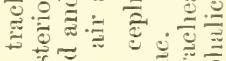

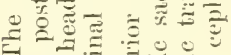

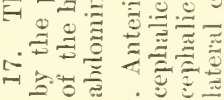

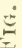


fat-body is not graitly developed they occupy almost the whole of the basal portion of the abdomen. They give off internally a large number of tracheate which ramify anong the viscera and provide a large portion of the contents of the abdomen with air.

From the anterion sicte of the anterior thoracic spiracle a

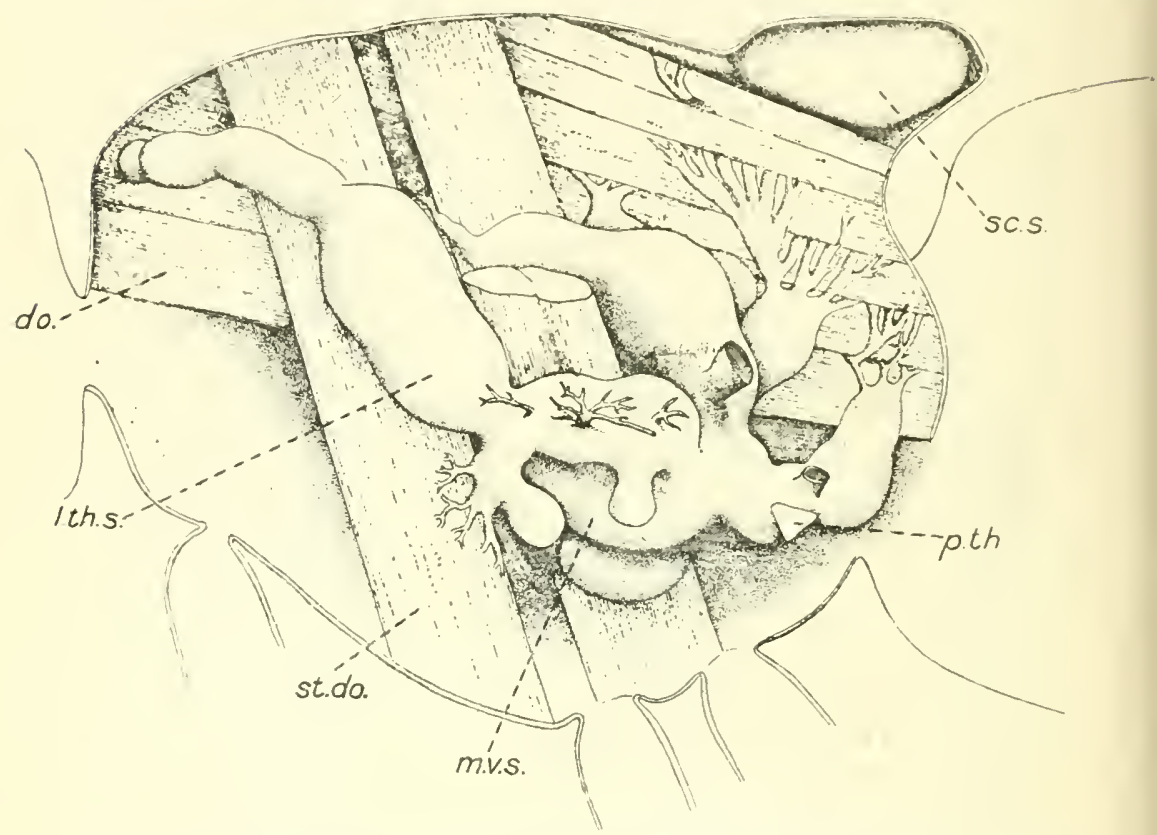

Firi, 18. The tracheal sacs supplied by the posterior thoracic spiracle. In this figure the left side of the thorax las been removed, together with the wing muscles and the posterior sterno-dorsales. It must be imagined that this figure is superimposed on fig. 17.

do. Dorsales. l.th.s. Lateral thorncic sac. m.t.x. Median ventral sac. p.th. Posterior thoracic spiracle. se.s. Scutellar sac. st.do. Sternodorsales.

flattened sac arises. On its ventral side this gives off a branch which supplies the muscles of the neck and the anterior leg. 'The sac then narrows into a rather thick-walled cervical tracheal duct (c.tr.), which passes through the neck alongside the cephalothoracic nerve-cord and enters the head.

Tracheal Sacs of the Head. 'The tracheal sacs of the head accupy the greater portion of the head capsule. They entirely 
fill up all the space which would otherwise be haemocoel. Theses. tracheal sacs are supplied by the tracheal ducts which, on entering the head capsule, curve dorsally behind the cephalic galloglion. Before curving upwards each gives off a lauge ventral duct (fig. 1!), tn.d.) which spreads out beneath the cephalic ganglion, forming a structure of a tentorial nature upon which the ganglion rests. The dorsal cephalic duets unite behind the cephalic ganglion above the oesophagus. From the point of junction three ducts arise, two lateral ducts and a median dorsal duct. The median dorsal duct (m.d.) opens inter a large bilobed dorso-cephalic sac lying on top of the ganglion, and ocerupying the dorsal region of the head capsule. It gives off branching tracheal twigs supplying the antero-dorsal portion of the optic ganglion (periopticon). Each of the lateral duets (l.d.) sup-

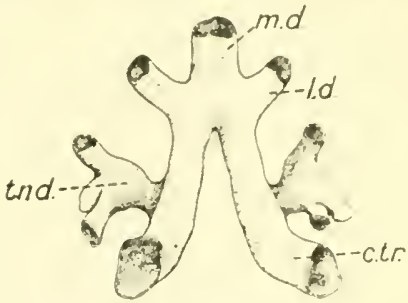

Fig. 19. Posterior view of the tracheal ducts which supply the cephalic sacs and tracheae.

c.tr. Cervical tracheae which fuse above the oesophagus on the posterior side of the cephalic ganglion. l.d. Lateral duct. m.d. Median dorsal duct. tr.d. Tentorial tracheal ducts which spread out beneath the cephalic ganglion. plies the posterior cephalic sacs. It first commmicates with a sac (fig. 17, p.c.s.) lying behind the dorsal portion of the optic ganglion to which it gives off a large number of tracheal twigs. This sac opens into an elongate rertical sac which occupies the ventro-posterior region of the head capsule. The remaining tracheal sacs of the head are supplied by the tentorial tracheal ducts (fig. 19,tr.d.), which spread out beneath the cerebrum in a fan-shaped manner and are bilaterally distributed. Each half, in addition to giving off internally tracheal twigs to the optic ganglia, communicates with two tracheal sacs. An intemal duct leads into a large spherical sac, the anterior cephalic sac (fig. 17 , a.c.s.), situated in the anterior region of the head dorsal to the fulcrum. From the dorsal side of this sac a branch is given off which supplies the antenna of its side; the ventral side is continned down the fulcrum as a narrow tracheal sac. The lateral portion of the tentorial tracheal duct opens into the ventro-lateral cephalic sac (v.s.c.) sitnated posterior to the optic ganglion. The lower end of this sac gradually narrows at it enter's the rostrum which it traverses, giving off half-way along 
its length a trachea which supplies the palp of that side. On reaching the haustellum it takes the form of a trachea proper, having annular thickenings. Shortly after entering the haustellum it gives off two branches to the muscles of this region. The main trachea is continued into the oral lobe of its side, where it divides into anterior and posterior branches, and these again divide into numerous small tracheae running to the edges of the oral lobes. Lowne, in his description of the tracheal system of the blow-fly, describes and figures the tracheal supply of the proboscis as being of the nature of tracheal sacs and capable of distension; he also describes a trefoil-shaped tracheal sac at the base of the oral lobes giving off very regular branches, the dilation of which, he claims, causes the inflation and teusion of the oral lobes. The mechanism of the proboscis will be discussed later (p. 62), but it may be noticed here that in $M$. domestica there is no trace of a trefoil-shaped sac at the base of the oral lobes, and that all the tracheal structures of this the haustellum region are definite annular tracheae, and therefore incapable of distension.

The Posterior Thoracic Spiracle (figs. 6, 18, p.th.) is triangular in shape and is guarded by dendritic processes. The tracheal sacs of this system (fig. 18) have not the extenderl range of those supplied by the anterior thoracic spiracle, but are confined to the thorax, chiefly in the median and posterior regions which are not aerated to any great extent by those of the other system. They supply chiefly the large muscles of the thorax. Laterally a series of sacs (l.th.s.) extends anterodorsally in an oblique direction, external to the sterno-dorsales muscles, to the humeral region. From the first of these sacs a large number of tracheal twigs arise and supply the muscles of the wing and the anterior sterno-dorsales muscles. Ventral to this sac a large sac (m.v.s.) penetrates internally between the anturior and merlian sterno-dorsales muscles and supplies the lower dorsales muscles.

From the dorsal side of the distributing sac a number of sacs arise, some of which penetrate between the sterno-dorsales muscles and supply the upper dorsiles muscles. A more posterior set supplies the posterior regions of the dorsales muscles, 
ranifying between them in a very extensive mammer, sme ultimately terminating in the tracheal sacs beneath the sentum and the scutellar sac (sc.s.).

The Abdominal spiracles differ in number in the two sexes. In the male there are seven pairs of abdominal spiracles: in the female I have only been able to find five pairs. In both sexes each of the large tergal plates which cover the abdomen has near its lateral margin a small circular spiracle. The first abolominal segment which has fused with the second pair has a pair of small spiracles (see fig. 22) slightly anterior to those of the second (apparent first) abdominal segment. In addition to these the malc possesses two pairs of spiracles in the membrane at the lateral extremities of the rudimentary sixth and serenth abdominal segments (nee fig. 25). In the fenale I have been unable to find any additional spiracles. Each of the abdominal spiracles is prorided with a restibule and atrium which are separated by a valve controlled by a minute chitinous lever. All the spiracles of the abdomen communicate with tracheae which ramify anong the riscera and fat-body. There are no tracheal sacs in connection with these spiracles.

\section{The Vascular System and Body Cavity.}

By the great development of the tracheal sacs in the head, the muscles in the thorax, and the fat-body and air-sacs in the abdomen, the haemocoelic space in the fly is greatly reduced. The blowd is colomrless, and is crowded with corpuscles, mostly containing substances of a fatty nature.

The Fat-body varies greatly in the extent of its development. In some cases it may almost fill the body-cavity, pushing the intestine back into a postero-dorsal position: this is generally the case in flies before hibernating; in other cases it may be only moderately developed. The fat-body receives a very rich tracheal supply, and stores the products of digestion which are conveyed to it by the blood with which it is bathed. It consists chiefly of very large cells, both uninucleate and multinucleate: the fat-cells of the head are not so large.

The Dorsul Vessel or Heart lies in the pericardial chamber, 
immediately beneath the dorsal surfice. It extends from the posterior end to the anterior end of the abdomen, and four large chambers, corresponding to the four visible segments, and a small anterior chamber can be recognised; the last represents the chamber of the first abolominal segment. The chambers are not separated by septa, but each has a pair of dorso-lateral ostia situated at its posterior end where the alar muscles of the pericardium arise. 'The walls of the heart are composed of large cells. The pericardiun contains fat-cells and tracheae, and its Hoor is composed of large cells of a special nature. The alar muscles run laterally in the flor of the pericardium to the sides of the dorsal plates where they are inserted. The anterior end of the heart is continued as a narrow tube (fig. 13, d.a.) along the dorsal side of the ventriculus, where it terminates in a mass of cells (l.g.) which are usually considered to be of a lymphatic nature.

\section{The Reproductive System.}

The two sexes are slightly different in size, the fenales being larger than the males; the sexual dimorphism of the width of the frontal region of the head has already been noticed. There loes not appear to be any great disparity in the numerical proportions of the sexes; near breeding-places there is naturally a preponderance of females, but in houses the sexes are approximately equal in number. In this respect they differ from the lesser house-fly Fannia canicularis.

\section{The female reproductive organs.}

The generative organs of the female consist of oraries, spermathecae or vesiculate seminales, accessory glands and their ducts.

The Ovaries, when containing mature ova, occupy the greater part of the abdominal cavity (fig. 20, ox.). They lie ventral to the gut, occupying the whole of the ventral and lateral regions, the gut resting on the V-shaped hollow between them. Each wary contains about seventy ovarioles, in each of which ova in various stages of derelopment can be seen. The two short thinwalled oviducts (ov.d.) unite on the rentral side of the abdomen 
to form the common oviduct (c.o.d). The walls of the common oviduct are muscular, and when the ovipositor is in a state of rest, retracted into the abdominal cavity, the oviduct curves forwards and florsally to enter the ovipositor (ovp.) ventral to the rectum (rect.). Here it swells slightly to form a sacculus

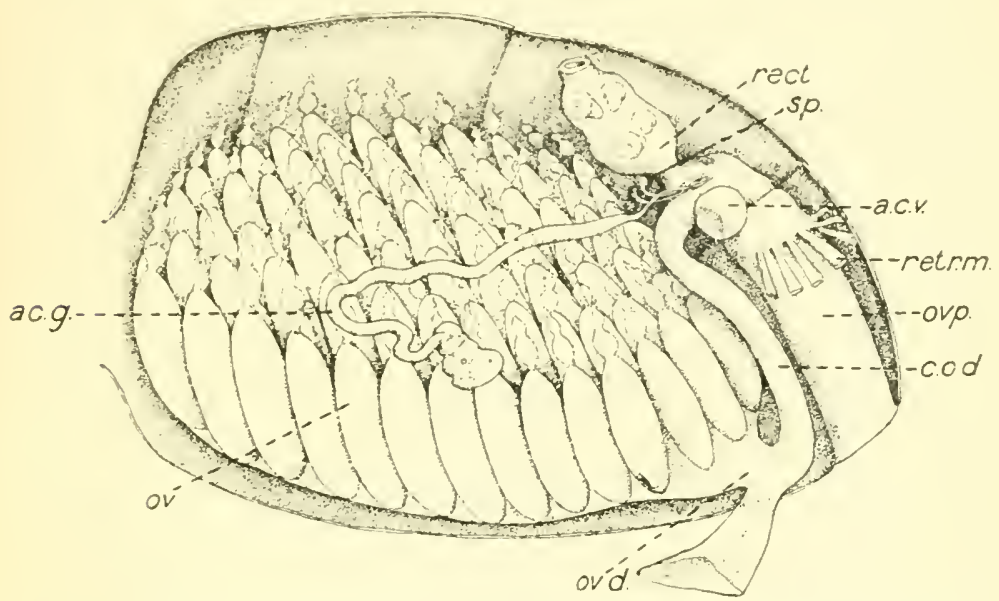

FIG. 20. Female reproductive organs in silu; the left ovary and the viscera have been remored. The oripositor (orp.) is shown retracted, in which state the common oviduet (c.o.d.) is doubled back.

ac.g. Accessory gland. a.c.r. Accessory copulatory vesicle. or. Ovary composed of about seventy orarioles, and containing ova in various stages of development. ov.d. Oviduct. retr.m. Retractor muscles of the ovipositor. $s p$. Spermathecae or vesiculae seminales.

(fig. 21, sac.), which leads into the muscular vagina (vag.). The vagina opens into the ventral side of the ovipositor immediately behind the sub-inal plate.

The Spermathecae (sp.) or Vesciculae Seminales are three in number, two on the left side and a single one on the right. Each consists of a small black, oviform, chitinous capsule, the lower half of which is surrounded by a follicular investment continuous with the cellular wall of the duct, the whole having the appearance of an acorn with a long stalk. The ducts of the spermathecae are lined by a thin chitinous intima continuous with the chitinous capsule, and they open at the posterior end of the sacculus on the dorsal side. 
There is a single pair of accessory glands (ac.g.) which are fairly long, and on nearing the vagina they become narrower to form a slender duct which opens on the dorsal side of the vagina immediately behind the ducts of the spermathecae. The accessory glands are closely united with the fat-body. They probably socrete the adhesive fluid which corers the eggs when they are

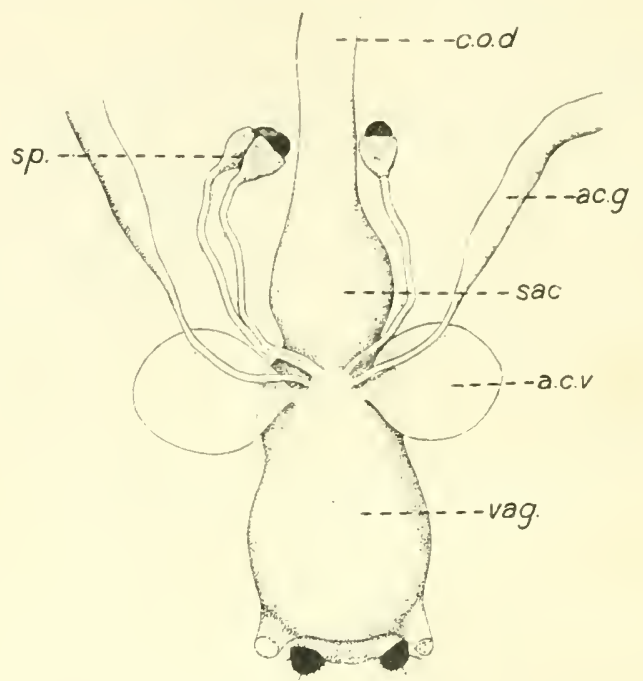

Fig. 21. Terminal region of the female reproductive organs, showing the accessory glinds, ete.

sac. Sacculus. vag. The muscular vagina which evaginates during copulation; a pair of retractor muscles are shown. Other lettering as in fig. 20.

laid, and causes them to adhere to each other and to the material upon which they are deposited. Behind the accessory glands there is a pair of thin-walled transparent resicles (tasche dell' ovidutto of Berlese), which I propose to name the accessory copulatory vesicles (a.c.v.) on account of the part they take in ensuring firm coitus with the male when copulating, during which process they expand to a much greater extent.

\section{The ovipositor (fig. 22).}

The terminal abdominal segments of the female are much reduced in size to forin a tubular ovipositor, the chitinoms selerites being rednced to form stender chitimons rorks. When extended it 
equals the abolomen in length. It is composed of segments vi, vii, viii, and ix, each being separated from the adjacent segments by an extensible intersegmental membrane, which is covered with fine spines. When the oripositor is retracterl (fig. 20, ovp.) it lies

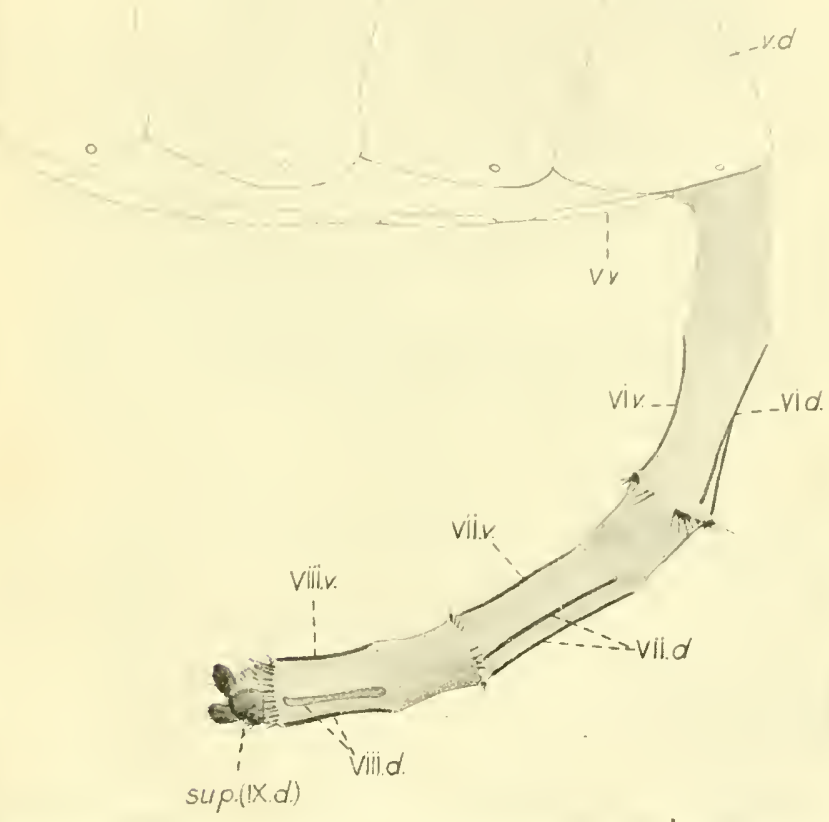

Fif. 22. Abdomen of female showing the extended ovipositor.

$v, d$. to ix, d. Fifth to ninth dorsal arches or plates of the abdomen. v, $v$. to viii, $r$. Fifth to eighth ventral plates or arches. su.p. The suranal plate (ninth dorsal arch).

The anus is situated between the two hateral terminal tubercles.

in the interion of the posterior end of the abdomen, the segments being telescoped the one within the other, so that only the terminal tubercles are visible from the exterior. The dorsal arch of the sixth abdominal segment is reduced to a $\boldsymbol{\Lambda}$-shaped sclerite (vi, d) lying on the dorsal side of the segment. The ventral arch of this 
segment is reduced to a slender ehitinous rod (vi, $v$.) in the midvestral line. The dorsal areh of the seventh segment is represented by two slightly-curved sclerites (vii, d.) with their concave faces opposite; the ventral areh (vii, v.) is similar to that of the sixth segment. At the junction of the posterior ends of the sixth and seventh segments with the inter-segmental membranes succeeding them there are several setose tubercles arranged more or less in pairs, but they vary in development in different individuals. The (lorsal arch of the eighth segunent consists of two parallel and slender selerites (viii, d.), not so narrow as those of the two preceding segments. A pair of slender sclerites (viii, $v$.) also represents the ventral arch. The terminal anal segmont, which I consider represents the reduced minth segment, has a dorsal chitinous sclerite, the sub-inal plate (su.p.) which is triangular in shape, and a ventral sub-anal plate of the same shape. The female genital aperture is situated at the anterior end of the latter plate, between the eighth and anal (ninth) segments. A pair of terminal setose tubereles is sitnated laterally at the apex of the anal segment.

\section{The male reproductive organs.}

The male reproductive organs (fig. 23) are situated ventral to the alimentary canal, and lie within the fifth abdominal segment. They consist of a pair of testes, vasa deferentia, ejaculatory duct and sac, and the terminal penis. There are no accessory genital glands in the male.

The Testes (te.) are a pair of brown pyriform bodies, with their long axes placed transversely, and their pointed ends facing. In young males they have a bright red appearance. They are covered with a follicular investment of cells, which varies in thickness apparently according to age. The thin brown chitinous capsules contain the developing spermatozoa. The pointed end of each testis is continued as a fine vas deferens (v.d.) which meets that of the other testis in the median line, where they open into the conmon ejaculatory duct (d.e.). This runs forwark for a short distance, and then bends to the left ventrally, and, after several convolutions on the left ventral side of the abdomen, the duct narrows considerably, forming a narrow ejaculatory duct. This 
crosses over the dorsal side of the rectum to the right side, where it runs forwards for a short distance and then curres bick in the median ventral line, opening into a pyriform ejaculatory sac (e.s.). The walls of this ejaculatory sac are muscular, longitudinal muscles, giving the walls a striated appeanunce. It contains a phylliform,

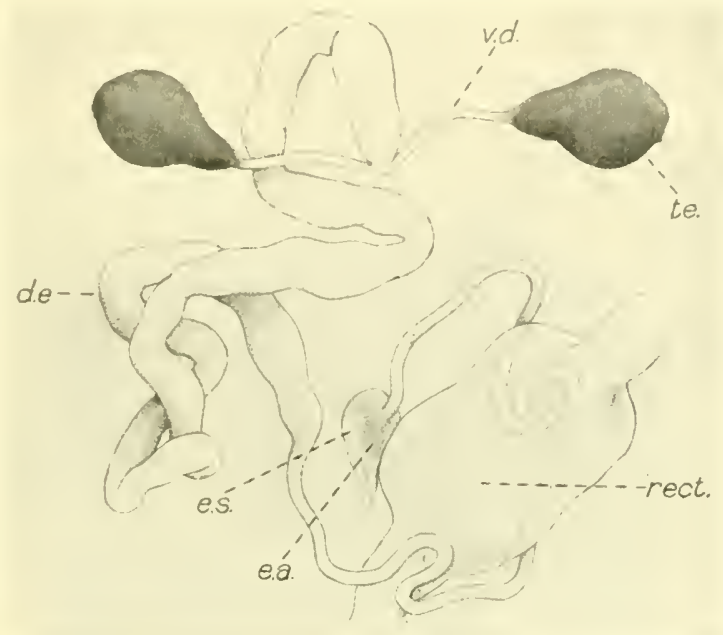

FIG. 23. The male reproductive organs. They have been slightly spread out, and the rectum (rect.) has been turned over to the right side.

d.e. Ejaculatory duct.

te. Testis.

e.a. Ejaculatory apodeme.

v.d. Vas deferens.

e.s. Ejaculatory sac.

chitinous sclerite-the ejaculatory apodeme (e.a.) which has a short handle at the broad end. This sclerite is no dould of great assistance in propelling the seminal fluir along the ejaculatory duct during copulation. A short distance behind the ejaculatory sac the duct opens into the penis.

\section{The male gonapophyses.}

The extremity of the abdomen in the male (fig. 24) has undergone consiclerable modification in the formation of the external genitalia. The visible portion of the abdomen, as seen from above, consists of the first five abrlominal segments; the remaining three segments are slightly withdrawn into the fifth segment, and on looking at the abdomen from the posterior end, only the terminal 
segment, the eighth, surounding the anus, can be seen. The sixth and seventh segments have been greatly reduced. The sternal portion of the fifth segment eonsists of a curdiform sclerite $(v, v$.), the apex of which is clireeted forwards, and each of the lateral margins is profluced to form a short process, swollen at the tipthese lateral processes form the primary forceps (p.f.), and lice at each side of the aperture of the male genital atrium ( $g . a$.$) , of which$ the posterior edge of the selerite forms the lower or interior lip.

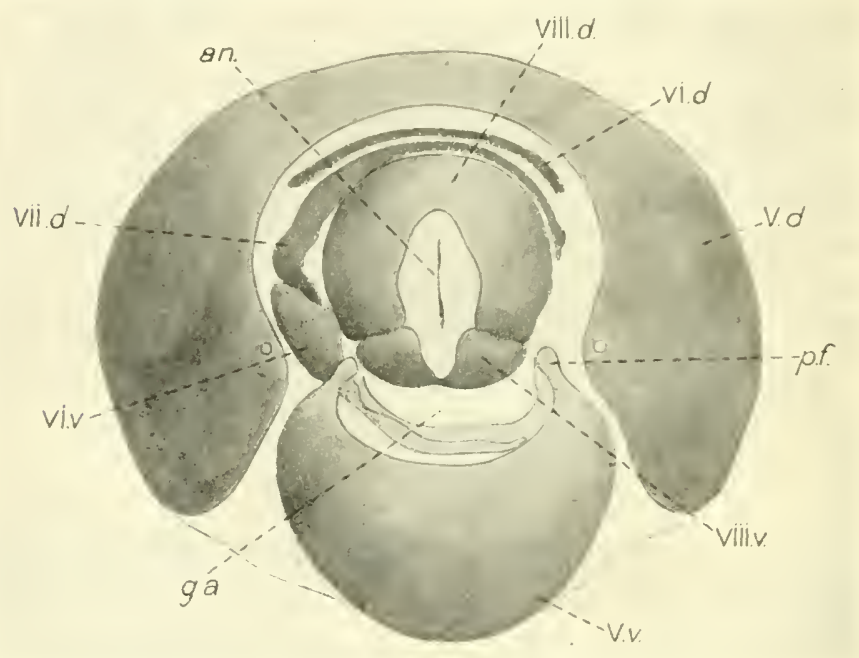

FIg. 24. The posterior ent of the abdomen of the male seen from behind, showing the pronounced sinistral asymmetry.

$\mathrm{v}, \boldsymbol{d}$. to viii, $d$. Fifth to eighth dorsal plates or arches. v, $v$. to viii, $r$. Fifth to eighth ventral plates or arches. $\quad a n$. Anus. atrium. p.f. Primary forceps. g.a. Aperture of genital

The dorsal plates of the sixth and seventh segments lie on the membrane which is tucked underneath the posterior edge of the fifth abdominal segment. The dorsal plate of the sixth segment $\left(v i, d_{0}\right)$ is a narrow transverse selerite; its lateral edges, which do not extend down the sides, are slightly produced anteriorly. 'The ventral plate of the sixth segment (vi, v.) is asymmetrical, and, with the dorsal plate of the seventh segment, produces a pronounced asymmetry of the posterior end of the male abdomen. It consists of a spatulate plate on the left side, the anterior or 
ventral side of which is produced into a narow bar extending across the ventral side of the aperture of the genital atrium, its distal extremity bifmeating. The dorsal plate of the seventh segment (vii, d.) is asymmetrical. It comsists of a narrow sclerite, which, on the dorsal side, is similar to the sixth dorsal plate, but the left side (see fig. 25) extends down the side, and broadens ont into a somewhat triangular-shaped area; the anterior edge of this is incised, and receives the seventh spinacle (vii, a.sp.); the ventral edge is internal to the spatulate portion of the sixth ventral plate. 'The ventral arch of the seventh selerite has been completely withdrawn into the abdomen, and consists of a pair of curved sclerites

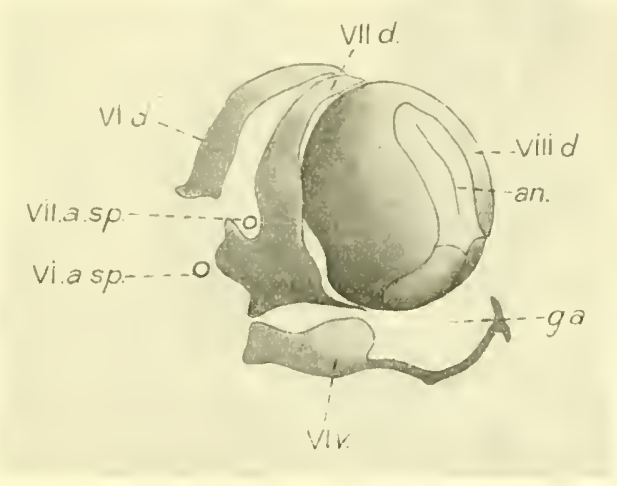

Fig. 25. Lateral view of the terminal segments of the abdomen of the male after their removal from the fifth segment.

vi, a.sp. and vii, a.sp. Sixth and seventh abdominal spiracles. Lettering as in fig. 24.

(fig. 26, vii, v.) somewhat rhomboidal in shape, lying dorsal to the fifth ventral arch and ventral to the penis $(P$.$) ; they form the$ secondary forceps. 'Their lateral edges, which are thickened, articnlate with the alar processes of the body of the penis (c.pe.), and with the dorsal arch of the eighth abdominal segment (viii, d.). 'Their inner edges are curved, and almost meet in the mid-ventral line. The dorsal arch of the eighth and last abdominal segment (viii, d.) forms the apex of the abdomen. It consists of a strongly conver selerite, deeply incised on the ventral side; in this incision the vertical slit-like anus (fig. 25, an.) lies. The ventral portion of the segment is completed by a pair of convex sclerites (fig. 26, viii, v.) 
which are united in the mid-ventral line, forming the ventral border of the anal nembrane and the dorsal side of the entrance to the genital atrium.

All the sclerites of the posterior segments except the sixth and seventh are setose.

Berlese (1902) in his accomnt of the copnlation of the house-fly describes the genitalia. From his account of the male genitalia he appears to have missed the narrow dorsal arch of the sixth segment, or what is very probable, he may have mistaken it for the fifth dorsal arch, as he terms the serenth dorsal arch the sixth, and

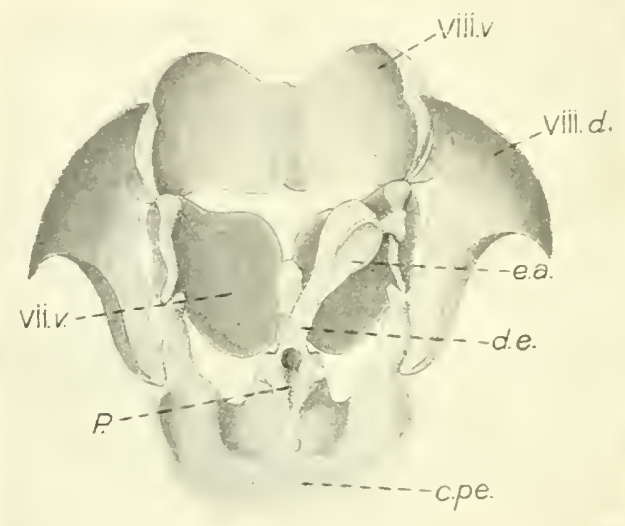

Frg. 26. Dorsal view of the penis and the ventral half of the terminal abdominal segments. The median portion of the eighth dorsal arch has been removed, leaving the lateral portions attached to the body of the penis (c.pe.) and the ventral arch of the seventh segment (vii, r.). Lettering as in fig. 24 .

describes what I have called the rentral arch of the serenth as the dorsal arch of that segment. This mistake in nomenclature has probably arisen from the fact that he consiclered the visible portion of the abdomen as consisting of four segments instead of five, in which case the narrow dorsal arch of the sixth segment would naturally be taken for that of the fifth?

The Penis (figs. 26, 27) lies intemally on the ventral side of

1 Berlese describes a sinistral asymmetry of the posterior segments, but his figures show a dextral asymmetry, a mistake probably in the reproduction of his figures which has escaped the author's notice. 
the abdomen, dorsal to the ventral arches of the fifth and sirenth segments. It is composed of several sclerites. A median sclerite (c.pe.), the anterior and rentral edge of which is ronghly semicircular in outline, forms the body of the penis. This is produced laterally to form two alar processes; at the bases ef these processeres the lateral extremities of the lorsal anch of the eighth segment articulate with the borly of the penis; the extremitios of the processes are attached to the lateral extremities of the ventral sclerites of the seventh segment, the secondary forceps. 'The penis proper. consists of a hollow eylindrical tube, the theca, which receives the

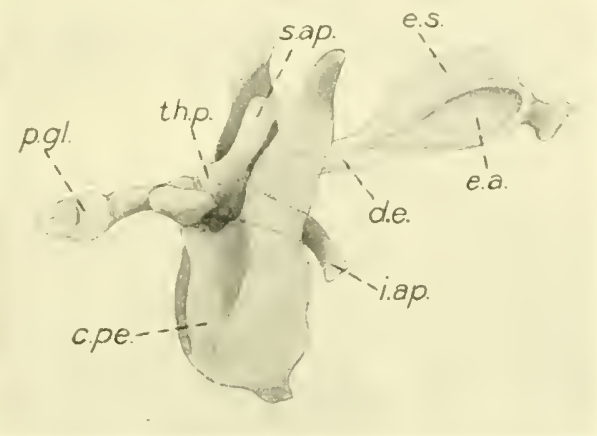

Fit. 27. Penis seen from the right side after it has been removed from within the terminal abdominal segments.

i.ap. Inferior apophysis. th.p. Theca of penis. p.gl. Glans. s.ap. Superior apophysis. Other lettering as in tig. 26 , etc.

ejaculatory duct. The theca articulates with the body of the penis by means of a pair of small chitinous norlules ("cornetti" of" Berlese): pusterior to the attachment the theca is constricted slightly. Below the aperture of the entrance of the ejaculatory duct, the theca is produced into a ventrally directed curved process, the inferior apophysis (i.ap.); above the aperture a short cylindrical process, the superior apophysis (s.up.) arises. The anterior end of the theca is continued as a slightly intlated hyaline structure, the glans $(p \cdot g l$.), at the curved extremity of which the ejaculatory duct opens. 


\section{CHAPTER IV}

THE INTERNAL STRECTURE OF THE HEAD AND PROBOSCIS OF MUSCA DONESTICA

THE exo-skeleton and tracheal system of the head and proboscis have already been described. An aceount will now be given of the intemal structure and musculature of the head and pharynx ancl also of the oral lobes.

The posterior region of the head (fig. 3) not occupied by tracheal sacs is usually filled up with small multinucleate fit-cells (f.c.), which are also occasionally found on the proboscis. The frontal sac or ptilinum (Pt.) fills up the anterior portion of the head not occupied by the air-sacs. Its crescentic opening, the lumule, has already been described. It is attached to the wall of the cephalic capsule by muscles which vary considerably in the extent of their development. In recently emerged flies the musclesupply of the ptilinum is considerable, as they have served to retract the sac after it has been inflated to assist the exclusion of the inago, but in older specimens it bromes loss. The walls of the ptilinum are muscular and lined by a chitinous intima covered with small broad spines.

\section{The Musculature of the Proboscis.}

The chief muscles controlling the movements of the pharymx and proboscis are as follows:

The Dilators of the Plarynx (Figs. 3, 28, d.ph.). 'This pair of muscles occupies the interior of the fulcrum. Each muscle is attached to the antero-lateral regions of the fulcum and inserted into the dorsal plate of the pharynx (r.p.). These muscles are the chief agents in pumping the liquirl food into the oesophagus, and in drawing it up through the pharyngeal tube. 
The Retractors of the Fulcrum (r.f.). These muscles are attached to the internal anterior edges of the genae, amd are inserted into the posterior cornu (p.c.) of the fulcrum. Their contraction causes the rotation of the fulcrum on the epistome as a hinge in the retraction of the proboscis.

The Retractors of the Haustellum (r.h.). These muscles have their origin on the dorso-lateral regions of the occiput. They are long and narrow, and running on each side of the common salivary duct are inserted into the dorsal margin of the thecal.

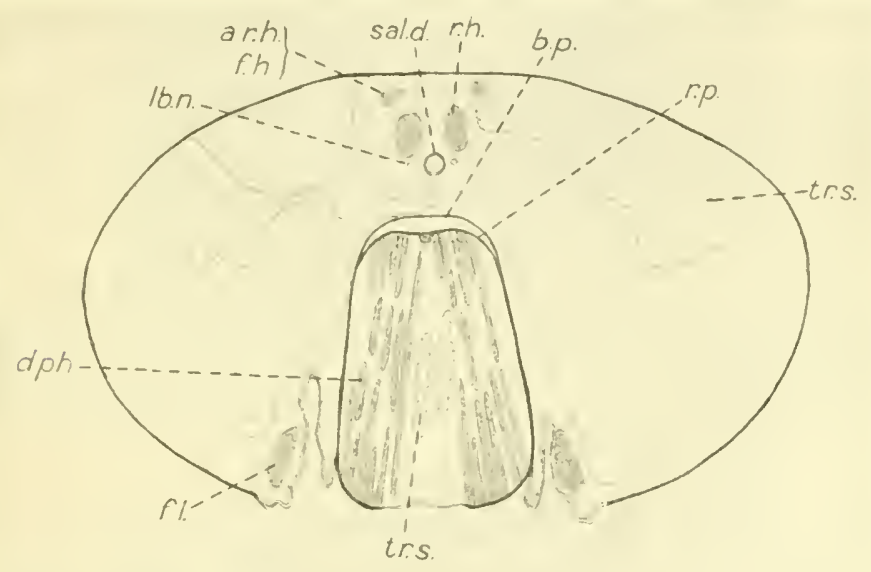

FIg. 28. Transverse section through the lower portion of the head-capsule, show. ing the muscles and tracheal sacs in this region and the fulcrum in section. (Camera lucida drawing.)

b.p. Floor of phargnx. r.p. Roof of pharynx. tr.s. Tracheal sae. Other lettering as in fig. 3.

The Retractors of the Rostrum (r.r.). This pair of muscles has its origin at the sides of the occipital foramen, and is inserted into the posterior side of the membranous rostrum about half way down its length. In the retraction of the proboscis these muscles draw in the rostrum.

The last two pairs of muscles acting together assist in the retraction of the whole probuscis.

The Flexors of the Haustellum ( $f . h$.) have their origin close to that of the retractors of the rostrum at the sides of the occipital foramen. They are inserted into the base of the labral apodeme 
(ap.) and serve to flex the haustellum on to the anterior face of the rostrum.

The Ertensors of the Haustellim (ex.h.). Each of these muscles arises from the distal cornu of the fulcrum, and is inserted inte the head of the labral apodeme.

The Accessory Flexors of the Huustellum ( $a . f . n$.$) are attached$ to the lower (distal) anterior margin of the fulcrum, and inserted with the extensors into the head of the labral apodeme.

The Flexors of the Labrum-epipharynx (f.l.). These muscles have their origin on the anterior and upper alge of the fulcrum, and are inserted into the proximal end of the labrum-epipharynx.

The first pair of the last three sets of muscles serve to extend the haustellum in the extension of the proboscis, and the remaining two pairs assist in the retraction of the proboscis by flexing the hanstellum on to the rostrum.

A pair of very fine muscles (s.m.) have their origin at the base of and internal to the posterior cornua of the fulcrum. They are inserted into the dorsal side of a small valve (s.r.) on the common salivary duct which regulates the flow of the secretion of the lingual salivary glands.

The muscles of the haustellum are:

The Retructors of the Furca ( $r$ : fu.). A pair of muscles having their origin on the upper part of the theca. Each is inserted along the upper proximal half of the lateral process of the furca. When the muscles contract the lateral processes of the furca, which, in a state of repose, are brought together by the elasticity of the rentral cornua of the theca, are diverged, and thus cause the divergence and opening of the oral lobes.

The Retractors of the Discal Sclerites (r.d.s.). These muscles have their origin on the lateral edges of the upper part of the theca, and are inserted upon the sides of the discal sclerites. They work together with the retractors of the firca, their contraction causing the divergence of the discal sclerites, and the consequent opening of the oral pit.

The Dilators of the Labium-hypopharynx (di.l.). 'These fanshaped museles arise in the middle region of the theca on either side the median line, and diverging are inserted in the lateral 
edges of the labium-hypepharygeal sclerite. By their contraction they will widen the chamel of the labium-hypupharyx.

The Dilators of the Labrum-epipharyne' (fig. 29, di.l.). 'These: form a series of short museles attached to the anterion and posterior walls of the labrum-epipharynx. The size of the pharyngeal channel will be regnlated by these muscles.

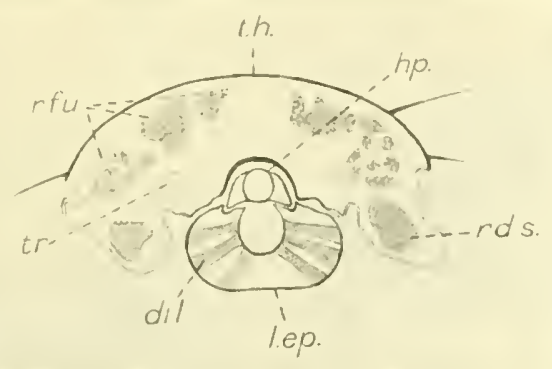

Fig. 29. Transverse section through the lower half of the haustellum, where the hypopharynx $(h p$.$) has become free from the labium. (Camera lucida draw.$ ing.)

di.l. Dilator muscles of the labrum-epipharynx. as in fig. 3.

$t r$. Trachea. Other lettering

\section{The Oral Lobes.}

The external structure of the oral lobes has already been described. Their internal structure and histology will now be given.

The setigerous cuticle and the pseudo-tracheae lie on a hypodermis of cubical cells (fig. 30, hy.). Beneath the hypodermis of the aboral surface is mother layer of cells containing a large amount of dark pigment. Each of the large marginal sensory bristles (g.s.) of the aboral surface has a fine channel rumning down the whole length of the seta. This channel communicates with the cavity of a pyriform mass of nerve-end cells (s.p.), consisting of five or six cells. These masses of cells occupy a large part of the interior of the oral lobes. As these gustatory bristles are exposed and directed ventrally when the proboscis is retracted, they may assist the fly in testing the nature of its food before extending its proboscis. On the oral side of the oral lobes the nipple-like 
gustatory papillae (figs. 3, 30, g.p.) have already been described. The aperture at the end of the papilla learls into a fine duct, which encks in a pyriform sensory bulb (s.g.p.). The tracheae (tr.) can be seen rumning through the cells, some of which contain several nuclei, and from their appearance are probably derived from the firt-body. No tracheal sacs could be found either in the oral lobes

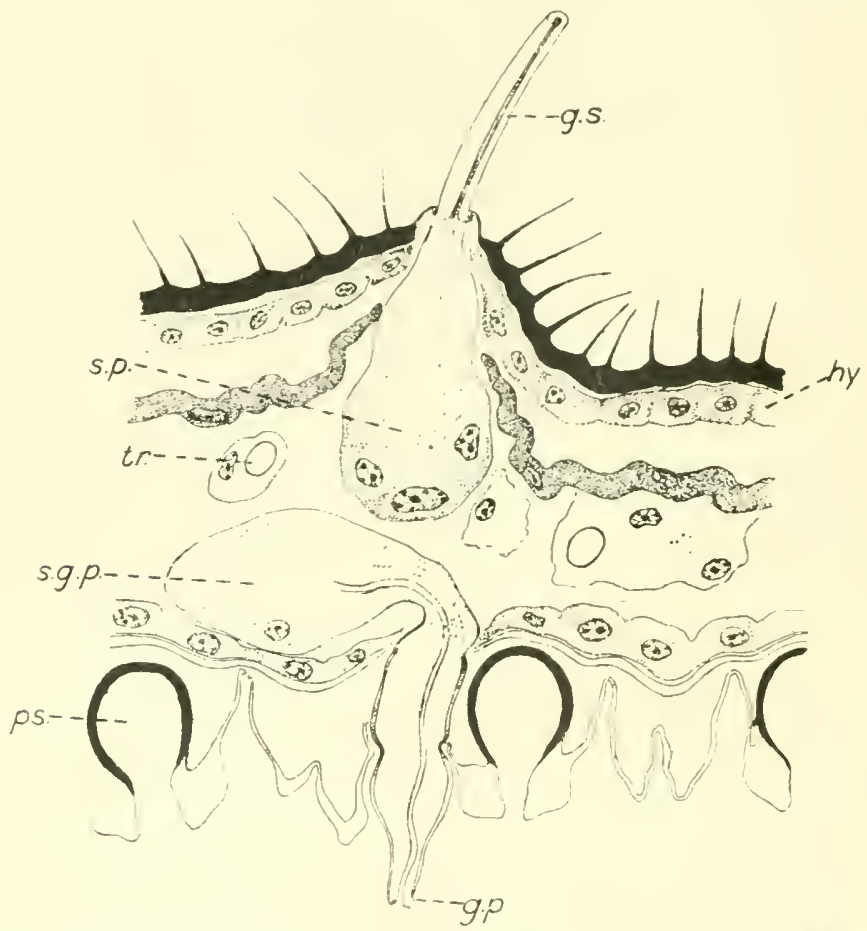

FIG. 30. I'ortion of a transverse section of the oral lobes, showing the two types of gustatory sense organ, etc.

g.s. Gustatory seta. g.p. Gustatory papilla. hy. Hypodermis under which
lies a pigmented layer.
bulb of gustatory papilla.
s.p. Psendo-trachea in section. Sensory bulb of gustatory seta.

or at their bases, but the annular tracheae are continuous with those of the proboscis. The haemocoel of the oral lobes is well developert. This supports the view set forth by Kraepelin, and with which I agree, that the inflation of the oral lobes is due to the blowl. I consider that the extension of the proboscis is due to the intlation of the tracheal sacs of the head. The probuscis having 
been protrucled the oral lobes are then diverged by the contraction of the retractor muscles of the furca and discal sclerites, and distended by the inrush of blood which keeps them turgid.

The Labial Salivary Glunds (figs. 3, 31, lb.sl.). These salivary glands lie in the hanstellum at the base of the oral lobes. The glands, which are spherieal in shape, are composed of a large number of gland cells somewhat triangular in shape. Each gland cell

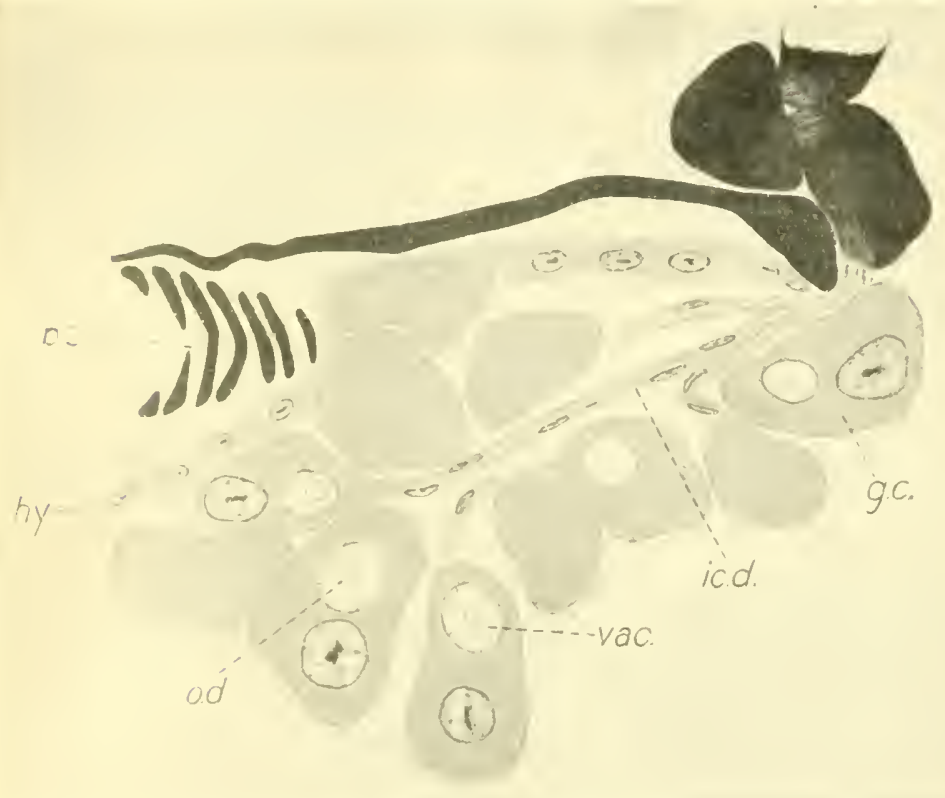

Frg. 31. Transverse section of labial salivary gland, to show the structure of the gland cells (g.c.). (Camera lucida drawing.)

hy. Hrpodermis. ic.d. Intracellular duct. p.s. Pseudo-trachea. ol. Opening of intracellular duct into the permanent vacuole (vac.) of the gland cell.

is $40 \mu \mathrm{inn}$ size, and possesses a large nucleus $(12 \mu)$, and internal to this a permanent circular vacuole (vac.) which is $16 \mu$ in size, and is lined by a thin chitinous intima. The duct of each gland cell (1)pens into the side of the vacnole (od.). The ducts (ic.d.) are intracellular, and rum from the centre of the gland, some of them miting, to form a number of fine ducts on the rentral sides of the discal sclerites, which mite and open into the oral pits by a median 
pair of pores. Kraepelin, in his description of the probuscis of the blow-fly, described the labial glands and their ducts (but not their histology) of that insect, his descriptions being similar to the condition I find in M. domestica. Lowne, however, states that in the blow-fly he traced the ducts of the gland cells throngh the oral lubes to the apertures of the gustatory papillae, which he regarded therefore as the alpertures of the labial salivary glands. GrahamSuith (1911) figures what he calls the "salivary gland of the oral (lise" but does not refer to its structure or relations in his paper on the proboscis of the blow-fly.

The appearance of the labial salivary glands of $M$. domestica calls to mind the maxillary glands of the ant Myrmica levinodis which Janet has described and figured. The secretion of the labial salivary glands serves, I believe, to keep the surface of the oral lobes moist. 


\section{CHAP'TER V}

\section{THE HABITS AND BIONOMICS OF THE HOUSE-FLT}

\section{Local Distribution and Comparative Abundance.}

THE local distribution of thes is almost entirely governed by two factors: the presence of breeding places and of food, the former being mulonbtedly the most important. This fact is supported not only by ny own observations extending over a number of years but by those of such observers as Niven and Hamer who, in particular, have studied the question of the factors governing the local distribution of flies.

Compared with the other species of thies which inhabit or occasionally visit homses, the house-fly, Muscr domestica, is by far the most abundint. Nevertheless, even in houses a slight variation in the relative abundance of $M$. domestica and Fanmia canicularis may be fomnd, for whereus the formel will be more numerous in warm places snch as the kitchen and dining room where food is present, a large proportion of Famia canicularis will occasionally be found in the other rooms of houses. In country houses the proportions sometimes vary by the intrusion of Stomoxys calcitrans? In 1905 in a certain northern comntry cottage, ont of several hundred flies captured, S. calcitruns constituted about 50 per cent. of the total, the rest being chiefly $F$. curicularis together with a few Anthomyia radicum, whose lavae breed on horse manure with those of $M$. domestica.

1. Jennings and King (1913), in discussing the occurrence of S. calcitrans in dwellings in South Carolina, U.S.A., state: "Strong preference was shown for the living rooms and in more than half of the houses studied these were the only rooms infested."

H. H.-F. 
The following records taken from a "Hy census" that was made in 1907 may be taken as illustrative of the proportional abundance of the different species in different situations; although the numbers of these recorts are small the proportions are more obvions.

Place
Restaurant, Manchester
Kitchen, detached suburban
house (six records). Lan-
cashire
Kitchen, detached suburban
house in Manchester
Stable, suburban house
Bedroom, suburban house

$\begin{array}{cc}\text { M. do- } & \text { F.cami- } \\ \text { mestica cularis } \\ 1869 & 11\end{array}$

$\begin{array}{rrl}581 & 265 & 14 \\ 682 & 7 & 14 \\ 22 & 153 & 14(12 \text { s. calcilim: }) \\ 1 & 33 & 4(.1 . \text { stribulan: })\end{array}$

Ont of a total of 3856 thes canght in different sitmations, such as restaurants, kitchens, stables, bedrooms and hotels, 87.5 per cent. were $M$. domestica, 11.5 per cent. F. canicularis, and the rest were other species such as S. calcitrans, Muscima stabulans, C. erythrocephula, and Anthomyia radicum. These figures are comparatively small, but are representative of the arerage occurrence, as I have observed, of the different species.

In a collection of thies eaught in rooms where food supplies were exposed in different cities of the United States, Howard (1900) found that ont of a total of 23,087 flies, 22,808 or $98 \cdot 8$ per cent. were Musce domestica and of the remaining 1\%2 per eent. $F$. cancularis was the commonest species. Hamer (1908) found that more than nine-tenths of the Hies caught in the kitchens and "living rooms" of houses in the neighbourhood of depots for horserefuse, manure, etc., were $M$. domestica. In a further report Hamer gives more details as to the different species that were found. In one lot of 35,000 flies caught on four fly papers exposed in similar positions, 17 per cent. were $F$. canicularis, less than 1 per cent. were C. erythrocephale and considerably less than 1 per cent. were Muscina stabulans; whereas of nearly 6000 flies caught in another situation in four Hy balloons 24 per cent. were F. caniculuris, 15 per cent. were $C$. erythrocephulu and nearly 2 per cent. were 1 . stubulans. In his report for 1909 he gives an excellent diagram illustrating the seasomal prevalence of the six principal genera of thies caught in houses.

Niven found that out of 8553 flies caught in six different 
localities in Manchester 8196 were M. domestica, 29:3 were F. canicularis and 64 were other species.

In Birmingham Robertson (1909) found the different speciess of Hies in the following proportions in a collection of 24,562 Hies: M. domesticu 22,560, 91 per cent.; $F$. conciculuris 1154, 47 per cent.; the blow-fly C. erythrocepherle 840,34 per cent.; and other species, 218 or 9 per cent.

From the foregoing figures it may be taken that as a general mle Muscu domesticu constitutes more than 90 per cent. of the total fy population of a house. The proportions of the other species vary, the variation depending largely on the situation of the house, whether it is urban, suburban or rural and also upon the sanitary conditions prevaling in the neighlourhool.

\section{Seasonal Prevalesce of Fles.}

As a gencral rule honse-tlies are most abundant during the lootest months of the raar. In Europe and North America, north of Mexien, they are most numerous during the months of July, Angust and September. In Sonth Africa they are abundant from October to February. The Hy season in Austratia extends from October to March. In more tropical countries they are prevalent during a more extended periorl.

\section{Flisht or Distaxce travelled by House-Flies.}

The distance that house-Hies are able to travel either by their own exertions or by the aid of the wind is manifestly an important question in view of its connection with the spread of infection by these insects and the location of their breeding places. We are not concerned here with the ability of flies to travel in electric street cars, trains or steamboats; the fact that they are able to be transported by these means is a matter of common observation. The question I am about to discuss is: how fiu do thies travel under natural conditions?

Nomally they do not Hy great distances. I have previonsly compared them to domestic pigeons which hover about a honse and the immediate neighbourhood. On sumny days they may be 
found in large numbers out-of-dours but when it becomes chondy, (1) should it rain, they retire indoors.

In August 1906, Dr M. B. Arnold (see Niven, 1907) carried ont some exact experiments at the Monsall Fever Hospital, Manchester, on the distance travelled by flies. Three hundred Hies were captnred alive and markerl with a spot of white enamel on the back of the thorax. These marked flics were then liberated in fine weather. Out of the 300 five were recoveres in Hy traps at distances varying fiom 30 to 190 yarks from the place of liberation and all the recoveries were within five days. The maximm distance of 190 yards was determined by the limitations of the hospital gromds and did not indicate the possible limit of Hight.

In the summer of 1907 when visiting the Channel Islands I found $M$. domestica from $1 \frac{1}{2}$ to 2 miles from any house or any likely breeding place so far as I was able to discover. The fact that the honse-fly is able to fly at a considerable height above ground is indicated by the fact that I have frequently found them Hying at an altitude of 80 feet above the ground. Flight at so great a height conjoined with a steady wind would enable them to cover a considerable distance.

Howard (1911) records an experiment of J. S. Hine who caught 350 Hies and marked them with gold enamel before liberation. Flies so marked were observed abont dwellings from 20 to 40 rods (600 to 1200 yards) from the point of liberation up to the third day. Hine states: "It appears most likely that the distance flies may travel to reach dwellings is controlled by circumstances. Almost any reasonable distance may be covered by a $\mathrm{Hy}$ under compulsion to reach food or shelter. When these are close at hand the insect is not compelled to go far and, consequently, does not do so." The experiments which I am about to mention, however, show that flies will travel a considerable distance even where houses occur. The same author also states that Prof. S. A. Forbes had experiments carried ont in which it was shown that marked flies spread naturally for at least a quarter of a mile.

An interesting and valuable series of experiments on the range of flight of flies moler rumal conditions was carried ont by Copenam, Howlett and Merrima: (1911), an opportunity being atforded by an unusual plague of house-tlies in the neighbourhord of a small 
vilkage, Postwick in Norfolk, where the observations wore made. The work was much hampered by the meteorolugical conditions, which were for the most part infaromable, the temperatme remaining low while lain showers were fiequent and high winds often prevalud. The flies were caught in a not and were marked by being placed in a patper batg containing fincly puwdered coloured chalk of which that of a yellow colom was found to give the best results. Describing the results of the experiments the authors state: "Nevertholess, on each occasion on which several hundred marked flies were liberated, a certin number were subsequently recovered, within forty-eight homs or less, from human habitations in Postwick, at points of the compass which were apparently clependent, for the most part, on the direction of the prevaling wind, and at distances ranging from 300 yards to 1700 valds from the refuse deposit. On one particular occasion on which chalk of a bright cantry yellow colour was employed for marking the flies, the day being fine and sumny with a gentle north-west breeze, the results were specially interesting. Of these flies several wore observed and captured along the stretch of river bank between a point opposite the refuse heap and Postwick Hall, within half an hour of their liberation. Two other marked Hies were caught in a large open-fronted house on the lawn of Postwick Hall, a clistance of 800 rards in a direct line from the point at which the were set free-one thirty-five minutes and another forty-five minutes after being liberated. Within the next four days, more than forty of these yellow-coloured Hies were caught, on hanging fly papers, in the kitchen and outbuildings at Postwick Hall, while isolaterl specimens were also trapped in various parts of the village, at greater distances and at different points of the compass, from the refuse deposit of the marked flies caught on "tanglefoot" paper's and a certain proportion probably were overlonked, owing to the fact that the colour of the chalk soon gets considerably obscured by the ghtinous material becoming spread over the bodies of the Hies in their struggles to free themselves."

In riew of the results of the foregoing experiments on the range of Hight of house-flies under rural conditions, it sermed to me very desirable that experiments should be carried out under city conditions, where so many factors are present which may affect 


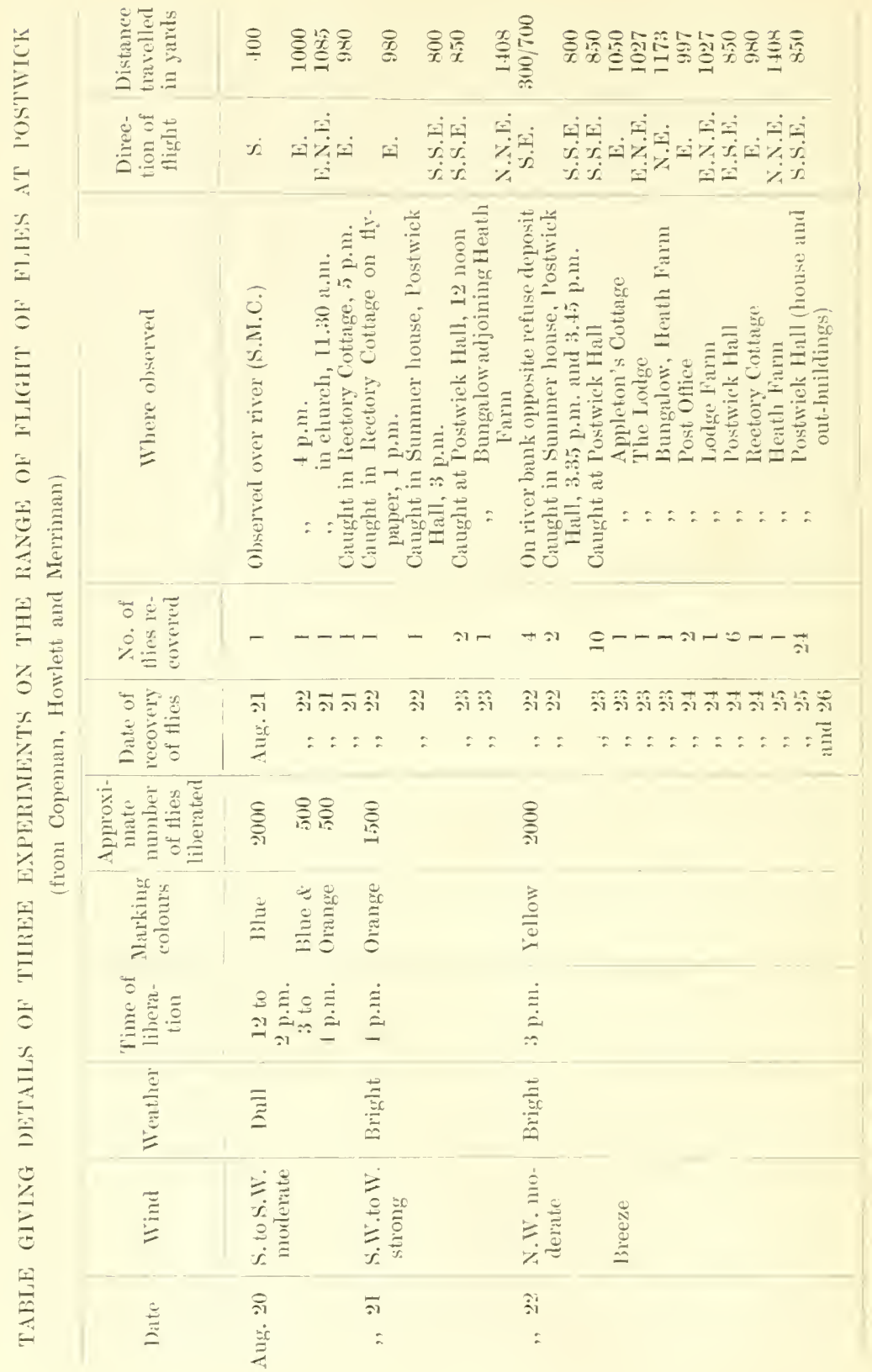


the flies' ability and desire to travel. 'The range of thight of Hies in eities has a direct bearing on the possibilities of the carriage of infection and location of breerling places and muisances. Accorrlingly in the summer of 1911 I aranged a series of experiments in the eity of Ottawa which were carricel out, moler my direction, by Mr. G. E. Sanders, a field officer of the Division of Entomology, to whom belongs the credit of devising the excellent method of marking the flies.

The point of liberation of the Hies was on Porter's Island, a small island abont 1000 feet long, lying in the Rideau River, which runs through a part of the city and is a tributary of the Ottawa River which it joins a short distance further along its course. The surronding district forms a pontion of the north-eastern part of the city and consists chiefly, especially on the northern side of the river which is known as $\mathrm{New}$ Edinburgh, of working-class dwelling houses. On this island which is comnected with the bank by at small brirlge, small-pox cases were isolated in a small wooden house userl as a hospital, or in tents. The land rises gently from the river on the sonthern side.

The flies used in the experiments were obtained and marked in the following manner: Stable refuse, in which the larvae were found in large numbers, was placed in breeding boxes, provided with a circular aperture at the top and balloon fly-traps were placed over these apertures. The flies, on emerging firm the pupae, entererl these cages and were thus obtained in a healthy and minjured condition. They were marked by spraying them while in the wire cages with a solution of rosalic acid (rosaurin or methyl-aurin $\mathrm{C}_{20} \mathrm{H}_{16} \mathrm{O}_{3}$ ) in 10 per cent. alcohol, applied by means of a fine spray. This method of marking insects was rlevised by Mr Sanders, who first used it in experiments with ants. It is simple, ham less and reliable as a means of detection. The presence of a marked fiy on a sticky fly-paper is indicaterl by its producing a searlet coloration when the paper is dipper into water mate slightly alkaline. In these experiments the flies were reared and narked in the Division of Entomology, which is situated abont three miles from Porter's Island, to which they were carried in the cages and liberated on arrival. "Tanglefoot" Hy-papers were placed in as many as possible of the houses in the neighbouring 
district on both sides of the river. The papers were placed chiefly in the kitchens of houses and were collected one or two days after being distributed. They were usually collected in that portion of the district towards which the wind had been blowing from the direction of the island, as it was found that the wind was the chief factor in determining the direction of the distribution from day to day.

\section{EXPERIMENTS.}

Flies liberated on Porter's Islund.

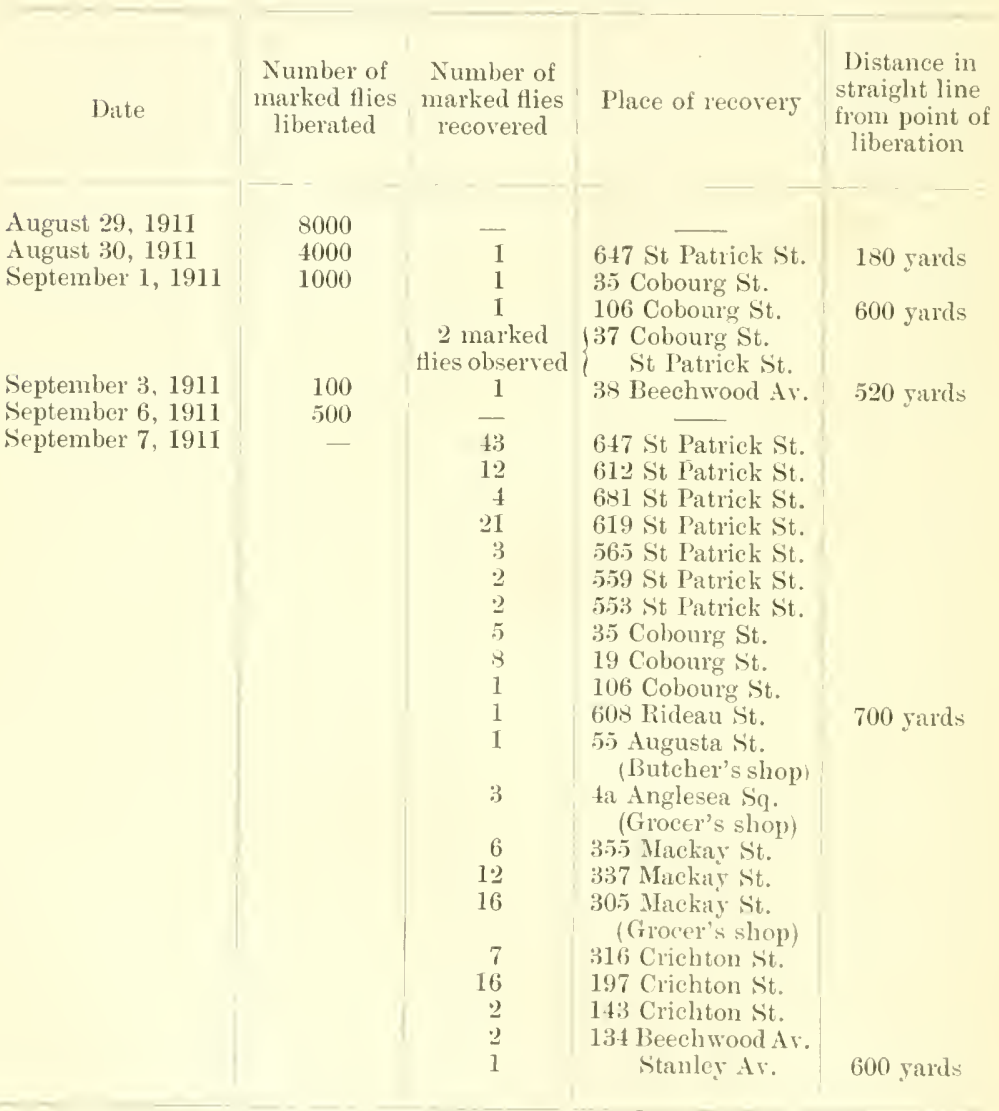

As will bes seen fiom the dates given, these experiments extend orer a short time only, having been terminated by the arlvent of a 
peried of cold weather which checkerl the flies' activity. Nerertheless, they are of value as indicating the ponsibilities in the way of the range of thight of flies under normal city conclitions. There is no doubt that given the necessary conditions with regand to wind and elevation above the ground the range would be considerably greater than was actually fomol in these experiments. The

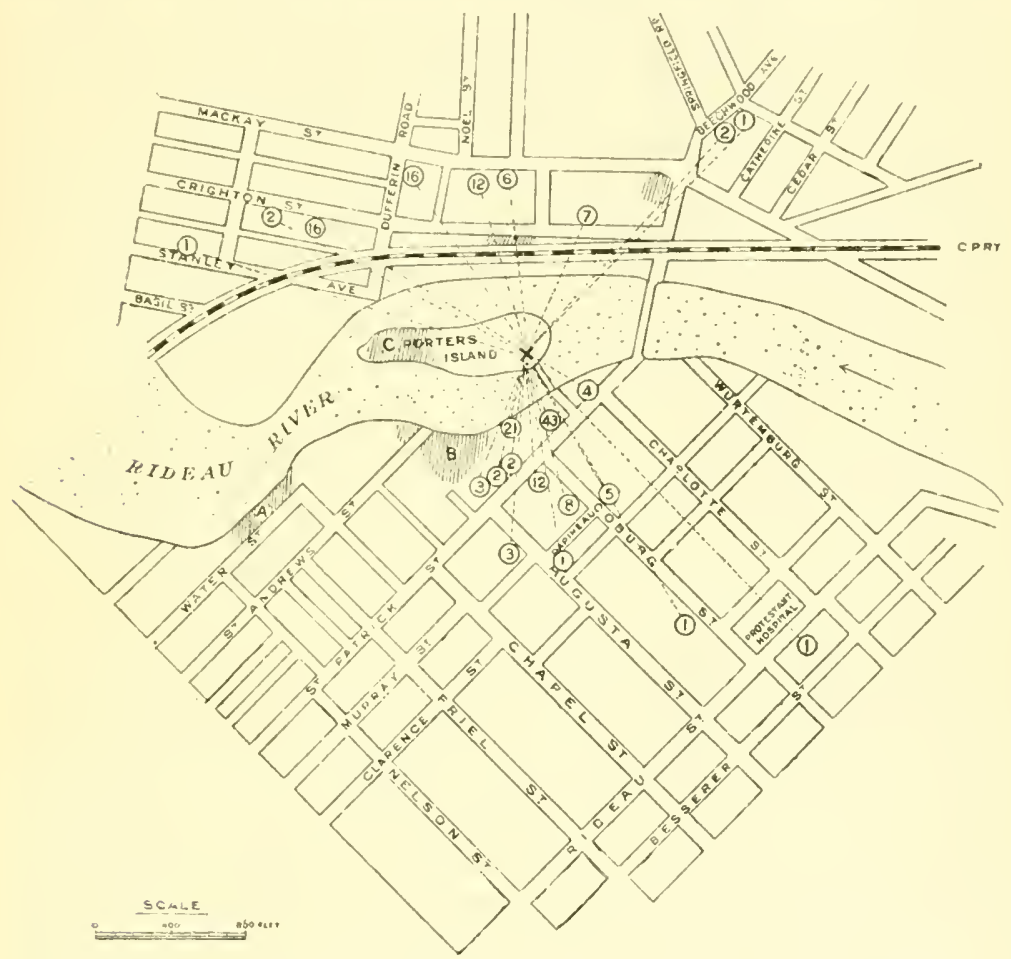

Map of portion of City of Ottawa showing range of flight of marked flies.

X Point where marked Hlies were liberated. Shaded portions A, B, C, etc. inticate breeding places of flies. Numbers in circles indicate number of marked flies recovered at the various points.

greatest range of flight obtained in these experiments, namely 700 yards, represents an actual flight of considerably greater distance than is represented by a straight line from the place of liberation to the point of capture.

The chief breeding places of house-flies on a large scale are shown on the accompanying map as shaded areas. The western 
extremity of Porter's Island was used as a garbage dump (C) until June 1911, this being about 170 yards from the isolation tents and hospital. Between the end of Water Street and Rideau River garbage was being dumped (A), a large proportion of which consistert of stable refuse (borse mannre). At this place, which is about 5:30 yards from the hospital, flies were found breeding in considrable numbers. At the foot of $\mathrm{St}$ Andrews Street, adjoining the river and about 270 yards from the hospital, about 100 tons of horse manme and compost had been dmmperl (B). There were in adrlition numerous breeding places apart from an unusually large number of 110 protected heaps of horse manure in stable rarrs. Consequently flies were extremely abundant on the island and throughont the district. The presence of comntless numbers of flies in the district which were bred in these natural breeding places made the recovery of 172 marked flies ont of a total of 13,500 which were liberated all the more remarkable.

The results of these experiments indicate in a significant manner the distances which, moler city conditions, flies are able to travel from their breeding places or from a sonce of infection?

\section{Feeding Habits axd the Influence of Food.}

The fact that the Hy ingests micro-organisms on account of its indiscriminate feeding habits and that bacteria remain in a viable condition in the alimentary canal for a greater length of time and in larger numbers than externally renders a consideration of the

1 Since the above was written the results of further experiments on the range of flight of house-flies have been published.

Nuttall, Merriman and Hindle (1913) earried out a series of experiments in Cambridge. They liberated upwards of 25,000 flies marked with coloured chalk dust. The maximum Hight in thickly-housed localities of the flies recovered was about a quarter of a mile; in one case a single $H y$ was recovered at a distance of 770 yards, part of which distance was across fen-land. It is considered by the authors that the chief factors farouring the dispersal are fine weather and warm temperature. The nature of the locality is a considerable factor.

Zetek (in a paper presented at the meeting of the Ent. Soc. of America, Atlanta, Ga., Dee. 31st, 1913) deseribes experiments earried out in the Panama Canal Zone. He showed that marked flies had flown from the breeding place (cow manure) to dwelling places situated 2.500 feet away and at a lower level of 150 fcet.

Hodge (1913) in explanation of the discovery of thies $1 \frac{1}{4}, 5$ and 6 miles respectively out from the shore of Lake Erie (U.S.A.) suggests that they were carried by the wind. 
feeding habits of the fly exsential to a thorough comprehension of the possibilities of bacterial dissemination by Hies. This problem will be fully discussed later when it will be shown that the transportation of bacterial and other organisms in the alimentany tract is of greater import than the transportation of such organisms externally, on the legss, proboscis, etc., of the fly.

Most people are acyuainted in a general way with the fererling habits of the house-fly. Its visits to the rlining table are a matter of common knowledge: the general ignorance in regard to its visits to repositories of filth and excrementoms matter has been largely responsible for the indifference of the majority of people to the hygionic aspect of the house-fly.

The anatomy of the proboscis and of the alimentary tract, a knowledge of which is essential to molorstanding the feeding habits of the $\mathrm{fly}$, have already bren describer. Although I made extended obsirvations on the feerling habits of the honse-fly from the beginning of my sturly of this insect, these observations were not recorded in my earlier papers and to Graham-Smith belongs the credit of first recording any extensive and accurate observations on this subject. In his papers (1910, 1911 " and 1911b) he has given an excellent account of the general behariour of flies during feeding and of the digestion of the food and his observations fully confirm those which I had made; he also makes a large number of new observations in connection with his bacteriological studies and his study of the structure and function of the oral sucker of the blow-fly is invaluable.

The probuscis of the house-fly is adapted to a sucking function and the absorption of liquid or liquefied food. Except under certain circumstances it does not and cannot take in solid particles of ford. Nicoll (1911) in his experiments on feeding flies on the eggs of tapeworms found that flies were "apparently unable to ingest particles of larger size than $045 \mathrm{~mm}$." A careful examination of the structure of the oral lobes or sucker makes plain the reason for this. As I have shown in describing the structure of the mal lobes, and as Graham-Smith in his study of the oral sucker of the blow-fly also pointed ont, communication between the surface of the oral lobes and the pseudo-tracheal chamels is effected by way of the spaces between the bifid extremities of the chitinous rings 
which keep open the pseurlo-tracheal channels. In the house-fly these interbificl spaces, as Graham-Smith aptly termed them, measure from 004 to $.00: 3 \mathrm{~mm}$. in riameter, indicating how impossible it would be for particles of fool to be absorbed with the ford in the normal manner and pass along the pseudo-tracheal channels to the mouth. The only possible manner in which solid particles such as the eggs of tapeworms could gain access to the pharynx would be by direct entrance into the mouth. In experimenting with Indian ink I found that through the sucking action of the oral lobes the solid particles were heaped up in a slight ridge in the channel between the lobes and remained between the lobes while the $\mathrm{H}_{\mathrm{y}}$ continued feeding. Graham-Sinith observed the same process in feeding the blow-Hy with pollen grains. It is not difficult to understand how, when feeding on solid foor which is being liquefied or on liquid food containing minute particles, such particles which were not too large might be sucked up into the oral pit and into the month. This undonbtedly happens in the case of the absorption of the tapeworm eggs. Ordinarily, however, the entrance of foor into the oral pit is prevented by the prestomial teeth and the close apposition of the imner edges of the enshion-like oral lobes.

In orler to feerl on dry substances such as sugar, dried specks of milk or sputum, etc., the fly has first to liquefy the substance. This is accomplished by the secretion of what I termed the lingual salivary glands. This is poured down the habium-hypopharynx into the mal pit and on to the surface of the solid substance, both directly and through the pseudo-tracheal channels. This process can be observed by inverting a film of dried up sugar solution on a slide orer a glass capsule containing a Hy, the process being watched through a Zeiss binocular microscope. The solid matter is soon liquefied by the rapid sucker-like movements of the oral lobes moistened by the salivary secretion. Frequently the liquefaction is aided or brought about by means of the regurgitated ford when the fly has fed previonsly. Graham-Smith found carmine stains in the proboscis marks of flies feeding on semi-fluid material as long as 22 hours after they had been fed on carmine colomed food, indicating that some of the previous meal had been apparently regurgitated, therely assisting the salivary secretion. 
In flies which have nover previonsly ferl or have not fied fior some time, I believe the solid food is liquefied solely by the action of the silivary secretion: this would specially apply to flies which have recently emerged from the pupal caste or from hibermation. In feeding on dried films of tood material such as sugan, milk, ete, the Hy generally sucks clean the surfice to which the oral lobes are applied, leaving a heart-shaped area and the whole of a small area is rapidly eleaned 11p in this manner (see fig. 32). In some cases only the impressions of the psentotracheal chimnels are left (fig. 33). In the case of fluirls the resulting fluid is sucked up into the oral pit through the psemelo-tracheal channels and by the action of the powerful pharyngeal pump), the action of which may be seen when the feeding fly is observed from the front ${ }^{1}$, it is sucked up into the oesophigus through which it runs into the crop. If the food is colonred with nigrosin or carmine the filling of the crop can be readily observed. The slightly concive, ventral surface of the abdomen of the hungry fly rapidly becomes convex

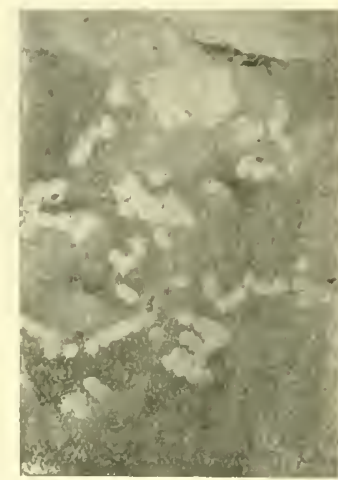

FIG. 32. Proboseis marks of $M$. domestica allowed to feed upon film of sweetened Indian ink. Enlarged.

in the anterior region where the crop lies. The tilling of the crop takes place very rapilly in the case of liquirl food: sometimes it is gorged in less than a minute, as Graham-Smith also observed. If feerling continues the food begins to flow directly inte the ventriculus, and the abdomen, as a whole, becomes rather distenderl. Such gorges, however, frequently prove fital, as I find that there was greater fatality among abnormally gorged flies than among those which fed, as one might say, rationally. As a rule flies ro not appear to cease feeding until they are gorgerl. 'Their meals are frequently disturbed and here, I believe, we see the natural function of the crop as a food reservoir. Food can be taken into

I I have fourd that the action of the pharyngeal pump can be studied most advantageonsly in Stomorys when the same is allowed to feed on the back of the hand and watched through the Zeiss binocular microseope. 
the crop rapidly. The fly then rests in a quiet place. The absorbed foor now begins to flow through the proventriculus, which acts as a pmup amit valve, into the rentriculus'. I have compared this to the feerling of the rmminating animal, as the crop of the fly calls to mind the storage stomach of the ruminant.

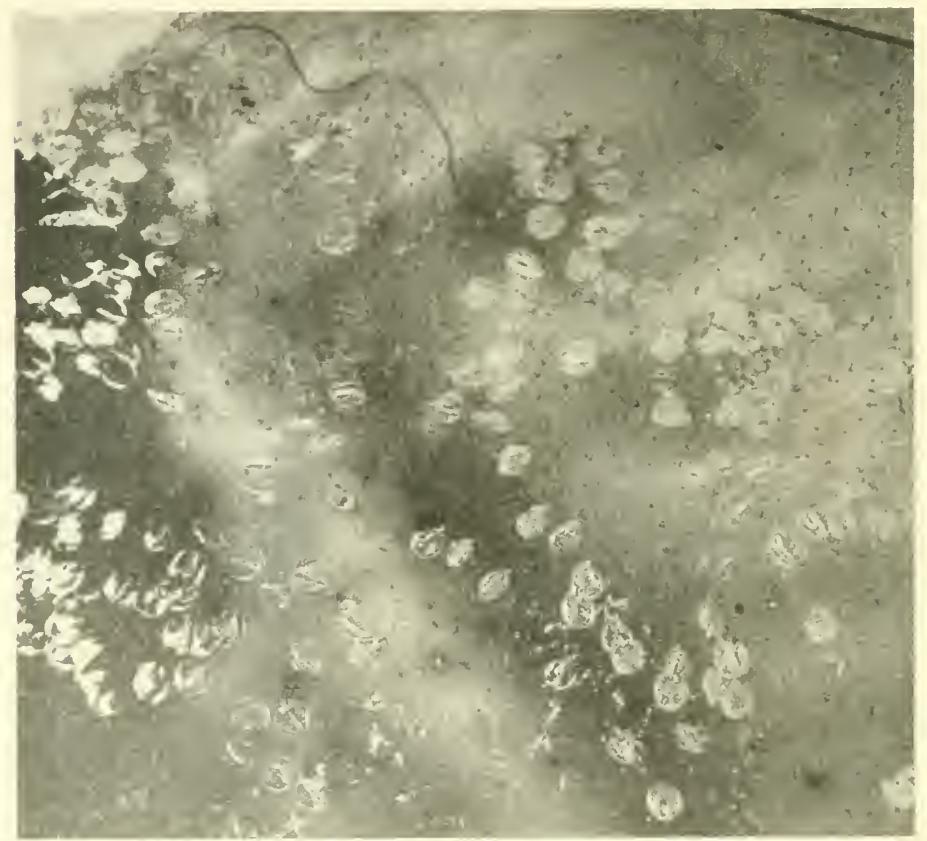

FIf. 33. Proboscis marks of a $\mathrm{Hly}$ (not $M$. dumesticu) allowed to feed on film of Indian ink (sweetened); showing the alternating light and dark lines, the former being where the film has been removed by the pseudo-tracheae. Greatly enlarged. (Photographed by H. T. Giissow.)

Graham-Smith formd that the rate at which ford passes into the intestine from the crop appears to rary, flepending to some extent on the nature of the foxd and the temperature. If flies were kept in an incubator at $57^{\circ} \mathrm{C}$. and fed on carmine gelatine mueh of the forsl may rach the rectal valve within one hour of feerling. He gives the following tables which inclicate the rate

1 Wheeler (1910) mentions the fact that in ants the proventriculus not only pasies the liquir foor back tror. the crop to the stomach but also fills the crop in the first plinee. 
at which the forml passes from the crop and the periond diring which colomed food may remain in the coup.

TABLE SHOWIXG THE RATE AT WHICH FOOI l'ASSES THROIGH THE CROP INTO THE INTESTINE.

(from Graham-Smith.)

\begin{tabular}{|c|c|c|}
\hline $\begin{array}{l}\text { Time after } \\
\text { feelling }\end{array}$ & $\begin{array}{l}\text { Number of } \\
\text { tlies lissected }\end{array}$ & Results \\
\hline 3 minutes & 1 & $\begin{array}{l}\text { Crop full of red Huid, but none found in } \\
\text { ventriculus or intestine }\end{array}$ \\
\hline 6 minutes & 1 & $\begin{array}{l}\text { Crop full of red fluil, but none found in } \\
\text { ventrieulus or intestine }\end{array}$ \\
\hline 10 minutes & 1 & $\begin{array}{l}\text { Crop full of red thuid and some fluid } \\
\text { beginning to pass into ventriculus }\end{array}$ \\
\hline 1.5 minutes & 1 & $\begin{array}{l}\text { Crop full of red tluid and upper third of } \\
\text { intestine red }\end{array}$ \\
\hline 20 minutes & 1 & $\begin{array}{l}\text { Crop full of red fluid and upper third of } \\
\text { intestine red }\end{array}$ \\
\hline \multirow{3}{*}{2 hours } & 3 & $\begin{array}{l}\text { Crop full of red fluid and upper third of } \\
\text { intestine red }\end{array}$ \\
\hline & 4 & $\begin{array}{l}\text { Crop full of red thuid and upper half of } \\
\text { intestine red }\end{array}$ \\
\hline & 1 & $\begin{array}{l}\text { Crop full of red fluid and upper three- } \\
\text { quarters of intestine red }\end{array}$ \\
\hline
\end{tabular}

TABLE SHOWING THE PEIIOD DURING WHICH COLOURED FOOD MAY REMAIN IN THE CROP.

(from Graham-Smith.)

\begin{tabular}{|c|c|c|c|c|}
\hline $\begin{array}{l}\text { Time after } \\
\text { feeding }\end{array}$ & $\begin{array}{l}\text { Number of } \\
\text { flies disseeted }\end{array}$ & & Results & \\
\hline 24 hours & 2 & $\begin{array}{l}\text { Crop red and } \\
\text { throughout }\end{array}$ & distended. & Intestine rec \\
\hline 48 hours & 3 & $\begin{array}{c}\text { Crop red and } \\
\text { throughout }\end{array}$ & distended. & Intestine re \\
\hline 3 days & 3 & $\begin{array}{c}\text { Crop red and } \\
\text { throughout }\end{array}$ & distended. & Intestine rec \\
\hline 4 days & 2 & $\begin{array}{l}\text { Crop pink and } \\
\text { tbroughout }\end{array}$ & distended. & Intestine re \\
\hline
\end{tabular}

In most cases on dissection the crop was found to be nearly empty on the third day after feeding, although the intestine still contained large quantities of red material. The above results indicate that the crop is not completely emptied for many hours and in some cases for days, even though no further food is given. This tact has been confirmed in my own observations. Flies which have 
been allowed to feed natmrally on coloured jam have been found with jam still in their crops on the second day after feeding.

After feerling the fly uswally retires to a quiet spot. It invariably cleans its head and proboscis, as is also the case with Stomoxys. Very frequently it regurgitates its foor from the crop in the form of large drops of fluid which may equal in dianeter the depth from firont to back of the head (fig. 34). This regurgitation of "vomit" drops conveys, as Graham-Smith, who has also observed and recurderl the fact states, the impression that the flies "have distended their crops to an uncunfortable degree and that some of the food is regurgitated to relieve the distension." While this is conceivable, it is not unlikely that the regurgitation of the food may be prinarily concerned in the digestion, as I have observed it to take place when there hard been no unusual distension of the

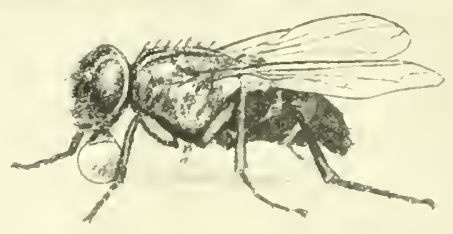

FIs. 34. M. domestica in the act of regurgitating food. $\times 4 \frac{1}{2}$.

crop. One cau understand that the regurgitation wonld enable the foor to become mixer with an additional amount of salivary Huid which would further facilitate the digestion on the absorption of the drop. The drops are slowly extruded and then withdrawn. One fly which I had under observation alternately and regularly regurgitaterl and absorbed a drop of fluirl eight times, ench regurgitation and absorption lasting one and a half minutes. In some cases these "vomit" drops are deposited upon the surface on which the fly is resting and they may be easily recogniserl as lightcoloured opaque spots (see fig. 35). Their colour will, of course, vary according to the nature of the flies' last meal. GrabamSuith found that flies fed on coloured sycup often regurgitaterl coloured fluid 24 or more hours later, though fed in the interval on mocolomed syrup. In his infection experinents he observerl that "when infected ford has been given, the infecting organisms 
are usually found in great nmubers in these 'spots' and moreover, as will be shown later, fluid regurgitatert from the crop is nserl to dissolve or moisten sugar and other similar dry food materials."

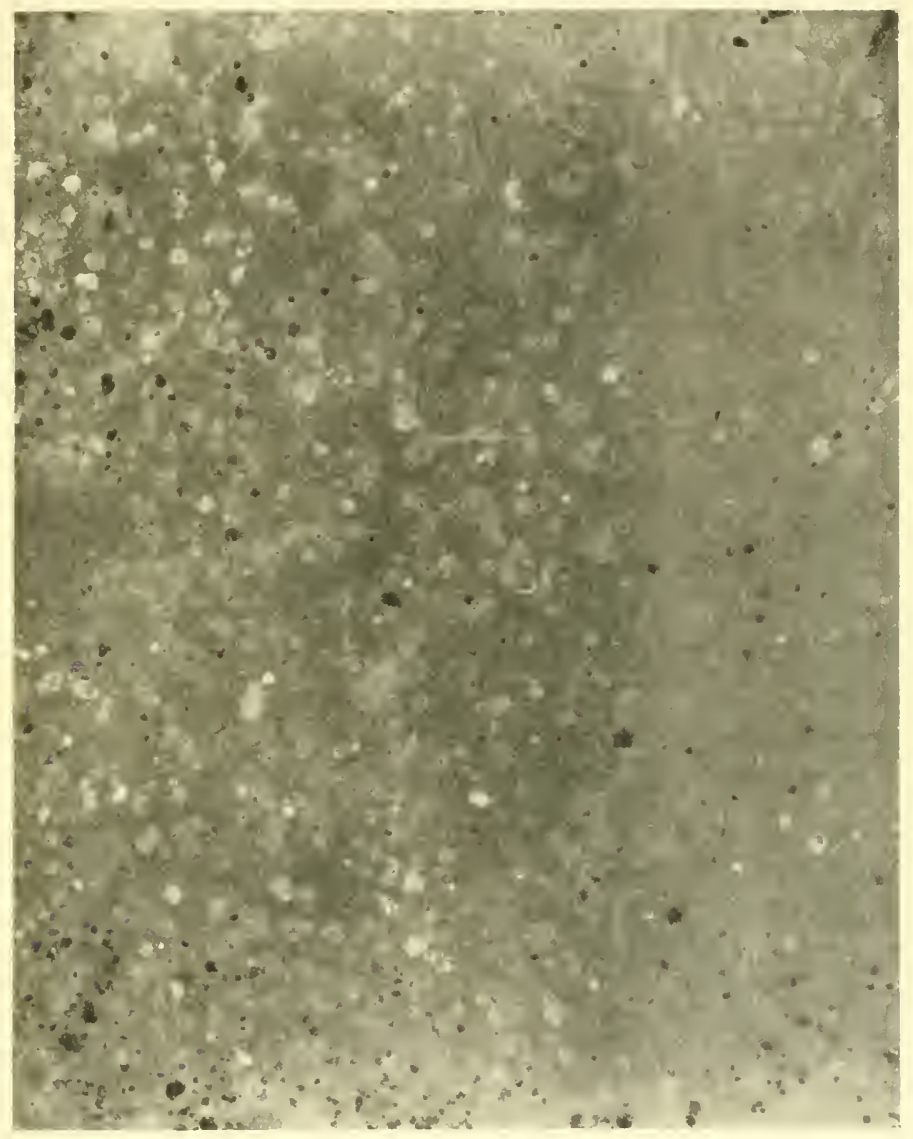

Fit. 35. Portion of window pane from Hy-infested cow-shed, showing darkcoloured faecal spots and more numerous light-coloured vomit spots. Natural size.

The importance of this habit, from the point of view of bacterial contamination, cammot be emphasized too strongly.

The rate of digestion depends chiefly on the temperature and the nature of the food. At ordinary room temperatures the H. 11. $-\mathrm{F}$. 
colomed faeces produced by feeding Hies on coloured syrup are not deposited until several hours after the meal. Graham-Smith in his experiments found they were not repusited within two hours after feeding. He made a number of interesting observations on the rate of defiecation and the effect of different kinds of food on the same. The yellowish to dark brown firecal spots or fly "specks" are well known. A series of ten flies which had been given one feed of nilk produced in a period of 22 hours an arerage of 12.5 vonit spots and 39 faceal spots. A series which were allowed to feed on milk whenever they wished proluced an arerage of $17 \cdot 9$ romit spots and 4.5 faecal spots in 22 hours. The average number of "spots" both faecal and vomit, prodnced by the two series in 2.2 hours was 16.4 and 20.4 respectively. In a further experiment the average number of spots, faecal and romit, which were deposited per fly in 24 hours was $30 \% 7$. Three series of flies were fed on syrup, milk and sputum for sereral days. Those fed on syrup produced an average of 4.7 deposits (faecal and vomit) per Hy per day, those fed on milk 8.3 and those fed on sputum 27.0. In the Jatter case Graham-Smith points ont that the faeces were much more voluminous and liquid than usual and in fact the flies seemed to suffer from diarrhoea.

The rate of deposition and number of the facal vomit spots deposited is highly significant in connection with the question of the bacterial contammation of food and especial attention is drawn to the bearing of the abundance and character of the spots deposited by thies feeding on sputum on account of its bearing on the dissemination of the tubercle bacillus.

Mention will be made later of the inflnence of food on the development of the larvae; the experiments which were carried out showerl that the larvae develop more rapidly in certain kinds of foorl, such as horse mamure, than in others. It has yet to be discovered what are the chemical constituents which farour the more rapid development. It was found that insufficient food in the larval state retarded development and produced flies which were subnormal in size. Bogdanow (1908), in an interesting experiment, fed $M$. domestica through ten generations on unaccustomed fool such as meat and tenacetum in different proportions, and he formot that the resulting Hies did not show any change. 


\section{The Inflenence of Temperature.}

The influence of temperature on the development of the larrat and on the life-history will shortly be discussed. Temperature also directly affects the adult insect; house-flies are most active at a high sunmer temperature and their metabolism is correspondingly active. Cold produces inactivity and torpor. They are able, however, to withstamel a comparatively low temperature. Bachmetjew (1906) was able to submit $M$. domestice to ats low a temperature as -10 C., and vitality was retained, as they recovered when brought into ordinary room temperatme. Donhotf (1872) performed a number of experiments previous to this with interesting results. He submitter $M$. domestice for five hours to a temperiature of $-1.5^{\circ} \mathrm{C}$, and they continued to move. Exposed for eight homrs to a temperature of first $-33^{\circ} \mathrm{C}$. and then - $-2 \mathrm{C}$. they moverl their legs. On being submitted for twelve homs to a temperature first of $-3.7^{\circ} \mathrm{C}$. and then $-6.3^{\circ} \mathrm{C}$. they appeared to be dead, but on being warned they recovered. When exposed for three hours to a temperature of $-10^{\circ} \mathrm{C}$. which was then raised to $-6^{\circ} \mathrm{C}$., they died. These experiments show that $M$. domestica is able to withstand a comparatively low degree of temperature.

\section{The Ixfluexce of Light axd Colour Preferexce.}

The adult house-fly seeks the light, that is, it is positively heliotropic, and as Felt showed, is unwilling to enter very dark places to depusit its eggs, although in placing the eggs it endea rours to place them as far away from the light as possible.

A series of experiments were carried out by Galli- Talerio (1910) with a view to ascertaining whether flies had preferences for certain colonrs. Flies were placed in a cubical glass-sided box measuring $35 \mathrm{~cm}$. each way. On the sides of the box pieces of coloured paper of equal size were pasted. The flies resting on the different colours were then comted, the cage being turned in different positions to aroid error. The colour preferences which he found were as followis, the preference for clear light colours being strongly indicated:

$\begin{array}{lllllr}\text { Clear green } & 18 & \text { Azure } & \ldots & \ldots & 13 \\ \text { Ruse ... ... } & 17 & \text { Clear red... } & \ldots & 10 \\ \text { Clear yellow } & 14 & \text { Dark grey } & \ldots & 9\end{array}$




\begin{tabular}{|c|c|c|}
\hline White... & 9 & Pale rose ... \\
\hline Dark red & 8 & Very clear green \\
\hline Pale grey & $\check{5}$ & Black $\quad \ldots \quad \ldots$ \\
\hline Dark yellow & 5 & Blue ... ... \\
\hline Dark green... & 5 & Pale violet \\
\hline Red $\ldots$ & 4 & Dark brown \\
\hline Orange & 3 & Lemon yellow \\
\hline Clear brown & 3 & \\
\hline
\end{tabular}

While these results are interesting further experinents would be required before any general conclusions conld be drawn'.

\section{Hibernation.}

The disappearance of Hies towards the end of Oetober and during November is a well known fact and the question is frequently asked, what becomes of them? Olservations on this question were made from the beginning of my study of this insect.

Three causes contribute to the disappearance of the flies, lamely, retreat into hibernating quarter's or into permamently heated places, natural death and death from the parasitic fungus Empuse muscue. The last canse of disappearance is fully comsidered later and it accounts for a large proportion of the summerbred Hies. The natural cleath of Hies may be compared, I think, to the like phenmenom that ocems in the case of the hive-bee, Apis mellifice, where many of the workers die at the end of the seasom by reason of the fact that they are simply worn ont, their function having been fulfilled. The flies which die naturally have probably lived for many weeks or months during the summer and antumn, and in the case of the females have depensited many batches of eggs; their life work, therefore, is complete. Those Hies which hibernate are, I believe, the most recently emerged, and therefore the youngest and most vigorous. On dissection it is found that the abdomens of these hibernating individuals are packed with fat cells, the fitt-body having developed enomomsly: The alimentary canal shrinks correspondingly and oceupies a very smatl space: this is rendered possible by the fact that the fly does

${ }^{1}$ Hindle (1913) has more reeently carried out a series of experiments in which strips of coloured cardboard were exposed to catch thies which settled on them. The experiments appear to demonstrate that the flies did not display any marked colour preference. 
not take ford during this period. In some females it was fomd that the waries were very well developerd, while in others they were small, and mature spermatozoa were found in the males. Like most animals in hibemating, $M$. domestica becomes negatively heliotropic and creeps away into a dark place. In houses they hatve been found in varions kinds of erevices such as ocem between the wodwork and the walls. They have been found behind pictures, books and curtains. A farourite place for hibernation is between wall parper which is slightly loose and the wall. A certain number hibernate in stables, where, owing to the warmth, they do not become so inactive, and they emerge earlier at the latter end of spring. 1)uring the winter the hibernating Hies are sustained by means of the contents of the fat-body, which is found to be extremely small in hibernating flies if dissected when they first emorge in May and June. The abolominal cavity is at first considerably decreased in size, but the fly begins to feed and soon the alimentary tract regains its normal size, and togother, with the development of the reproductive organs, causes the abelomen to regain its normal appearance. The emergence from hibernation appears to be controlled by temperature, as one may frequently find oxld thes cmerging from their winter quarters on exceptionally warm days in the early months of the year. A few Hies may occasionally be found active throughout the winter. I have found active thies frequently during the months of Decomber to February in such warm places as kitchens, restaurants and stables during which time they are able to breerl. Jepson (1909) caught flies in the bakehouse of one of the Cambridge colleges in February and used these flies in his breeding experiments. He records the reported occurrence of flies in the college sculleries throughont the winter months. These active and periorlically active flies, together with the wholly dormant flies are the progenitors of the summer millions.

1 Skinner (1913) asserts on the circumstantial evidence of a single recently emerged fy, found entering a window, unsupported by experimental evidence, that house-flies pass the winter in the pupal stage. So far, I have been unsuccessful in carrying pupae of $M$. domestica over the winter months. Skinner's Hy was probably one bred in a warm place during the winter.

Copeman (1913) calls attention to the desirability of securing further evidence as to where and under what circumstances surviving flies pass the winter. 


\section{Regeneration of Lost Parts.}

If the wings or legs of $M$. domesticn are broken off they do not appear to be able to regenerate the missing portions, as in the calse of some insects, notably certain Orthoptera. Kammerer (1908), however, experimenting with H. domestica and C. romitoriu, has found that if the wing is extirpated from the recently pupaterl Hy it is occasionally regeneraterl. The new wing is at first homogeneous, and contains no veins, but these appear subsequently.

\section{LONGEYITY.}

The difticulty of experimentally determining the length of the natural life of a house-fly can be appreciated only by those who have attempted it. Those who have not done so will hardly realise it. Few insects are more lifficult to deal with under experimental conditions. One would inagine that these insects Hying about everywhere as they do, could be easily kept in a large roomy cage if given the necessary food and water. In my experience, however, this has not been the case; I have never succeerled in keeping Hies alive in captivity for a longer period than seren weeks. In the winter it is apparently more easy to keep them alive in captivity. Jepson (1909 b) kept alive for eleven and a half weeks flies which had been reared in confinement in February. Flies which harl been cinght in the kitchens dluring the same month, and ware, therefore, probably thies of the previous antumn, were kept in captivity for ten wecks. Jepson states that in the summer he was unable to keep flies in eaptivity for more than three weeks. Griffith (1908) succeeded in keeping a male Hy alive for sixteen weeks. The evidence which is avaliable clearly indicates, I think, that the late antumm lnerl Hies, if they escape death from Empusu and other cansw, live throngh the winter to produce eggs in the following spring. I am inclined to regard the winter breeding of $\boldsymbol{M}$. domestice as unnatural, as it is induced by conditions which are, strictly speaking, artificial. The summer flies are probably shorter lived owing to their extremely active lives which endure probably for about two months (i) sis. 


\section{PART II}

\section{THE BREEDING HABITS'; THE IIFE-HISTORY}

ANI) STRUCTURE (jF THE LARVA

\section{CHAP'TER V']}

THE BREEDING HABITS OF UCSCA DOLESTICA

THE meagre nature of the information concerning the lifihistory and the breeding habits of the house-fly which was available at the time ny investigations were begun has been indicated already in the introductory chapter, in which the history of 1 m knowledge of this insect was tracerl. Gleichen and Taschenberg in Emope, Packiard and Howard in the Uniterl States, had been the chief contributor's to om knowlerlge of the breeding habits.

Carl de Geer (1776) was one of the first to lescribe the breeding habits. He stated that the honse-fly developed in warm and hmmid dung, but dirl not give the time ocenpied by the different developmental stages. He refers to the enormous quantities of thies occurring fiom July to August. His statement concerning their development is especially interesting, as he appears to be the first investigator who called attention to what I consider to be one of the most important factors in the development of the Hy, manely, the process of fermentation oceuring in the substance in which development is taking place. He says (p. 76): "Les larves de cette espèce vivent donc dans le funier, mais miquement dans cehni qui est bien chand et hunide, ou pour mienx dire qui se trouve en parfaite fermentution" (the italics are mine). 
(xleichen (t.c.) found that the eggs hatcherl from twelve to twenty-fon homs after deposition. He rearerl the larvae in decaying grain where, no doubt, fermentation was taking place: also in small portions of meat, slices of melon, and in old broth. His observations are extremely interesting, and, excluting mistakes which were due to the lack of morlem apparatus, his accome is still a valuable comtribution to on knowlerge of the subject. Bonche (1834) describes the larvace as living in horsemanure and fowl-ding, especially when warm. He does not give the time occupied by the earlier derelopmental stages, but states that the pupal stage lasts from 8-14 days.

Packard (l.c.), working at Salem, Massachusetts, U.S.A., found that the larvae energe from the eggs twenty-four hours after deposition: the times taken by the three larval stages-for he fomnd that there were two larral eclyses-were: first, about twenty-four hours; the second stage, he thought, was from twenty-foum to thirty-six hours: and the third was probably three or four days: the entire larval life being from five to seven days. The pupal stage was from five to seven days, so that in Angust, when the experiments were carried on, the time from the deposition of the egg to the exchusion of the imago was ten to forrtern days.

Taschenberg (t.c.) incorporates the work of Gleichen and Bonché, and he does not appear to ard materially to the facts abready mentionerl. He states that the female flies deposit their eggs in rlamp and rotting food-stuffs, barl meat, broth, slices of melon, dead animals, cesspools, and manure-heaps. He further. says that they have also been observerl laying their eggs in spittoons and open snuff-boxes. With reference to the last statement, I find that the larvae will feed on expectoratixl matter. mixed with a solid substance, such as warth, if they are kept warm, though they cannot feed on salivary sections merely. It is interesting to note in comnection with tho statement as to flies depositing their eggs in sunff-boxes that Fubes, as recorded by Howard (1911), reared $\mathbf{M}$. domestica in 18S9) fiom latrate found in a box of sunff at Kensington, Ill., T.S.A.

Howard (1896-1906) first studied the breerling habits of the Hy in 1895 in Washington, T.S.A., and he describerl them in 
1896, and more fully subsequently. He found that they comld be rarely induced to lay their eggs in anything lout horse-mamure and cow-dung, and that they pretered the finmer. The periods of develepment he fomml were as follows: from the deposition of the egg to the hatching of the larva about eight homs: the first larval stage one day: secomel larval stage one day: thind lamval stage-that is, from the second ecdysis to pupation-three days, and the Hies emerge five days after the pupation of the larvate, thus making the whole period of development abont ten days. The same author, in a valuable study of the insect fauma of human excrement (1900), describes experiments in which he was snccessful in rearing $M$. domestica from human excrenent both in the form of loose firees and in latrines.

My own studies were commenced in 190.5, and a short preliminary account of some of the results were published in the following year (1906). The complete account of my investigations on the loreeding habits and development of the Hy was not published mintil 1908 .

Newstear (1907) formd that horse-manure, spent hops, and ashpits containing fermenting materials and old bedding, or straw and paper, paper mixed with humam excreta or old rags, manure from rabbit hutches, all constituted permanent breeding places. He also found that the following served as temporary breeding places: collections of straw mixed with other vegetable matter and feathers lying in a fermenting condition in open spaces in poultry yards, accumulations of mamre on wharves, berdling in ponltry pens. He was mable apparently to confirm the observations made by Howard and myself as to the breeding uf $M$. domestica in hunan excretil.

In my experiments, which were carried ont mnler both artificial and natural conditions, the larvae of $M$. domestica were succesfully reared in, and the flies bred from, the following substances: horse-manure, cow-dung, fowl-dung, human excrement, both as isolated faeces and in ashes containing or contaminated with excrement, obtained from ashpits attached to privy middens, and such as is sometimes tipped on to public tips. I found that horse-nanure is preferred by the female flies for oviposition to all other substances, and that it is in this material that the great 
majority of larvale are reared in nature: mamme-heaps in stable vards sometimes swarm with the larvae of $M$. domestica. It was also foum that the larvae will feed on paper and textile fabrics, such as woullen, cotton garments, and sacking which are foulerl with excremental products if they are kept moist and at a suitable temperature. They were also reared on decaying regetables thrown away as kitchen refinse, and on such fruits as bananals, apricots, cherries, and peaches, which were mixed, when in a rotting condition, with earth to make a more solid mass. Althongh they can be reared in such food-stuffs as bread soaked in nilk and boiled egg, when these are kept at a temperature of abont $25^{\circ} \mathrm{C}$., I was mable to rear then to maturity in cheese, althongh they fed on the substances for a few days and then gralually died: my failure mal have been due to the nature of the cheese which was used, only one kind being tried. In addition to rearing the larvale on isolated human faces, such as are frequently fomm in insanitary comrtyards and similar places, they were found in privy middens, and also on a public tip among the warm ashes and clinker where the contents of some pricy middens had also evidently been emptied: I bred the flies ont from this material.

In Canada I have further found that $M$. domestica can be reared in germinating wheat, no donbt owing to the heat engendered by the fermentation which takes place.

Jepson (1909) reared $M$. domestica during the winter months on moist breat in which the process of fermentation had begun.

Nash (1909) records that in 1904 he found the spaces romol moveable excreta boxes in privies swarning with fly larrae. He refers to in interesting observation of Austen's, commmicated by the latter in 1908. Austen fomnt the larvace of $M$. domestica in rubber which was suspender in a drring-room at a temperatme of $100^{\circ} \mathrm{F}$. They were apparently full-grown, and the circumstances indicated that they conld not have been more than three days in developing from the egg stage, which indicated a rapid growth at this excerdingly high temperature. Nash records the breeding of the house-fly in stored house-refuse, and he reared them on breall, peatr, potato, banama peetings, beiled rice and wh patper. 
Theobald has reported the breeding of thies on refuse tips. In India Surgeon-Majom Snith has also found that horse-manure is the commonest breeding place of $M$. domesticu, especially around the military camps. He hats alsu reared it from cowllung.

Orton (1910), in some investigations quoted by Howard (1911), found house-fly larsae in a mixture of horse and cow-manure? underncath a fimm bam, and it is interesting to note that the larvae and puparia were more abundint in that portion of the pile where the horse-manure was cither pure or predominated. Pupae were also found in piles of pig-manure mixed with straw bedding exposed to the air and rain. An omce of this material taken from a point a few inches below the surface showed 868 pupae. Flies were also found breeding in spent hops and brewery Waste (malt); an ounce of the latter contained 1018 maggots. In an experiment one pound of material constituting these breeding places was taken and kept in screen-covered glass jars in the laboratory for ten clays. The following was the result:

\begin{tabular}{|c|c|c|c|c|c|c|c|}
\hline \multirow{2}{*}{\multicolumn{2}{|c|}{$\begin{array}{l}\text { Stable-manure } \\
\text { Farm barn, horse end }\end{array}$}} & $\ldots$ & ... & \multicolumn{4}{|c|}{ no adult thes issuerl } \\
\hline & & $\ldots$ & $\ldots$ & 77 & & " & , \\
\hline$"$ & mixed ... & ... & ... & 19 & $"$ & $"$ & , \\
\hline " & cow end & $\ldots$ & $\ldots$ & 1 & , & $\mathrm{fly}$ & " \\
\hline Piggery ma & nure pile & $\ldots$ & $\ldots$ & 361 & , & flies & $"$ \\
\hline Spent hops & $\ldots$ & $\ldots$ & $\ldots$ & 129 & , & " & 3 \\
\hline Barley malt & $\ldots$ & ... & ... & 539 & , & , & , \\
\hline
\end{tabular}

As Howard points out, these results were no doubt in the main correct, althongh the identification of the flies was by no means thorough, as Orton admits.

During the summers of 1908 and 1909 Prof. S. A. Forbes, State Entomologist of Illinois, U.S.A., had obsersations camied out in Urbana, Ill., by Mr A. A. Gisult, and in Chicago by Wr. J. J. Davis, on the breerling habits of the house-fly with a view to discovering what substances, other than the umal breeding place, horse-manure, served as breeding places. The results of these observations have been published by Howarl (1911) and are as follows: 


\begin{tabular}{|c|c|c|c|}
\hline Date & \multicolumn{2}{|l|}{ Breeding material } & \\
\hline Sept. 1 -3 & \multicolumn{3}{|l|}{ Rotten water-melon and musk-melon } \\
\hline $\begin{array}{l}\text { Aig. } 18 \text { and }) \\
\text { sept. } 8-11\}\end{array}$ & Rotten carrots and cncumber's & $\cdots$ & 23 \\
\hline Sept. T & Rotten cabbage stump & & \\
\hline Siept. 7 & Banana peelings $\quad \ldots$ & $\ldots$ & \\
\hline Aug. 30 & Rotten potato peelings & $\ldots$ & \\
\hline sept. 2.; & Cooked peas $\quad \ldots$ & $\ldots$ & \\
\hline Oet. 1 & Ashes mixed with regetable waste & $\ldots$ & \\
\hline Sept. $7-14$ & Rotten liread or cake ... & $\ldots$ & \\
\hline Aug. 몰 & Kitchen slops and offal & $\ldots$ & 193 \\
\hline Sept. 10-26 & Mixed sawdust and rotting vegetab. & & 41 \\
\hline Aug. 30-Sept. 4 & Old garbage, eity dump & $\ldots$ & 15 \\
\hline Aug. 14 and 28 & Rotten meat, slaughter-houses & ... & 40 \\
\hline Aug. 30-Sept. 11 & Carrion in street & ... & 267 \\
\hline Sept. 7 & Seepage from garbage pile & ... & \\
\hline Aug. 17-20 & Hog's hair, slaughter-house waste & ... & \\
\hline Ang. $23-28$ & $\begin{array}{c}\text { Sawdust sweepings, stock vards } \\
\text { slanghter-house } \quad \ldots\end{array}$ & & 110 \\
\hline Ang. 23 & Sawdust sweepings, meat market & $\ldots$ & \\
\hline Aug. $16-28$ & Animal refuse, stock yards $\quad \ldots$ & ... & 39 \\
\hline Ang. 14 & $\begin{array}{c}\text { Contents of pamnches of slaughte } \\
\text { cattle } \\
\text { ca. }\end{array}$ & & 168 \\
\hline Nept. $2-11$ & Rotten chicken feather's & ... & 258 \\
\hline Ang. 16 & ('hicken manure, stock-car dump' & $\ldots$ & \\
\hline Ang. 31 -Sept. 7 & Cow-dung, stable, Urbana, Ill. & ... & 997 \\
\hline Sept. $7-10$ & Cow-dung, outdoor yard & $\ldots$ & 22 \\
\hline Sept. 6 & Cow-dung, pasture $\quad \ldots$ & $\ldots$ & \\
\hline Ang. 24 -Sept. 16 & Human excrement & ... & 196 \\
\hline
\end{tabular}

The above observations are of great interest and importance: as indicating the breeding habits of the flies when they have a choice of substances and under natural conditions, and are confirmatory of my own experiments under laboratory conditions where thies were confined in cages with the rarious substances with a view to ascertaining not only whether they would deposit their egrgs on the substances in question, but also whether the larvae could feed on them and the effect of the different substances upon the rate of development, of which mention is marle later. I also confimed most of the laboratory results by breeding Hies from material exponed or collected in the open. As my experiments were mainly carried out in England, many having been since confirmed in Canada, the observations of Forbes, recorded 
above, made in Illinois under different comrlitions as rugands climate, etc., are of arklitional interest. 'They indicate that the breeding habits are practically the sime whatever the geographical position or climatic conditions maty be.

Milliken (1911) found the rgges and larvae of $M$. domesticu in alfalfa or lncerne ensilage in Kansis, U.S.A. The formentation taking place un doubt attracterl the adult flies.

Pratt (1912) bred fifty specimens of $\mathbf{M}$. domestica from cowmanure at Dallas, Texas, U.S.A. He states that "this is one of the most common species in stables. Fresh manmre attracts it in great numbers."

Paine (1912) mate a study of the species of Hies breeding in garbage in the city of Boston, Mass. U.S.A. Larvate were collected fiom the contents of garbalge-pails as they were emptied into the seavenger's waggon. In some castes they were so abmodant that the interior of the receptacle appeared as a wriggling mass. The larvae were allowerl to complete their derelopment moker laboratory conditions, being fed on moist bread: they pupated in a small quantity of eath. The following table gives the results of these rearings:

Number and species of Muscids renred from city garbuge, Boston, Massuchusetts, U.s.A.

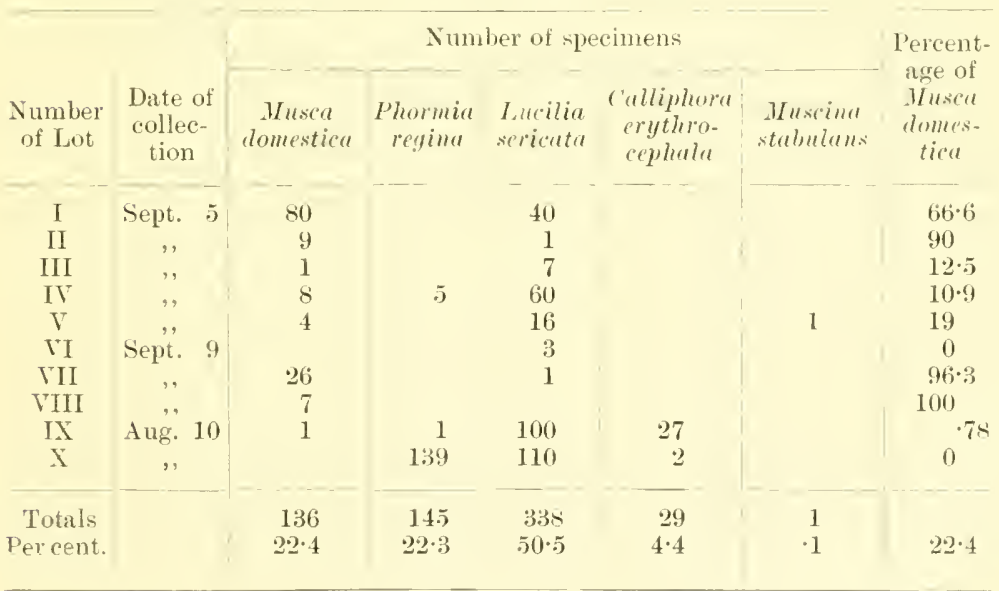


It will be seen that, ont of 649 flies of varions species which were bred from larrae found in garbage, 136 or 22.4 per cent. were Musca domestica.

\section{Sumadry of Substances in which Mesed monkestica BREEDS.}

All the foregoing observations on the breeding places and substances in which flies breed may be conveniently summarised as follows:

\section{Excrementous}

Horse-manure

Human excrement

Fowl excrement
Cow-manure

Pig-manure

Rabbit-manne

l'egetable

Sipent hops

l)ecaying grain

C'ooked peas

Rotten water melon

, musk or other melons

". cucumber

„ carrots

". cabbage

, potato and peelings

Boiled rice

Barley malt

Excreta-soiled straw

Bread or cake

, and milk

Rotten apricots

" bauanas

" cherries

, plums

" peaches

Animal matter

Rotten meat

Carrion

Cattle paunch contents
Rotten fowl feather's

Old broth

Boiled egg

Miscellaneons

Kitchen refuse

Fermenting substances in ashpits

Sawdust and excrementous refuse

Garbage pile drainage

('esspool

\author{
Snuff' \\ Expectoration with earth \\ Excreta-soiled paper, rags \\ Ensilage \\ Rubber
}

All observations which have been made indicate that the chief breerling place of the house-fly is horse-manure or stable-refuse, and that, in addition, it is able to breed in other firms of excrement and in rotting or decaying animal and regetable substances, especially when they are in a fermenting condition. 


\section{Locaton of BreediNg Place.}

The female thies, as a rule, prefer to deposit their eggs on substances or heaps of breeding material exposed to the light. General observations on the occurrence of the larrae have shown that fewer larvae are found in proportion as the sitnation of the substance in which they are living is further away from the light. Felt (1910) has demonstrated experimentally that the absence of light has a very marked influence on the ovipositing impulse of the fly; the darker the situation was, the fewer were the number of thies which were to be fomm there. The fact that Hies are disinclined to penetrate a dark place to oviposit has some practical significance in their control.

\section{Breeding Season.}

All my experiments and observations on the breeding habits of the house-fly indicated the important fact that, if suitable larval food were present and the temperature of the suromoling air were sufficiently high to permit the prolonged activity of the Hies, the female honse-flies will deposit their eggs and the larvae will develop at any time of the year. Under ordinary circumstances, howerer, the condition regarding temperature is not satisfied in temperate climates during the whole year round. Consequently, we find that in the temperate region the breeding season is contined to the period June to October; exceptional circumstances may extend this period a few weeks earlier or later. During these months, as the breeding and activity of the homse-Hy is directly lependent upon the temperature, the greatest breeding activity takes place during the hottest months, July, August and September.

During the winter months, under natural conditions, the outsicle temperature will not permit breeding to take place, but under such conditions as are found, for example, in warm stables and cowsheds, restamrants and kitchens, female thies may be often found either oripositing or able to do so. On dissecting such thies I have fomel mature ova in the oraries and living spermatozoa in the spermathecae. I have obtained eggs from 
Hies canght in restanrants in l)ecember. Griffith (1908) has sncceeded in rearing $M$. domestica from eggs in Novenber; December and January under artificial conditions as regards temperature. Jepson (1909) canght thes in January in a Cambridge bakehonse and, under artificial conditions, namely, in a greenhouse in the laboratory with a temperature varying firom $65^{\circ} \mathrm{F}$. in the morning to $75^{\circ} \mathrm{F}$. in the evening, he was able to rear the flies sncessfully, the whole life-history lasting about three weeks. Gleichen (t.c.) mentions the fact that he obtained eggs in Januiny.

Hermes (1911) states that at Berkeley in California he has seen homse-flies emerging from their breeding places during every month of the winter seasm. In early March a veritable plagu, of Hies was encountered while on a trip throngh the Imperial Valley in California. In sub-tropical and tropical climates the breeding season is continuous thronghout the rear.

\section{Abundance of Flies in relation to Breening Places.}

To anyone who studies the breeding places and habits of the house-fly one of the most striking firets is the enormons number. of thies which are able to develop in a certain quantity of breeding material such as horse-manure or excrement. Some interesting observations have been made by observers in different comntries on this print.

Faichne (1909) records experiments carried ont in India in which he reared about 4000 thies from one-sixth of a cubic fort of gromed fiom a latrine and as many as 500 firom a single dropping of human excreta.

Herms (1909) in California took samples from a pile of mammre after an exposmre of four days. The lanvale in these simples were comted with the following results: the first sample, 4 bos, contained 6873 larvae: second sample, 4 lbs., contained 1142 larvae: thiml sample, 4 lhs., contained 15s5 lanvae: forth sample, $3 \mathrm{lbs}$, contained 682 larvac: the total quantity examined, comprising $15 \mathrm{lls}$, contained, therefore, 10.282 larvale. All these larvace were nearly or quite full-grown, and the average number per pound of manure was 685 larrae. The weight of the 
On the onter side of the tracheal trumk a large branch arises; this, the visceral branch (v.tro), bends ventrally to the lateral trunk, and thus becoming internal to it enters the convoluterl risceral mass with its fellow of the other sicle.

'The visceal branches extencl anteriorly as firr as the serontl segment. In the twelfth and thirtexth segruents the lateral tracheal trunk has a double appearance. A dorsal and a ventral branch arise in most of the segments, the dorsal branch chiefly supplies the fat-hody, and the ventral branch supplies the viscera; both give off branches to the muscular bod ly-wall. The anterior commissure (a.com.) is situated in the fourth segment. It crusses the oesophagus immediately behind the pharyngeal mass. On the internal sicle of the portion of the lateral tracheal trunk, that is anterior to the commissure, a branch arises, and rumning ventral to the pharyngeal mass it supplies the anterior end of the larvat and the oral lobes. A branch that supplies the muscles of this region is given off external to the origin of the anterior commissure. Intermal to the origin of the commissme two tracheat arise; the anterior branch enters and supplies the pharyngeal mass, and the posterior branch $\left(t r^{\prime}\right.$.) enters the ganglion ventral te the cerebral lobes. In the fifth segnent another internal tracheal branch ( $t r^{\prime \prime}$.) enters the ganglion. These tracheas which supply the ganglion appear to run chiefly in the peripheral regions, where they divide into a number of branches, the fate of sone of these being interesting. These branches are extremely fine, and ther arise, as I have previously mentioned, in association with a number of the segmental nerves with which they run to the borly-wall.

\section{The Vascelar Systey axd Boty Cavity.}

The relations and structure of the vascular system of the larva are on the whole similar to those of the $\mathrm{H}_{\mathrm{y}}$; there are, however, a number of morlifications.

The dorsal vessel, which includes the so-called "heart," is a simple museular tube lying on the dorsal side immediately beneath the skin, and extenting from the posterior tracheal commissure to the level of the cerebral lubes of the compound sanglion in the fifth segment. Its wall is composed of fine striated muscle-fibres arranged transversely and longitudinally, but chiefly in the latter 
direction. The swollen posterior region (fig. 63), which is called the heart, lies in the last three or four segments, its anterior limit being hard to define. It consists of three distinguishable chambers,

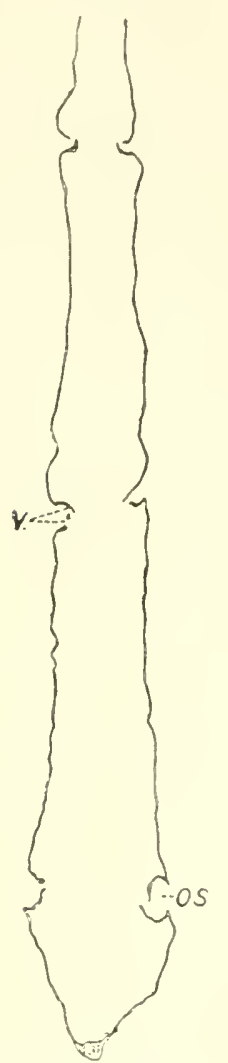

FIG. 63. Horizontal section of posterior or "cardiac" region of the dorsal vessel. (From cameralucidadrawings.)

os. Ostium. v. Valvular flaps guarding the same. which, however, are not divided by septa. Three pairs of ostia (os.), each provided with a pair of internal valves $(v$.), are situated laterally, and place the carliac cavity in communication with the pericardimm, in which this portion of the dorsil vessel lies. There are three pairs of alar muscles controlling the action of this posterior cardiac region of the dorsal ressel. Lowne describes other openings in the wall of the "heart" of the blow-fly larva, but I have been unable to find others than those already described in this larva; it has three pairs only.

The dorsal aorta is the anterior continuation of the dorsal ressel, which gradually diminishes in dianeter. When it reaches the fifth segment and lies above the ganglion, it terminates in a peculiar cellular structure (fig. 53, c.r.), which in the blow-fly has a circular shape and was called by Weismann the "ring." In the larva of $M$. domestice it has not so pronounced a ring-like appearance, but is more elliptically compressed and rather $\Lambda$-shaped. The cells of which it is composed have a very ehalacteristic appearance, and are rather similar to a small group of cells lying on the neck of the proventriculus and at the anterior end of the dorsal ressel of the fly: From the lower sides of this cellular structure (c.r.) the onter sheaths of the major cephalic imaginai discs depend, and extend anteriorly to the pharyngeal mass, enclosing between them the anterion portion of the great rentral blowd sinus. 
The pericardium lies in the four posterior segments of the body, and is delimited rentmally from the general body-anity by at double row of large characteristic pericandial cells. These cells have a fine homegeneons structure and are readily distingnished from the adjacent adipose tissuce cells, whose size they do not attain. The pericardial cavity contains a profinse supply of fine tracheal ressels which indicates a respinatory function. A similan. condition aceurs in the blow-fly lanva, and Imms (1907) hats described a rich pericardial tracheal supply in the larva of Anopheles maculipennis, als also Vancy (1902) and Dell (1905) in the larva of Psychode penctute.

The adipose tissue-cells (fig. 66, f.c.) form the rery prominent "fat-borly." They are arangerl in folderl cellular laminate that lir. chiefly in the dorso-lateral regions of the body, and in section have the appearance shown in the figure. The cells have a similar structure to those of the adult fly; they are very large with reticular protoplasm containing fat globules, and there may be more than one nucleus in a single cell. As in the Hy, the fat-body is clesely comnected with the tracheal system by means of a very rich supply of tracheae.

Two chief blood-sinuses can be distinguished-the pericartial sinus, which has aheady been described, lying in the dorsal region in the four posterior segments, and the great ventral simus. The latter lies between the onter sheaths of the major cephalic imaginal dises and extends anteriorly into and about the pharynx; posteriorly, it encloses the ganglion and the convoluted visceral mass above which it opens into the pericardial sinus between the pericardial cells.

The blood which fills the heart and sinuses and so bathes the organs is an almost colourless, quickly congnlable fluid, containing colourless, nucleated, anoeboid corpuscles and small globules of it fatty character.

\section{The Imaginal Discs.}

As in other cyclorrhaphic Diptera, the imaginal discs of some of which have been described by Weismann (1864), Kunckel l'Herculais (1875-78) and Lowne, the imago is developed from

II. II. $-\mathbf{F}$. 
the larrat by means of these imaginal moliments, which are gradually formed during the later portion of the larval life. They do not all appear at the same time, for whereas some may be in at well-developed state early in the third larval instar, others do not appear motil the larva reaches its resting period or even later. The imaginal dises appear to be hypodermal imaginations, though their origin is difficult to trace in all casses: in many

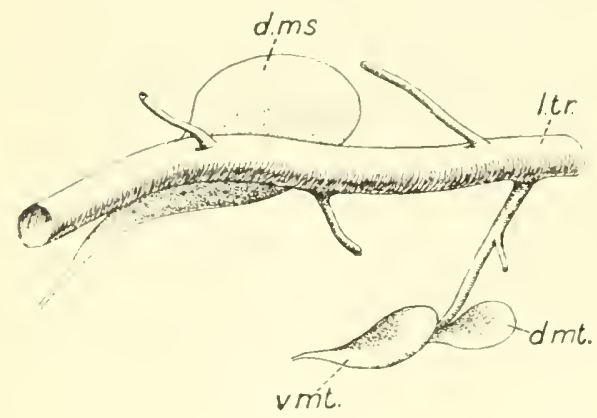

FIG. 64 .

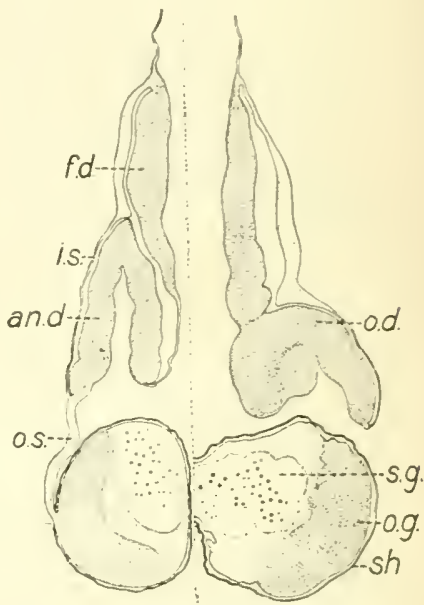

FIG. 6.5.

FIG. 64. Internal aspect of the posterior thoracic imaginal discs of the right side.

d.ms. Dorsal mesothoracic or alar imaginal disc. d.mt. Dorsal metathoracic

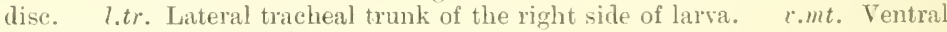
metathoracic imaginal dise.

FIG. 65. Longitudinal sections through the major cephalic imaginal discs of mature larva to show the position of the individual imaginal rudiments. The dextral section is more dorsal than the sinistral. (Camera lucida drawings.)

an.d. Imaginal disc of the antenna. f.d. Facial imaginal disc. i.s, Sheath of imaginal rudiments. o.t. Optic imaginal dise: $\quad 0 . \%$. Imaginal disc of the optic ganglionic structures. O.s. Optic stalks. ‥?. Fumlament of the imaginal supra-oesophageal ganglionic. sh. Slieath of cerebral lobe.

instances they are connecterl with the hypodermis by means of a stalk of varying thickness. The imaginal dise or rudiment may comsist of a simple on of a folded lamina of eleeply-staining columnar embrymic cells, as in the wing discs, or of a number of encentric rings of these eells, as in the antenual and crumal disces. They are usmally closely combeted with the tracheae and in some cases are 
innervated by fine nerves. Although the inaginal dises of $M$. domestica are similar in some reppects to those of the hlow-fly, ats described by Lowne, there are several inportant differences, chicef of which is the position of the imaginal dises of the metathoracic legs.

D)ring the resting period of the larva the cephalic and thoracic dises can be distinguished, but the abdominal discs are small and not so obvious except in sections.

\section{The cephulic discs.}

The chief eephalic rlises are contained in what at first alpears to be a pair of cone-shaped structures in fiont of each of the cerebral lubes of the ganglion (fig. 53, m.c.l.); the cone, however, is not complete. 'The onter sheath of each of these major eephatic inaginal ruliments is continued dorsally, and joins the cellular structure mentioned previonsly (see fig. 66), thus enclosing a triangular space which is a portion of the ventral sinus. These sheath are continned anteriorly and are comnected to the pharyngeal mass, and it is through this connecting strand of tissme that the discs are everted to form the greater part of the head of the nymph. Immerliately in front of the cerebral lobe is the so-called optic disc (fig. 65, o.d.), which in its earlier stages is cup-shaped, but later it assumes a conical form, having a cup-shaped base adjacent to the cerebral lobe. The optic disc is comnected to the cerebral lobe laterally by a stalk of tissme, the optic stalk (o.s.), which becomes hollow later, and it is through this stalk that the optic ganglion and associated structures contained in the cerebral lobe appear to evaginate when the final metamorphosis and eversion of the imaginal rudinents takes place. 'The optic discs form the whole of the lateral regions of the head of the fly.

The remaining portion of the head-capsule of the fly is formerl from two other parts of imaginal rudiments, the antennal and facial discs. The antennal disc (an.d.) lies in front, and internal to, the optic dises. Each consists of an dongate comieal structure, in which at a later stage the inclividual antennal joints can be distingnisherl. The facial dises (f.d.) are anterior to the antennat dises and extend to the anterior end of the conical strncture 
containing these three pairs of major cephalic discs, which will form the cephalic capsule.

In addition to these two other pairs of cephalic dises are found. A pair of small flask-shaped maxillary mdiments are situated one at the base of each of the oral lobes: a second pair of imaginal discs, sinilar in shape to the maxillary discs, is found adjacent to the hypostomal sclerite; the latter, I beliere, are the labial ludiments, and will form almost the whole of the proboscis of the fly.

The thoracic discs.

In 1 . domestica there are five pairs of thoracic dises. 'The prothoracic imaginal discs (figs. 53 and $66, p r . d$.) are attached to

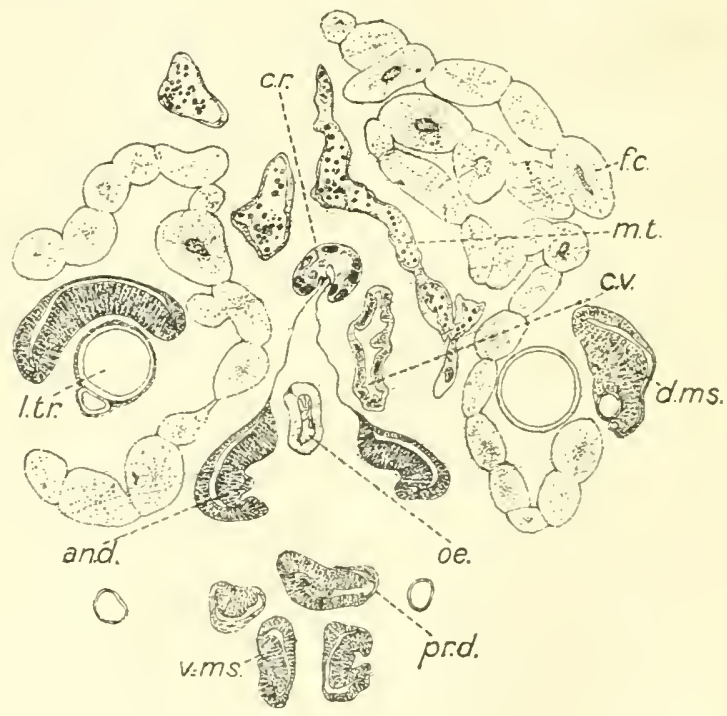

FIs. 66. Transverse section of mature larva anterior to the ganglion and cerebral lobes to show the position of certain of the imaginal discs. The body-wall and muscles have been omitted. The folded character of the adipose tissue laminae can be seen in this section, and also the degenerating anterior portions of the malpighian tubules (m.t.). (Camera lucida drawing.)

an.d. Antemnal disc. c.r. Problematical cellular structure (Weismann's "ring "). c.r. Caecum of ventriculus. d.ms. Dorsal mesothoracic (alar) imaginal dise. f.c. Adipose tissue cell. l.tr. Lateral tracheal trunk. m.t. Mlalpighian tubule cut rather longitudinally. oe. Oesoplangus. pr.d. Prothoracic imaginal dise. $\quad$.ms. Ventral mesothoracic imaginal dise. 
the anterior end of the ganglion and slope oblingely finwards; the distal end of each is attached to the body-wall on the ventral side between segments three and fomr. These dises develop inte the prothoracic legs, and probably also into the much-reduced prothoracic segment, as I was mable to discover any other rudiments corresponding to the dorsal intaginal dises of the mesothoracic and metathoracic segments. Arising from the sides of the ganglion immerliately behind the attachment of the prothoracic ruliment are the imaginal rucliments of the mesothoracic legs and sternal region (e.ms.): the distal stalks of this pair of inaginal discs are attached to the body-wall at the posterior border of the fourth segment. The dorsal mesothoracic inaginal discs, from

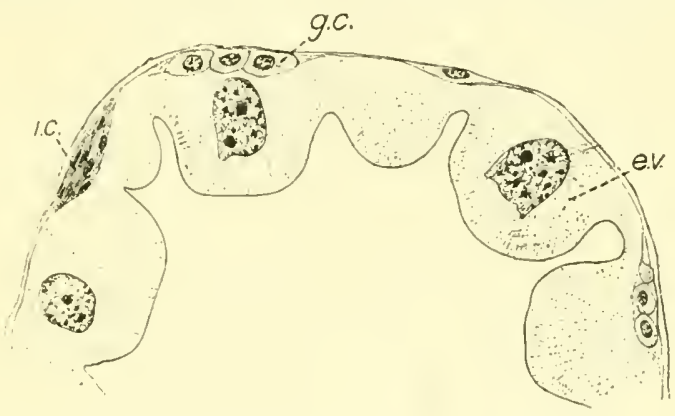

FIG. 67. Transverse section of a portion of the ventriculus of mature larva. (Camera lucida drawing.)

e.x. Epithelial cell of ventriculus showing large active nucleus and striated peripheral region of cell. g.c. Probable gland cells. i.c. Group of imaginal cells.

which originate the mesonotal region and the wings, may be termed the alar a wing discs. They form a pair of flattened pyriform sacs (fig. 64, d.ms.), lying me on each side of the ventral side of the fifth segment and slightly external to the lateral tracheal trunk (fig. 66, d.ms.), to a rentral branch of which each is attached. The metathoracic discs consist of two pairs of small pyriform masses (fig. 64) lying immediately behind the alar discs in the intersegmental line. They are attached to a ventral branch of the lateral tracheal trunk. The anterior rudiment $(v$.mt. $)$ is the larger, and forms the imaginal metathoracic leg and sternal region: in the blow-fly and in Volucella it is interesting to note that this pair of imaginal discs is situated further forward, and is in 
association with the corresponding prothoracic and mesothoracic rentral discs. The smaller and nore posterior disc (d.mt.) will develop into the remaining portion of the much reduced metathoracic segment, incheling the halteres.

Reference bas already been made to other imaginal moliments which occur in the abolominal region as regular patches of embryonic cells. The abtominal segments develop fiom numerous segmentally arranger plates of a similat nature which are found duriug the early pupal stage.

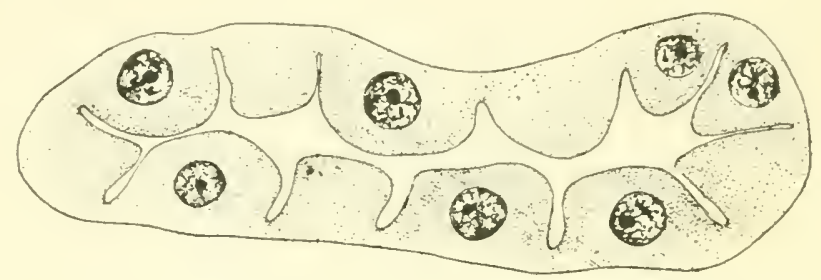

FIg. 68. Transverse section of one of the salivary glands of the mature larva. (Camera lucida drawing.)

1)uring pupation the imaginal rudiments increase in size and are not destroyed by the phagocytes in histolysis, as is the case with most of the larval structmes. The cephalic discs are evaginated by the eversion of their sacs by way of the anterior end of the larva, a cord of cells attached to the dorsal wall of the anterior end of the pharynx marking the path of eversion. A similar process takes place in the case of the thoracic imaginal dises, which, by their eversion, build up the whole of the skeletal cise of the thorax and its dorsal and rentral appendages, the wings, halteres and legs. 


\title{
PART ITI
}

\section{THE NATURAL ENEMIES ANI) PARASTTES OF} THE HOUSE-FLY

\section{CHAPTER X}

\author{
ARACHNIIS ANI) IIRIAPOIS
}

\section{CIIERAES WOMOSCS SCHRANK.}

'THERE are frequently found attached to the legs of the housefly smatl scorpion or lobster-like creatures which are Arachnids, belonging to the order Pseudo-scorpionidea; the term "chelifers" is also applied to them on account of the large pair of chelate appendages which they bear. The species which is usmally fomml attached to $M$. domesticu is Chernes nodosus Schrank (fig. (i9). It is very widely distributed, and my observations agree with those of Pickard-Cambrirlge (1892), who has described the group.

'The species is $25 \mathrm{~mm}$. in length and Pickard-Cambridge's rescription of it is as follows:

"Cephatothorax and palpi yellowish rerl-brown, the former" rather duller than the latter. Abdominal segments yellowishbrown; legs paler: The caput and first segment of the thorax are of equal wilth (from back to front); the second segment of the thorax is very narrow. The surface of the cephalothorax and abdominal segments is very finely shagreened, the latter grannlose on the sides. The hairs on this part as well as on the palpi and abolomen are simple, but obtuse. The palpi are rather sharp and strong. The axillary joint is considerably and somewhat subconically protuberant above as well as protuberant near its base underneath. The humeral joint at its widest part, behind, is 
considerably less broad than long; the cubital joint is very tumid on its inner side; the bulb of the pincers is distinctly longer, to the base of the first claw, than its wioth behind; and the claws are slightly curved and equal to the bulb in length."

They appear to be commoner in some years than in others. Godfiey (1909) says: "The urdinary habitat of Ch. nodosus, ats Mr. Wallis Kew has pointed ont to me, appears to be among refuse, that is, acemulations of decaying vegetation, manure healps, frames and hot-beds in gardens. He refers to its ocemrence in at

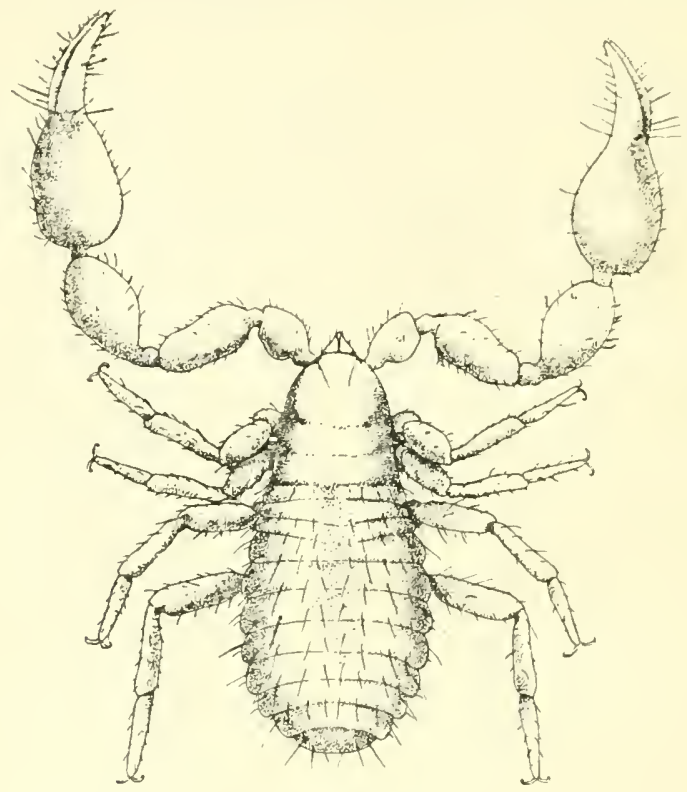

Fis. 69. Chemes nolosus, Schr, $\times 30$.

manure-heap in the open air at Lille, and draws my attention to its abundaner in a melon-fiame near Hastings in 1898, where it was fomml by $\mathbf{M r}_{\mathrm{r}}$ W. R. Butterfield." In view of these facts it is not difficult te understand its frequent oecurence on the leges of Hies, which nany have been on the rubbish heaps either for the purpose of laying eggs, ar, what is more likely, becanse they late recently emerged from pupae in those places and in crawling abont, dluing the process of drying their wings, etce, their legs were scizod by the C. nodosus. 
The inter-selation of the Chemes and $M$. domestica, howerer, is one of no little complexity; much has been written and many diverse views are held concerning it. An interesting historical aceount of the ocenrence of these Arachnids on various insects has been given by Kew (1901). Three views are held in explat nation of the association and they are briefly these: First, that the Chernes, by clinging passively to the Hy, uses it as a means of transmission and distribution: second, that the Arachnirl is predaceous; and, third, that it is parasitic on the Hy. (Owing to the unfortumate absence of convincing experimental proof in favour of either of the last two opinions, it is practically impossible to give any definite opinion as to the validity of these views: neverthelesi they are worthy of examination.

The dispersil theory was held by Pickard-Cambridge and Moniez (189t). Whether the other views are held or not there is no doubt that snch an association, even if it were only accidental, would result in a wirler distribution of the species of Chernes, as the Hie's are constantly visiting fresh places suitable as a habitat for the same. Except in one or two recorded cases, the Arachnirls ale always attached to the legs of the Hy, the chitin of which is hard and conld not be pierced, a fact which is held in support of this theory as the only explanation of the association.

The parasitic and predaceous views are closely related. The Pseudo-scorpionidea feed upon small insects, which they seize with their chelae. It is suggested by some that the Chernes seizes the legs of the fly without realising the size of the latter. Notwithstanding its size, however, they remain attached until the fly dies and then feed upon the borly. In some cases as many as ten of the Arachnids have been found on a single fly, and if the morements of the insect are impeded by the presence of a number of the Chernes, it will be easily understood that the life of the Hy will be curtailed thereby. Pseurlo-scorpionidea have been observed feeding on the mites that infest certain species of Coleopterat, and it has been snggested that they associated with the flies for the same purpose, although I do not know of any recorded citse of a Hy infested with mites carrying Chernes also. If this were the case the Chemes would be a frienct and not a foe of the Hy, as Hickson (190.5) has pointed out. 
There an fow records to support the viow that the Chernes is parasitic on the fly. Ionovan (17.97) mentions the erecurrence of a Psendo-scorpionid on the boxly of a b]ow-fly, and Kirby and Spence (1826) refer to their being occasionally parasitic om Hies, especially the blow-Hy, under the wings of which they fix themselves. It is pubable that the Ghernes seldom reaches such at position of comparative security on the thome of the Hy; should it sncceed in loing so, however, it womld become paratsitic in the true semse of the word. As I have proviously printed ont, little experimental evidence is at present available and further investigation is necessary before it is possible to maintain mose than a tentative opinion with regard to this association between the Chermes and the fly. It is obvioms that the association will result in the distribution of the Psendo-sconpionid, but whether this is morely incidental and the real meaning lies in a parasitic or prelaceous intention on the part of the Arachnid, as some of the observations appear to inclicate, further experinents alone will show'.

\section{MITES OR ACARINA BORNE BY HOUSE-FI_IES.}

Most careful observers and even casmal observers have noticed that homse-flies are uccasionally infested with small reddish mites which are attached to their bodies in various positions.

As carly as 1735 de Geer observed small reddish Acari in large numbers on the head and neck of $\boldsymbol{M}$. domestica. They ran about actively when tonched. The budy of this mite was oval in shape, completely chitinised, and polished; the dorsal side was convex and the rentral side flat. Limaens (1758) called this mite Acarms muscurum from de Geer's description, and Geoffroy (1764) found what appears to be the sane, or an allied species of mite, which he called the "brown fly-mite." Murray (1877) describes a form, Trombidium parasiticum, which is a minute blowd-rerl mite parasitic on the house-fly. He sigys: "In this combtry they do not seem so prevalent, but Mr Riley mentions that in North Amorica,

I I have since encleavoured to throw some light on this question ly keeping Chernes and flies in small vials. In no case, however, did I observe the Chomes feeding on the living ty, although they would feer oceasionally on the dear thics. 
in some seatsons, scarcely a $\mathrm{H}_{y}$ can be canght that is not infesterl with a number of them clinging tenacionsly romed the base of the wings." As it only possossed six logs it was clonlotloss a lanval form. This species was namerl Atoma paresiticum and later Astome paressiticum hy Latreille. Mr A. 1). Michatel informent me that the genus was founderl on Trombidimm puresiticam of de Geer. They were really lanval Thembidielae and Atrma was founded on lambal characters; pobably any haval Trombidinm came under the specific name.

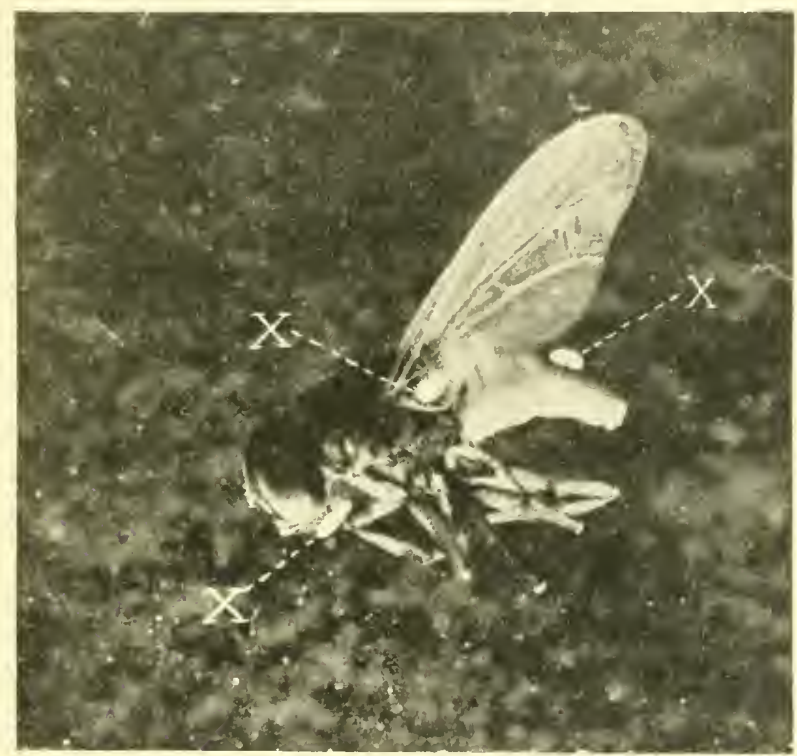

FIg. 70. M. domestica infested with Trombidium mites (X). Magnified nearly six times.

Howard (1911) quotes the following on the authority of Banks: "Latreille based a new genus and species on mites from the house-fly and he called it Atomus parasiticum. 'This is the young of one of the Harvest Mites of the family Trombididae but the adult has not been reared and is still unrecognised in Europe. Riley found these harvest mites on honse-flies in Missomi, in some years so abundantly, he says, that scarcely a fly could be canght that was not infested with some of them clinging tenacionsly 1 Magazin Encyclopedique, Vol. rv, p. 15, 1795. 
at the base of the wings. Later he succeded in rearing the adult, and described it as Trombidium muscurum. In recent roars Oudemans has described Trombidium muscae from larval inites found on house-flies in Holland. All these forms are mimute, six-legged, red mites which cling to the body of the fly and with their thread-like mandibles suck up the juices of the host. When ready to transform they leave the fly and cast their skins, the mature mite being a free-living, hairy, scarlet creature about $1.5 \mathrm{~mm}$. long. The adults are usually found in the spring and early smmmer, while the larrae are usually found in the antum on house-flies and other insects." I have illustrated (fig. 70) a $\mathrm{Hy}$ caught in Ottawa in September, 1909, which is infested with this species of mite.

Howard states further that "mites of the genus Pigmeophorus, of the family Tarsonemidae, have also been taken on house-flies. They cling to the abdomen of the fly, but it is not certain whether they feed on the insect or use it simply as a means of transportation. The hypopus or migratorial nymphal stage of several species of Tyroglyphus has been found on house-flies. This hypopus attaches itself by means of suckers to the body of any insect that may be convenient. The nites do not feed on the fly but when the fly reaches a place similar to that inhabited by the mites the latter drop off, cast their skins and start new colonies."

Anyone who has collected Diptera as they have emerged from such breeding places as hot-beds, rubbish and manmre heaps will have noticed the frequently large number of these insects which are to be found carrying immature forms of the Acari. These are being transportert merely by the flies in the majority of cases. Mr Michael informed me that he used to call such Hies "the emigrant waggons"-a very descriptive term. Many of these mites belong to the group Gamasidae- the super-fimily Gamasoidea of Banks (1905). These mites have usually a hard coriaceens integument. In shape they are flat and hroad and have rather stont legs. Sometimes immature forms of these miter swarm on flies emerging from rubbish heaps. Banks holds the (1) pinion that they are not parasitic, but that the insect is only used as a means of transportation. It is difficult to decide whether this is so in all cases. I have ilhustrated (fig. 71 ) a specimen of 
the Lesser Honse-Hy, f'. cuniculuris, canght in a roum; on the underside of the fly's abdomen a number of immature Gamalsids are attached, apparently by their stomal regions. Mr Micharel, to whom I submitted these mites, said that it was extremely difficult to irlentify immature Gamasids owing to the scarcity of our knowlerlge as to their life-histories, but he stated that they were very like Dinychella asperata Berlese.

These specimons may be truly parasitic, as I am inclined to believe, since many Acari are parasitic in the immature state, althongh the adnlts may not be so; on the other hand this form of attachment may be employed as a means of maintaining a more sceure bold of the trinsporting insect.

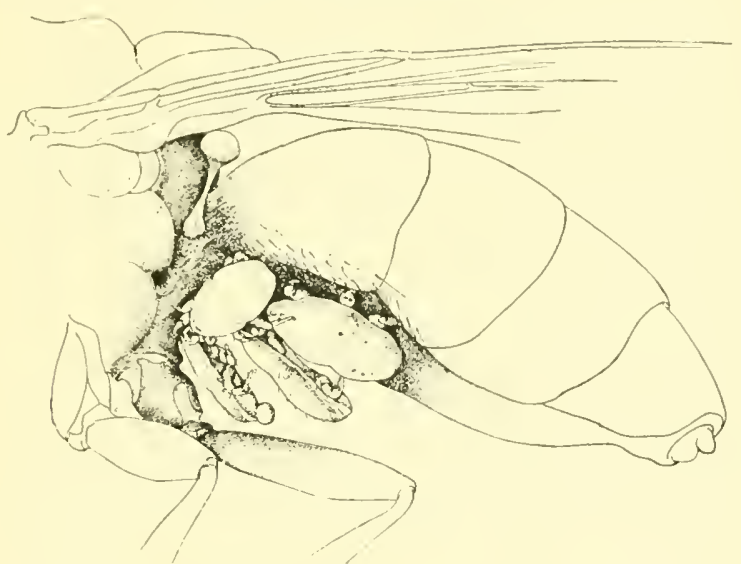

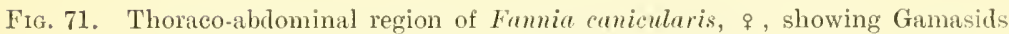
attached to the ventral side of the abdomen.

Ewing (191:3) describes a new species of Gamasid mite Macrocheles muscue which is parasitic on $\boldsymbol{M}$. domestica, always attaching itself, accorling to the author, in a definite place, namcly, at the base of the abdomen on its rentral side, the anterior end of the larva being directed forwards. It feerls on the host. Its colour is dark yellowish brown; length $0.97 \mathrm{~mm}$., width $0.62 \mathrm{~mm}$. It has been found in the States of Oregon and New York.

Hamer (1909) records Gamasid mites as particularly affecting Muscina stabulans, especially in early June. 
Berlese (1912) has reared what he considers to be the Acorus muscamm of Jinnaens from the Stable-Hy, Muscina stabulans, and finds that the adult belongs to the genus Histiostoma. He alwo illustrates two Acarids attacherl to $M$. domestica; attached to the right anterior tibia is a larval Tronbidium and attached to the left hind tibia is a migratory Holostaspis marginatus Herm., a species which is accustomed to attach itself to coprophagoms insects.

By the transference of the hypopal or migratorial stage of those species of mites which are destmetive to cheese and other foods, house-flies are frequently responsible for infecting such foods with mites. While their food is abundant the arlult mites reproduce rapidly, the young mites developing into adults in a very short time. Should the food supply become exhansted or other unfavouralble conditions supervene the almost fully grown mites develop the hard protective shells characteristic of the hypopal or migratorial stage. Thus protected they attach themselves to honse-flies or other flies and trust that the inquisitive wanderings of their tramporting host will carry them to pastures new.

\section{Centipenes ANi Spiders.}

The carnirorons habits of the centipertes are well-known but the peculiar gemus Scutigera contains a number of species which feet upom insects, including the house-fly, when the opportunity aceilirs.

In the southem and eastern regions of the United States a species, scutigere forceps Raf, occurs rery frequently in houses where, according to Howard, its food consists principally of household insects such as $1 /$. domesticu, clothes moths and small cockroaches. It is a small fiagile-looking animal with unusually long lege and foreds at night, its long legs apparently being of great service to it in capturing its prey.

Komekel d'Herculais (1911) records the occurrence of scutigeru coleoptera L. in France where it occurred apecially in privies. hunting flise by night, its ehief prey being the latrine Hy Fennia

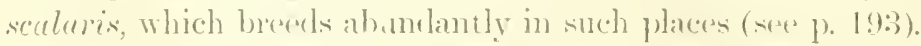

The genus Soutigern is very wirlely distributorl, st. smithii 
Newport accurs in Austratia and, like the afonementioned species, has been found to hunt the house-fly by might?

The retations which exist between sprielers and Hies are sol miversally recognised that it is difficult to make an eriginal observation on the subject and perhaps hadly necessing in an accomnt of this nature. Howse spollers and garden sprider's will devour whatever house-flies "watk into their parlons," and the" little jumping spiler stalticus scenicus may be freduently wherved leaping upon Hies almost twice its size.

I hecently, I captured Scutigern forceps in Toronto (Camada) and fed it on flies. 


\section{CHAP'TER XI}

\section{THE FUNGAL DISEASE : EVPUSA MUSCAE COHN}

Probably the most important of all the enemies of the housefly is the parasitic fungus Empusa muscue. Towarls the end of the simmer large numbers of flies may be found attached in a rigid condition to the ceiling, walls or window-panes. They have an extremely life-like appearance, and it is not until one examines them closely or has tonched them that their inanimate, so far as the life of the fly is concernerl, condition is discorered. These flies have been killed by the fungus Empusa muscue Cohn, and in the later stages of the disease its fungal nature is recognised by the fact that a white ring of fungal spores may be seem around the fly on the substratum to which it is attacherl (fig. 72). The abdomen of the fly is swollen considerably, and white masses of sporogenons fingal hyphae may be seen projecting for a short distance from the body of the fly, between the segments, giving the abdomen a transversely striped black and white appearance.

The majority of Hies which die in the late antumn-and it is then that most of the flies which have been present during the summer months perish-are killed by this fingus. Its vecurrence, therefore, is of no little economic value, especially if it were possible to artificially cultivate it and destroy the flies in the early smmmer instear of being compelled to wait motil the antmm for the natural comrse of events.

Empusa muscte belongs to the groul Entomophthoreae, the members of which confine their attacks to insects, and in many caser, as in the ealse of the present species, are productive of great mortality among the individuals of the species of insect attacked. In England it may be found from the beginning of July to the 
end of October and ustally oceurs indoors. Howard states that the epidemic usually ceases in Washington, U.S.A., in December. Its distribution almost coincides with that of the honse-fly and it is the only species of Empuse which has, as yet, been recorderl from the southern hemisphere. While it is nucommon ont-ofdoors, I have found specinens of Musca domestica killed by it ontof-doors in Canarda, at Ottawa. It has been recorded mit-of-roors in England where it was found attacking a species of Syrphid,

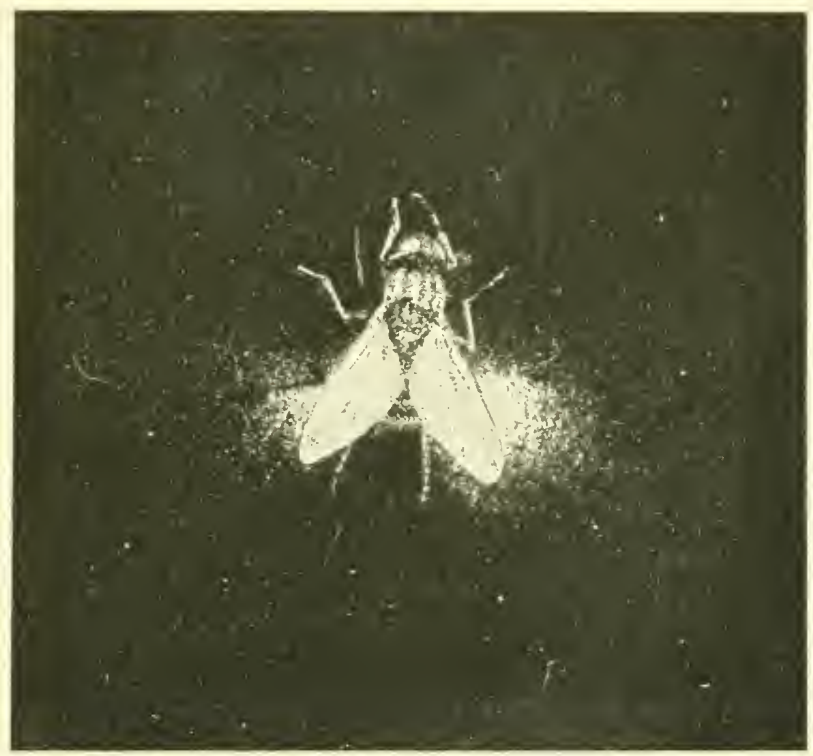

FIG. 72. M. domextica killed by Empuxa muscae, showing discharged spores (conidia). (Photo by H. T. Güssow.)

Melanostomum scalare Fabr. on Esher Common ${ }^{1}$. Thaxter (1888) also mentions two cases of its occurrence out-of-doors in the United States, in both of which cases it had attacked species of Syrphidae. The same anthor states that Empusa muscue is probably the only species which occurs on flowers attractive to insects, but he only observed it on flowers of Solidago and certain Unbelliferae. He also records two other species of Empusa attacking the house-fly, namely, E. sphaero-spermu (Fres.) Thaxter and

1 Trans. Ent. Soc. London, Proceedings, p. 57, 1908.

H. H.-F. 
E. americuna Thaxter. E. americana attacks blow-flies and other Hies similar in size to the house-fly and is frequently found ont-ofdoors.

E. muscae, besides occurring on $M$. domestica has been found on several species of Syrphidae and also on Luciliu cuesar and Culliphora vomitoria.
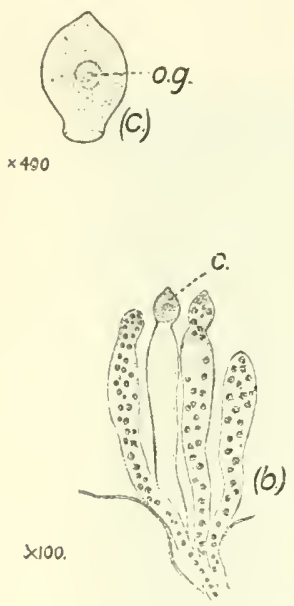

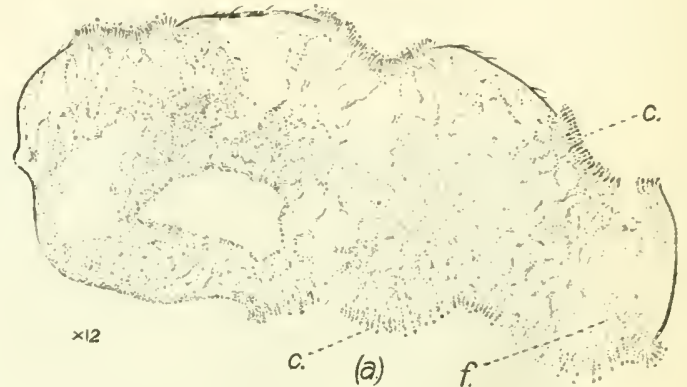

(a)

Fig. 73. (a) Longitudinal (sagittal) section of abdomen of $M$. domestica, which has been killed by Empusa muscae, showing the feltwork of fungal hyphae filling the inside of the abdominal cavity and the production of conidia in the inter. segmental regions. $\times 12 . \quad c$. Conidiophores producing conidia, $f$. Fungal liypliae.

(3) Four conidiophores showing the formation of conidia (c). $\times 100$ (approx.).

(c) Conidium of Empusa muscae. $\quad \times 400$. o.g. Oil globule.

The development of the honse-fly fungus Empusa muscue was very carefully studied by Brefeld (1871). An Empusa sjore which has fallen on a fly rests among the hairs corering the insect's borly and there arlheres. A small germinating hyph develops, which pierces the chitin, and after entering the body of the rictim penetrates the fat-body. In this situation, which remains the chief centre of development, it gives rise to small spherical structures which germinate in the same manner as yeast cells, forming gemmae. These separate as they are formed, and falling into the blood sinus are carried throughout the whole of the body of the fly. It was probably these borties that Cohn (18.5.5) found, and he 
explained their presence as being due to spontaneous genoration; he believed that the fly first becane diseased and that the fungrus followed in consequence. After a periond of two or three days the Hy's borly will be found to be completely penetrated by the fungus, which destroys all the internal tissmes and organs. The whole borly is tilled with the gemmate, which germinate and produce ramifying hyphe (fig. $73, a$ ).

The latter pierce the softer portions of the body-wall between the segments and produce the short, stout conidiophores (c.), which

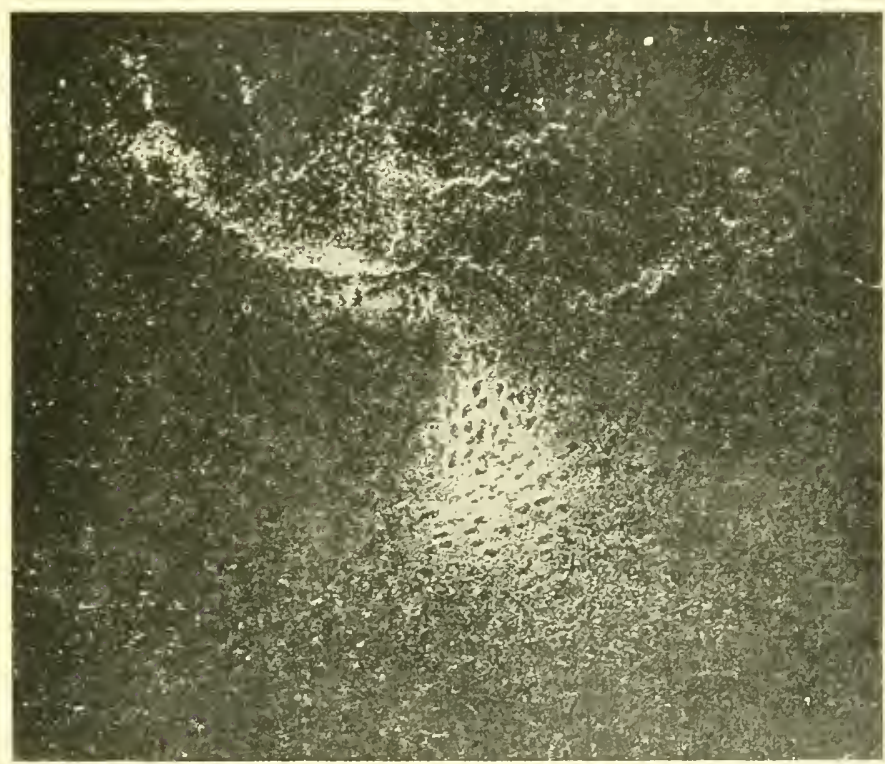

Fic. 74. Discharged conidia of Empusa muscae upon which $\Psi$. domestica has been feeding as indicated by the proboscis marks. (Photo by H. T. Güssow.)

are closely packed together in a palisade-like mass to form a compact white cushion of conidiophores, which is the transverse white ring that one finds between each of the segments of a diseased, and consequently deceased, fly. A conidimm now develops (fig. $73, b$ ) by the constriction of the apical region of the conidiophore. When it is ripe the conidium (fig. $73, c$ ) is ustally bellshaped, measuring 25-30 $\mu$ in length; it generally contains a single oil-globule (o.g.). In a remarkable manner it is now shot 
off from the conidiophore, usually for a distance of about a centimotre, although I have seen spores discharged to a distance of $70 \mathrm{~mm}$. In this way the ring or halo of white spores, which are seen around the dead fly, are formed. My friend Mr H. T. Guissow has confirmed in conjunction with me the external infection by the conirliospores. He has also found that the conidiospores may be taken up through the mouth, and fig. 74 shows the proboscis marks of flies which have been feeding on the discharged conidiospores.

In some cases, although I find that it is not an invariable rule as some would suggest, the fly, when dead, is attached by its extended proboscis to the substratum. Giard (1879) found that blow-Hies killed by Entomophthora calliphora were attached by the posterior end of the body. If the conidia, having been shot off, do not encounter another fly, they have the power of producing a small conidiophore, upon which another conidium is in turn developed and discharged. If this is unsuceessful in reaching a Hy a third conidium may be produced, and so on. By this peculiar arrangement the conidia may eventually travel some distance, and it is no doubt a great factor in the wide distribution of the fungus, once it occur's. On the fly itself short conidiophores may be found producing secondary conidia.

Reproduction by conidia appears to be the only form of generation, as we are still uncertain as to the occurrence of a restingspore stage in this species. Winter (1881) states that he found resting-spores in specimens of $\boldsymbol{H}$. domesticu oceurring indours: they also produced conidia which he identified as $E$. muscue. These azygospores measured $30-50 \mu$ in diameter, and were produced laterally or terminally from hyphae within the infected fly. Giard (l.c.) describes resting-spores which were produced externally and on specimens found in cool situations. Brefeld, however, is of the opinion that E. muscae does not produce resting-spores. The question of the production of resting-spores needs further investigation, and it is one of some importance. In the absence of confirmatory evidence it is extrenely difficult to understand how the gap in the history of the Empusa, between the late autumn of one year and the summer of the next, is filled. A number of suggestions have been made, many of which cannot be aceepted; for 
example, Brefeld believes that the Empusa is continued over the winter in warner regions, migrating northwards with the Hies on the return of the summer: In the case of Entomophthora culliphora, Giard believes that the cycle is completerl by the corpsese of the blow-tlies filling to the ground, when the spores might germinate in the spring and give rise to conidia which infect the larvae. Olive (1906) studied the species of Empuse which attacks a species of Sciara (Diptera) and found the larvae infected. He accordingly thinks that the disease may be carried over the winter by those individuals which breed during that period in stables and other favourable places. As I have shown, M. domestica, under such favourable conditions as wamth and supply of suitable larval food, is able to breer dluring the winter months, althongh it is not a normal occurrence so fiar as I have been alole to discover. If, then, these winter-produced larvae could become infecter they might assist in carrying over the fungus from one year to the next, and thus carry on the infection to the carly smmmer boods of Hies. This suggestion and the pussible occurrence of a restingspore stage or the infection by conicliospores surviving firm the previous year, appear to me to be the probable neans by which the disease may be carried over from one "fly-season" to the next.

Until this gap in the life-history is filled it will not be possible to determine experimentally the practical value of this fungns as a means of destroying the house-fly. No one, so far as I am aware, has yet succeeder in rearing the fungus on artificial media although many attempts have been made. Nor has it been possible in my own experience to infect flies from flies of a previons year which have been killed by the fungus. Investigations are now being conducted, according to Bernstein (1910), on this parasitic fungus in comnection with the enquiry of the Local Govermment Board and the results will be awaited with interest?

I Since the above was written two interesting papers on this subject have appeared.

Güssow (1913) has given the results of a careful investigation on the life-history of $E$. muscae. He did not succeed, however, in carrying cultures of the fungus from spore to spore outside the fly and failed to find resting-spores. His observations indicate that flies may become infected by ingesting the spores into the alimentary tract.

Buchanan (1913) studied chiefly the possibility of bacterial dissemination by the spores of $E$. muscue and found that the spores were able to take up, and to carry 
when discharged from the bodies of the flies, bacteria of the colon group. He was unable to cultivate the fungus artificially. From the fact that in the body of the discased fly the fungal hyphae closely invest the chorion of the eggs he believes that the larvae emerging from such eggs might become infected with the fungus and thus transmit the infection to the next generation. I should point out, however, that there are two strong objections to this possibility. First, once a fly is attacked by the fungus it would be incapable of ovipositing by the time the disease had reached a stage where the ovaries have bccome infected with the fungus. Sccondly, even did the first objection not exist, the emergence of the larva from the egg is of such a nature as to permit the larra to escape infection, especially as the fungal hyphae do not penetrate the chorion of the egg.

Buchanan records the fact that Morgan has succeeded in obtaining an artificial culture of the fungus (see Brit. Ied. Journ. Jan. 4th, 1913). 


\section{CHAP'TER XII}

\section{INSECT ANI) VERTEBRATE ENEMIES}

\section{PARASTTIC INSECTS.}

LikE other insects, the house-fly is subject to the attack of a variety of parasitic enemies and in the course of some investigations in 1908 on the house-fly in Illinois, Girault and Sanders $(1909,1910)$ found a number of Chalcidoid parasites of $M$. domestica and its near relatives. They all appeared to belong to the family

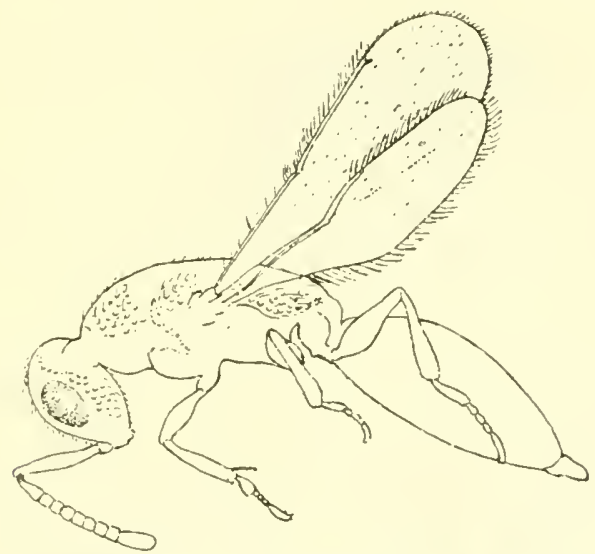

FIG. 75. Spalangia sp., a parasite reared from 1 . domestica. $\times 20$.

Pteromalidae and three genera, namely, Spalangia (fig. 75), Nasonia and Muscidifurax were discovered attacking $\boldsymbol{M}$. domestica and other Muscids, the last genus being previously undescribed.

In the first of the two papers mentioned the parasite Nasonic brevicornis, a new species, is described. This parasite, the anthors state, is "stolid and serious, little heeding external influences and disturbances, quietly, persistently giving its whole attention to 
reproduction." It attacks $M$. domestica in the pupal stage. The female is a minnte insect measuring from $1 \mathrm{mmm}$. to $2.30 \mathrm{~mm}$. in length and is of a metallic dark brassy-green colour; the eyes are garnet coloured. The male is about one-third smaller than the fernale, varying in length from $0.60 \mathrm{~mm}$. to $2.00 \mathrm{~mm}$. It is lighter in colour, more brassy in appearance, metallic and green; the eyes are sometimes a brilliant carmine. The wings of the nate appear to be functionless as they have never been seen to fly and although the female is able to fly both sexes appear to prefer to crawl and are able to crawl quickly. They reproduce very mpilly like most Pteromalid parasites. Maggots and puparia of $M$. domestica were placed in a breeding jar with females of Nasonia brevicomis on September 9, 1908; reproduction of the parasites cocurred, and on September 26, 1908, males and females of the Pteromalid parasites emerged. The arerage life-cycle of Nasonia brevicornis under natural temperatures is $22 \frac{1}{2}$ days; the duration of the development is longer in the spring than in the summer. The parasite hibernates in the larral stage in the puparium of its host and transforms to a pupa in the spring: a number of species of Pteromalicls have this habit.

Another parasite of this group which these authors have found attacking the homse-Hy is Pachycrepoideus dubius. It was reared in experiments with Nasonia breviconreis and was obtained from the pupae.

The same authors also describe a third Pteromalid parasite attacking Husce domestica and its coprophagous allies. This species they have named Muscidifurax raptor; it is a minute black insect with clear wings and is somewhat solitary in its habits. The female apparently lays from thirty to forty eggs which are depositer in the pupae, in the interior of which the last annual brood passes the winter as a full-grown larva. The average duration of the summer brooks was between nineteen and twenty days.

Richarrlson (1913) has described a new species, Spalangia muscidarum, which was brerl from the pupae of $M$. domestica and of Stomoxys calcitrans ${ }^{1}$.

1 More recently Richardson (1913) has described the habits and development of spalangia muscidarm. The highest proportion of parasitised house-fly puparia 
There is no doubt, jurtging from the numericil abundance of the above parasites which the anthors indicate in their papers, and from my own observations in the case of another species of Pteromalid, that these parasites are of importance in holding M. domestica in check where the parasites are sufficiently abundant.

In addition to the many Chalcid parasites of $M$. domestica, a number of parasites belonging to the fanily Cynipidae have been reared from the honse-fly. Most of the Cynipidae are minute gall-forming insects, causing some of the well-known galls on plants such as the oak galls. One sub-family, the Figitines,

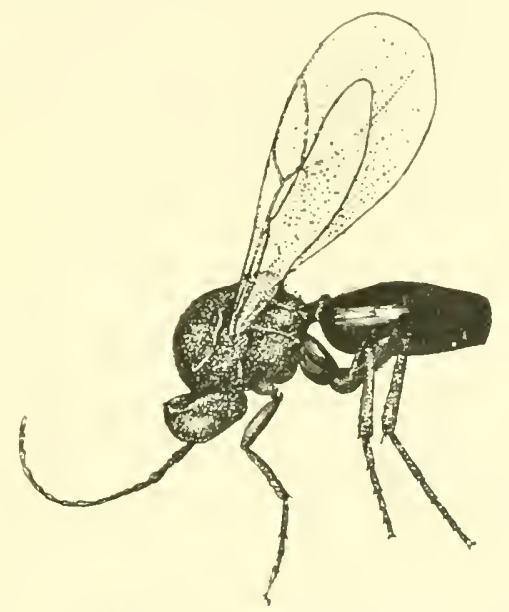

FrG. 76. Figites sp. Muscid parasite. $\times 2$ s.

however, are parasitic on the larvae of insects, having been obtained from dipterous, neuropterons and coleopterous larvae, and they do not attack plants. These insects are describerl by Kieffir.

found was 9 Spalangia larvae and pupae from 22 puparia. He found two generations, and a third more or less irregularly, each year in Massachusetts. The winter is probably passed in the pupal stage and the parasites emerge in the spring. The second and strongest generation emerges during late July or August, while a third may appear late in September or early October.

Bishopp (1913) found S. muscidarum a parasite of $M$. domestica, Stomorys calcitrans and Haematolia serrata in Texas.

Pinkus (1913) studied the life-history and habits of Spalangin muscidarmm as in parasite of $S$. calcitrans at Dallas, Texas. The parasitism of $M$. dompstica was also studied and he discusses the possibility of the artificial propagation of the parasites. 
(1902) in his monograph on the Cynipidae. The members of the genus Figites (fig. 76 ) are parasitic on dipterons larvae which live in various kinds of excrement, and in consequence the minute adult Hies may be caught frequenting human, horse, cow and other kinds of excrement for the purpose of depositing their eggs on the dipterous larvae which may be found there. The species most commonly attacked belong to the genera of the dipterous families which have coprophagous larvate, such as the Muscidue, Anthomyidae, Surcophargidae and Scatophagidar. The commonest species, Figites scutellarius Rossi, has been reared by Förster from 1I. domesticu accorling to Dalla-Torre. Other species which have been reared from 11 . domesticu are $F$. striolutus and $F$. anthomyiarum. Further investigations will no doubt indicate that a number of the species of Figites which have already been described are able to parasitise $\boldsymbol{M}$. domestica.

\section{Predaceous Ixsects.}

As Howard has pointed out, it is a remarkable fact that the larvae of $\boldsymbol{H}$. domesticu are not destroyed to a greater extent than our observations would appear to indicate by the numerous species of predaceous insects which feed upon soft-bodied insects. To a small extent the ground-beetles (Carabidae) and rove-beetles (Staphylinidae) may sometimes be found feeding or induced to feed upon the larvae of M. domestica, but not to the extent that they are accustomed to feed upon other soft-bodied larvae such as many lepidopterons, coleopterous and other dipterons larvae.

Packard (1874) records the occurrence of what was probably a Dermestid beetle, which he figures; this was found by him in a pupa of $M$. domestica. Berg (1898) states that in South America a species of beetle, Trox suberosus F., locally known as "Champi," is an indirect destructor of the common fly.

Ants are frequently responsible for the destruction of $M$. doimestica in the egg, larval and adult stage. Wheeler (1910) records ants feeding on house-flies and their larvae. He informs me that he has seen the Fire Ant Solenopsis geminute Fab. at Quiragná, Guatemala, feeding upon the larvae of M. domestica which they extracted from hmman excrement. Howard (1911) refers to the 
observations of a number of persens on the destrnction of M. domestice by ants. Capt. P. L. Jones found it impossible to rear $M$. domestica in the Philippine Islands unless the aggs and lanvae (in manme) were protected from ants. Stallman (1912) reports the destruction of fly larvac by red ants in Arizona. It would appear, however, that usmally ants do not prey upon M. domestion to an extent sufficient to make the results of their predatory habits alpreciable.

The common species of wasps ( Vespa spp.) have been frequently observed by myself and others preying upon flies which they occasionally destroy in large numbers. A Canadian engineer, who had been engaged in railroad construction in northern Ontario, described to me the mystification cinsed by the presence of large numbers of the wings of tlies on the table of their cabin. On investigation, it was found that a large species of wasp was catching the flies in the cabin; after capturing a fly the wasp took it to a bean immediately over the table and there cut off the wings before eating it or carrying it away.

The large hairy Robber-flies of the dipterous family Asilidae frequently catch flies. I have observed and captured Laphriu crenis Will. in the act of catching and eating $M$. domestica'.

In some parts of India it is the custom, I have been informed by residents in that comntry, to employ a species of Mantis, one of the predatory "praying insects," to destroy the house-flies.

Compere (1912) has found earwigs destroying the maggots of stable-flies in fresh manure in southern China and believes that they are an important factor in the control of house-flies in Hongkong. It is hardly likely, however, that they would exert so great an influence as is suggested.

The destruction of the larvae of $M$. domestica by the larvac of the allied muscid Muscina stabulans and of Hydrotaea dentipes, is recorded by Portchinsky (1913). He found that the larvae of M. stabulens, having completed the second stage, follow and attack the larvie of $M$. domesticu and soon exterminate all that happen to be living with them. The larva of Mi. stubulans that had killed

1 Since the above was written I have described (Hewitt, 1914) the predaceous habits of the common yellow dung fly Scutophaga stercoraria L. which was found destroying $M$. domestica and other Muscidae. 
the larva of $M$. domestica was never observed to devour it alone, a number of other individuals usually joined in the feast. Nor were the larvae of $M$. stubuluns ever scen to levour each other. Portchinsky also found that they would bore into and eat the bodies of dearl flies. The habits of M. stubuluns are considered later (pp. 207-210).

\section{Vertebrate Enemes.}

That the house-fly has a number of rertebrate enemies, exclusive of man, is a matter of common observation. Cats will sometimes sit in a window and catch flies. Rats have also been observerl destroying flies. Birds will destroy M. domestica in both the adult and larral stages though not in preference to other species of insects.

Ponltry will feed upon the larvae and pupae of M. domestica which they may find in the stable-yard and are sometimes of some service in this respect.

Lizards, toads and frogs will capture the adult flies whenever an opportunity occurs, but their influence in the matter of control is ter slight to be noticeable. 


\title{
CHAP'TER XIII
}

\author{
PROTOZOAL PARASITES
}

\section{HERPETOMONAS MCSOAE-DOMESTICAE BURNETT.}

THE Herpetomonas of the house-fly, Herpetomonas muscuedomesticue Burnett, has been known for many years as a Hagellate parasite of the alimentary tract of $M$. domesticu, but the discovery of the relation to certain diseases of a number of species of Trypanosomes and allied fiagellates has been responsible for a considerable addition to our knowledge of the life-history of this and other species of Hagellates inhabiting the alimentary tracts of insects.

In 1878 Stein figured a flagellate which he called Cercomonas muscue-domesticue, identifying it with the Bodo muscue-domesticue describerl by Bumett and the Cercomonus muscurum of Leidy. For this form Kent (1880-81) instituted a new genus Herpetomonas. When the haemo-flagellates were being studied some years later, Prowazek (1904) described with great detail the development of this species. In the previous year Léger (1908-1909) had given a short account of the species. Patton (1908-1909) has also described the life-history of $H$. muscue-domesticue, and his account has been confirmed by Porter (1909), Mackinnon (1910) and Wenyon (1911 and 1913) who in his later paper gives a careful account of the cytology of the flagellate.

The full-grown Hagellate (fig. 77, VIII) measures $30-50 \mu$ in length. The body is Hattened and lancet-shaped, the posterior end being pointed aid the anterior end bluntly rounded. The alveolar endoplasm contains two nuclear structures. In the centre is the large "trophonucleus" (tr.); it contains granules of chromatin, but is sometimes difficult to see. Near the anterior end 
the deeply staining rod-shaped "kinetonucleus" (blepharoplast of many authors) ( $k$ : ) lies, usually, in a transverse position. The single stont Hagellum, which is a little longer than the body of the flagellate, arises from the anterior end, near the kinetonucleus. Prowazek describes the flagellum as being of a double nature and having a double origin; this, which is a mistaken interpretation is repeated by Lingard and Jennings (1906). Prowazek (1913) has corrected what he consirlers misinterpretations of his original statements concerning $H$. muscae-domesticue. By statistical methods he has found that the greater number of the flagellates examined in Rovigno are bitlagellate.

This mistake concerning the double nature of the Hagellum was pointed out by Léger and Patton, and their ideas have since been confirmed by Porter, Mackinnom and Wenyon, who have studied this and other species of Herpetomonas. In some flies Porter found that practically every $H$. muscae-domesticue which was seen exhibited the so-called "double-flagellum." The appearance of a double-flagellum represents the beginning of the longitudinal division of the Hagellate (VI). Patton (1908) figures a stage in H. lygaei with a double-Hagellum, and Léger (1902) and Porter found the same appearance in $H$. jaculum preparatory to division. From the figures that these anthors give it may be understood how this mistake has arisen. Through this misinterpretation Prowazek was led to consicler that the parasite was of a bipolar type, in which the body has been doubled on itself so that the two ends came together and the flagellum remained distinct. The flagellum, according to Léger, is continued into the cytoplasm as a thin thread, which stains with difficulty, and terminates in a double gramule above the kinetonucleus; this double granule is no doubt the "diplosome" of Prowazek. According to the latter author another deeply staining double thread (s.t.), that appears to be spirally coilert, runs backwards from the kinetonucleus and terminates posteriorly in a distinct granule, shown in fig. 77, VIII. Wenyon (1913) believes that a cytopharymx is present, using as an argument the presence of bipolar bodies which he believes are bacteria taken up by the Herpetomonas.

The Hagellates congregate in the proventriculus or in the pusterior region of the intestine, where they become united by 


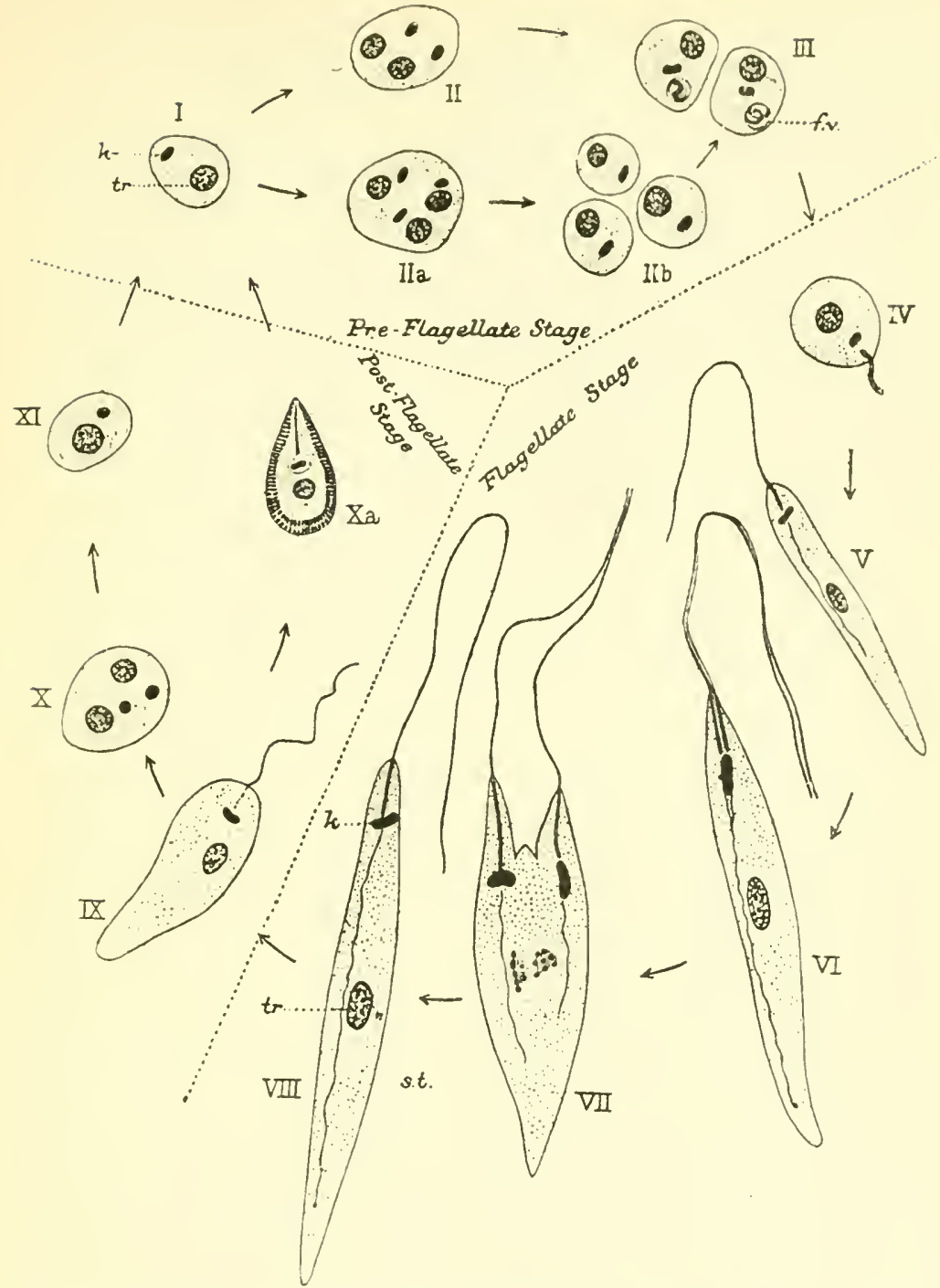

Fig. 77. Diagram of the life-cycle of Herpetomonas muscae-domesticue Burnett. Arrangement chiefly after Patton; figures after Léger, Patton, and Prowazek. I--III. Pre-flagellate stage. IV-VIII. Flagellate stage: V. Young flagellate. VI. Flagellate beginning to divide, flagellum having already divided. VII. Advanced stage of division. VIII. Adult flagellate. IX-XI. Postflagellate stage: IX. Degeneration of Hagellum. X $\iota$. Post-flagellate stage completed by formation of gelatinous covering, containing double row of granular bodies (Prowazek). $f . x$. Flagellar vacuole. $k$. Kinetonucleus. s.t. Spiral chromophilous thread. tr. Trophonucleus. 
their anterior ends to form rosettes. Prowazek states that in the rosette condition the living portion of the flagellate resides, as it were, in the long tail-like process.

Patton rlivides the life-cycle of $H$. muscue-domesticue into three stages-the pre-flagellate, Hagellate, and post-flagellate. The last two are common, but the first stage is not common, and Prowazek appears to have overlowked it. For convenience I have described the flagellate stage first, and the process of division in this stage is simple longitudinal fusion. The nuclei divide independently, and the kinetonuclens usually precedes the trophonuclens. The latter undergoes a primitive type of mitosis, in which Prowazek recognised eight chromosomes (VII). The flagellum divides longitudinally, and each of the two halves of the kinetonucleus appropriates one of the halves with its basal granule.

The pre-flagellate stage, which Patton (1909) describes, usually uccurs in the masses which lie within the peritrophic membrane'. They are round or slightly oval bodies (I), their average breadth being $55 \mu$. The protoplasm is granular and contains a trophonuclens and kinetonuclens. Division takes place by simple longituclinal division or multiple segmentation, and in this manner a large nmmber of individuals are formed (II $b$ and III). These levelop into the flagellate stage: a vacuole, the flagellate racnole (III, f. $x$.) appears between the kinetonncleus and the romded end of the pre-flagellate form, and in it the flagellum appears as a single coiled thread, which is extencted when the racuole has approached the surface.

The flagellate form has already been described, and in the conchnding portion of the flagellate stage, which, according to Prowazek, is found in starved flies, these forms are found collecting in the rectal region, and attaching thenselves by their flagellar ends in rows to gut epithelium. The more external ones begin to shorten, during which process the flagella degenerate (IX) and are shed. Thus a palisade of parasites is formed, the outer ones being romded and devoid of flagella, and some of them may be found dividing $(\mathrm{X})$. Léger (1902) terns these the "formes gregariemes," and maintains that the existence of these "gregarine" forms is a

${ }^{1}$ I assume that Patton refers to this membrane by the term "peritricheal membrane." 
powerful argmunt in farour of the thagellate origin of the Sporozon, which he had previously suggesterl, and which Butschli had put forward in 1s8t. After the degeneration of the Hagellum : thickened gelatinous corering is formol, containing a donble row of gramular bodies $(\mathrm{X} u)$, and these cysts are regarded by Patton as the pust-flagellate stage. Wenyon (l.c.) finds that muclear multiplication may occur during encystment. Dumkerly (1911) describing the life-history of a flagellate under the naunc of Leptomonas muscue-rlomesticue, to which reference is made later, records the occurrence in the rectum of Hies of snall oval borlies similar in appearance to these cysts: they were fomm near the rectal glands, and Hies containing these cysts contained no Hagellate forms.

The cysts pass out with the facees of the fly and dropping on the moist window pane or on food are taken up by the proboscides of other Hies which are thus infected.

Prowazek describes dimorphic forms of the Hagellate stage, which he regards as sexually differentiated forms, but Patton, in a letter to me, says that he is mable to find any of these complicated sexual stages. According to Prowazek, one of these forms is slightly larger than the other, and has a greater affinity for stain. The dimorphic forms conjugate; their cell substance and nuclei fuse, and a resting-stage crst is formed, but the subsequent stages have not been followed. He further states that the sexually differentiated forms may force their way into the waries where they undergo antogany and infect the subsequent broor. Mackinnon in her study of Herpetomous was unable to find, after a careful search, any infection of the ova. She never found any larval infection in $M$. domestica, but it was commonly found in Scatophoge and Fonniu. It is sliggested that the infection of the adult fly is probably fresh and is independent of that of the larva.

In Madras Patton found that 100 per cent. of the flies were infected with the flagrellate; Prowazek found it in 8 per cent. of the flies at Rovigno. In the cold season in the plains (India) Lingard and Jennings (l.c.) found the Hagellate in less than 1 per cent. of the Hies examined; in the hills (Himalayas), at an elevation of 7500 feet, the flagellates were most numerous during the hottest season of the year, and gradually decreased in number to October and November, when none were discovered. Wenyon

H. 11.-F. 
(l.c.) found that the majority of honse-flese at Aleppo, Syria, contained $H$. muscaedomesticue. Although filns of the contents of the alimentary tracts of a large number of house-flies were makle and examined by me at Manchester (England) I was unable to find with any certainty these Hagellates, nor was Dunkerly (l.c.) more successful.

One of the chief points of interest in connection with this Hagellate is its similarity to the parasite of Kalitazar. This resemblance prompterl Rogers (1905) to suggest that the latter parasite was a Herpetomonas which Patton has since nut only conclusively proverl to be the case but has also shown that the beel-bug ean act ats its carrier.

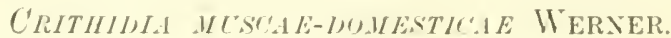

Werner (1906) describer this parasite from the alimentary tract of $M$. domestica, wher: he stated that it accurred in the alimentary tracts of forr out of eighty-two flies eximinesl.

It measures 10-13 $\mu$ in length, the length of the borly being $5-7 \mu$ and the flagellum $2-6 \mu$. As in other members of the genus Crithidiu, which is clusely allied to Herpetomones, the brearlth of the body is great compared with the length, and the kinctonucleus and trophomuclens are rather close tugethar. A short, staining, rod-like body lies between the kinetomuclens and the base of the flagellum. The Hagellom is single. J)iviling forms undergoing longitudinal division wore freguently fomnd. The kinetonuclens appears to divide first, followed in sucession by the Hagellum and the trophonncless. Forms andergong division and showing a single trophonucleus and double kinetonucleus and Hagellum were also fomnt. Cases occurred in which the fission began at the nonflagellate end of the body. No conjugating forms were found, nor any wandering into the waries.

Lingard and Jemnings (l.c.) reseribe certain flagellates of at Hag-shaped or rhomboidal natme, which I am strongly of the opinion are speceies of Crithidiu and not species of Herpetomonus. Closely following Prowazek's account of $H$. muscue-dlomesticue they describe and figure all their forms as having two flagellate in the Hagellate stage. If on allows for the rupture of the Hagellum 
fiom the burlies of the organisun in making the film, some of their figures are not unlike those of Coithilin gerridis, parasitic in the alimentary tract of an Indian water-bugr, rerris fussurnm Fabr.. and leacribed by Patton (190s).

Riensenbusch (1910) describes this species of r'vithidin as being very numerous. The Hagellates were timnel covering considerabl. patches of the peritrophic nembrane of the intestine to which they were attached by their anterior ends. 'They showed irregulill' Hagellate movements. In shap they were Hattenter laterally, the end of the body gradually tapering off to a blunt extremity. The pointed anterior end terminates in the free Hagellum. Rusenbusch gives the following as the dimensions of his flagellates: length. 8-25 $\mu$; width, 1-2 $\mu$; length of Hagellum, 12 $\mu$. Pust-Hagellate stages were also found; these were shortened and rommded and possessed no Hagellum.

It should be pointed out that there is in the minds of a number of those who have studied these flagellates a rlumbt as to whether these flagellates, which have been described as C'rithidiu, are really distinct parasites: they may be stages in the life-history of Herpetomonus. Patton and strickland (1908) call attention to the marked resemblance of Werner's parasites to the post-Hagellate stages of Herpetomonus muscre-domesticae. In living specimen: Patton has seen the Hagellates of the house-Hy collecting in masses in the rectmu of the insect where the typical long forms shorten, divide and eventually round up, and these authors rightly point out that Werner's contention that the difference in size between his parasites (Crithidiu) and the Hagellates of $H$. muscue-domesticue is an argument in farour of their being unconnected forms will not hold good in view of the marker dissimilarity in form found in the different stages of the life-history of $H$. muscue-domesticue. Dunkerly (l.c.) has described as a distinct flagellate Leptomonos muscue-domesticue, to which I shall refer shortly. Here again a non-specialist of the flagellates is in doubt as to its relationship. Further investigation will alone clear up these uncertain and disputed points: in the meantine I am recording these Hagellates under the names and in the manner in which they have been deseribed. They may be distinct or developmental forms of two species or of only one. 
Leptomonas muscue-domesticue. In a paper on some stages in the life-history of what he consirlers to be a distinct flagellate, Dunkerly (l.c.) attempts to show that Crithidic is not a valid genus and camnot be applied as a generic name to any form, as it has simply been the name given to two stages of a Leptomonas. He describes a Leptomonad which actively divides in the intestine or in the malpighian tubules of the fly and also very active slender forms which often show an undulating membrane. Encystment while attached to the rectal wall in large numbers probably takes place and the cysts may be passed ont with the fareces and thus infect fresh Hies. Porter (1911) calls attention to the faulty reasoning contained in Dunkerly's paper, as she considers it, and the lack of evidence. Wenyon (l.c.) believes that the Leptomonus of Roubaud and others is merely a not actively dividing Herpetomonus muscue-domesticue and that both may pass through a transition into flagellates of a trypanosome type.

Patton (1909) refers in a critical paper to the discovery which he made of another flagellate in the malpighian tubules of II. clomestica but I am maware of any further reference to it. 


\section{CHAPTER XIY}

THE PARASITIC NEMATODE: IIABRONEMA WCSCAE (ARTER

Carter (1861) appears to be the first to have described a parasitic worm in $M$. domestica. He describes a bi-sexual nematode infesting this insect in Bombay and found that: "Every third Hy contains from two to twenty or more of these worms, which are chietly congregated in, and confined to, the proboscis, though occasionally found among the suft tissues of the head and posterior part of the abdomen." His description of this nematode, to which he gave the name Filaria muscue, is as follows: "Linear, cylindrical, faintly striated transversely, gradually diminishing towards the head, which is obtuse and furnished with four papillae at a little distance from the mouth, two above and two below; diminishing also towards the tail, which is short and terminated by a dilated round extremity covered with short spines. Houth in the centre of the anterior extremity. Anal orifice at the root of the tail." He gives the length as being one-eleventh of an inch and the breadth as one three hundred and thirteenth of an inch. In his description of his figures of the worm he calls what is evidently the anterior region of the intestine the "liver." Leidy (1874) found from one to three specimens of $F$. muscue in about one Hy in five. He stated that this parasitic worm was one-tenth of an inch long and occurred in the proboscis. Ercolani (1874) describes the discovery of a nematode in the proboscides of flies. Von Linstow (1875) describes a small nematode, which he calls Filaria stomoreos, from the head of Stomoxys calcitrans; this larva measured 1.6 to $2 \mathrm{~mm}$. in length. Ransom (1913) points out that this may be the larva of Habronema microstoma. Harrington (1883) refers to a 
paper read by Taylor before the Montreal meeting of the American Assuciation for the Advancement of Science on "The Honse-fly as a Carrier of Contagion." This observer, when dissecting a housefly, noticerl a minute thread-worm emerging from the ruptured proboscis measming eight-hundredths of an inch in length. Incirentally, the same investigator reported the results of feerling flies on the spores of the red rusts of grasses (Tricholoma) and found these ingested. Generali (1886) describes a nematode from the common fly, which he calls Nematodum spec. It is highly probable, as my frient Dr. A. E. Shipley suggested to me, that Generali's nematode and the $F$. muscue of Carter are identical. Diesing (1861) created the genus Habronema fir the Filuria muscae of Carter, and his description is practically a translation of Carter's original description. Piana (1896) describes a nematode from the proboscis of $M$. domestica, which, in the occurrence of the male and female genital organs in the same individual, he says, resembles Carter's nematode. He finds that at certain seasons of the year and in certain localities it is very rare, while at others it may ocenr in 20-30 per cent. of the flies. The larva, after fixation, measured $2.68 \mathrm{~mm}$. in length and $0.08 \mathrm{~mm}$. in breadth. It was cylindrical and gently tapering off at the extremities, with the mouth terminal.

In many hundreds of flies which I dissected when making the morphological studies which have been described in the earlier chapters of this book, only two specimens of this nematorle were fomnd, but as I did not seek it specially it is very possible that specimens may have been unnoticed. The specimens which I found measured $2 \mathrm{~mm}$. in length and agreed entirely with the descriptions of Habronemu muscue (fig. 78). Both specimens were found in the head between the optic ganglia and the cephalic air sacs.

Recently, a very complete and unusually interesting sturly of Hubronemu muscue (Carter) has been made by Ransom (1911, 1913). This author has cleared up the mystery which hitherto surrounder the parentage of this nematode and has discovered that the adult is a parasite of the horse, the house-fly acting as a carrier of the larvil form. The following account is taken from Ransom's description of the occurrence, structure and life-history of $H$. muscue. 
One hundred and thirty-seven flies were axamined by him for the presence of IIubronema; 39 of these, or 28 per cont. were formet to be infesterl. While Carter firmol as many as 20 larval nematedes in a single fly, Rimsom never fomel more than 8. Ont of 43 flies of which a record was liept 2.5 had but one parasite, 6 had 2 paunsites, 6 had 3 parasites, 3 had 4 parasites, 2 had 5 parasites, and 1 hat 8 parasites.

A recorl was kept of the location of the parasites in the case of 37 flies. In 17 casses the head was infested, in 8 cases the thorax, and in 19 cases the abrtomen. In 12 cases the head only was infested, in 4 cases the thorax only, and in 15 cases the abdomen only. In one case 6 larvae were fomml in the head: the largest number found in the abdomen was 5 (in one case). Encysted larvae were found in the abdomen in 6 Hies, in 5 of which no worms were present in either the head or thorax. All of the flies in which encysted larvae were found had recently emerged.

One humdred and thirty-seven pupae were examined and a record kept and larvae of Habronema were found in 23, that is in 17 per cent. The author points ont that some of the younger stages of the parasites may have escaped retection. Encysted worms were found in 11 out of 23 pupace. The location of the larvae in the pupae was as follows: abdomen infested nine times, head once, thorax once. Only one nema-

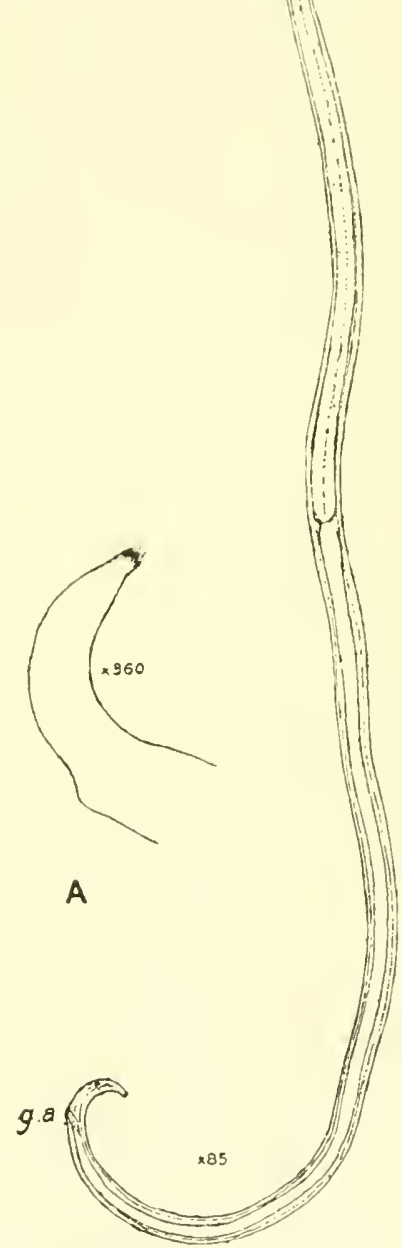

(2)

Fig. 78. Habronema muscac(Carter). Full grown larva. $\times 85$. g.a. Genito-anal aperture.

A Caudal end of Habronemu muscue. $\times 360$. 
tode was found in 170 larvae of $M$. domestica: this specinen was encysted.

The adults of Hobronema muscue were found in the stomach of the horse together with the last larval stage, which is the last stage in the fly and the first in the horse. The arlult male of $H$. muscue varies in length from 8 to $14 \mathrm{~mm}$., and from 2.50 to $300 \mu$ in maximum willth. The female raries in length from 13 to $22 \mathrm{~mm}$, and in wilth in the region of the valva from 2.50 to $400 \mu$. The cuticle is faintly marked with transverse striations. The head is amed with two lateral and four submedian papillate. The tail of the male curves ventrally. The spicules are very dissimilar; the left spicule is long and slender measuring alwout $25 \mathrm{~mm}$. in length, the right spicule is shorter and thicker measuring about $500 \mu \mathrm{in}$ length. In the female the vulva is situated about onethird of the length of the body from the anterior end.

The eggs in the nterus of $H$. muscce measure about $40-50 \mu$ long by 10-12 $\mu$ wide. The embryos pass out of the body of the horse in the freces. It has not been determined whether they undergo further development before entering the larvae of M. domestica or whether their entry is forcible or with the food; the latter method of entry seems the more probable. The earliest definitely known larval stage of $H$. muscue found in the Hy occurred in a pupa from a culture of horse faces. This specimen measured $450 \mu$ in length. Second stage larvae were found enclosed in a cyst. The sixth larval stage, which is the final larval stage, was found in both flies and horses; the length varies from 2.6 to $3.2 \mathrm{~mm}$., and the width at the wirlest part from 5.5 to $70 \mu$. The larval stage is reached about the time the Hies emerge from the pupal state. The infection of the horse probably takes place by the swallowing of infected thies or of larvae which have escaped from thies. As the proboscis of the Hy is a common location of the larval nematodes the escape of the larral nematodes on to the moist surface of the horse's lips is not unlikely.

Ransom points out that the presence of larval nematodes in thies is of interest to entomologists and sanitarians alike, as it may serve as in means of determining with some degree of accuracy what proportion of thies in a given locality find their breeding place in horse manure. 
The ocenrence of parasitic mematodes in the hearl of the fly in of further ecimonic interest, for although $M$. domestica is not a blood-sucking species and the nematode previonsly describert is not of the nature of the pathogenic Filuria buncrofti, there is an reason why the house-Hy shomll not, under the necessary conditions, carry pathogenic nematodes which might easily get on to the food of man. 


\section{PAR'T IV}

\section{OTHER SPECIES OF FLIES FREQUENTING HOUSES}

\section{CHAPTER XV}

THE LESSER HOUSE-FLY FANTIA CANICULARIS L AND THE LATRINE FLY, $F$. SCALARIS FAB.

THE two species of Hies Fannia canicularis L. and $F$. scalaris Fab. are, on account of their habits, of considerable economic importance in their relation to man. They belong to the dipterous family Anthomyidae, many of which resemble the house-fly in general appearance, on which account $F$. caniculuris is very frequently mistaken by the uninitiated for $M$. domestica which are net full grown or "young" house-flies. They are characterized chiefly by the close approximation of the eyes of the male, the comparatively large squamae or lobes on the posterior sides of the bases of the wings, and the open first posterior or apical cell $\left(\begin{array}{ll}5 & R\end{array}\right.$.) of the wing (cf. fig. 7 ). Most of the larvae feed upon decaying regetable or animal substances.

Writhout close examination, the two species under examination are liable to be mistaken for the same species, but such an examination will serve to separate them. The abdomens of both species are conical, but the basal segments of the abdomen of $F$. canicularis are partially transhncent, and the abdomen of $F$. scularis is black overspread with bluish grey: each of the mid tibiac of the latter species bears a distinct tubercle which is not found in F. canicularis (fig. 81).

1 Until recent years this species has always been referred to as Homalomyia canicularis, but by the rules of priority the generic name Famnia of Robineau Desvoidy, 1830, which was given in his Essai sur les Myodaires, will have to replace Bouche's genus Homulomyia, by which generic name these species have been previously designated but which genus was not created until 1834 . 


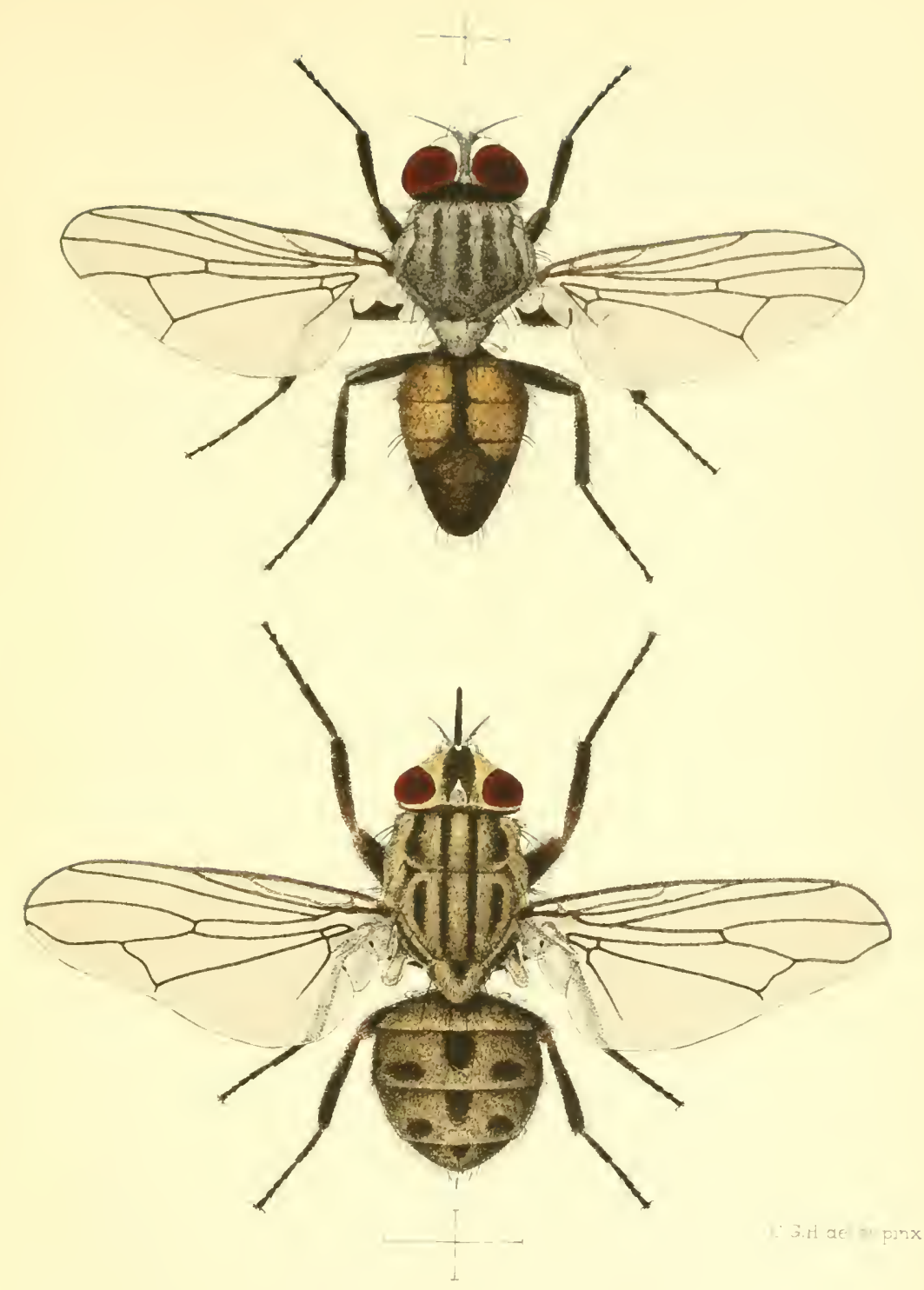

Fra. 79. Lesser House-fly, Fannia canicularis L. Male. FIG. 80. Stable Fly, Stomoxys calcitrans L. Female. 

The Lesser House-fly. Fannia cenicularis $\mathrm{I}$.

This species (fig. 79) is the lexs common of the two species of thies found in houses. Its accurrence and fresuency are, however, very varlable, and no valid explanation has bern found so fin in $n y$ investigations to accomnt for this variability. F'. cunicularis is more abundant than $M$. domestica for a short time during the early part of the summer, usually in May and June. With the beginning of the hot weather the numbers of the latter increase enormously and replace the Lesser Honse-fly. In many cases which were observerl the latter seemed to retreat in small numbers to the rooms of the house not devoterl to cooking, and they may
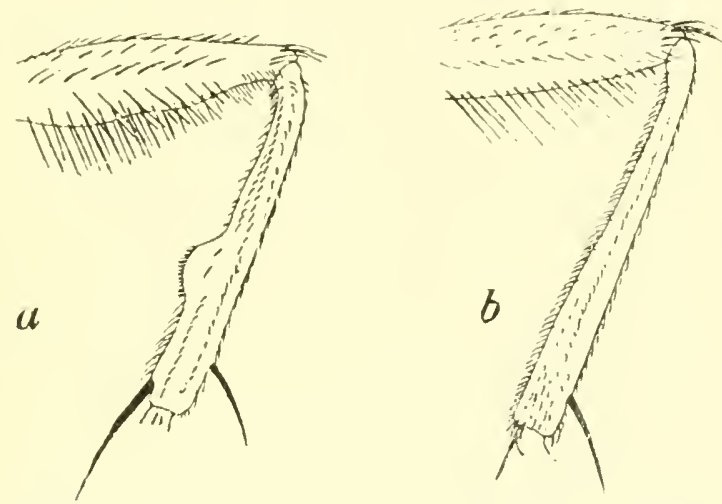

FIg. 81. Median joints of middle pair of legs (right); posterior aspect. a. Famia scalaris.

b. F. conicularis.

be frequently found flying in a characteristic, jerky and hovering manner around chandeliers, etc., in the living and bed rooms. In country houses, however, they frequently occur in numbers in the kitchens, as an examination of fly-traps and papers in such places indicates. An observation recorded by Austen (1911) illustrates the earlier occurrence of $F$. cunicularis as compared with $M$. domestica. Ont of a collection of more than 430 flies caught in a kitchen in Leeds, from May 19th to July 18th, only 48 specimens of $M$. domestica occurred, all the rest being $F$. canicularis, which outnumbered the former in the ratio of 8 or 95 to 1 . 
The numerical abundance of $F$. canicularis in comparison with the abundance of $M$. domestica varies considerably. In a collection of 4000 Hies which I marle in different situations, such as kitchens, restaurants, bed-rooms, etc., in 1907 , this species formed $11 \%$ per cent. of the total number. In 1900 Howard found that in collections made in different cities of the United States only about 1 per cent. of a collection of over 23,000 Hies made in rooms where food was exposed were $F$. cuncularis, and orer 98 per cent. were $\boldsymbol{M}$. domestica. Hamer in 1908, in collections made in kitchens and "living roons" of houses near depots for" horse-manure in Londom, found that the percentage of $F$. caniculuris varied from 17 per cent. to 24 per cent. Niven gives the results of collections made at six different stations in Manchester. The total number of flies eaught was 8553 , of which 8196 were 11. domestica, $293 \mathrm{~F}$. canicularis, and 6t were other species. Thus $F$. canicularis constituted $3 \cdot 4$ per cent. of the total of the Hy population. Robertson (1909) gives the results of similar collections made in Bimningham where, of 24,572 Hies canght, 91 per cent. were $M$. domestica and $4 \cdot 7$ per cent. were $F$. caniculuris. From observations which I have made in many localities in different neighbourhoods, I do not think that this species would often form more than 25 per cent. of the total Hy population. After $\boldsymbol{M}$. domestica, howerer, it is the next fly of importance inhabiting houses, and well deserves the title of the Lesser Honse-tly. It is known in Germany as "die kleine Stubentliege."

The male of $F$. canicularis differs from the female in some respects. In the male the eyes are close together, and the frontal region is consequently very narrow; the sides of this, which are the inner orbital regions, are silvery white, separated by a narrow black frontal stripe. In the female the space between the inner margins of the eyes is about one-third of the width of the hearl: the froms is brownish black, and the inner orbital regions are lark ashy grey. The bristle of the antenna of $F$. camicularis is bare; in $M$. domestica, it will be remembered, the bristle bears a row of setae on its upper and lower sides. The dorsal side of the thorax of the male is blackish grey with three rather indistinct longitudinal black 
lines. In the female it is of a lighter grey, and the three longitudinal stripes are consequently more distinct. The aberomen of the male $F$. canicularis is narow and tapering compared with that of M. domestica. It is bronze-black in colons, and each of the three abolominal segments has a lateral transluernt area, so that when it is seen against the light, as on a winchw-pane, three and sometimes four pairs of yellow transhlncent areas can be seen by the transmitted light. In the female the abrlomen is short in proportion to its length and is pyriform in shape, greenish or brownish-grey in colour with a golden attachment. The average length of the species is $5 \cdot 7 \mathrm{~mm}$.
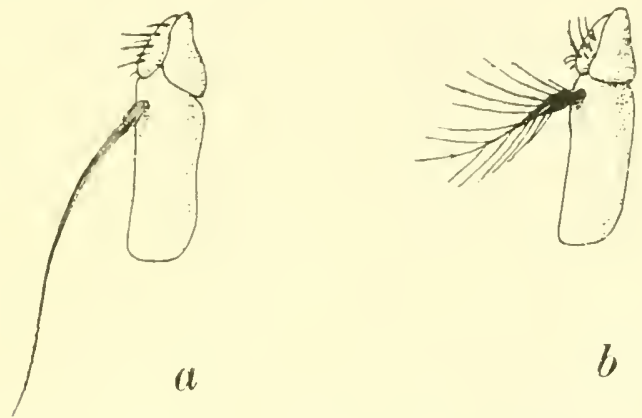

Fig. 82. Antennae, $(a)$ of $F$. canicularis, (b) of $M$. domestica.

Great disparity in the proportion of males to females is found in this species as it occurs in houses. Hamer showed, in 1909, that the males comstitute from 75 to 85 per cent. of the total flies of this species caught in balloon fly-traps and on fly-papers. This, however, does not indicate a disparity in the proportion of males to females in the species, as I have found that the females are more commonly found out-of-doors, especially in the neighbourhood of the breeding-places.

The breeding habits of this species are somewhat similar to those of the house-fly, M. domestica. The larvae breed in decaying and fermenting vegetable and animal matter, and also in excrementous matter. In 1848 Heeger recorded it as living in the caterpillars of Epischnia canella ${ }^{1}$; Roth found them in

1 Larvae of $F$, canicularis were found feeding on the body of a dead caterpillar (Xylina sp.) in a breeding cage in my laboratory on September 5th, 1913. 
the nest of the humble bee, Bombus terrestris, and Schiner observed them in the bottom of a box in which a dormonse had been kept. Taschenberg also records the larvae as being fonnd in snails, in old cheese and in pigeon-nests; he reared the flies from sugar-beet, and Brischke found the larve in the stalks of rape. I have found them commonly in human excrement and in a variety of decaring vegetable substances, even in rotting grass (cf. Stomoxys). In England they may be found in the larval stages from May to October. Howard has reared them from hmman excrement during the same period in the United States, and in Canada 1 have observed the same period for the occurence of the larval stages. Larrae of $F$. conicularis were found by Carter and Blacklock (1913) in a case of external myasis in a monkey (Cercopithecus callitrichus). They were removed, together with the larvae of Muscina stabulans and Calliphora erythrocephala, from the nasal and facial region and the right side of the body near the groin, but it is probable, as these authors point out, that they may have been derived from an external sonrce. The eggs are white and cylindrically oral.

The larvae of $F$. canicularis (fig. 83) is wholly different from that of $M$. domestica, its body being provided with a number of appendages or spiniferons processes. These are arranged in three pairs of longitudinal series, and there are in addition two pairs of series of smaller processes.

The body is compressed dorso-rentrally, and the surface is roughenerl in character and in places spiniferous. It consists of twelve segments, of which the first, or psendocephalic segment, is often withdrawn into the second or prothoracic segment, as shown in the figure. The posterior end of the body is rery obliquely truncate. The full-grown larra measures 5 to $6 \mathrm{~mm}$. in length. The three series of pairs of spiniferons flagelliform processes, or appendages, are arranged as follows: A dorsal series consisting of ten pairs of processes, commencing with an antennalike pair of processes at the anterior border of the prothoracic segment (segment II) and slightly increasing in size pusteriorly. A latero-dorsal series of ten pairs of processes which commence on segment III and is continner to the posterior end of the borly. A latero-rentral series which commences on segment III 
and is continued posteriorly. These Hagelliform processes are spiniferous, the spines being well developed at the basses of the processes and gradually decreasing in size distally. The twelfth or anal segment is provided with three pairs of these processes of mequal size: the most anterior pair is the longest on the body, and the intermediate pair is shorter.

There is a series of pairs of small, almost sessile brancherl appendages (fig. 85) situated near and slightly posterior to the bases of the latero-dorsal appendages. These were described by Kieffer. Each of these processes has three to four branches, and they cary a suall nucleiform organ which Cherril (1909) has also described. He believes that this organ is of the nature of an exurial gland and correspondent to Verson's gland.

On the rentral surface of the body, and extending posteriorly from segment III, there is to be found a series of pairs of small spiniferous papillae. Between these there is on each segment a transverse row of four groups of spines.

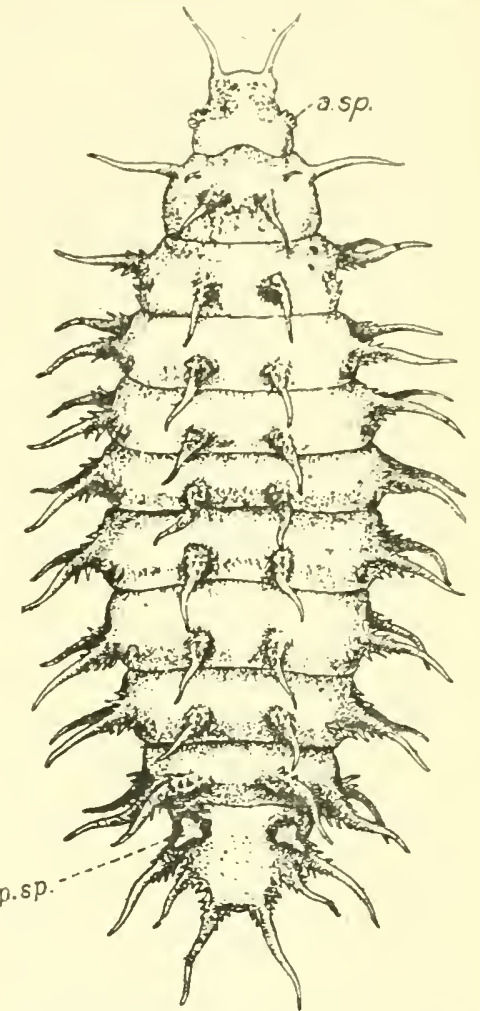

Fig, 83. Mature larva of Fannia canicu. laris, L. $\times 17$.

a.sp. Anterior spiracular processes. 1.sp. Posterior spiracular processes.

The anterior or prothoracic spiracular processes (fig. 84) have usually seven finger-like lobes, though the number way vary from five to eight, and between the second and third lobes there appears to be a small stigmatic organ. The posterior spiracular processes have a trilobed appearance, but a close exanination reveals their four-lobed character shown in fig. 86 ; a stigmatic orifice is situated at the extremity of each lobe. 
The spiny character of the flagelliform appendages and body of the larva caluses particles of dirt to adhere readily to the bodies and appendages of the larvae. In comsequence the larvae have a very dirty appearance, and their external features are almost hidden by the accumulated particles of dirt and filth adhering to them.

The larval period may extend over a week, or it may last for three or four weeks if the substances in which the larvae are feeding become rather dry. When fully grown it is covered fairly thickly with dirt, which is of great assistance in the formation of the pupal case, as this is formed of the larval skin.

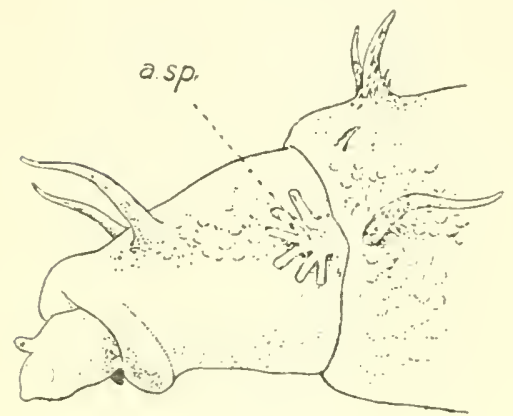

FIG. 84.

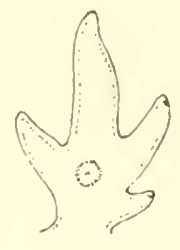

FIG. 85.

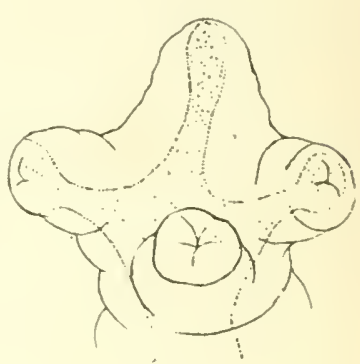

FIG. 86.

Fig. 84. Fannia canicularis. Lateral aspect of cephalic region of larva; a.sp. anterior spiracular process.

Fit. 85. F. camiculuris. Palmate and sessile dorsal appendage of larva.

FIG. 86. F. canicularis. Posterior spiracular process of larra.

In changing into the pupa, the cephatic region is retracted and the length of the larva is thereby decreased. The larral skin, with its covering of dirt particles, forms the co-arctate pupal case. Before pupating, the larva leaves the very moist substance in which it maty have been living and seeks a dryer situation. The pupal perior extends over a period of seven to twenty-one days, or longer, and it is not unlikely that larvae, which have developed rery late in the seasun, pass the winter in the pupal state, as is the case in certain other species of Anthomyid flies. The adult fly emerges by pushing oft the anterior segments of the pupal case. 
The Latrine Fix. Fumiu scalaris Fab.

This species, which, on account of its most common breeding habits, may be called the Iatrine-fly, is very common both in Eumpean countries and in North Anerica. Owing to its general similarity, it is often confused with the lesser Honse-fly, Fumio canicularis, but the chief differences have already been indicated.

In the male the frontal triangle on the head is black and is continued as a thin line to the vertex, being bordered on each side by a silvery white stripe. The antennae and palps are black. The thorax and scutellum are black and somewhat polished: the humeri are light-coloured. The abdomen is black, oversprearl with bluish-grey, and has a darker median stripe from which dark transverse bands arise, forming by their junction with the median stripe black triangular markings. The legs are black and the middle fimur is swollen ventrally, bearing on its broader side a group of brush-like bristles, as will be seen from fig. 81. The middle tibia is provided, as shown, with a distinct tubercle near the distal end.

The colouring of the female is more distinctly grey, with a faint longitudinal striping on the thorax; the transverse markings on the abdomen are also indistinct. 'The head is grey with a wide frons.

$F$. scularis is slightly larger than $F$. cuniculuris, measuring up to $6 \mathrm{~mm}$. in length.

The habits of this species are somewhat similar to those of $F$. canicularis, but it prefers excrementons matter as a nidus for the eggs and is commonly found breeding in human excrement. It has been recorded breeding in human excrement by Schiner, Taschenberg, Howard and Newstead, and I have also bred it from this material in England and in Canada, both in privies where the excrement was found in a semi-liquid condition and on rubbish-tips or dumps, where it was mixed with ashes or clinkers. Swammerdam figured what would appear to be the larva of this species as breeding in hmman excrement. Taschenberg also refers to its breeding in mushrooms. In 1908 Dr David Sharp submitted the larva of this species to me for examination. He had found it in rotting fungus in the New Forest H. H. $-\mathrm{F}$. 
in September 1905 and noticed its similarity to Swammerdan's Latrine Larva.

The larvae emerge as early as eighteen hours after the deposition of the eggs, and become full-grown in six to twelve days.

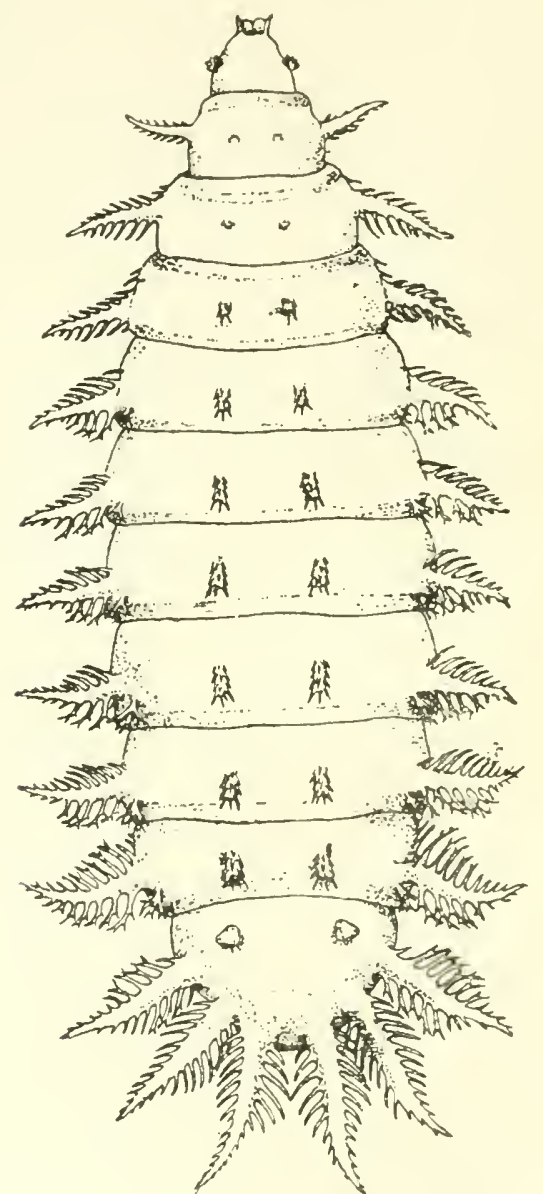

FIG. 87. Larra of Latrine Fly, Famnia scalaris Fab. $\times 12$.

The shortest time which I have recorded for the pupal stage was nine days, which was in the month of August, but I believe that, under very faroumble conditions, the pupal stage would be passed in a shorter time. 
The larva of this species (fig. 87) has a general resemblance to that of $F$. canicularis, but a closer examination will reveal very marked differences and a number of distingnishing characters. In shape it is similar to the larva of $F$. canicularis, being compressed dorso-laterally. The appendages or processes, however, are very different. The pair of antenna-like processes at the anterior and upper edge of the prothoracic (second) segment are much shorter than those of $F$. canicularis, as will be seen from the figure, where they are shown dorsal to the oral lobes. On the dorsal side of the larva, from segment III to segment XI, is a series of nine pairs of short and somewhat thick processes of a very spiny character; the first two pairs being little more than spinous tubercles. As the processes of the third segment differ from the succeeding segment, they may be mentioned separately. There is a pair of latero-dorsal processes bearing spines. Ventral and slightly anterior to the base of each of these processes is

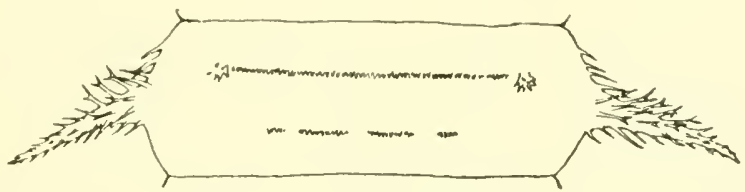

Fig. 85. Fannia scalaris. Larva. Tentral aspect of segment vir.

a small spiniferous papilla. A short spinous latero-ventral appendage is situated slightly more posteriorly. Viewed from above, the larva is seen to be surrounded by a fringe of feather-like processes. Segments IV to XI are each provided with a pair of pinnate latero-dorsal processes which gradually increase in size posteriorly. Three pairs of these pimate processes surround the obliquely truncate dorsal surface of the twelfth segment. Sitnated laterally and ventral to the series of pinnate processes is a series of latero-ventral processes which are spinous (as shown in fig. 88), but much less pinnate and shorter than the laterodorsal series. The latero-ventral processes of segment XII are situated more ventrally than those of the preceding segments, and their usual place is taken by a small group of spines. Posterior to the base of each of the latero-dorsal processes of segments $V$ to XI is a small branched process. 
On the ventral side of the larva, extending from segments IV to XI, there is a series of pairs of small spiniferons papillae as shown in fig. 88, each of which is situated at the end of a transverse row of spines. Posterior to this transverse row of spines there is a shorter row of spines, divicled into four groups. The anterior or prothoracic, spiracular processes are six to eightlobed, the usual number of the lobes being seven. The posterior spiracular processes are very similar to those of $F$. canicularis. Vugler (1900), who has given a good description of this larva, illustrates the anterior spiracular processes with eight lobes, and his figure of one of the posterior spiracular processes is not very clear.

The feathery character of the processes of $F$. scularis is probally associated with the fact that the larvae usually live in substances of a semi-liquid character, where such processes will be more advantageous than those of $F$. canicularis for life in such a medium. It may be of interest to note in this connection that the spiniferous and branched lateral appendages of the larvae of the genus Fannic were considered by Walsh (1870) and probably by other entomologists, to be "branchiae" or gills. Walsh (l.c.) stated: "The larvae......wallow in moist decaying matter, whether animal or vegetable; and as in such situations they would be sometimes stifled for want of air, if they breathed through the spiracles or breathing holes with which all airbreathing insects are supplied, nature has replaced the spiracles by lateral 'branchiae' or gills, by means of which they are able, after the manner of a fish, to extract the air from the fluids around thein," and he compares them to the gills of the Ephemerid larvae.

Prior to pupation the laria leaves the moist situation for one of a drier character, and the pupation is similar to that of F. canicularis.

$F$. scalaris is more commonly found than $F$. caricularis as the cause of intestinal inyiasis, and it also breeds more commonly in human excrement. These facts make its economic relation to man one of some inportance. 


\section{CHAPTER XVI}

THE STABLE FLY, STOMOAYS CALCITRAMS LINN. (fig. 80)

OWING to a general resemblance which this species bears to Mrsca domestica, and to the fact that it is a blood-sucking species, it is frequently mistaken for Musca domestica, which is supposed to "bite" under certain conditions. This has led to the popular" but obviously inaccurate idea that house-flies bite. The biting Hy is usually stomorys culcitrons. It is naturally an out-door species and loves the sunlight, coming indoors usually on the approach of rain when the sky is dull, hence it has been named the "Storm-fly," and this fact, namely, the presence of s. calcitrons indoors during dull weather, has led to the popular misconception that house-flies bite during such meteorological conditions.

In England and Canada I have found this species common and widely distributed, occurring especially in the country from July to October. In the United States it appears to be abundant during the same period. During these months it may be often found in houses, although Hamer's observations (1908) appear to indicate that the presence of cowsheds in which they occur in large numbers, does not affect their numbers in houses. In England I have found S. calcitrons in large numbers in the windows of a country house in March and April, and it may be found frequently out-of-doors on a sunny day in May and throughout the ensuing summer months. It occurs occasionally in-doors in November and is commonly found in cowsheds and stables throughout the winter months. Its association with the cowsheds and stables has given it the name of stable fly, by which it is now generally known. 
The recent investigations in Massachusetts, U.S.A., by Brues, Shepprard and Rosenan (see 1911 to 1913), on the relation of $\therefore$ calcitruns to polionyelitis or infantile paralysis, in which they experimentally demonstrater the ability of the Hy to transmit the disease to healthy monkeys, which experiments were confirmed in Washington by Anderson and Frost (1912), have resulted in increased attention being paid to this species, which is now being studied by a number of investigators including myself. In later experiments Anderson and Frost (1913) faited to confirm their previous results ${ }^{1}$.

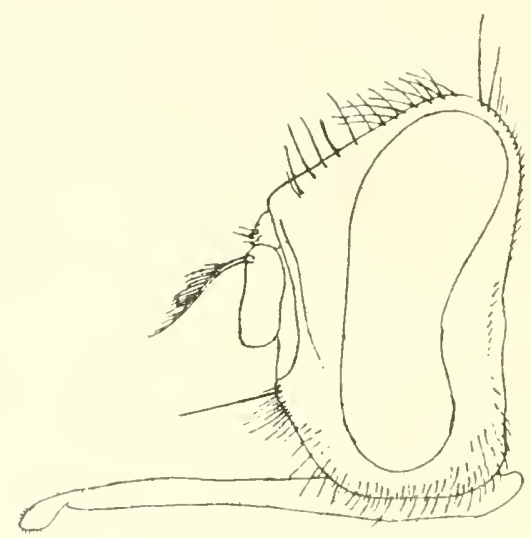

FIg. 89. Head of Stomorys calcitrans L. Left lateral aspect.

Stomorys culcitrens is slightly larger and more robust than II. domestica, measuring about $7 \mathrm{~mm}$. in length. It can be readily distinguished by the awl-like proboscis which projects horizontally forward and slightly upwards from beneath the surface of the head (fig. 89). The bristles of the antemne bear setae on their upper sides only, as in the allied Glossinc. The general colour is brownish or greyish with a greenish tinge; the dorsal side of the thorax has four dark longitudinal stripes, the ontermost pair being interrupted. At the anterior end of the dorsal side of the thorax the medium light-coloured stripe has a golden appearance which is very distinct when the insect is seen against the light.

+ In a more recent paper Sawyer and Herms (1913) describe a series of experiments in which they were unable, under varied conditions, to transmit poliomyelitis from monkey to monkey through the agency of $S$. calcitrans. 
The abdomen is broad in proportion to its length, and ench of the large second and third segments has a single median and two lateral brown spots; there is also a median spot on the fourth segment. The fourth longitudinal or median nervmre (cf. fig. 7 , $M .1+2$ ) of the wing in $S$. culcitrens has not the pronounced angular bend found in the same nervure in $1 \%$. domestica.

The life-history was first sturlied in anything like a complete manner by Newstead (1906) and I was able to confirm his observations during 1907, 1908 and 1912. Portchinsky added to our knowledge in 1910. In the United States Bishopp (191:3) has recently made a valuable contribution to the knowledge of the insect's biology and life-history, and Mitzmain (191:3) has given a summary of his investigations in the Philippine Islands which have extended over two years. These references are given as it is not intended to give an exhanstive account of this inseet here. It may be added that morphological studies have been made by Newstead, Tulloch (1906) and Brain (1912). The following account of the life-history is taken from the foregoing accounts and my own notes.

Both sexes are able to suck blood. After emerging from the puparium the proboscis lies extended backwards, along the ventral side of the thorax. It soon bends forward and hardens, and in six to eight hours after emergence the fly may take its first meal. The feeding period lasts from two to twenty minutes. It has been fornd to feed chiefly on cattle, horses, dogs and man, being especially attentive to the ears of dogs. Bred flies may begin ovipositing on the ninth day, usually after they have had the third or fourth feed. This species breeds in the following substances, apparently with varying preferences in different countries: horse manure, cow manure, sheep dung, human excreta, the straw of oats, rice, barley and wheat, fermenting cut grass, decaying regetable substances, including fungi, and in animal substances, no doubt in a state of decomposition.

The eggs may be laid singly or in batches of as many as seventy-two (Newstead). The eggs are white, cylindrically oval in shape, somewhat resembling a banana, and measuring $1 \mathrm{~mm}$. in length. A groove widening at the anterior end runs along the side of the egg. Mitzmain states that the maximum number of 
eggs deposited at one period was ninety-four, and that the maximum number of eggs reposited by a single feriale may be placed at, at least, six hundred and thirty-two. Bishopp found that two feedings are usually necessary between the deposition of each lot of eggs.

There are three larval stages and the larvae are creamy white in colour and have a shiny translucent appearance; the young larvae are even more translucent. 'The adult larvae, which measure abont $11 \mathrm{~mm}$., are rather similar to those of $M$. domestica, but they can be distinguished by the character of the posterior spiracles. These (fig. $90, A$ ) are wider apart than in $M$. domestica and are triangular in shape with rounded corners; each of the corners

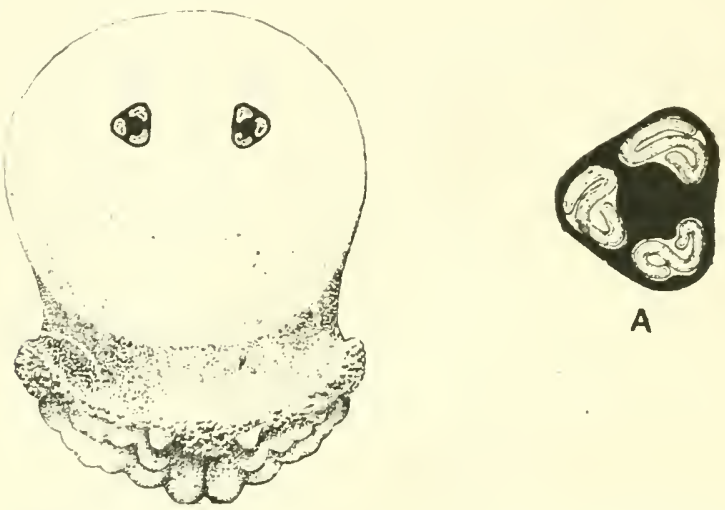

Frc. 90. Posterior end of mature larva of S. calcitrans.

A Posterior spiracle of the same, enlarged.

subtends a space in which a sinuous aperture lies. The centre of the spiracle is occupied by a circular plate of chitin. The anterior spiracular processes are five-lobed.

The developmental stages, according to my own and the observations of those who have studied the life-history in temperate and tropical climates, are as follows: egg stage, twenty hours to four days: larval stage, seven to thirty days; pupal stage, five to twenty days. The whole life-history, therefore, from the deposition of the eggs to the emergence of the adults, may vary from about thirteen days to seven or eight weeks. The longest time which I observerl in any of my experiments was a few days over ten weeks (Oct. 4th to J)ec. 15th). In temperate elimates it 
is p-oible that the pupae way exist thrugh the winter. and the larval stages may als be found in waru stuations during the winter. In surlying the longevity if the aldes Bi-hopl fomb that ther could be kept. when water and strar - rzup were supplind. for iwenty-ihre dars. Jirzmain fioml that a temale ty can live a maximum of at leas serenty-tw day and a male a pori 1 wi ninety-fur day. The lengih ot the life-hisory depenl on the cunditions with regard is temperature. mossure and nature it foud: ab-ence or presence of light alos appoar of infuence th. rate oi derelopment.

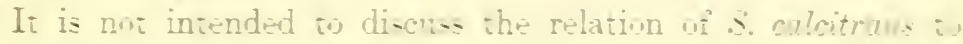
disease: the reader is referred to the excellent account of Brues. Pusenau and Sheppard, and alw those of Anderwn and Frost ${ }^{1}$, for an acooun if their ob-errations and experiment on the relation

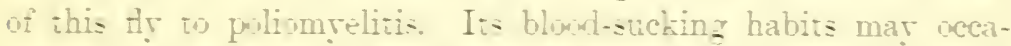
sionally enable it to be the rector of the anthrax bacillu-cam-ing anthras in cattle and maligmant putule in man:. Schubery and Kuhn (1911) have experimentally demon-trated that $\therefore$ oflctome can inicc animal, with irpanowne- and spirochates ${ }^{3}$.

1 See a

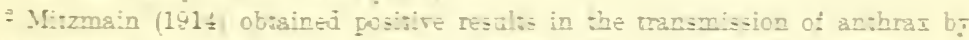
S. abisisan.

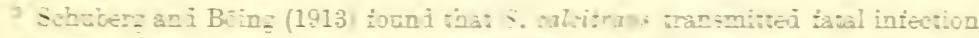

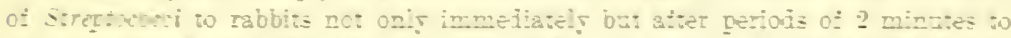

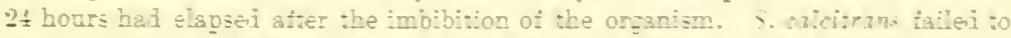
conrep anthras infection is the goai. bat iti so in the case ot one ot tro sheed experimen:eil with. 


\section{CHAP'TER XVII}

'THE BLOW-FLIES, CALLIPIIORA ERTTIIROCEPIIALA MEIC. AND $\because$ VOMUTORIAL L., AND THE SHEEP MAGGOT OR "GREEN BOTTLE" FLY, LCCILIA CALSAl' I.

THE large blow-fly or "blue bottle," C. erythrocephulu, is a widely distributed and common species in Europe and North America. In the past, but less commonly now, the name of the other species, C. vomitoriu, has been indiscriminately applied to both species. C. vomitoria is, howerer, much less common than C. erythrocephula. They can be distinguished by the fact that in the latter species the genae are fulvous to golden yellow and are beset with black hairs, whereas in C. vomitoria the genae are black and the hairs are golden red.

Culliphora erythrocephulu has been described in detail by Lowne $(1870,1895)$. Its appearance, with its bluish-black thorax and dark metallic blue abdomen, is sufficiently well known as to render a description of the adult flies unnecessary. Its length varies from 7 to $13 \mathrm{~mm}$. The larvae are necrophagous, and the flies deposit their eggs on any fresh, decaying or cooked meat, and also upon dead insects; Howard (1909) has found the fly on fresh hmman faeces. On one occasion, when obtaining fresh food material in the form of wild rabbits upon which to rear the larvae of $C$. erythrocephala, I found the broken leg of a live rabbit, which had been caught in a spring trap set the previous erening, a living mass of small larvac, which were devouring the animal while it was still alive. An enormons number of eggs are laid by a single insect: Portchinsky (Osten Sacken, 1887) found from 450 to 600 eggs, though I have not found so many. Fabre, in his Soutenirs entomologiques, records C. romitoria depositing 300 eggs in one batch and nore were subsequently deposited, and he bchieved, on the evidence which he secured, that as many as 900 may be 
deposited. He fomd tha flies would emerge fiom pupare buried under $60 \mathrm{~cm}$. of sand.

With an arerage mean temperature of $2: 3 \mathrm{C} .\left(7355^{\circ} \mathrm{F}\right.$ ) and using fresh rabbits as food for the linvae, the following were the shortest times in which I reared $C$. erythrocephalu. The eggs hatehed from ten to twenty hours after deposition. 'The larvace

88

A

\section{s}

B

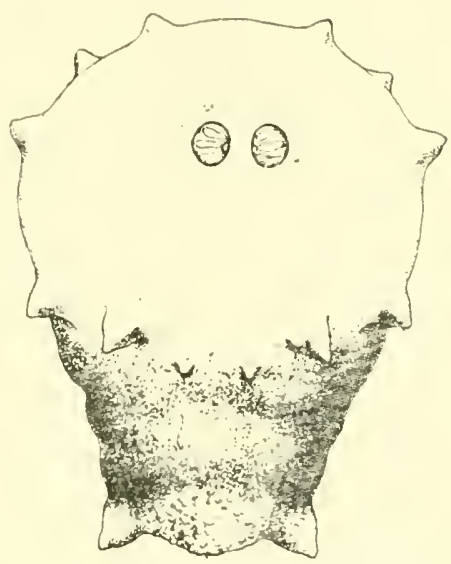

Fis. 91. Posterior end of mature larva of C. erythrocephala.

A Posterior spiracles of first larval stage of C. erythrocephulu, Mg.

B Posterior spiracles of second larval stage of $C$. erythrocephula.

C Posterior spiracle of mature larva of $C$. erythrocephala.

D Anterior spiracular process of mature larva of $C$. erythrocephala.

mderwent the first ecrlysis eighteen to twenty-four hours after hatching; the second moult took place twenty-four hours later, and the third larval stage lasted six days, the whole larval life being passed in seven and a half to eight days. Fourteen days were spent in the pupal state; thus the development was complete in twenty-two to twenty-three days. I have no doubt that this time could be shortened by the presence of a very plentiful supply of food, as an enormous amount, comparatively, is consumed. 
The full-grown larva may measure as much as $18 \mathrm{~mm}$. in length. There are two distinct mandibular sclerites. The anterior spiracular processes (fig. $91 \mathrm{D}$ ) are usually nine lobed. The posterior extremity is surrounded by six pairs of tubercles arranged as shown in fig. 91; there is also a pair of anal tubereles. The posterior spiracles (fig. $91 C$ ) are circular in shape and contain three straight slit-like apertures. In the second larval instar there are only two slits in each of the posterior spiracles (fig. 91 $B$ ) and in the first larval instar each of the posterior spiracles (fig. $91 \mathrm{~A}$ ) consists of a pair of small slit-like orifices.

C. erythrocephale is an out-door fly, but it frequently enters houses in search of material upon which to deposit its eggs, and also for shelter. From its habit of frequenting faeces, which may often be observed, especially in insanitary courtyards and similar places, it is not improbable that it occisionally may bear intestinal bacilli on its appendages or body or intermally, and thus carry infection. Its flesh-seeking habits may also render it liable to carry the bacilli of anthrax should it have access to infected flesh, and such meat-seeking habits render the ingestion of the larvae into the human digestive system extremely possible. Buchanan (1907) recovered the bacillus of swine fever from blow-flies which were canght on the carcases of pigs which had died of swine fever. Further infection experiments with C.erythrocephala are discussed in a later chapter.

\section{The Sheep Maggot or "Green BotTle" Fly, LUCILIA CAESAR L.}

This fly is an out-door species which is sometimes found in houses, into which it is generally driven by adverse weather conditions for the purpose of shelter. It is more commonly found in farm and country houses. Although it is not so large as C. erythrocephala, being more similar in size to M. domestica, it is frequently called a "blue bottle" and is often referred to as the "green bottle" fly. The colouring is more brilliant than that of C. erythocephala, being of a burnished gold, sometimes bluish appearance and sometimes of a shining green colour.

The flies are usually found on dead animals and carrion; they also oceur on the excrement of man and other animals. On all 
such substances the lirvace are able to feerl. In Europe the larvak feerl on the matted wool and on the Hesh of the backs of sheep, from which habit they are popularly known as "sheep maggots." In Canada, however, as a result of a careful inquiry I have only been able to discover a few eases of such a feerling habit for the larvac, which results in the production of large nleerated areas on the backs of the sheep, eausing severe loss of flesh and sometimes death. Banks (1912) states that Meinert has reared Lucilia nobilis from larvae taken from the ears of a sailor. An excellent necount of the Lucilia flies has been given by MacDougall (1909), and Herms (1911) gives a full account of the habits of L. caesur. In England I have usually obtained it from the backs of sheep. Howard (1900) reared it from human exerement.

The larvae are very similar to those of $C$. erythrocephala except in size, and Portehinsky considered them otherwise indistinguishable. The full-grown larva measures 10 to $11 \mathrm{~mm}$. in length. The larval life lasts about fourteen days and the pupal stage a similar length of time, but my experience in the field would lead me to believe that under favourable conditions development may be completed in a much shorter time.

\section{PROTOCALLIPIORA GROENLANDICA.}

In the careful investigation which he carried out Hamer (1908 and 1910) found this species, and occasionally P. azurea, in the neighbourhood of a glue and size factory, and also at a railway siding to which were brought, in addition to stable manure and other refuse, the bones for the glue factory. Hamer states that so numerons were the larvae in the sacks of bones that "the ground beneath some vans containing these sacks was found one day last summer to be covered with larvae so that from a little distance this portion of the yard surface had the appearance of snow." The adult flies were canght in the neighbourhood of the factory from the middle of June until mid-September and it was found that the arloption in the late summer of a system of destroying the larvae had some influence in lessening the fly nuisance in surrounding houses.

The larvae of Protocalliphora are similar to those of Culliphora. 


\section{CHAP'TER XVIII}

\section{THE CLUSTER FLY POLLEIIA RUDIS FAB. AND MLSCINA STABCLALS FALL.}

The first of these two species, Polleriu rudis, is common in Europe and North America. On account of their habits and general appearance they are usually mistaken by the uninitiated for house-flies emerging from their winter sleep. Early in spring and sometimes during mild days in winter they may be found crawling sluggishly around, as is their habit. Out-of-doors one may find them on the snow around buildings or on the walls. In-doors they buzz lazily, frequently in considerable numbers, in the windows and especially on the windows of unoccupied rooms. I have found them out-of-cloors on the snow at Ottawa as early as the middle of March. In England I have observed them entering the sun-lit window of a bed-room in a country house and swarming over the window panes. They appear to frequent especially country houses covered with creepers and vines. The name "Cluster-fly" has been given to them on account of their habit of congregating in large numbers in and about houses and other occupied buildings. They appear to prefer unocenpied rooms, no doubt on account of the absence of disturbance.

Howad (1911) refers to the observations of Dall in the United States, which confirm my own made on the habits of this fly in England and Canadia. Dall states that this fly was a great nuisance in comntry honses near Geneva, New York State. They were a terror to housekeepers since they were found in all kinds of places such as in and on beds, wardrobes, behind pictures, etc. They would form large chusters about the ceilings of clean, dark rooms seldom nsed. It was stated that abont the first of April 
they came ont of the grass and flew up to the sumy side of houses, which they entered. 'T'hry remained in eviclence until some time in May and then disippeared mutil September. Large numbers were said to occur often under buildings, between the earth and the Hoor. An exmmination of these flies and a comparison with Musca domestica will show their distinct character. Their characteristic sluggish habits have already been mentioned. They are slightly larger in size and darker in enlour and the thorax is sparsely covered with yellowish coloured hairs. When at rest the wings are folded more closely together over the back than is the case of the house-Hy.

As in the case of many other common species of Diptera, we have little information in regard to the breeding habits of this species. Robineau-Desvoidy states that the flies of the genus Pollenia deposit their eggs on decomposing animal and vegetable matter; in this regard they resemble, in general, the other members of the Muscidae. Howard (1910) records the rearing of a single specimen of $P$. rudis from cow manure in Washington D.C. in December, and quotes J. S. Hine as reporting the rearing of numbers of Cluster Hies in the summer of 1910 from cow manure in the pasture. Copeman, Howlett and Merriman (1911) record the occurrence of three specimens of $P$. rudis in a collection of 200 larvae and pupae obtained from fresh refuse on the Norwich Corporation tip at Postwick. Keilin describes $P$. rudis as parasitic on a species of earthworm Allobophora chlorotica Sav. He states that it pupates in the earth, the pupal stage lasting from thirty-five to forty-two days.

\section{MESCLYA STABTLAXS FALL.}

So similar is this tly to the true house-fly in general appearance, though slightly larger in size, that it is almost invariably mistaken by the untrained observer for a large house-fly. According to my own observations it usually oceurs in and near houses in the early summer, about June, and generally about the same time that the Lesser House-Hy, Famia canicularis, is the predominant domestic species. Hamer (1910) found that the largest number of $M$. stubulans were captured in August and early September. In large collections which have been made in 
North America and England of the flies occurring in honses, a number of specimens of this species are usially found (see p. 66). Cleland (1912) records it in New south Wales as occuring in houses on the window panes or on the table at meal time: in the neighbonrhood of houses he states that it is found feeding in house refuse and round the garbage can.

It is larger than $\boldsymbol{H}$. domestica and more robust in appearance. It varies from $T$ to nearly $10 \mathrm{~mm}$. in length. Apart from its greater size it may be distinguished from 1 . domestica by the fact that the median or fourth longitudinal vein (cf. fig. $7,1 / .1+2$ ) of the wing is only slightly curred rentrally instead of being bent upwards through a pronounced angle as in $M$. domestica.

Its general appearance is grey. The head is whitish-grey with a "shot" appearance. The frontal region of the male is velvety black and narrow; that of the female is blackish-brown, and is about a third of the width of the head. The bristle of the antenna bears setae on the upper and lower sirles. The dorsal side of the thorax is grey and has four longitudinal black lines; the scutellum is grey. The abdomen, as also the thorax, is really black covered with grey; in places it is tinged with brown, which gives the abdomen a blotched appearance. 'The legs are rather slender, and are reddish-gold or dirty urange and black in colour.

The eggs are laid and the larvae feed upon various kinds of decaying or decomposing regetable and animal substances. They have been reared from fungi, decaying fruit, such as apples and pears, cucmmbers and miscellaneons vegetables. They sometimes attack growing regetables, and I have reared them in considerable numbers with root maggots from radishes. In the latter case the eggs or young larvae nay be introduced with the manure, but I have found them also attacking growing plants where no manure had been used. Aldrich has reared it in Idaho from rotten radishes. They breed in excrement, such as cow dnng and human excrement from which Howard (1900) reared specimens. Cleland (1912) describes this species as occuming on human faeces and honse refuse in Australia. In Enrope they have been found feeding on caterpillars and larval bees and in Canada Fletcher (1900) records the species as parasivic on the noctuid caterpillar Peridromiu saucia Hbn. in British Columbia. In the United States they 
have been reared from the pupase of the cottom-wo'n and the Gipsy moth: Riley was of the opinien that in the first ciss rotten pupate only were fecl upon. In 1891 it was reared on the masses of larve and pupae of the Elm-leat beetle. Other observers record it as being reared from the pupare of such Hymenoptera as Lophyrus.

The most complete accomnt of $M$. stubulans is that given by Portchinsky (1913). Reforence has already been made to its habit of destroying the larvate of $1 \%$. domestice. This author states that the larvate have been fomnd not only in the excrement of man, cattle and horses, but also in raw and conked meat, on carcises of different vertebrates such ats mammals, birds and amphibians, on invertebrates such as insects, their larvae and pupae, in rotten bulbs and vegetables, in fungi and in old cheese, ete. Portchinsky in his detailed aceomt of the life-history and habits of $M$. stubulans states that 160 eggs are deposited; they are spreact singly or in lines over the larval fool. He confirms Bonchés statement that the fly is able to priss through its developmental stages in about a month, and thus several generations a year may be produced.

The larva may reach a length of $11 \mathrm{~mm}$. It is creany white in colour. There are two closely approximate mandibles. The anterior spiracular processes are usually five-lobed (occasionally six) and are somewhat like hands from which the fingers have been amputated at the first joint. The posterior spiracles are separated by a space less than the diameter of each; they are rounded, and each encloses three triangular-shaperl areas containing each a slit-like aperture. I have not been able as yet to sturly the complete life-history; Taschenberg $(t . c)$ states that it occupies five or six weeks, but my observations would indicate that this period ean be shortened.

The habits of this species which lead it to frequent excrement and food render it a potential disease-carrier, as Portchinsky also affirms. Banks (1912) records the passing by a child suffering from diarrhoea of a considerable number of the larvat of this species and refers to Laboulbene's record of the larvae of $M$. stubulans being vomited by a person suffering from bronchitis. Carter and Blacklock (1913) record the occurrence of the larvae in a case of external myiasis in a monkey, together with the larvae of If. I1.-F. 
Fanniu coniculuris. The relation of this species to intestimal myiasis is referred to later.

It is interesting to note in conclusion that Haner (1910) states that a remarkable point in regard to Muscina was the frequency with which it was infested with parasites. These were apparently Gamasid mites. In ararly flme, ont of 300 flies examined, 40 specimens were infested. So elosely together were the parasites aggregated in sone instances that no part of the fly's abdomen was visible, the mites forming a kind of chain mail. Berlese (1912) records the occurrence of the common mite A.muscorum (sec p. 1.58) on this species of Hy, and it is not unlikely that the aforementioned mites may have been the same species. 


\title{
CHAPTER XIX
}

\author{
ALLIEL ULS(II) FLIES ANI) MLE'ELLANEOL' FLIES \\ FOUND IN HOUSES
}

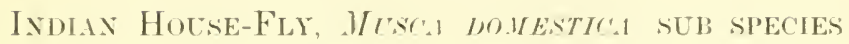
DETERMIIATA WALKER.

Thes Indian variety of the house-fly was described by Walker (18.56) from the East Indies. His description is as follows: "Black with a hoary covering; heal with a white covering; frontalia broad, black, narower towards the feclers; eyes bare; palpi and feelers black: chest with four black stripes; abdomen cinereous, with a large tawny spot on each side at the base: legs blark: wings slightly grey, with a tawny tinge at the base; praebrachial vein forming a very obtuse angle at its Hexure, very slightly bent inward from thence to the tip: lower cross vein almost straight: alulac whitish, with pale yellow borler; halteres tawny."

In appearance and size it is rery similar to $1 \%$. domestice. Its breeding habits are also similar. Aldridge (1904) states that at certain seasons of the year it is present in enormous numbers. The methort of disposal of the night soil is to bury it in trenches about one foot or less in depth. From one-sixth of a cubic foot of soil taken from a trench at Meerut and placed in a cage, 404.2 Hies were hatched. Lieutenant Jwyer collected 500 from one cage covering three square feet of a trench at Mhow. Specimens in the British Yuseum collection were obtained from hospital kitchens, and smith found them in a warl at Benares.

They have also been recorded from the N.W. Provincis, Kangar Valley (4500 feet), Dersa, and I have received specimens from Aden. 


\section{MCACA ENTENTATA BIGOT.}

This species of homse-ty has a distribution somewhat similar to the last species and like it has a marked resemblance to 1\%. domestice as Bigot's (1887) description indicates: "Front très étroit, les yenx, tontefois, séparés. Antennis et palpes noirs: face et jones blanches; thorax noir avec trois larges bandes longitudinales grises; flancs grisâtres, écusson noir avec deux bandes semblatles; cuillerons et balanciers d'un jaunatre très pâle; abdomen fauve, avec une bande dorsake noire et quelques reflets blancs: pieds noirs; ailes hyalines; cinquième nervure longitudinal (Rondin) condée suivant un angle légèrement arrondi, ('nsuite un peu concave; denxième transversale (l'extrême) presque perpendiculaire, légèrenent bisinueuse, soudée à la cinquieme longitudinale, à égale distance du conde et de la première nervure transversale (l'interne)."

1I. entenutu measures 4 to $5 \mathrm{~mm}$. in length. The British Museum collection contains specimens sent by Major F. Smith from Benares, with these notes: "Bred from hmman ordure; hospital ward fly: at an enteric stool; bred from cow dung fuel cakes." I have received specimens from Suez and Aden, and it is recorded as breeding in human excrement in Khartoum (Balfour, 1908 ) and in stable refuse, as also are $1 \%$. domestica and $M$. corvinu. It will be seen, therefore, that its breeding habits are very similar to those of.$I$. domestica and the sub-species determinate. It is interesting to note the choice of cow dung as a breeding place, especially in conjunction with the exonomic status of the cow in India.

\section{MEATA IETESTLSTLA WALK.}

This is a common species in Australia and can be readily distingusher from $M$. domestice by the silvery white-thoracic stripes. Cleland (1912), who reprints Walker's description of the species, writs of it as follows: "This fly is essentially an out-ofdoor species. Very rarely indeed is it fomnd within the hoise. and only occasionally in ont-houses with open doors and windows. When found in these situations it is usually attracted by some 
sourer of fond, such as the carcass of an animal, even though freshly killerl. They have been found in abundince feeding on the pus of hlood from the sores on the heral of a sheep. As soon as. one rentures outside, if the wather is wam, this specios attaches itself to one's person. In some comntry situations that part of one's elothing sheltered from the wind may be covered with a dense mass of these insects. They are especially annoying by hovering around and finding their way into one's eyes, nose and mouth."

It is very common in the neighbourhood of Sydnoy, N.S.II., and in all the comntry districts in New South Wales. It is also common in Itelbourne, around Adelaide, and oceurs in Perth, West Australia.

The abundance of this fly and its habit of hovering round and alighting on the face of hunan beings makes it probable, as Cleland suggests, that if such eye diseases as epidemic conjunctivitis and trachoma are transmitted by flies, this species would be incriminated. It will readily eat dried blood. Cleland states that smears of anthrax blood were made on glass slides, and after several days were confined with one of these flies in a test tube. Some of the blood was eaten and anthrax bacilli were cultivated from the resulting faeces, and the fly itself, on being emulsified in saline solution and injected into a guinea pig, gave the animal anthrax.

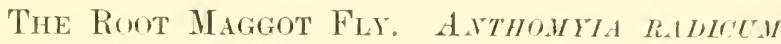 Meigen (fig. 92).}

This member of the Anthomyidae has been found in houses, especially those in or near the country. It is not, however, a house-fly in the same sense as its congeners, $F$. cunculuris and $F$. scaluris, and while its habits lead it in search of excrement it is not likely to be a serions factor as a vector of pathogenic organisms. It may occasionally be responsible for intestinal myiasis and a case recorded by Austen (1912) is referred to later.

In size and general appearance this species resembles Funniu. The female, which is shown in fig. 92, is olive grey in colour and 
has the upper frontal region of the head, that is, between the eyes and superior to the bases of the antemnae an orange rufous colour. The male is darker in colour, the dorsal side of the thorax being blackish with three black longitudinal stripes; the frontal region is very narrow; the abdomen is grey with a dark median stripe. The average length of the hody is .5 $\mathrm{mm}$.

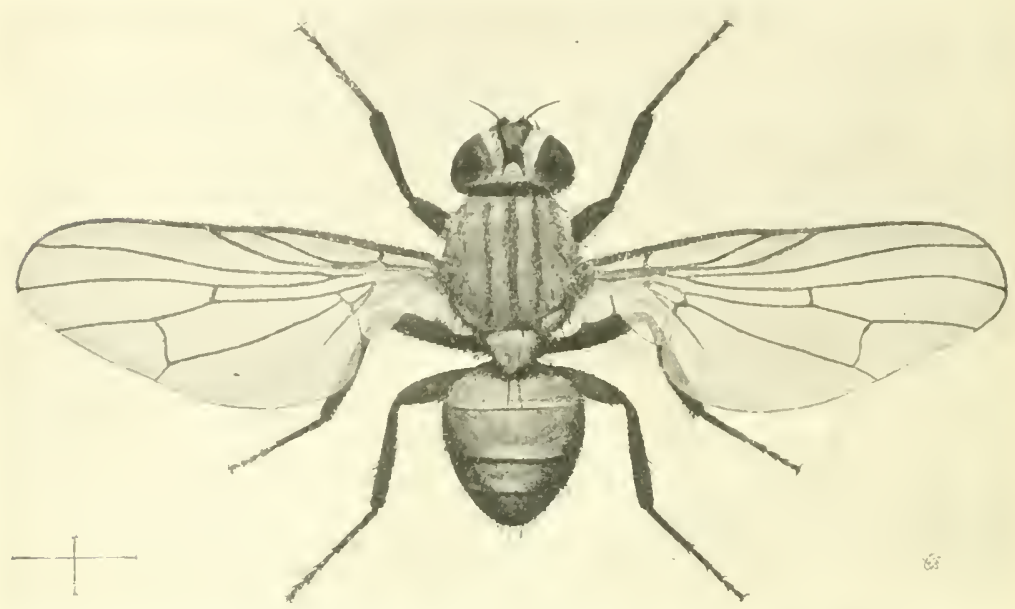

FIt, 92. The Root Maggot Fly Anthomyia rudicum Meig. Female. $\times 9$.

The flies are common in the summer and may be found in the neighbourhood of manure. In a study which I made (1907) of the life-history of this species it was found that the eggs were rery frequently deposited on horse manure which served as a common breeding place for this fly. The insect's popular name has been derived from the fact that the larrae also commonly feed upon the roots of certain cultivated cruciferons plants such as cabbages, radishes, etc.

The eggs hatch out from eighteen to thirty-six hours after deposition. The first larval stadium lasts twenty-four hours, the secent forty-eight hours, and five days later the larra changes into a pupa, the whole larval life occupying about eight days. The pupal stage lasts ten days, so that in warm weather the development may be completed in nineteen to twenty ditys. The 
full-grown larvae (fig. 93) measures $8 \mathrm{~mm}$. in length, and may be distinguished by the tubercles surrounding the caudal extremity.
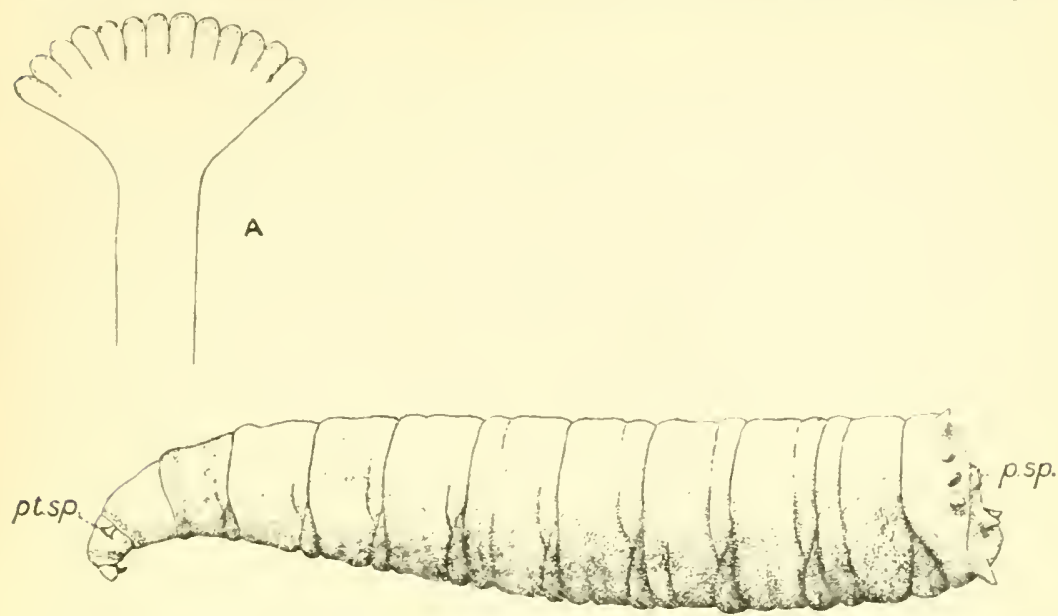

Fir. 93. Hature larva of Anthomyiu radicum Meig. $\times 12$.

p.sp. Posterior spiracle. pt.sp. Anterior spiracular process, A same enlarged.

In this species there are six pairs of spinons tubercles sumounding the posterior end, and a seventh pair is situated on the ventral surface posterior to the anus. The tubercles of the sixth pair,

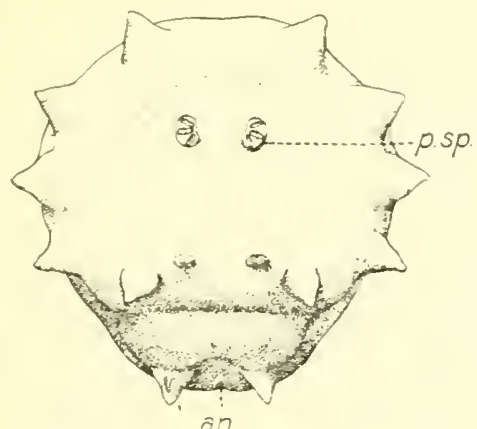

FIG. 94.

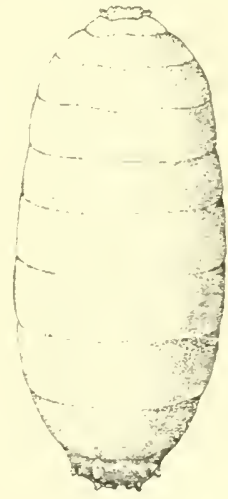

FIG. 95 .

FIr. 94. Posterior end of mature larva of Anthomyia radicum Meig. an. Anus.

FIg. 95. Pupa of A. rudicum. $\times 11$.

counting from the dorsal side, are sualler than the rest, and are bifid. The arrangement of the tubercles can be seen in fig. 94. 
The anterior spiracular processes (fig. 93 $A$ ) are yellow in colour and have thirteen lobes.

\section{The Уoth Flies. Psienum spe.}

There may be found frequently on window panes suall, grey, moth-like flies known as "moth flies" or "owl midges." The wings of these minute insects are large and broad in proportion to the size of the borly and are densely covered with hairs; when the insect is at rest the wings slope in a roof-like manner. The larvae of some species breerl in excrement; Newstead (1907) has found the larva in human excrement; others occur in decaying vegetalle substances. I have bred them from rotting potatoes, while certain species breed in water, especially when it is polluted with sewage. Such aquatic species have the spiracular apparatus modified to suit their changed life. Welch (1912) has recently described the life-history of a new species, Psychodu albimuculatu, which was found breeding in the sewage and water of the experimental tanks of the Chicago sewage works. Although a form, Plilebotomus, which occurs in southern Europe, northern Africa and north India, has blood-sucking habits, most of the species are of little economic importance in their relation to man except in their role as scavengers.

Anong other species of thies which occur in or visit honses may be mentioned the Cheese Maggot Fly, Piophila cusei L., whose larva the well-known "cheese skipper" lives in cheese, ham and other animal substances, usually of a decomposing character. The life-history of this species may be passed in so short a time as three weeks, or it may be more prolonged. Occisionally the larvae may be more responsible for cases of intestinal myiasis. The Hesh-tlies, of which group sarcophage comaria is a common species, occasionally occur in housus. They breed in excreta and decomposing animal matter, especially deat insects. The Yellow Dung Fly, Scotophaga stercoraria L., a rather large yellow Hy which is commonly found on and breeding in cow dung and other excreta, is ionnd in conntry honses on rare occasions. Reference has alveady been made (1. 171) to the useful charactel. 
of this speeies as an enenty of $M$. domestica. Sonctimes small shining black Hies belonging to the genus Scenopinus are found in the winlows of houses. They measure about one puarter of an inch in length and have been called "window Hies" by Constock. The larvar of these flies appear to be carnivoroms in their habits.

Many other thies accidentally stray into houses, but so far as we have been able to ascertain by their feeding and breeding habits, the species which have been considered are the only flies which are of special economic interest. No general statement, however, can be made, for in spite of the advance in our knowledge as to the economic relationships of the Diptera which has taken place during the past few years, the information we now have available only serves to indicate how little we really know coneerning this important order of insects. 


\section{PART T}

\section{THE RELATION OF HOUSE-FLIES TO DISEASE}

\section{CHAPTER XX}

THE DISEMINATHON OF PATHOGENIC ORGANISHS BY FLIES

Althotgh $M$. domestica is unable to act as a carrier of pathogenic micro-organisms in a manner similar to that of the mosquito, an far as we know at present, nevertheless its habits render it a very potent factor in the dissemination of disease by the mechanical transference of the disease germs. These habits are the constant frequenting and liking for substances used by man for food on the one hand and excremental products, purulent discharges, and moist surfaces on the other. Should these last contain pathogenic bacilli, the probuscis, body and legs of the fly are so densely setaceous (see fig. 96) that a great opportunity occurs, with a

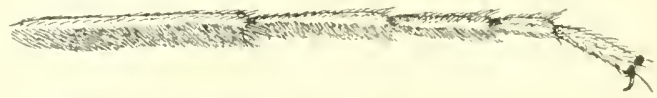

Fig. 96. Tarsal joints of one of posterior pair of legs of Muscr domestica. Lateral aspect to show densely setaceous character.

maximmm amome of probability, for the transference of the organisms from the infected material to either articles of foer or such moist places as the lips, eyes, otc. As I have already pointed out (1907), M. domestica is mable to pierce the skin, as certain persons have suggesterl. The structure of the probuscis will not permit the slightest piercing or pricking action, which fact eliminates such an inoculative methorl of infection. It is as a mechanical carrier, brietly, that 1 . domesticu, and such allies as F. coniculuris, 
etce, though to a less degree, may be responsible for the spreat of infections discase of a bacillary natue, and an account will now be given of the role which this insect plays in the dissemination of certain discases ${ }^{1}$.

While thies have been shown, as the evidence artianced later will indicate, to carry pathogenic and non-pathogenic organisms, apecially the non-spore-bearing micro-organisms, on the extrion of their bodies, recent investigations, notably the excellent sturlies of Graham-Smith (1909-13), Torrey (1912) and of (ox, Jew is and Glym (1912), would appear to indicate forcibly that the carriage of micro-organisms in the digestive tract and infection therefrom is even more important than mechanical transterence on the appendages and exterior of the body. 'The longer duration of the life of the nicro-organism carried in the digcstive tract of a Hy increases the possibility of infection either by "vomit" spots resulting from regurgitation or by fareal spots. This inportant aspect of the problem will be discussed shortly.

It should be pointed out that whereas in some of the diseases the epidemiological "vidence adduced in support of transference of disease germs by thes is confirmed bacteriologically, in other's only the former evidence exists. Should neither form of evidence be available in support of the idea that $M$. domestica plass a part in the dissemination of the infection of a particular disease, it is essential, nevertheless, that if such a methol of transforence is conceivable the possibility of this insect being able to carry the pathogenic organism shonld be realised. This possibility is governed by such factors as the presence of $M$. domestica: its access to the infected or infective material, this being attractive to the insect either because it is moist or because it will serve as foor for itself or its progeny; and a certain power of resistance for a short time against desiccation on the part of the pathogenic organisms, athough, as in the case of the trphoid bacillus, the absence of this factor is not fatal to the idea, as it may be wercome by the fact that the $\mathrm{Hy}$ is able to carry the organisms in its digestive tract or to take on its appendages an amount sufficient to resist

1 Though it should be unnecessary, I wish to explain, as I have been occasionally misunderstood by medical men and others, that.$M$. domestica is not regarded as being the cause of any disease, but as a carrier of the infection. 
desication for a short time. The last factor is the presence of suitable culture media, such as certain fords, or moist surfaces as the mouth, eves, wr wommls, for the reception of the organisms which have been carried in the digestive tract or on the body or appendages of the fly. If these conditions are satisfied the possibility of $M$. domestica or its allies playing a part in the transference of the infection should be carefully considered, and this suggestive or circumstantial virlence will be discussed in certain of the diseases which follow, in ardition to the epidenomberal and bacteriological evidence.

\section{HistORICAL.}

There is no doubt that if a careful search were made in old writings many references would be found attributing rnhealthy conditions to the presence of flies. The idea is a rery old one, the scientific examination and experimental proof, however, is of comparatively recent date.

Mercurialis in 1577 (quoted by Nuttall), beliered that flies carried the virus of plague from persons suffering from the disease to the food of healthy people. Riley (1910) refers to an early and remarkable statement of Kircher who, in his Scrutinium Physicu-medicum, published in Rome in 1658, said: "There can be no doubt that Hies ferel on the internal secretions of the diseaserl and dying, then Hying away, they deposit their excretions on the ford in neighbouring dwellings, and persons who eat it are thus infected." Kircher attributes this theory to Mercurialis. Sydenhan (1666) considered that if swams of house-flies were abundant during the summer, the autumn would be unhealthy, although Holscher (184:3) disagreed with this idea. Crawford (1808) believed that insects in a general way, especially house-flies, acter as disseminators of disease. Leidy (1871) declared his belief that house-flies were responsible for the spread of hospital gangrene and womd infection drung the American Civil War and reaffimed his convictions in later writings. In 1871 Lord Arobury callert attention to the habits of Hies which alight on decomposing substances and corry impurities especially the secretions of unhealthy wounch. Rather than regard them as dipterons angels 
dancing attendance in Hygeial, he said we shonlel lowk upon them as wingeed sponges sprearling hither and thithere to carly ont the forl behests of Contagion. Many ohthers have called attention to the general fiacts and also their commection with spreific discases; the latter anthorities will be mentioner in consistering the varions diseases. Of the former the following may be mentioned: Hewson (1871), Cobbuld (1879), Megrmm (1875), Laboulbene (1875), White (1880), Slater (1 s81), Grasisi (1883), Taylor (1883), Moore (189:3), Coplin (1899), Parker (1902), Martini (1904), Bergey (1907), Scott (1909), Skimner (1909) and others (see Bibliography).

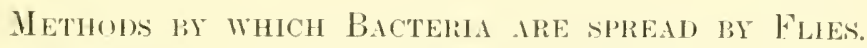

In discussing the relation of house-Hies to disease the viarions methorls by which they are able to distribute the pathogenic and other bacteria must be borne in mind. It has generally been understood that the mechanical transference of bacteria and other micro-organisus on the exterior of the $\mathrm{H}_{\mathrm{y}}$, that is on its borly and appendages, was sufticient to aceome for the distribution of infection. In the experimental evidence which is quoted in the snceceding sections this assumption has generally been made by the investigators. Now while this is true in many instances, there is very strong evidence derived fiom careful experiments that the infection from the exterion of the $\mathrm{Hy}$ is far from being the sole method of bacterial distribution.

Flies which frequent infections matter not only inevitably contaminate the exterior of their body and their appendages, but by feeding upon such matter, which is one of the two reasons for their visiting it, they take the bacteria and other organisms which it contains into their alinentary tracts. In consequence the crop, the stomach and the intestines become the temporary resting places of the bacteria. In the gat of the fly the micro-organisms, especially those of a non-spore-producing kind, will naturally remain in a viable condition for a considerably greater length of time thim on the exposerl external surfice of the insect, and the period during which infection nay be distributed will be lengthened. In treating of the various pathogenic organisms I shall have occasion to quote many instances of the last fact. 
From the gut of the $\mathrm{H}_{\mathrm{y}}$ the infection may be distributed in two ways, either from the month or from the anus. In describing the method of feeding, the habit which flies have of rogrogitating the form and depositing the liquid in the form of "romit spots" was mentioned. Such romit spots may distrihnte micro-nganisms taken up with the food. Also, during the act of feerling, microorganisms previously alsorber when ferding on infected matter may be deposited by the probuscis. Infection fiom the anm may take place by means of infecteel finceal mattrel, so promiscuously depositul as "fly specks."

A most thorough and valuable series of experiments with a view to ascertaining the possibilities of the aforementioned methods of distributing infection has been conducter br GrahamSuith (1910-13) in connection with the Local Guvermment Bond's incuiry. The importance of this aspect of the problem warrants my quoting the results of his experiments somewhat fully.

The groater possibility of non-spore-bearing bacteria smeviving in the gut of the Hy than on the exterior and also probable infection by the probuscis were shown in his experiments with Bacillus enteritidis (Gaertner). It was shown that $B$. enteritidis may be present in the contents of the crops and intestines of Hies for at least seren days after infection. Flies can infect plates over which they walk for some days (seren days in the experiment) in spite of the fact that the organisms can be seldom isolated from their legs (once in 32 cultures). When walking over the cultme plates flies constantly place their proboscides on the medium and in most cases leave imprints on its surface. The colonies of bacteria develop romel these marks. As Graham-Smith points out, the infection of the plate is probably due to inoculation by the proboscides of the Hies.

'The sane investigator in another series of experinents utilised Bacillus prodigiosus, which was chosen on account of its being easily contivated and identified on plate cultures. Furthere, it sermed likaly that its results would give some information as wo the behavion of other and-spore-bearing organions. Experiments (n) the duration of life of $B$. modigiosus on the exterior and in the alimentary tratet of Hies showed that this organism may remain 
alive on the leges and wings for at least 18 hours after fording. In exceptional cases it may remain alive longer. In the contents of the erop and intestine and on the proboscis it is present for four al five days, after which time its numbers gladually diminish and after 17 days the cultures yieded negative results.

A carefinl series of experiments with a viow to deternining whether B. prodigiosus multiplied in the crop appeared to indicats. that no multiplication takes place. In this connection it mal be remarked that Nicoll (1911), to whose experiments reference will be made later, finds that certain of the non-lactose fermenting bacteria appear to be capable of multiplying in the intestine of the Hy.

The extent to which the persistence of $B$. prodigiosus, and no donbt other bacteria of like character, in the faecal deposits, that is, the infectivity of the Hies in this respect, is affected by the character of the fiod, is shown ly a series of experiments in which the fineces from infected Hies which harl been fed on milk, syrup, and sputum were collected at varions periods and cultures made. b. prodigiosus was not recovered after 48 homrs from the faeces of Hies ferl on sputmm. The faeces of flies fed on milk contained the bacteria, that is, were infective, fir seren days and those of flies ferl on syrup for fimr days after feeding.

That infecter flies will infect both liquid and solid food upon which they feed was shown by feeding thes artificially infected with $B$. prodigiosus and also B. pyocyaneus on milk and with the former organism on sugar. It was shown that flies infected with these non-spore-producing organisms were able, by feerling upon it, to contaminate milk for ten or eleven days (in the case of b. prodigiosus). That the contamination wonld appear to have been solely from the alimentary tract or proboscis was shown by the fact that the organism (B. prodigiosus) cond not be cultivated from the limbs of the infected flies eleven lays after infection, although the limbs were hearily contaminated on the second day. After feeding thies on s.rup infected with $B$. prodigiosus it wats shown that they could infect strgar, loy being allowerl to feed upom it subsequently, for at laast two days.

Flies, when unusually hungry, will suck at the deposits of other Hies which they may fincl, in the same way that they will 
suck at dried milk spots, and it was shown that clean, mninfected flies will infect themselves from the leposits, both faecal and vomit, of infected flies. The clean flies will sometimes infect themselves from the romit or faeces deposited by infected Hies several days after infection. In no case were the limbs of the flies infected.

The $\mathrm{fly}$ in the milk is unfortunately an occurrence altogether too common. The infection of milk by the immersion of infected flies was shown by Graham-Smith in his experiments, in which B. prodigiosus, B. pyocyanens and a pink Cocons were used, to be possible for as long a period as 74 hours after the flies had fed upon the infected matter. The micro-organisms were uswally to be found in the crops or intestinal contents of the flies during that period.

Experiments along similar lines were carried out with blowHies (Calliphora erythroceplala) which were able to produce gross infection with non-spore-bearing bacteria (b. prodigiosus and b. pyocyaneus) for six to nine days.

The foregoing experiments clearly indicate the manner in which and extent to which infected Hies may infect milk and sugar, and no doubt other foods containing these ingredients, by feeding upon them. They also demonstrate the more serious nature of such infection compared with infection by means of the limbs or body owing to the infective organisms persisting for a much greater length of time in the alimentary tract of the fly.

\section{INFECTION FROM FLIES BRED IN INFECTED MATERIAL.}

In addition to the direct mode of transference of the typhoid bacillus, by mechanical means or by feeding on infected material, some experiments of Faichnie (1909) indicated what may be a still more important means of dissemination. He believed that one of the most important sources of Hy infection was from flies bred in enteric excreta; such insects thereby becane carriers of bacilli for the remainder of their lives, spreading the infection chiefly by means of their excreta. They were, in fact, typhoid "carriers."

On Angust 12th, 1909, three onnces of faeces infected with B. typhosus were placed in a box of earth and covered with a wire 
calge into which abont 30 tlies were liberated. These flies died in a day or two, but on August 26 th, fourtern days liter, a single fly hatched and twelve tlies energed on the day following. The box of earth was now replaced by a sterilised carthenware plate, and the wire calge wats changed for a bell-shapred mosquito net. The Hies were fed upon sugar and wate'. (In August 26th one fly, a day old, was ehloroformed and transfixed with a red-hot meedle: its body was Hamed (i.e. singed) and it was put into a bottle of sterile salt solution. After shaking up, I e.ce of this solution was put inte McConkey broth which remained unchanged for ts hours. The Hy was then crushed with a sterile glass rod and a drop plated: this gave B. typhosus. On August 27 th four other Hies were sinilarly treated: the control experiment in HcConkey was negation but B. typhlosus was obtained from the crushed flies.

Similar results were obtained on September :3rd from two sixday ud thies and on September bith from two nine-day old Hies treater in the sane manner. On September loth two Hies, thirteen days old, were pliced in a sterile bottle for 24 hour's and then r'moved. The bottle was washed ont with salt solution, and from this B. typhosus was recorered. The two thies were then crusherl in salt solution, not having been flamed, and B. typhosiss was obtained. On September 1:3th al sixteen-day old fly was placed in a sterile bottle for half an hour and then removed: two drops of excrement were visible and from sterile salt solution which was added B. typhosus' was obtained. 'This fly was flamed and crushed and the bacillus was recovered. B. typhosus was not recovered firm another sixteen-day old fly similarly treated.

A second series of experiments was carried ont with the fateces of a man suffering from paratyphoid fever (B. paratyphosus A.), the diagnosis having been made by a blood culture.

On August 22nd two ounces of liquid faeces infected with b. paratyphosus A. were put into a box of earth and about thirty Hies were allowed to feed on it, etc. In a day or two they died owing to the absence of water. On September 1 st one Hy hatched ont; on September 3rd, 12 Hies were scen, and on that date the earth was replaced by a sterile plate as in the previous experiments. (On September lst one fly, one day old, was examined as before: the IIcConkey broth control was negative and after being flamed

H. H. F. 
and crushed b. peratyphosus $\Lambda$. was obtained. Similar results were obtained from four Hies examined on September 3rd. On September 10th, three Hies each seven days old were placed in a sterile bottle, and from their excrement $B$. puratyphosns A. was recorered: the Hies were then examined, the McConkey broth test was negative, and the bacillus was recovered from the crushed flies. On September 10th, a fly ten days old was examined but the bacillus was not recovered: it was recovered, however, from two other Hies also ten days old.

From these experiments, which Faichnie appears to have carefully carried ont, it will be seen that ont of thirteen flies bred from a typhoid stool six at least contained B. typhosus in their intestines, and the bacillus was recovered from the excrement and intestine of a Hy sixteen days old. Similarly, from a paratyphoid stool at least four thies out of eleven contained B. puratyphosus A. in their intestines and in each series of experiments one fly only was fomcl not to contain the bacillus.

He also found B. typlosus in Hies from Lahore, once: from Kamptee, twice; from Nasirabar, once in Hies from the bungalow of an officer who had enteric ferer, and once from flies in the officer's mess there: from Nowgong, twice, once in Hies from the Royal Artillery Coffee-shop, and again in flies from the trenching ground; making a total of nine times in three months. Except in the case of the flies from Nasirabad, two Hies were always Hamed before examination, and a control of the washed flies was. taken before crushing, so that there is no floubt that the bacillus was actually in the interior of the Hy most probably in the intestine.

Summarising the conclusions reached as the result of his firt series of experiments (1909) carried out at Kamptee, he says: "Experience seems to show that infection conveyed by tlies' legs, natural though it may appear to all from experiments carried out to prove its possibility, is not a conmon nor wen a consilerable canse of enteric fever. On the other hand infection by the excrement of flies bred in an infected material explains many conclusions previously difticult to aceept. In a word, it is the breeding ground that constitutes the danger, not the gromd where the thies breed." 
In al series of experinents with Bacillus pyocyanens Bacot (1911) appears to prove conchisively that this bacillus if ingested during the larval life of $M$. domesticu is able to retain its existence during the complex changes accompanying metamorphosis and to contina its existence in the gut of the adult fly after emergence from the puparimu. He points out that the flies in Faichnie's experiments may have re-infected themselves by feeding on the contaminated material. To avoid the possibility of this in his experiments the pupae were sterilised and placed in clean sand in clean tubes. Commenting on Bacot's experiments, Ledinghan states in a footnote that he has successfully isolated B. typhosus from purae of M. domestica, the larvate having fed on the organism. All chances of external infection from the exterior of the puparium were removed by the eareful method he devised of examining the bacterial content of the prupal interior. The puparium was held lightly between the left thumb and forefinger so that its blunt extremity was free. The extremity was seared by means of a small searing iron, and at the same time Hattened. It was then piered by a fine capillary pipette controlled by a rubber teat. The pupal contents are stirred up by the extremity of the pipette and finally drawn up into the tube whenee they are squirted on to culture plates.

In a later paper Ledinghan (1911) has carried his investigations still further, and shows that although B. typhosus was supplied in considerable quantities to the larvae of $M$. domestica, all attempts to demonstrate the bacillus in the pupae or resulting adult Hies were unsuccessful until recourse was har to the disinfection of the ora. After this preliminary disinfection both larvae and pupae gave pure growths of B. typhosus. 'The author's chief conchusion appears to be that the typhoid bacillus can lead only a rury precarious existence in the interior of the larvae or pupae which possess apparently a well-defined bacterial flora of their own, as Nicoll (1911) has recently shown. In the experiments it was not really possible to determine whether the B.typhosus, though recoverable from the pupae, was in fact actively multiplying in the pupal interior or gradually dying out. There was some indication that the latter was the case, as the typhoil colonies recovered from the pupa in the one suecessful instance were extremely fow 
in number, while the larrate which had been feeding on B. typhlosus contained enormons numbers of the bacilli an both conltural and microseopical study demonstrated.

Graham-Smith (1911) carried ont experiments on flies bred from artificially infected larvac. He nsed the blow-Hy Culliphora eiythreceplala and fed the larvac on meat infected with the anthrax bacillus. 'These experiments gave results of a positive character' and are described in a later chapter on anthrax.

In a further report (imanm-Suith (1912) finds that of the non-spure-producing organisms only those which are adapted to the conditions prevailing in the intestine of the larvae, such as Morgan's bacillus and certain non-lactose fermenting bacilli survive through the metamorphosis and are present in the adult flies. Such organisms as Bucillus typhosin, B. enteritidis and B. prodigiosus rarely survive.

Hore recently 'Tebbutt (1912) has found that such pathorgenic organisms as Bucillus dysenteriue (type " $\mathrm{Y}$ ") cannot be recovered from pupae or flies reared from larvae to which these organisms have been athministered. When larvale which have been reared from disinfected ova have been fed in B. dysenteriue (type "Y") the organism is recovered in a small proportion of cases from the pupare and Hies. Under sinilar conditions B. typhosus was not recovered. Furthor experiments appeared to indicate that the process of metamorphosis is accompanied by a considerable destruction of bacteria present in the larval stage. Tebbutt believes that there is but a remote possibility of flien becoming infected from the presence of pathugenic organisms in the loreeding gromel of the larvae.

Nevertheless, it wonld appear that the experiments which have been described demonstrato the possibility that flies, bred from larvale which have bred in infected matter, nay carry infectiom intermally, and the practical significince of these results surely neerls no explanation. 


\section{CHAPTER XXI}

THE CARRIAGE OF TYPHOID FETER PY FTIES

OF all infections diseases the conditions incidental to this disiase are most tavourable for the transference of infection by $M$. domestica, and it is no clombt on this accomnt that the greatest attention has been paid to the rôle of house-flies in the dissemination of this disease. The chief farourable condition is that the typhoirl bacillus occurs in the stools of typhoid and incipient typhoir and "carriel" cases. Human exerement attracts flies not only on account of its moisture but as suitable food for the larvale. The infected excrement is often very accessible to flies, aspecially in military camps, as will be shown shortly; the flies also frequent articles of foud and not infrequently the moist lips of man. Such are the conditions most suitable for the transference of the bacilli, and it is on account of the frequent coincidence of these conditions that flies can play, and hare played. such an important rôle in the dissemination of this disease among communities, in spite of the fact that the typhoid bacillus cannot survive desiccation, which I think is an argument against its being carried by dust. The danger incident to the carriage of this non-spore-bearing bacillus in the digestive tract of the fly probably exceeds that resulting from direct carriage on the appendages and body of the insect.

The possibility of Hies becoming infected with Bucillus typhosus is increased with the frequent accessibility of thies in numbers to infected material. This fact is most clearly demonstrated in military and construction camps, and during typhoid epidemics in the slum and insanitary portions of towns and cities. 
A new danger is also adderl by the discovery of typhoid "carriers." Although canses of walking typhoid or anbulatory enteric fever hare been known for a number of years and the occurrence of chronic carriers was recognised in Germany, it is only within the last few years that the attention of medical men generally, in Europe and America, has been drawn to this important fact. The nccurrence of these chronic carriers, who are not ill but continue to give out the typhoid bacillus in their excreta and urine, is discussed at some length by Howard (1911). He quotes from an important article in the Boston Medical and surgical . Fonrmel and gives the following quotations and rases:

"It is asserted by Kutscher that, in south-western Germany, direct contact is a more important factor in the sprearl of typhoid fever than polluted water, and that about four per cent. of typhoid patients become chronic carriers of the specific bacilli which they excrete in both mine and fiteces, sometimes for long periorls. Toerr, for example, cites cases reported by Irober and Hunner, in which the bacilli were isolated from the gall-bladiler seventeen and twenty years after recovery, and Lentz asserts that if after ten weeks convalescence the excretion of the bacilli has not ceased, it will most likely continue permanently and uninterrupterlly, in spite of medication. He cites a number of cases in which, after ten, thirty and even forty year's after recovery, the excretion continuerl. Levy and Kayser report that in the autumn of 190 . a number of cares of typhoid ferer occurred in an insane asylum, in which two rears previomsly an inmate had had the rlisease and had recorered. On the appearance of these later cases this person was examined and was found to be exereting the bacilli in her faeces. Further examinations were made at intervals of several works and the bacilli were fomm ten times. In Octuber 1906, she died of a typhoid bacillery septicemia due to anto-infection from the gall-bladder, and on antopsy the bacilli were isolated from the spleen, liver, bile, wall of the gall-blarder and from the interior of a large gall stone."

Nieter and Liefmann report a similar ease vecurring in an insane asylum containing 250 inmates among which seron chronic carriers were foumd. 
To contimue the accomnt of carrier calses :

"Klinger found, among 1700 persoms, twenty-thres typhoid canluers, ranging in age from cightren months to sixty years, eleven of whom had no typhoid history. Of 842 convalesecuts from the disease, sixty-three, or thirtern and wne-tenth per ant., were found to be vereting the bacilli, and right were still toing si six weeks after recoverv.

"Kayser, tracing ontbraks to their somrees, found a boy of twelve years, a member of a millsman's fimily, to be a chronic carrier and the probable somree of infection in a nmber of cases. Another outbreak in which seventeen persons were seized (two deaths) was traced to a woman who had no typhoid history hut wats exeroting the specific bacilli. She was employed in the diry from which the persons seized had obtained their milk. ()f :260 cases of typhoid fever investigated, 60 were traced to infected milk. Anong the sixty vietins were thisty mairls and kitehen girls, twelve bakel's and forty-four persons engaged more or less in kitchen work. In all, twenty-eight cases were traced direetly to apparently healthy typhoid carriers."

The final case recorded is probably that of the now celebrated "Typhoid Mary." Six years previons to the institution of the enquiry this womam appeared to have had a milel attack of typhoid fever. "since that time there have been moloubterly twentyeight eases of typhoid ferer in the families in which she worked. The number of cases in a family within a few weeks of her adrent varied from ane or two up to six ont of seven nembers. The evidence seemed so strong that she was at once removed to Reception Hospital by force. Examinations of her fieces and urine were made and the typhoirl bacilli fomm in her facees confirmed positively our suspicions (says the witer of the account) with regard to the possibility of her comveying typhoid fever."

The signiticance of the eccurrence of so large a number of chromic carrers as these selected observations indicate is very great, especially when eonsiflered in relation to the question of the possibility of Hies having access to infected matter mnder what one might call normal ennditions. Flies would have as equal aecrss to the infeeted freces of these mmecognisud "carriers" as to the faeces of a healthy person. Further investigations are certain to 
disclose a considerable percentage of "carriers" who are, unknowingly, distributors of the typhoid bacillus.

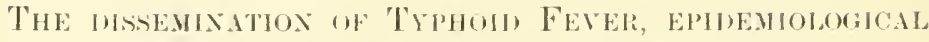
ANI) (IRCUMSTANTIAL, EVIDENCE.

In discussing the powible methork of the dissemination of the typhoid bacillus in the report on the prevalence of typhoid fever in the District of Columblia, Kober (1895) states: "The agency" of flies and other insects in carrying the germs from box-privies and other receptacles from typhoid stools to the food cannot be ignored": and in discussing certain special cases he says: "There is abundant evidence of mlawful surface pollution...and as the germs find a suitable soil in such surroundings it is possible that the flies, which abound wherever surface pollution exists, may carry the germs into the houses and contaminate the ford." Later he states: "A large percentage of the cases occurred in houses supplierl with box-privies which, apart from being an important cause in soil pollution, are believed to be otherwise instrumental in the dissemination of germs chietly through the agency of flies."

There is a very large amount of testimony given as to the rôle playert ly thies in the spread of enteric in military stations and camps, and especially during the two wars - the Spanish-American and the Boer. War. All the conditions most favourable for the dissemination of the bacilli by thies were, and in many military stations are still, present; open latrines or filth-trenches accessibl to flies on the one hand and on the other the men's foorl within a short distance from the latrines. I cannot do better than quote the evidence in the words of the witnesses and allow it to speak for itself:

Vaughan, a momber of the United States Army Typhoil Commision of 1898 , states:

"My reasons for believing that flies were active in the dissemination of typhoid fever may be stated as follows:

"(a) Flies swamed over infected faecal matter in the pits and then visited and ford upon thr food prepared for the soldiers in the mess-tents. In some instances where lime had 
recently been sprinkled over the contents of the pits, flies with their feret whitenerl with lime wer son walking orel the foorl.

"(b) Officers whose mess-tents were protected by screrns suffered proportionately less from typhoid forer than did thoso whose tents were not so protreted.

"(c) Typhoil fever gatalually rlisappearerl in the fall of 1898 with the approach of cold weather and the comseguent disabling of the fly.

"It is possible fin the Hy to carry the typhoid bacillus in two ways. In the first place faecal mattre containing the typhoid germs may arthere to the fly and be mechanically transporterl. In the sceond place, it is possible that the typhoid bacillus may be carried in the digestive organs of the fly and mar bo deposited with its axcrement."

One of his conchusions was that infected water was not an important factor in the dissemination of typhoid in the national encampments of 1598 , since only about one-fifth of the soldiers in thr national ancampments during the summer of that year developed typhoil fever, whereas abont 80 per cent. of the total deaths were due to this disease. In the latter connection Sternberg (1899) refers to a report of Reed upon an epidemic in the Cuban War, in which it was stated that the epidemic was clearly not due to water infection but was transferred from the infected stools of the patients to the food hy means of Hies, the conditions being especially farourable for this means of dissemination.

Stemberg, as Surgern-General of the [T.S. Amy, issued the following instructions": "Sinks should be dug before a camp is occupied or as soon as practicable. The surface of the faecal matter should be corered with fresh earth or quicklime or ashes three times a day.'

I think that the instructions of that ancient leader of men, Noses, who probably had experienced the effects of flics, were even better than these. He said (Dent., ch. xxiii, r'. 12, 13): "Thou shalt have a place also without the camp whither thou shalt go forth abroad: and thou shalt have a paddle (or shovel) among thy weapons; and it shall be, when thou sittest down abruad, thou

1 Cirenlar No. 1 of the Sinryeon-Generul of the I.S. Army, April, 1898. 
shalt dig therewith, amel shalt turn bark and cover that which cometh from thee."

Sternberg is of the eprinion that typhoid fever and camp diarthesa are frequently communicated to soldiers thromgh the agencer of thies, "which swarm about fiecal matter" and filth of all kinds depesited upon the ground or in shallow pits, and directly convey infections material attached to their feet or contained in their excreta to the food which is exposed while being prepared in the common kitehen, or while being served in the mes-tent."

Veeder (1895), in referring to the conditions existing in the camps of the Spanish-American War, says that in the latrine trenches he saw "faecal matter" fresh from the borwel and in its most dangerous condition, covered with myriarls of flies, and at in short clistance there was a tent, equally open to the air, for dining and cooking. To way that the flies were busy travelling back and from between these two places is putting it mildly:" Further, he says, "There is no donht that air and smlight kill infection, if given time, but their vory access gives opportunity for the Hies to to serions mischief as conveyers of fresh infection wherever they put their feet. In a very few minutes they may load themselves with the dejections from a typhoid or dysenteric patient, not as yot sick enough to be in huspital or under observation, and cary the prison so taken np into the rery midst of the forl and water rearly for use at the next meal. There is no long and romd-abont process insolved. It is very plain and direct. Yet when the thousands of lives are at stake in this way the danger passes nnnoticed, and the conseruences are disastroms and seen mrsterions until attention is directed to the point: then it becomes simple enough in all conscience."

The following statements which I have noted in reading the voluminous report of the Commission which was chargerl with the investigation of the origin and spread of typhoid fever in the Enited States military camps luring the Spanish War in 1898 (see Reed, Vaughan and Shakespeare, 1904), give the opinions of observers in different amps:- p. 62 , the epidemic was dne to Hies, not to the water: the careless disposition of filth: p. it, flies were swarming orer sinks, kitchens and mess tables: p. s8, the "pidenic was dne to the infeetion of foul by Hies: p. 104, 
thoroughly convineed that the ehief agent in the distribution of typhoid ferer was the fly: p. 107, the callse was not the watersupply but fly contamination: Hices "had inflicted greater luss upon the Amorican suldiers than all the arms of Spain": pr. 206, the cook observed Hies with fret coreresl with disinfecting lime, on the fool: p. 27:3, where mosquite netting was used little or no typhoid was contracted; p. 279, flies observed carrying lime frum privy vanlts; repeated mention of sinks and thes in millins, of sinks near to mess tents; p. 53.5, the flies and the heat made a visit to the sinks (latrines) like a visit to purgatory: p. 665. Hies swarmed so numerously that the first faecal diopprings were covered before definecation was complete.

The above statements are all the more significant, when it is renembered that at that time (1898) the idoa of the homse-Hy as a discase carrier had hardly been conceived except in the minds of a limiter number of investigators. The evidence which was afforded, however, was convineing enongh and it was only natmral that the Commision came to the conclusion that: "Hies undombtedly served as carriers of infection." From this onward, the belief in the disease-carrying powers of the house-fly increased in strength and becane firmly established in people's minds.

Chmelicek (1899) in recording his experience of the conditions of camp life at Tampa, Florida, during the Spanish-American war, states: "The pits were only abont forty fert from the entrance of the kitchen tent and the number of thien around these holes was comntless." He calls attention to the fact, to which Aldridge $(1907)$ referred later, that the greatest incidence of typhoid was among the mounted troups, and he attributed it to the larger number of flies present. In reference to the conditions in the kitchens he mentions the fact that the flies travelled from tho latrines to the kitchen tent where sugar, which was exposed tirr hom's, was almost black with them and looked nore like a bag or box full of raisins than of sugar.

Dutton (1909) gives an interesting figure to demonstrate the manner in which thies would be carried from sources of typhoid infection (division hospitals and latrines) in the camps of the United States Army at Fernandina and Tampa to different prarts of these camps. He states that Sergeant Brady, who was stricken 
with typhoid fever at Fernandina, mentioned to him that the lime used about the latrines and garbage dumps was carried by Hies to the food which was being used in the camps.

In the Sonth African War, a year or two later, the same conclitions existed, and there was a very heavy loss of life from enteric ferer. Writing on the subject, Dunne (1902) says: "The plagne of Hies which was present during the epidemic of enteric at Bloemfontein in 1900 left a deep impression on my mind, and, as far as 1 can ascertain from published reports, on all who had experience on that occasion. Nothing was more noticeable than the fall in the admissions from enterie fever coincident with the killing off of the Hies on the advent of the cold nights of May and June. In July, when I had occasion to visit Bloemfontein, the hospitals there were half empty, and had practically become convalescent camps."

A similar experience is related by 'Tooth (1901). Referring to the rôle of thies he says: "As may be expecterl, the conditions in these large camps were particularly favourable to the growth and multiplication of Hies, which soon became terrible pests. I was told by a resident in Bloemfontein that these insects wore by no means a serious plague in ordinary times, but that they came with the army. It womld be more correct to say that the normal number of Hies was increased owing to the large quantities of refuse upon which they conld feed and multiply. They were all over our food, and the roofs of our tents were at times black with them. It is not unreasonable to lonk upon thies as a very possible agency in the spreading of the lisease, not only abroad but at home. It is a well-known fact that with the first appearance of the frust enteric fever ahmost rapilly disappears... It seems hardly credible that the almost sudden cessation of an epidemic can be due to the effect of cold mon the enteric bacilli only. But there can be no doubt in the mind of anybody who has been living on the open velit, as we have for three or four months, that Hies are extremely sensitive to the change of temperature, and that the cold nights kill them off rapidly." In the discussion on this paper. Cluurch stated that "many nurses told me that if one went into a tent or ward in which the patients were suffering from a variety of diseases, one conld tell at once which wer the typhoid patients. 
by the way in which the flies clustered abont their months and eves while in bed." It was further stated in the discussion that where the Anericans ased quickline in their latrines the conks in the neighbouring kitchens found that the ford became covereal with quicklime from the Hies which came firom the latrines to the kitchens.

Dr 'Tooth, in a letter to me, says: "I an atraid my witten remarks hardly express strongly enough the inportance that I attach to thes als a medium of sprearling infection. Of couree, I do mot wish to muler-rate the water sicle of the question, but once get, by that means, enteric into a camp the flies, in my opinion, are quite capable of comverting a sporadic incidence into an epirlenic. A pure water supply is an obvions necessity, but the prompt lestruction of refuse of every description is every bit as important."

smith (190:3), in speaking of his experience in South Africa. says: "On visiting a deserted camp during the recent campaign it was common to find half' a dozen or so open litrines containing a foetid mals of excreta and maggots." Similar olservations were marle by Austen (1904), who, describing a latrine that had been left a short time undisturbed, salys: "A buzzing swam of thies would suddenly arise from it with a noise faintly suggestive of the bursting of a percussion shrapnel shell. The latrine was certainly not more than one hundred rards from the nearest tents, if so much, and at meal times men's mess-tins, ctc., were always invaded by flies. A tin of jam incautionsly left open for a few minutes becane a seething mass of Hies (chietly Pycnosoma chloropygu Wied.), completely covering the contents."

Howard (1900), referring to an American camp where no effort was made to cover the faces in the latrines, says: "the camp contained about 1:00 men, and Hies were extremely numerous in and around the sinks. Eggs of Musca domestica were seen in large clusters on the faeces, and in some instances the patches were two inches wide and half an inch in depth, resembling little patches of lime. Some of the sinks were in a very dirty condition and had a very disagreeable odour."

A few examples of the prevalence of conditions favouring the dissemination of enteric by flies in permanent camps may be noted. Crockerill (1905), in describing camp conditions in 
Bermuda, mentions kitchens within one hundred yards of the latrines; the shallow privy, seldon or never cleaned ont, and middens are found which contain masses of filth swaming with Hies. He states that in more recent vears the perion of greatest incidence is in the summer, being chietly due to Hies and contaminated dust. Wanhill (1909) has furnished an interesting report on the typhoid conditions in Bermuda. From 1893 to 1902 Bermurla had the highest enteric fever rate among the troops of any command occupied by British troops. Wanhill was placed in charge in 1904 and in two years the disease was almost eradicated. He considered that Hies were the most important agents in the dissemination of the bacilli.

Quill (1900), reporting on an ontbreak of enteric in the Boer camp in Ceylon, states: "During the whole perior that enteric fever was rife in the Boer camp Hies in that camp amounted to almost a plague, the military caum being almost similary infested, though to a less extent. The outbreak in the Boer camp preceded that among the trons: the two camps were adjacent, and the migration of the Hies from the one to the other easy." Weir, reporting on an outbreak of enteric ferer in the barracks at Thbala, India ${ }^{1}$, says that most of the pans in the latrines were half or quite full, and thes were rery numerous in them and on the seats, which latter were soiled by the excreta conveyed by the flies' legs. 'The men stated that the plague of Hies was so great that in the morning they could hardly go to the latrines. He found that the Hies were carried from the latrines to the barrackrooms on the clothes of the men. This state of aftain's suggests another mode of infection, namely, per rectum. As smith has pointed ont (l.c.) it is not improbable that Hies under these conditions maly be inoculators of drsentery.

Alridge (1907) gives some highly suggestive statisties showing the inthence of the presence of breeding-places of thes. Flies are found in greater numbers in momted regiments than in infantry, and he shows how this atfects the incidence of enteric ferer. In the British army in India, 1902-05, the ratios per 1000 per annum of cases adnitted were: cavalry, 5.74, and infintry t.7. He states that: "A study of the incilence of enteric ferer shows that 1 Army Medical Department lieport, 1902, p. 207. 
stations where there are no filth trenches, or where they are at considerable distance from the barracks, all have an admission-late below the average, and all but one less than half the average."

.ones (1907) gives an interesting account of his experienee of typhoid fever in the army at Nisirabad, lurba. He states: "We have been led in this station to regated tly infection as the principal cause of the menviable prevalence of entric fever" and "Believing as we lo that Hies are the chief carriers of enteric fever in India, any plan which gets rid of them is worthy of consicleration." Howard (1911) calls attention to the significance of the methort adopted by Jones to persuade the high-caste nativen to adopt and carry out his views. Making nse of the word "kakophagy" (excrenent-eating) Jones writes: "1 presune no one wishes to be a kakophagist; yot we are so in spite of oulselves, if thes bred in filth pits alight on our food just before we eat it." 'This kind of alrgument would surely appeal to the most indifterent high-caste native or other jerson who was inclined to regard Hics as "wholesone and alpuetising:" Stratton (1907) discussing the seasonal prevalence of enteric at Meernt, India, states that the fever recurs with the reappearance of the dust and flies after the rainy seasm: luring the monsom there is a great diminution of enteric.

Aimsworth (1905) has studieel the relation between enteric fever and climatic conditions at the military stations at Ponna and Kirlee, India. His conclusion is that it is highly significant and at least suggents that a primu fucie case has been established for further investigation. By means of curves he illustrates the rise and fall of the number of flies, the typhoid evidence and the rainfall. As Nuttall, in refering to this paper, says: "The curves given on pages 497 and 498 are certainly vory striking, the fly curve reaching its acme abont two weeks before the maximum number of cases of typhoid occurred."

All these facts are equally applicable to the conditions in onl own towns and cities. Where the ofd conservancy methods are used, such ats pails and privy middens, the incidence of typhoirl fever is greater than in those places where the system of water disposal has been adopted. I have examined the ammal reporti of the medical ofticers of health of sereral largo towns where such 
conversions are being made, and they show a falling-off of the typhoid fever-rate coincident with this change. In Nottinghanu, for example ${ }^{1}$, in the ten rears 1887-1896, there was one case of typhoid fever for every 120 honses that had pail-closets, one case for every 37 houses with privy middens, and one case for every 5is honses with water-closets. The last were scattered, and not confined to the prosperons districts of the town.

Klein (1908) in discussing an ontbreak of typhoid fever at Wilshaw (Eng.) describes what is a common occurence in very many ontbrealis in towns and cities. He says "After the occurrence of a calse of enteric fever in a house forming one of a row, a number of typhoid cases making their appearance in the neighbouring houses. All known channels of transmission, for example, personal contact, defective drainage, polluted water or milk, conld be exclnded. The only condition common to all the houses of the row was this that they were swarming with Hies." Klein marle a bacteriological examination of some of the "Hies" (it is presuned they were Muscu domestica) after crushing them and found Bucillus coli and B. typhosus.

The insanitary conditions found in many of our towns and rities are admirably suited in every detail for the breeding of Hies, the disease-carriers and for their carriage of the germs. In a previous paper (1908) I have caller attention to these facts. It was pointed ont that: "wherever there are collections of either" excremental products or decaying and waste regetable substances and food stuffs, house-flies are able to breed. Consequently, where such conditions as the following exist we shall almost certainly find house-flies: heaps of stable-manure and other excremental products and house refuse which have stood for more than eight "I nine days, the time occupied by the development of the $\mathrm{H}_{y}$; such systems of excremental disposal as middens, dry ashpits and pails which are not regularly removed within the same time. I find that mblic tips frequently form permanent breeding places for Hins on account of the variety of substances tipped thereon. Honse refuse and excremental substances should not be deposited on public tips in the vicinity of homses but should be removed

1 "Typhoid Fever and the Pail System at Nottingham," Lancet. Nov. 29th, 1902 , p. $14 \times 9$. 
immediately, as their mere presence for at short time attracts the thies and their continued presenee serses to multiply the nuisance." In this comnection I called attention th the following evidence indicating the relation of the presence of flies to insanitary conditions and the prosence of misances: "In his report on the samitary conditions of Wigan ("Reports of Medical Inspectors of the Local Gorernment Boand m the General Simitary Circumstances and Administration of the County Boromgh of Wigan, with especial reference to Intantile Mortality and to Endemic Prevalence of Enteric Fevor and Diarrhoea,' 2.2 plo., 1906) I) Copeman says (p. 18): "At the Miry Lane lepot, as plevinusly mentioned, there is always stored (awaiting removal by firmers) an enormous anount of nightsoil mixed with ashes which in hot wather especially, is not only exceedingly offensive, but is buset by myriads of houseHies. Is the result of personal anguiry at the varions houses in the neighbourhood in which during the year 1905 deaths from diarrhora had occmred, I learnt that considerable nuisance from the foul odour was apt to be experienced diung the prevalence of hot weather, especially with the wind in the south or sonth-west, i.e. blowing from the Depot to the special area; so much on occasion as to render it necessary to shut all the windows, while the inhabitants of certain of the houses nearest the Corporation Depot stated that at certain times of the year their rooms were apt to be invaded by a veritable plague of thies which swormed over everything of an edible nature on the premises. (The italics are mine, C. G. H.) This being so, it would not appear improbable that these flies, some of which have doubtless had an opportmnity of feeding on and beconing contaninated with excremental. material of human origin, may have been the means of carrying infectious material to certain foolstufts, such, more particularly, as milk and sugar and so, indirectly, of bringing about infection of the human subject."

The county of Durham has the highest death-rate from enteric fever of any comnty in England or Wales. In discussing a preliminary report of an investigation into the subject Dr Newsholme, Medical Officer of the Local Government Board, as reported in The Times (weekly edition) of Angust 5th, 1910, states: "We come finally to the conditions with which the excess of enteric fever in the

$$
\text { II. H. F, }
$$


county of Durham can in a large measure be causally associated. These are the extremely filthy domestic arrangements, by which excremental matters are retained in the immediate vicinity of dwellings." The account goes on to state "The general position as regards the relation between conservancy methods and enteric ferer may be stated thus: throughout England and Wales counties persisting in the use of conservancy methols of dealing with excremental matters and not having adopted the water-carriage system have excessive enteric fiver, in all instances in which industrial conditions imply considerable aggregations of population."

One of the most important investigations on the relation of Hies to intestinal rlisease was that of Jackson (1907). He inrestigated the sanitary condition of New York Harbour and found that in many places sewer ontfalls had not been carried below low-water mark, consequently solid matter from the sewers was exposed on the shores, and that during the summer months on and near the majority of the clocks in the city a large amount of human excreta was deposited. This was found to be corered with Hies. The report, considered an a mere catalogue, is a most severe indictment against the insanitary condition of this great water front. By means of spot-maps he shows that the cases of typhoid are thickest near the points found to be most insanitary. He shows, as English investigators have also whown, how the curves of fatal cases correspond with the temperature curves and with the curres of the activity and prevalence of thes which were obtained by actual comnts. He also addnced bacteriological evidence, and it is stated that on Hy was found to be carrying over one hundred thousand faecal bacteria.

An instructive example of the part which flies may play not only in the carriage of typhoid bacilli to persons near the infected matter, but also, through the medium of milk, to a larger number of people, is communicated by Taylor (Colorado State Board of Health, U.S.A.) to the New York Merchants' Aswociation. He says: "In the city of Denser we haul a very sad as well as a plain demonstration of the transmission of typhoid fever by flies and milk. Early in Angust of this rear the wife of a dairyman was taken with trphoid ferer, remaining at home ahont three weeks 
before her removal to the hospital, Angist 2sth. Juring the first two weeks in September we receired reports of mmerons casts of typhoid fever in the northern portion of J)enver, and upon investigation found that all these eases had been securing their milk from this dairy. An inspection of this dairy was then male, and in addition to learning of the illness of the dairyman's wife, we also found the dairyman himself' suffering with a mild case of typhoid fever, but still up and delivering milk. The water supply of this dairy was fairly good. However, we found that the stools of both the wife and husband had been depusited in an open privy vault located thirty-five feet from the milk-house, which was unscreened and open to flies. The gelatine culture exposed for thirty ninutes in the rear of the priry vant and in the nillkhouse among the milk-cans gave nmmerous colonies of typhoid bacilli, as well as colon bacilli and the ordinary germ-life. The somrce of infection in the dairyman's wife's case is mnknown, but I am positive that in all the cases that ocenred on this milk ronte the infection was dne to bacilli carried from this vault by flies and deposited upon the milk-cans, separator and utensils in the milkhouse, thereby contaminating the milk. The dairyman supplied milk to 143 enstomers. Fifty-five cases of typhoid ferer occurred, and six deaths resulted therefiom ${ }^{1}$."

Washburn (1910) has shown how insanitary conditions in localities where little attention is paic to the prevention of health render easy the infection of food by thes and the rlissenination of the typhoid bacillus. In the report of an investigation into the prevalence of typhoid ferer at Charlestown, West Virginia, U.S.A., Ridlon (1911), in discussing the epidemiological factors, states: "The most probable souree of infection in five cases was from Hies. These cases were located within two hundred feet or less of other cases where the disinfection of the stools was inefficient, where there were no screens and where the abundant Hies had free access to both dejecta of patients and the fool." He continues: "That Hies under the proper conditions ean be a prominent factor" in the spread of infection is an undisputed fact, as is also the fact that their prevalence can be greatly diminished by proper care of

' The House-fly at the Bar, Indictment Guilty or not Guilty? The Merchants' Association of New York, April, 1909, p. 48. 
their breeding places, including stable-manure, houschold refuse and garbage."

An outbreak of typhoid fever, which was recently reported upon (October 1912) by Drs Amyot and Mc(lenahan, necurred in the Insane Asylum at Hamilton (Ontario, Canada). Since July 1912 there had been fourteen indoubted cases with two deaths. The investigation showed that the flies had been the responsille agents, carrying the infection from unsereened lavatories to the patients. The manure piles in the stables had been left exposed.

Terry (1913) describes the rerr great reduction in the typhoid death-rate in Jacksonville, U.S.A., which followed the control of the fly-borne typhoid by compulsory rendering of privies Hy-proof.

\section{The dissemination of Trphoid Fever, Bacterio-} LOGICAL EVIDENCE.

The bacteriological evidence, the result of exact experiments, indicates conclusively the ability of flies to carry the typhoid bacillus in a viable condition, not only internally but also externally.

A non-spore-bearing bacillus such as B. typhosus is less adapted to external transference than a spore-bearing bacillus. It is nerertheless interesting to note the length of time which elapses before B. typhosus is moribund. Howard (1911) states that Dr. Mohles informs him that B. typhosus will live in butter under common market conditions for 151 days and still be able to grow when transferred to suitable conditions. In milk kept under market conditions they retain active mobility for twenty days: after this they lessen in numbers and finally disappear in the forty-third day. An important fact is that observed by Delepine, namely, that B. typhosus can remain in a viable condition on the walls of a privy for twelve months. The bearing which this fact has on the possibility of flies becoming infecter subsequent to an epidemic of typhoirl ferer will be readily understood.

In order to form a correct estimate of the extent to which and the mamer in which flies distribute pathogenic and other bacteria, a sturly of the natural bacterial flora of the rigestive tract of the house-fly would appear to be desirable, if not essential. Until 
recently little attention hats been paid to this matter. Nicoll (1911) has begun such a stndy with interesting results. He fincls that the house-fly may carry at least twenty-seven varieties of Bacillus coli, by far the most frequent of which are $B$. coli commue and MacConkey's bacillus No.71. From the eharacter of these colon bacilli it would appear that the house-fly derives it. bacterial flora from excremental matter and other sources. The presence of colon bacilli in the digestive tract of the fly is only to be expected from the filthy feeding-habits of the insect: in fact, the absence of these bacilli would be more than remarkable. Nicoll also finds that certain non-lactose formenting bacilli appear to be capable of multiplying in the intestine of the fly. Of these Morgan's bacillus No. 1 is not an infrequent inhabitant of the fly's intestine and B. paratyphosus B. has been found on two occasions.

Grahan-Smith (1909) has also examined flies captured in various places with a view to ascertaining what percentage were infected with bacilli of the colon group. The results of his examinations of flies from the different sources was as follows: from the neighbourhood of decaying animal matter, Cambridge, 28 flies were examined and 545 per cent. were infected; from a railway-siding, Islington, 48 Hies were examined and 25 per cent. were infected; from a room used by men at a gas-works, 24 thien were examined and 16.6 per cent. were infected; from a house near a glue works, 26 flies were exanined and 15 per cent. were infected: from the kitchen of a London County School, 18 flies were examined and $22 \cdot 2$ per cent. were infected; from a house about fifty yards distant from a jam factory, Bermondsey, 40 flies were examined and 10 per cent. were infected. The Hies which were examined were $M$. domestica, Fanmia canicularis, Culliphoru erythrocephala and C. vomitoria, Stomoxys calcitrens and a few other small flies. Cultures were made of both the intestines and of the surfaces of the flies' bodies. Altogether 3.5 lactosefermenting organisms of the colon group were isolated, 2.? from surface cultures and 13 from the intestines. Although the numbers were comparatively small, the experiments indicated that the Hies were infected with bacilli of the colon group in proportion to the opportunities offered by the locality they were frequenting. The highest degree of infection was found on those 
tlies freynenting decaying animal matter and the next highest on those canght near manure.

Torrey (1912), in the United States, has also made a sturly of the numbers and types of bacteria carried by flies under city conditions. Flies eximined up to the latter part of June were funnd to be free from faecal bacteria and carried a homogeneous thora of coceal forms. During July and August there occurred periods in which the Hies examined carried several millions of bacteria, alternating with periods in which the number of bacteria was reduced to hundreds. The scanty flora, he considered, probably indicated the advent of large numbers of recently-emerged Hies. Faecal bacteria of the colon type were first encountered in abundance during the early part of July. The bacteria in the intestines of the fly were 8.6 times as numerous as those occurring on the external surface of the insects; an important fact to note. On the surface of the flies bacteria of the colon group constituted $13 \cdot 1$ per cent. of the total and within the intestine they constituted 37.5 per cent. of the total. Of the lactose-fermenting bacteria which were isolated and identified 79.5 per cent. belonged to the colon-aerogenes group and 20.5 per cent. belonged to the acidilactici group. Fifteen cultures of Streptococci, isolated and identified, were distributed among the equinus, faeculis and sulivarius groups. He found none of the pyogenes type. The most important isolations were three cultures of Bacillus paratyphosus, Type $\Lambda$. Bacteria of the paracolon type, causing a final intense alkaline reaction in litmus milk and fermenting only certain monosaccharides, were frequently found during August.

Further references to studies of this nature are given in a later section (p. 288). The foregoing experiments, apart from the indications which they give as to the nature of the flora of what one might call a normal $\mathrm{fly}$, demonstrate how necessary it is to exercise great caution in making deductions from the results of isolated examinations and cultures of flies both externally and internally;

Reference has already been made to the finct that Jackson gave bacteriological evidence as to the ability of house-flies to carry B. typhosus. There are, however, a number of workers who have carried out experiments along bacteriological lines and their results will be given. 
Celli (18ss) recovered Bucillus typhi abdominalis from the dejections of thes which had been fed on cultures of the same, and he was able to prove that they passed through the alimentary tract in a virulent state by subsepuent inoculation experiments.

Firth and Horrocks (1902), in their experinents, took a small dish containing a rich emulsion in sugar made from a twenty-fonr-

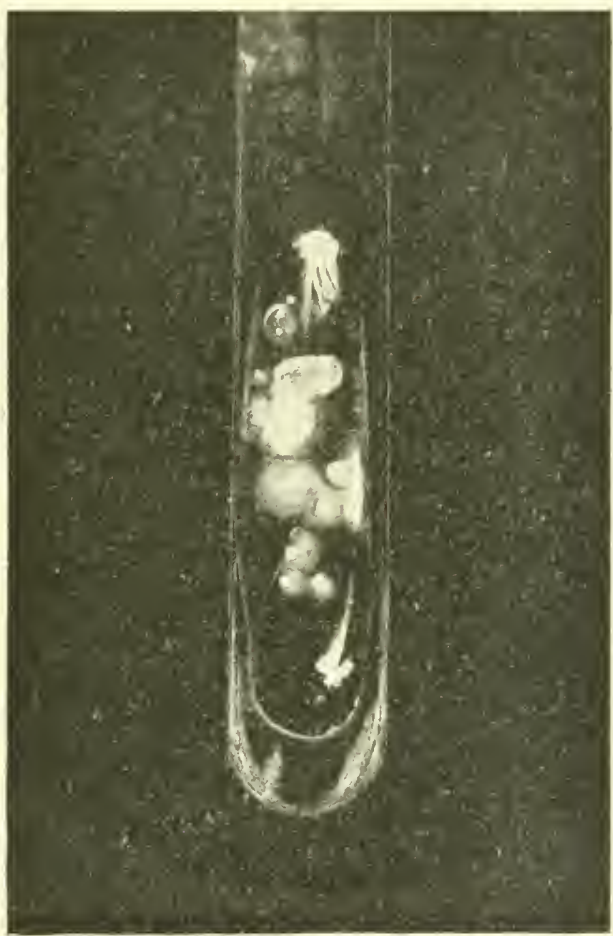

FIG. 97. Agar-agar slope culture of bacteria and moulds deposited by $M$, domestica caught in the author's laboratory (Jan. 1910) and allowed to make a single journey over the culture medium.

hour agar slope of Bucillus typhosus recently obtained firm an enteric stool and rubbed up with fine soil. This was introduced with some infected honey into a cage of Hies together with sterile litmus agar plates and dishes containing sterile broth, which were placed at a short distance from the infected soil and honey. Flies were seen to settle on the infected matter and on the agar and 
broth. The agar plates and broth were removed after a few days, and after incubation at $37 \mathrm{C}$. for twenty-four hours colonies of Bucillus typhosus were found on the agar plates, and the bacillus was recovered from the broth. In a further experiment the infected material was dusted over with fine earth to represent superficially buried dejecta, and the bacillus was isolated from agar

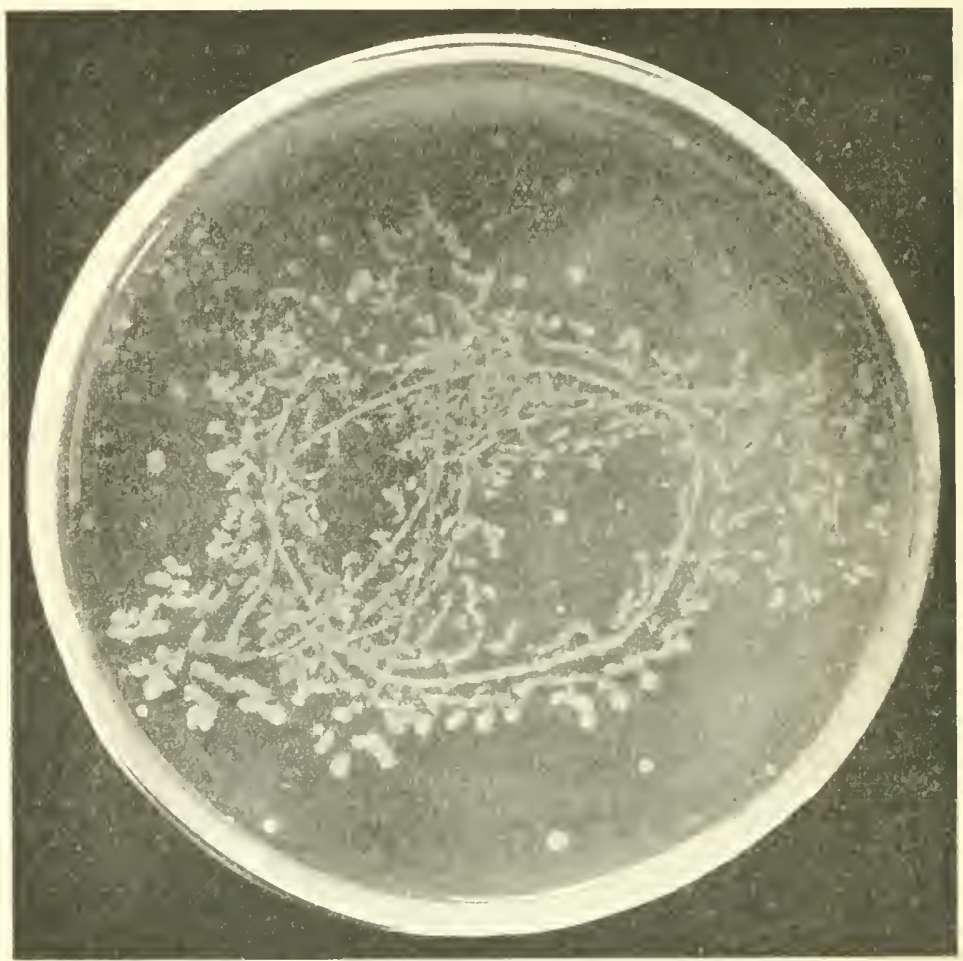

FIg. 98. Agar plate culture of tracks of $1 /$, domestica caught in a room and allowed to malk across and around the mediun. Natural size. (Prepared by H. T. Gïissow.)

plates upon which the flies harl sulwerpuently walkerl, as in the former experiment. They also fom the lacillus on the heads, wings, legs and lodies of thes which had bern allowed to have access to infected material.

Hamilon (1903) recoverend bucillus typhosus five tines in eighteen experinents from thies caught in two molained privies, 
on the fences of two yards, on the walls of two houses, and in the room of an enteric fever patient.

Ficker (190:3) found that when Hius were fed upon typhoid cultures they could contaminate objects upon which they rested. The typhoid bacilli were present in the head and on the wings and legs of the Hy five days after feeding. He also recovered B. typhosus fiom the flies 23 days after they had been infected. 'The bacillus was isolated from flies eaught in a house in Leipzig, where eight cases of typhoid had occurred. He calls attention to the fact that the value of Celli's conclusions is diminished owing to the fact that at the time the experiments were carried out the differentiation between B. typhosus and organisms of a similan character was hardly possible.

Buchanan (1907) was unable to recover the bacilli from flies taken from the enteric ward of the Glasgow Fever Hospital. Flies were allowed to walk over a film of typhoid stool and then transferred to the medium (Griubaum and Hune's modification of MacConkey's merlium), and subsequently allowed to walk over a second and a third film of medium. Few typhoid bacilli were recovered and none from the second and third fims.

Sangree (1899) performed somewhat similar experiments to those of Buchanan and recovered various bacilli in the tracks of the flies. This method of transferring the Hies immediately from the infected material to the culture plate is not very satisfactory, as I have already pointed out (1908), as it would be necessary for the thies to be very peculiarly constructed not to carry the bacilli. The fly should be allowed some freedom before it has access to the medium to simulate natural conditions. Experiments of this kind were carried out in the summer of 1907 by Dr M. B. Arnold (Superintendent of the Manchester Fever Hospital) and myself. Flies were allowed to walk orer a film of typhoid stool and then were transferred to a wire cage, where they remained for twenty-four hours with the opportunity of cleaning themselves, after which they were allowed to walk over the films of media. Although we were unable to recover B. typhosus the presence of $B$. coli was demonstrated. $B$. coli was also obtained from thies caught on a public tip upon which the contents of pail-closets had been emptied; the presence of $B$. coli, however, 
may not necessarily indicate recent contanination with human excrement.

Aldridge (1907) isolated a bacillus, apparently belonging to the paratyphoid group, from thies caught in a barrack latrine in India during an outbreak of enteric fover. In appearance and behaviour to tests it was very similar to $B$. typhosus.

A series of careful experiments were marle by Scllars ${ }^{1}$ in connection with Niven's investigations on the relation of thies to infantile diarrhoea. Ont of thirty-one batches of house-flies carefully collected in sterilised traps in several thickly populated districts in Manchester he found, as a result of cultural and inoeulatory experiments, that bacteria having inicroscopical and cultural characters resembling those of the Bacillus coli group were present in four instances, but they did not belong to the same kind or valiety.

In a report of investigations carried out at the Central Research Institute of India by Thomson (1912), the following conclusions are given: "The ingestion of typhoid germs in large numbers has no bad effect on the health of the Hies; they can retain living typhoid bacilli within their borlies and transmit infection thereby for a period of twenty-four hours after ingestion; they can carry the living germs on the exterior of their feet or bodies for a period of six hours, and so transmit infection."

Graham-Smith (1910) carried on infection experiments with B. typhosus. Flies were fed on syrup infected with this bacillus and afterwards on plain syrup. Sixteen hours after the removal of the infected syrup cultures on Drigalski-Conradi medium were made of the intestinal contents of five flies: eight Hies were allowed to walk on eulture plates and plates were also sown with emulsified faeces. B. typhosus was recovered in all cases. This experiment was repeated with Hies, two days, three days, and daily to six days after infection. The results showed that $B$. typhosus may remain alive in the intestinal canal for at least six dars and that Hies may infect plates upon which they walk for at least forty-eight hours after infection.

A typical instance of a small epidemic of typhoid fever is

${ }^{1}$ Recorded in the Report on the Health of the City of Manchester, 1906. by James Niven, pp. s6-96. 
reporterl by Cochrane (1912). 'This necumerl at St George's, Bermuda, and flies were considererl to be the probable carriers. There were eight cases of fever; three of these were in soldiers and the five civilian cases were in thre families. Two of the three soldiers were employed in two of the families. A fittal case of typhoid had occurred at a house 300 yards from the house where the first case occured in September of the previons year; three cases occurred in April and May. A dry earth latrine was used where the fatal cases of typhoid vecurred. A Hy was caught near this latrine. It was put into 5 c.c. of sterile salt solution for a minute and cultures made. The fly was emulsified and other cultures made. Bacillus typhosus was irolated from the washings. The house and the latrine were cleaned and disinfected and no further cases have occurred in the vicinity since. 


\section{CHAPTER XXII}

\section{THE RELATION OF FLIES TO SUMMER DIARRHOEA OF INFANTS}

THE conclusire nature of the eridence that the house-fly is an important factor in the spread of typhoid fever naturally directed the attention of medical men and investigators to the possibility of their being concerned in the dissemination of this serious intestinal complaint of infants. Niven (1910) defines summer or epirlemic diarrhoea as being "a term applied to an affection marked by a somewhat definite group of symptoms, in which vomiting sickness, copious diarthoea, rice-watery and green stools, and finally convulsions play a conspicuous part. This condition is not rarely somewhat prolonged, and is often attended with some degree of fever. On the one hand it shades into typhoid and paratyphoid fevers, and on the other it is not rarely the termination of a tuberculous enteritis or sone wasting affection." This disease is responsible for an enormous mortality among infants under two years of age, and in fact accounts for more deaths than any other disease.

In referring to epidemic diarrhoea in Portsmouth, Fraser (1902), cited by Nuttall and Jepson, states that "on risiting the houses in question I find that in all, almost without exception, the occupants have suffered from a perfect plague of flies. They told me every article of food is covered at once with Hies...I repeat that to this, and this alone, I attribute the diarrhoea in the Goldsmith Avente district."

Nash was one of the first medical observers to call attention (in 1902) to the remarkable coincidence between the abundance of Hies and the prevalence of this serious infantile disease. In the 
years 1902 and $190: 3$ the summers were wet and therefore unfavourable to the breeding and activity of $M$. domestica, and in these years the diarrhoal discases were less prevalent and the infantile mortality rate was considerably below the average. He suggested (190:3), in a paper read before the Epirlemiolngical Society of London in January, 190:3, that flies carried the infective material from all kinds of filth to the food supplies and were rosponsible for the spread of this disease and supported his contention with a further instance, namely, that "in the early purt of reptember, 1902, flies bucane preval'nt, and co-incidentally diarrhoea, which had hitherto been conspicuous by its absence, caused thirteen deaths in southend. Then came a spell of cold weather: the Hies rapidly diminished in number, and no further deaths from diarhoea were recorded" (1905). In 1904, by means of a "spot map" he found that the great majority of deaths from diarrhoea occurred in the proximity of brick fields in which were daily deposited some thirty tons of house refuse, an admirable breeding place for this insect. He has shown the actual danger which exists in flies camping bacterial organisms to milk as many other investigators have shown, and the danger resulting from the coincident occurrence of mcovered milk and infected thies is too obvious to need emphasis.

Newsholme (190:3) discussed the possibility of food infection by flies in the houses of the poor. He states: "The sugar used in sweetening the milk is often black with Hies which may have come from a neighbouring dustbin or manure heap, or from the liquid stools of a diarrhoal patient in a neighbouring house. Flies have to be picked ont of the half-empty can of condensed milk before its remaining contents can be used for the next meal." The observations of Copeman (p. 2\$1) have already been mentioned and similar instances of the relation between flies and the incidence of summer diarrhoei have been referred to by Snell (1906) and other medical officers of health in their reports. Sandilands (1906) states that there are "good grounds for the supposition that in this disease, which in some respects is analogons to typhoid fever and cholera, Hies may be carring agents of the first importance." He observes that the meteorological conditions which intluence the prevalence of diarrhoea exercise a precisely similar 
effect upon the prevalence of flies. He states: "The immunity of well-to-do infants may be explained, partly by the distance that separates the sick from the healthy, and partly by the small number of flies in their neighbourhoorl. In poor districts six or seren babies may occupy the tenements of one house with a common yard where flies congregate and flit in and out of the open windows, themselves conveying infected excrement to the milk of healthy infants, or depositing the excrement in the dustbin, whence it may again be conveyed into the house by other Hies. Cahn weather promotes diarthoea and high winds are unfavourable to the spread of diarrhoea and to the active migration of flies alike. Loose soil and fissurerl rock, containing organic filth in its crevices, favour the spread of diarrhoea and the breeding of Hies, whilst solid rock is unfarourable to both." Ainsworth (1909) studied the relation of flies to infantile diarrhoea in Poona and Kirkee, India, and by means of a yearly curve illustrates the relation, which, as in the case of similar curves constructed from English statistics, affords, or would appear to afford according to the critics, evidence of a close relationship between flies and summer diarrhoea.

The most exhaustive epidemiological study of the relation of flies to this disease has been made by Niven (1!)10) in Manchester. He commenced to make observations in 1903, and from 1904 systematic captures of flies were made at selected stations. After a consideration of the various factors which have been studied in relation to summer diarrhoea such as soil, temperature, etc., he states: "What we require for the explanation of the facts of summer diarrhoea is the presence of some transmitting agent rising and falling with the rise and fall of diarrhoea, the features pertaining to which must correspond and explain the features of the annual wave of diarmoea. None of the facts of which we have cognizance do afford such an explanation, and we come by exclusion to consider the house-Hy. The process of convevance is not striking and arresting as it is in military camps abroad; nor does the number of Hies usually approach that observed in tropieal and sub-tropical countries. We are, therefore, obliged to attack the question de noro, and exanine such eridence as we possess to see whether we may rest reasumably conficlent that in Hies we have 
found the transmitting agent sought for: If the house-fly is the transmitting agent in summer cliarhous, the following conditions should be fulfilled :-

"(1) (a) There should be evirlence that the house-Hy carries bacteria under the ordinary summer conditions: (b) horso-flies should be present in sufticient numbers in houses invaded by fittal diarrhoe:i.

"(2) There should be a close correspondence between the aggregate number of house-flies in houses and the aggregate number of deaths from diarrhoeat wek by week.

"(3) The life-history of the house-fly should explain any discrepancy between the observed number of flies and the observed number of deaths.

“( \pm ) The minority of breast-fed children not apparently accessible to infection should receive explanation.

“(5) There should be a closer correspondence of diarhweal fatality with the number of flies than with any other varying seasomal fiact.

"(6) Any other closely-corresponding seasonal fact should be capable of interpretation in terms of the number of house-flies.

"(7) Any variation from district to district in the annual curve of deaths should be accompanied by a similar variation in the curve of flies.

"(s) It will be at once manifest when we come to enteric fever that the house-Hy plays but a minor direct part in the production of the annual wave. Such part, however, should have reference to the number of flies and of pre-existing centres of infection. If it can be shown that that portion of the enteric wave which is connected with flies changes from one period of time to another in such a manner as to be explainable in terms of flies, but not of meteorological conditions, the evidence in farour of thies will be greatly strengthened.

"(9) No other available hypothesis must be capable of explaining the course of summer diarrhoea."

For the purposes of this study daily counts of the flies captured at the different observation stations which were selected 
were made from July (in one year from the end of May) until November during the years $190 \mathrm{t}, 1905,1906,1908$ and 1909. The complete data obtained are given; these include for each week the number of flies captured, the nmmber of death from diarrhoea, the number of fatal cases commencing, mean temperature in the shade, rainfall in inches, and the underground

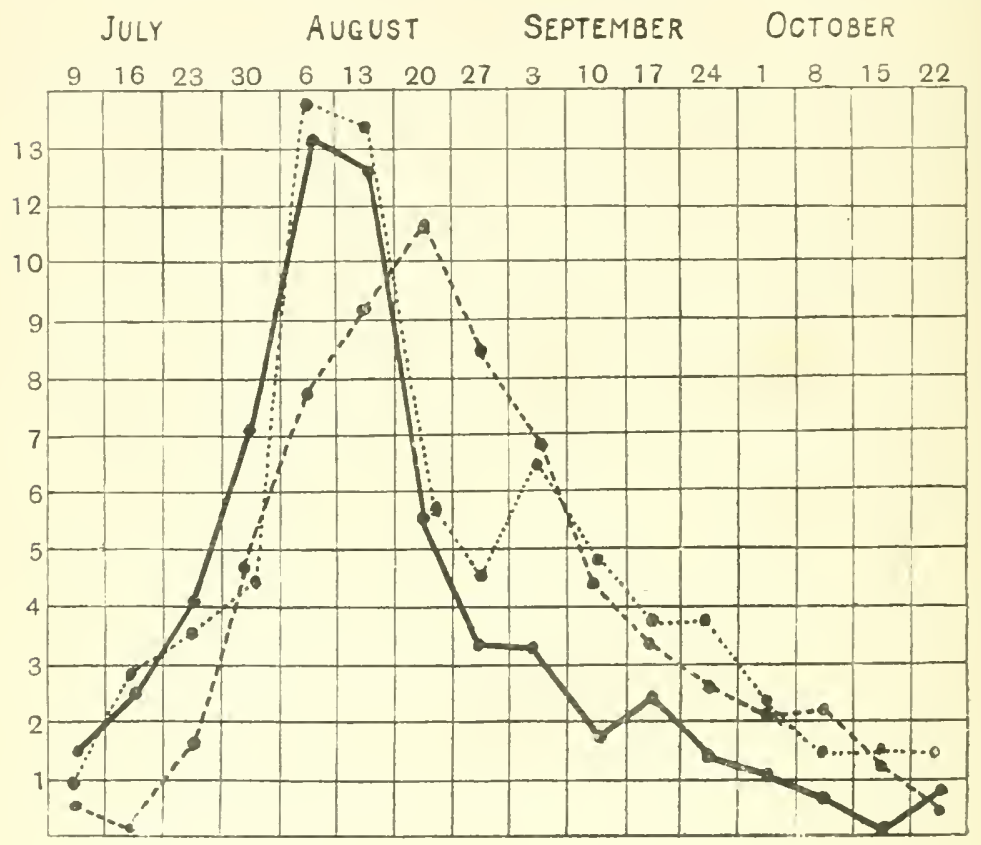

Numerical abunoance of Flies.

DEATHS FROM DIARRHEA.

Fatal Cases commencing.

$F_{I G}$, 99. Chart illustrating the relation of the numerical abundance of house-flies to summer diarrhoea in the eity of Manchester in 1904. Prepared from statistics and chart given by Niven.

temperatmes at 1 foot and 4 feet respectively. From these data charts are constructed. I have prepared Figs. 99 and 100 from the statistics and chart given for the years 1904 and 1909. Although in Fig. 99 the temperature curve has heen omitted, it may be printed ont that in Niven's charts there is no direct relation 
between the curves of temperature or rainfall and those of flies or deaths from diarrhoea. In adrlition he points out the manner in which the curve of fatal cases or deaths falls away from the curve of flies in the middle of the recline.

In pointing out the intimate correspondence of the curves of the cases and deaths to the number of flies captured week by

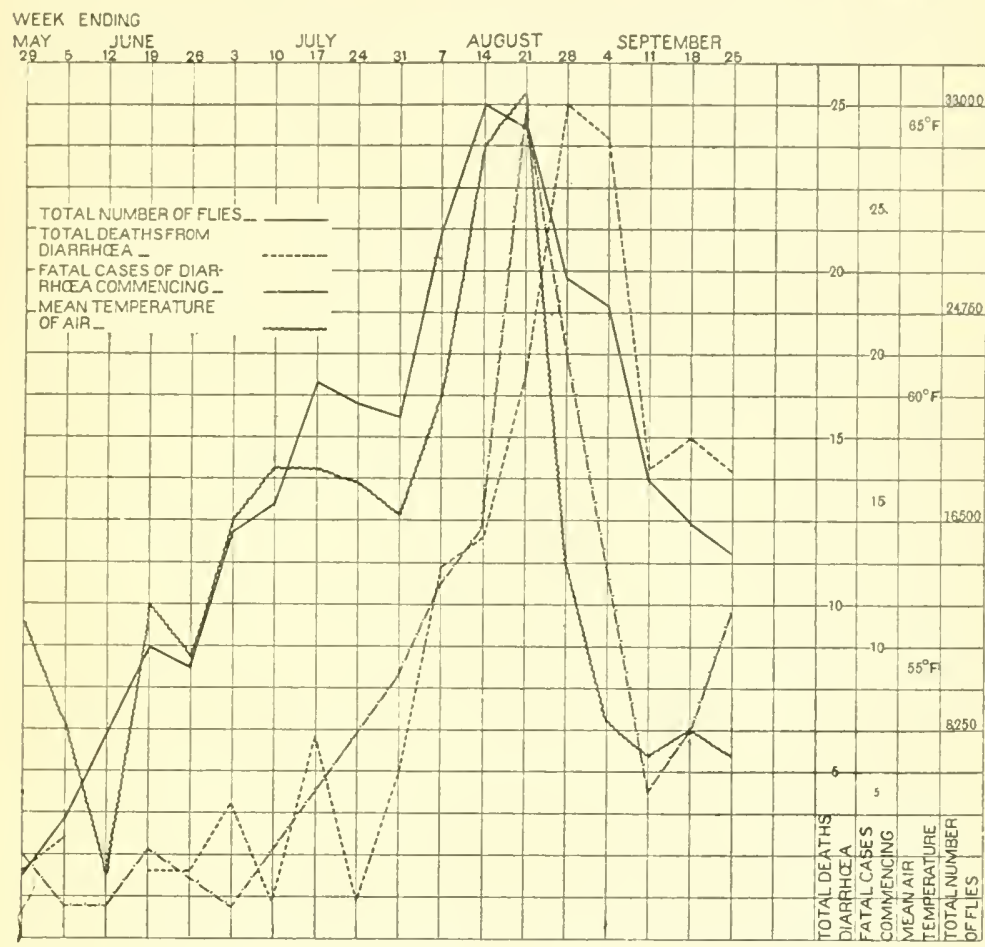

FIG. 100. Chart illustrating the relation of the numerical abundance of house-tlies to summer diarrhoea in the city of Manchester in 1909. Prepared from the statistics given by Niven.

week, Niven states: "The number of cases begins to increase until the flies captured attain a maximum. The naximum number of cases commencing in the years 1904 and 1905 is in the same week as the maximum number of Hies. The figures for the deaths are still more striking. The shape of the curves at an interval of a week to a fortnight near the maximum point is practically identical in the two. The errors of the curves will be subjected to examination afterwards. But, even with their manifest and 11. H, -F, 
necessary defects, they show a degree of correspondence which creates a high degree of probability that flies are the transmitting agents in summer diarrhoea. In all the curves it will be seen that deaths diminish more rapidly than do flies in the middle part of the decline. For this there are two causes. In years of high diarrhoca incirlence the more susceptible anrt exposed infants have been killed off or rendered immune. In every year towards the close of the Hy season the Hies are attacked by Limpusa muscue, and are hindered by cold from leaving the house, so that they cease to act as transmitting agents."

For a full discussion of the careful observations made by Niven in his exhaustive study of the epidemiology of this disease in Manchester, the reader is referred to the original paper. In summarising the results of his analysis Niven states, after declaring that summer diarrhoea is an infections illness: "The health of infants prior to attack-in other words, the social condition-has much to do with the fatality. The summer wave is not due to dust, nor is it conditioned by any growth of bacteria in or on the soil. There is nothing to support the riew that the infective organisms are of animal origin, and the connection between privy middens and diarrhoea goes far to prove the contrary. The disease becomes more fatal only after house-flies have been prevalent for some time, and its fatality rises as their numbers increase and falls as they fall. The correspondence of diarthoeal fatality is closer with the number of flies in circulation than with any other fact. The next closest connection is with the readings of the four-foot thermometer, with which, however, diarrhoeal fatality can have no direct relation. Flies and the readings of the four-foot thermometer are both functions of air and surface temperatures and of rainfall. Certain facts in the life-history of the fly throw light on discrepancies arising in the dechine of thies and cases. The close correspondence between Hies and cases of fatal diarrhoea receires a general support from the diarrhoea history of sanitary sub-divisions of the Manchester district. The few facts available for the study of the correspondence of flies and fatal cases in different sub-rlivisions, in the comise of the same year, also lend support to this riew. No other explanation even approximately fits the cuse." 
In the inrestigation which Hamer (19)\$, 1909) carried out in London with a riew to deternining the relationship which the presence of accumulations of refuse and offensive matter bears to the Hy misance, opportunity was afforded, and wisely taken advantage of, to study the question of the possible relationship of Hies to summer diarrhoea. Hamer indicates what appears to him to be a difficulty in the way of accepting this theory. He states: "It shonll be pointed out that there are certain difficulties in the way of accepting the thesis that the correspondence exhibited in the curves (he refers to the fly curve and diarhoea curve) affords reason for concluding that flies and summer diarrhoea stand to ore another in relation of canse and effect. At the commencement of the hot summer weeks, when the number of flies has begun to show marked increase, the diarrhoea curve is rapidly rising. After some weeks the number of Hies reaches the maximum, and then diminishes, and so, in almost precise correspondence, does the amount of diarrhoea. A period is later reached, towards the close of the hot weeks, at which the number of flies is still as markedly excessive as at the earlier period when the amount of diarhoea was increasing, but at the later period the amount of diarrhoea is dechining: it even anticipates decline in the number of flies. If the Hy is to be regarded as the carrier of the organism which causes diarrhoea, it might perhaps have been anticipated that at the later period-the number of flies still being excessive and infective material being then presumably more widely distributed than ever before-the amount of diarrhoea, instead of showing early and rapid decline, would still be increasing. It wouk almost appear that the advocate of the 'fly-borne diarrhoea hypothesis' must necessarily fall back in support of his theory upon the hypothetical organism, conveyed by the fly, which he may claim is affected by temperature in such a way as to bring about correspondence between the diarrhoea curve and the fly curre. The very closeness of the correspondence between these two curves may indeed from this point of view be thought of as constituting a difficulty rather than a point in favour of the hypothesis that summer diarrhoea is caused by Hies."

Against Niven's suggestion that one of the explanations of the decline of the diarrhoeal curve while the number of Hies still 
remains excessive Hamer brings forward two eonsiderations: first, that the comparatively early fall in the amount of diarrhoea is observed in years of very low mortality as well as in years of excessively high nortality in which such an explanation might hold good. Secondly, the hypothesis does not adequately account for the almost identically similar behaviour of the two curves both in their ascent and descent. The close correspondence between the curves, Hamer believes, accords better with the view that both are lependent upon variations of temperature than with the hypothesis that diarrhoea stands in direct cansal relation to $\mathrm{fly}$ prevalence. In his last report and in the light of three years' records (1907-1909) Hamer is still uneonvineerl that the evidence available can be considered to support a causal relation between summer diarrhoea and flies and a eritical attitude is still maintainer.

In regard to Hamer's chief eriticism, namely, that while the number of thies is still excessive, the diarrhoeal curve has begun to recline, I have previously pointerl out (1910) that a consideration of the habits of the honse-fly will probably afforl an explanation of this difficulty. Flies are very susceptible to ehanges of temperature. When the temperature falls flies become less active and retire into the shelter of houses and other buildings, although their numbers, as indicated by eaptures in traps set indoors, may still be considerable. In so far then as the activity of the flies is associated with the temperature, the temperature curve should be studied in addition to the fly and diarrhoea curves. If this is done, it is usually found that a fall in the number of flies is preeeded by a fall in the temperature and that these two curves are associated somewhat closely, that is, the numerical activity of the flies-since the numbers caught are more indicative of their numerical activity than of their numerieal abundance-is dependent upon the temperature and als, I have found, upon the state of the weather and sky. Therefore, if the flies become less aetive, they will be less liable to transmit the organisms causing summer diarhoea, and although the numbers caught in the houses may exceed in numbers those canght earlier in the season when the diarrhoen curve was rising, those which are very active will be less in number and consequently instead of 
increasing, the diarrhoea curve begins to full. The dissemination of summer diarhoea is brought abut ehiefly owing to the activity of the Hies ontside the houses as well as inside. A fall in temperature or a spell of dull weather decenses considerably this ontside activity and will, therefore, canse a decline in the number of diarthoea cases. The number of cases of diarthoea is dependent on the activity of the Hies and this is dependent on climatic conditions, chief of which is temperature. Considered in the light of these facts this seeming diffieulty is not an argunent against the ideat that we hold on the relation of flics to sumner diarrhoea, but rather one in support of it.

The relation of temperature and the activity of the Hies has also been commented upon by Nash (1909).

The great difficulty with which we are faced in discussing the question of the relation of thies to the prevalence of summer diarthoea is that it has not been proved to the satisfaction of most investigators what the specific pathogenic organism is; or perhaps there are associated organisms. It is possible that more than one etiological factor exists. Tarious organisms have been found in the diarrhoeal stools. Some epidemics in the United States have been associated with the dysentery (Flexner's) bacillus in the stools; in other epirlemics dysentery bacilli were not fount. Metchnikoff (1909) believes that Bucillus vulyure may be the causative organism. Morgan (1906-7) isolated a bacillus which he designated "No. 1," and which may be an inportant factor in the causation of the disease. In a further paper Morgan and Ledingham (1909) give a more complete account of their researches on Morgan's bacillus which belongs to the non-lactose fermenting group, to which group all the pathogenic bacteria inducing affections of the intestinal tract belong, namely, the typhoid and paratyphoid bacilli, the dysentery and food-poisoning organisms. In 1905, 58 cases of infantile diarthoea were examined and Morgan's bacillus was found in 48.2 per cent.; in 1906, in 54 cases it was found in 5.5 per cent.; in 1907, 191 cases were examined and it occurred in $16 \% 2$ per cent., and in 1908 it occurred in 53 per cent. of the cases, numbering 166 that were examined. It was found that rats and monkeys were susceptible to infection by feeding and that they succumbed after a period of diarhoea. 
One of the most interesting and highly suggestive results of the research was the discovery of Morgan's bacillus in flies. "Batches of thies came for examination from infected and uninfectert houses in Paddington and from a comntry house situated many miles from London, where no cases of diarrhoea had occurred, at any rate, within a radins of two miles. The flies were killer with ether vapour and crushed with a sterile rod in peptone broth. The result was that Morgan's bacillus was isolated from nine of the thirty-two batches from infected houses and from one of the thirty-two batches from uninfected houses ${ }^{1}$. It was also got in five out of twenty-four batches from the country house." Dr Morgan in the course of a letter to me says: "I certainly think they are carriers of summer diarrhoea, and the variety I especially suspect of doing this is the Musca domestica."

In a study of the micro-organisms occurring in flies caught in normal surroundings and in diarrhoea-infected locations GrahamSmith (1912) found that a greater proportion of flies is infected with the non-lactose-fermenting bacteria during August and the early part of September than at other times. Of the groups of bacilli into which these organisms can be divided the Morgan or Ga group is the only one which occurs frequently in flies from diarrhoea-infected houses and rarely in non-diarrboea-infected houses. He considers it certain that flies infected with Morgan's bacillus can contaminate materials on which they feed or over which they walk.

The epidemiological evidence for and against the hypothesis that the house-fly is an agent in the dissemination of summer diarrhoea has been subjected to a most careful and detailed examination and analysis by Martin (1913), whose paper is in my opinion the most judicious criticism of the problem as it now stands.

After pointing out that the observations of Niven and Hamer indicate the dependence of both the number of Hies and the epidemic upon the cumulative effect of previous warm weather, Martin calls attention to the fact that a notable feature of the

1 Morgan's bacillus has also been isolated from naturally infected tlies by Nicoll (1911) and Cox, Lewis and Glynn (1912). See pp. 2.55 and 296. 
curve is that the sime fly population is aceompanied by a rise in the number of cases in early August and by a fall in early September. If the time relations of fly prevalence and rliarhorea cases is to be regarded as something more than an interesting coincidence a satisfictory cxplanation must be found for these facts. He rightly states that the number of flies is dependent upon the accummlated effect of temperature becaus: a considerable period of warm weather, weeks or months, is required to produce an abundance of tlies from the few which come out of hibernation. The dependence of the epidemic upon this fuctor is not so obvious in the absence of exact knowledge as to the etiology of diarrhoea. But assuming an infective agent of a bacterial nature with which fool might become contaminated he shows that the dose of infection would not be dependent upon the accumulated effect of temperature during the previous three months. It is just comceivable that the virulence of the organism might be enhanced by the continued influence of warm weather. Describing the excellent a priori reasons for supposing that flies could transmit the infective agent of diarrhoea he says: "Anyone familiar with the domestic ménage of the average working man on a hot summer day, with the baby sick with diarnhoea and other small children to care for, must realize that the opportunities afforded for fly transmission are adequate enough."

After discussing the data relating to the question to which I have previously referred, namely, the decline of the epidemic while the number of flies is still considerable, he gromps the two factors which may contribute in a varying degree to the decline of the epidemic. First, a fall in temperature, diminishing $(a)$ the activity and number of the supposed transmitters, and (b) the dose of infection which the child ingests owing to the effect upon the rate of multiplication of the infective agent. Second, the exhaustion of the more susceptible individuals, as pointed out by Niven (l.c.), and also by Peters (1910) in describing an epidemic in Mansfield, where, under similar conditions, in one section of the town the epidemic was nearly finished whilst in another the aforementioned factors appears to predominate.

In commenting upon the evidence of Nash and Niven, which I have already given, upon the relation between the number of 
flies and the distribution of cases of infantile diarrhoea, Martin states, and I think justly: "I doubt very much whether any evirlence of great value could be obtained upon this point. Even supposing it to be true that Hy carriage is of first importance, I should expect that, if all the facts were known, a much higher correlation would be discovered between diarrhoea and carelessness with regard to disposal of excreta and protection of food from the risitation of flies than between diarrhoea and Hy prevalence."

As a conclusion to this résumé of the evidence for and against the hypothesis that the honse-fly is an important agent in the dissemination of summer diarrhoea, in regard to which idea a critical attitude is, in my opinion, not only justified but conducive to a more satisfactory elucidation of the problem, I do not think I can do better than to quote Martin's concluding paragraph. $\mathrm{He}$ says: "Nany of the facts which I have brought forward merely inclicate some form of infective agent and do not necessitate recourse to the hypothesis that carriage of Hies dominates the situation. I would point out, however, that:

"1. The fly-carrier hypothesis is the only one which offers a satisfactory interpretation of the extraordinary dependence of the epidemic upon the accumulated effect of temperature.

"2. That it offers a ready explanation of the spread of infection to neighbouring children who have no direct personal contact with the pratient.

"3. That the peculiarities of the relation in time between $\mathrm{fly}$ prevalence and the epidemic in different localities are not inconsistent with the view that fly carriage is essential to epidemicity. No other interpretation which is at present fortheoming is nearly so satisfactory, and it is at least worthy to guide in the meantime our efforts at prevention."."

${ }^{1}$ In a recent Bulletin Armstrong (1914) gives an account of an effort made in the summer of 1913 by the Department of Social Welfare of New Fork to determine the importance of the house-1ty in the transmission of diarhoeal disease among infants. Two congested areas in the Italian quarter were selected. In one every step was taken to make the houses sanitary and flyless by education, screening, cleaning up, etc.; in the other nothing was done. A careful census and weekly inspections were made. The statistical findings, if not entirely conclusive, were exceedingly interesting and dentonstrnted an apparent marked reduction in the 
amount of diarrhoeal disease in the protected area. In the protected area there were, in ehildren under tive rears of age, twenty cases of diarhoeal disease, and fifty-seven cases in the mprotected or tilthy area. In the former the duration of the disease was 273 days, in the latter the total days of sickness were 984 . Of the other suggestive statistics contained in this report the following may be mentioned. A bacterial count of the flies was made. The average number of bacteria on an agar culture from flies in the clean area was 13,986 and in the dirty area $1,106,017$. The average number per thy of bacteria on Conradi plates (indicating intestinal organisms) was 4489 on thies from the clean arca and 292,117 from flies from the dirty area. 


\title{
CHAPTER XXIII
}

\author{
THE DISSEMINATION OF OTHER DISEASES BY FLIES
}

\section{ANTHRAX}

Ix considering the relation of thies to anthrax several ficts should be borne in mind. As early as the eighteenth century it was believed that anthrax might resnlt from the bite of a $\mathrm{Hy}$, and the idea has been used by Murger in his romance Le Sabot Rouge. A rery complete historical account of these earlier ideas is given by Nuttall (1899). Nost of the instances in support of this belief, however, that thies may carry the infection of anthrax, refer to biting flies. As I have already pointed out, $M$. domestica and such of its allies as F. cunicularis, C. erythrocephala, C. vomitoria and Lucilia cuesar are not biting or blood-sucking Hies. The nearest allies of $M$. domestica which suck blood in England are $\therefore$. calcitrans, Haematobia stimulans Meigen and Lyperosiu irritans L.; the rest of the blood-sucking flies which may be considered in this connection belong to the family Tabanidae, including the common genera Haematopota, Tabanus, and Chrysops. These biting and blood-sucking Hies live upon the blood of living rather than dead animals. But it is from the carcases and skins of animals which have died of anthrax that infection is more likely to be obtained, and I believe that such Hies as the blow-tlies (Culliphoru spp.) and sometimes $M$. domesticu and Lucitiu cuesar which frequent flesh and the bodies of dead animals for the purpose of depositing their eggs and for the sake of the juices, are more likely to be concened in the carriage of the anthrax bacillus and the cansation of malignant pustule than are the bloor-sucking thies. Consequently, as .II. domesticu and its allies 
only are under consideration, and for the sake of brevity, the relation to anthrix of the non-biting Hies only will be considured here.

The earliest bacteriological evidence in support of this luetief was Raimbert (1869). He experimentally proved that the houseHy and the meat-fly were able to carry the anthrax bicillus, which he found on their proboscides and legs. In one experinent two meat-Hies were placed from twelve to twenty-four hours in a belljax with a dish of dried anthrax blood. One guinea-pig was inoculated with a proboscis, two wings and four legs of a $\mathrm{Hy}$, and another with a wing and two legs. Both were clead at the enr of sixty hours, anthrax bicilli being found in the blood, spleen and heart. He concludes: "Les mouches qui se posent sur les carlavres des animaux morts du Charbon sur les dépouilles, et s'en nourissent, ont la faculté de transporter les virus charbouneux déposé sur la peau peut en traverser les differentes conches." Davaine (1S70) also carrierl ont similar experiments with $C$. vomitoriu. which was able to carry the anthrax bacillus. Bollinger (1874) found the bacilli in the alimentary tract of Hies that he had caught on the carcase of a cow dead of anthrax. Sangree (1899) allowed a Hy to walk over a plate culture of anthrax and then transferred it to a sterile plate; colonies of anthrax naturally developed in its tracks. Buchanan (1907) placed C. romitoria under a bell-jar with the carcase of a guinea-pig (deprived of skin and viscera) which had died of anthrax. He then transferred them to agar medium and a second agar capsule, both of which subsequently showed a profuse growth of $B$. unthracis, as one might expect. Specimens of $M$. domestica were also given access to the carcase of an ox which had died of anthrax; they all subsequently caused growths of the anthrax bacillus on agar. I entirely agree with Nuttall, who says: "It does seem high time, though, after" nearly a century and a half of discussion, to see what would be the result of properly carried out experiments. That ordinary Hies ( 1 . domestica and the like) may carry about and deposit the bacillus of anthrax in their excrements, or cause infection through their soiled exterior coming in contact with wounderl surfaces or food, may be accepted as proven in view of the experimental evidence already presented." 
These experiments only prove the ability of Hies to mechanically transfer the anthrax biacilli from infected to uninfected matter. Graham-Smith (1910 and 1911), howerel; has carried these experiments further with a view to discovering, among other points, the length of time that flies may carry the bacilli or its spores, B. unthrucis being a spore-bearing bacillus and consequently more adapted for transference. Flies were placed for one hour in a cage containing the body of a monse just dead of anthrax, its body having been opened to enable the flies to feer upon its blood. The Hies were afterwards transferred to a clean cage which on the following morning was found to contain red spots of romit and yellowish faeces. B. anthrecis was found in the former both inicroscopically and by cultures. The flies were transferred daily to fresh cages and fed on syrup: at intervals specimens were remored and dissected and cultures were made on agar from their legs, wings, heads, crops and intestinal contents. Cultures were also made from the faeces. As a result of these careful examinations, it was found that the non-spore-bearing anthrax bacilli did not remain alive on the external parts of the fly for more than twentyfour hours. They remained alive in the intestine for three days and in the crop for five days, especially when this organ contained partially congulated blood. The bacilli were present in the faeces repositer forty-eight hours after infection. No spore-bearing forms were obtained from film preparations made at varions times from the contents of the crop and the intestine. Experiments were also carried on with the spores of $B$. unthracis. An emulsion of an old anthrax eulture was made and heated to $70 \mathrm{C}$. for fifteen minutes, after which a number of flies were allowed to feed on it. These thes were then transferred to fresh cages daily and fed on syrul, and as in the previons experinent specimens were caught and dissected at intervals, agar enltures being made from their legs, wings, heads, crops and intestinal contents and faecal deposits. Smears were made from the crop and intestinal contents at various times but the absence of anthrax bacilli on mieroscopic examination demomstrated that the spores do not develop in the fly. This experiment showed that Hies infected with anthrax spores may carry the spores upon their legs and wings for at least twelve days, and that the spores are present in considerable numbers in the 
crop and intestinal contents for at least seren days. The spores remained in a living condition in the romit and faecal deposits for six days or longer. Cultures were also made from drops of sugar after the Hies had been allowed to feed upon them and anthrax bacilli were obtainerl on the tenth day after the Hies harl ferl. It was also shown in another experiment that the anthrax spres may remain alive for at least twenty days upon the legs and wings and in the intestinal eontents of the fly and that fieces passed fourteen days after infection contained living spores. Dried faces and romit were shown to contain the spores in a vital condition for twenty days. Cultures were obtained from the boties of dead flies fom hundred and twenty-eight days after death and proved to be virulent by animal inoculations.

In connection with the experiments of Faichnie and others on flies bred from larvae infected with B. typhosus the results of Grahom-Smith's experiments with $B$. unthrucis are of interest. The larvae of $C$. erythrocephlale were fed on meat infected with anthrax spores. The flies bred from these larvae were heavily infected for at least two days after emerging. In a single series of experiments $B$. anthrecis could not be cultivated cither from the limbs or intestinal contents of Hies more than fifteen or nineteen days old. It was found that flies were able to infeet, rluring the first two days after emerging, materials over which they walk, and to deposit infected farees.

In a further report Graham-Smith (1912) states that he finds that a large proportion of Muscu domesticu which derelop from larvae infected with the spores of $B$. cuthrucis are infected.

These results confirm the suggestion made by Joseph (1887) and later by $\mathrm{N}^{\mathrm{u}}$ ttall (l.c.) that the non-biting flies, when infecterl, may spread anthrax by depositing bacilli upon wounds or food and they have a significant bearing upon the spread of the discase anong domestic animals and the production of malignant pustule in man.

\section{TUberculosis.}

With the proven existence of so many factors contributing to the dissemination of the tubercle bacillus, the significance of experiments of a positive nature indicating the ability of Hies to 
transfer the virulent germs may appear to be lessened. A careful consirleration of the facts, nevertheless, will show that this is far from being the case. My experiments and observations on the feeding habits of the fly have shown that this insect is especially fond of and attracted to sputum. This is a matter of common observation where spittoons or cuspidors are used and are not k'pt in a clean condition. 'There is no lack of opportunity, under natural conclitions, for Hies to infect themselves externally and internally with the tubercle bacilli. To what extent they may prove the means of infection depends upon their access to food. In my opinion their greatest danger lies in the possibility of their coming into contact with the months or food of helpless infants.

spillman and Haushalter were the first to carry out bacteriological investigations on the dissemination of Bucillus tuberculosis by flies. As early as 1887 they found this bacillus in large numbers in the intestines of flies from a hospital ward, and also in the dejections which occurred on the windows and walls of the ward. Hoffmann (1886) also found tubercle bacilli in the exereta of flies in the room where a patient had died of tuberculosis, and he also found the bacilli in the flies' intestinal contents. One out of three guinea-pigs which were inoculated with the flies' intestines died: two inoenlations with the excreta had no effeet, which led him to believe that the bacilli became less virulent in passing through the fly's alimentary tract. But Celli (l.c.) records exferiments in which two rabbits inoculated with the excreta of flies fed with tubercular sputum developed the disease.

Hayward (1904) obtained tubercle bacilli in ten out of sixteen cultures made from flies which had been caught feerling on bottles containing tuberculous sputum. Tubercle bacilli were also recovered from cultures made from faeces of flies which had fed in the same manmer, which apluarently cansed a kind of diarthoea in the flies, and they died from two to three days afterwards. Facees of Hies firl on tuberenlar sputum were rubbed np in sterile water and injected into the peritoneal cavity of guinea-pigs, which developed tuberculosis. Buchanan (1907) allowed thes to walk over a film of tubercular sputum and then over agar; the agar was then washed with water and a guinea-pig died of tubereulosis in thirty-six days by inoculating it with the resulting solution. 
Crobb (1905) is of the opinion that by the infection of human foor after feeding upon tubercular sputum flies may be an important factor in the dissemination of tuberculosis, and the force of his remarks is not mitigaterl by the acrid criticisms of Mays (1905).

Lord (1904) made a careful series of experiments as a result of which he reached the following conclusions: Flies may ingest tubercular sputum and excrete tubercle bacilli, the virulence of which may last for at least fifteen dars. The danger of human infection from tubercular fly specks is by the ingestion of the specks on food. Spontaneous liberation of tubercle bacilli from fly specks is unlikely. If mechanically disturbed, infection of the surrounding air may occur. He suggests that tubercular material (sputum, pus from discharging sinuses, faceal matter from patients with intestinal tuberculosis, etc.) should be carefully protected from thies lest they act as disseminators of the tubercle bacilli. During the fly season greater attention should be paid to the screening of rooms and hospital wards containing patients with tuberculosis and laboratories where tubercular material is examined. As there precautions would not eliminate fly infection by patients at large, foud stuffs should be protected from flies which may already have ingested tubercular material. The importance of these conclusions will be realised by those who are acquainted with recent work on tubercular infection by way of the alimentary tract.

Graham-Smith (1910) carried out a series of experiments with flies artificially infected with $B$. tuberculosis. A large number of Hies freshly caught were alluwed to feed upon an emulsion of a culture of human tubercle bacilli in syrup. After feeding, the Hies were transferred to a clean cage and fed daily on srrup. Smear preparations were made from the crop and intestinal contents of these flies which were caught at intervals. Smears were also made from romit and faecal material. As a result it was found that under experimental conditions the tubercle bacilli were present in the crop for three days. In the intestine they were found in considerable numbers up to six dars and were still present after twelve dars and possibly longer. In the faeces they were numerous up to the fifth day and occasionally found up to 
the fourteenth day after infection. In a further experiment flies were fer upon tuberculons sputum and afterwards on non-tuberculous sputum. The tubercle bacilli were found in the intestinal contents for at least four days, during which time the faeces were also infecterl. These careful experiments confirm the conclusions of the previons investigators as to the ability of flies to carry B. tuberculosis in a virulent condition.

\section{Choletia.}

The necessity of guarding food against flies in the belief that they might disseminate cholera was ealled attention to by Moore in 1853, according to Nuttall and Jepson (1909). He stated that "flies in the East have not far to pass from diseased evacuations or from articles stained with such excreta, to food cooked and uncooked."

One of the first to suggest that flies may disseminate the cholera spirillum was Nicholas (1873), who, in an interesting and prophetie letter, said: "In 1849, on an occasion of going through the wards of the Malta Hospital where a large amount of Asiatic cholera was under treatment, iny first impression of the possibility of the transfer of the disease by Hies was derived from the observation of the manner in which these voracious creatures, present in great numbers, and having equal aceess to the dejections and foor of the patients, gorged themselves indiscriminately, and then disgorged themselves on the fool and drinking utensils. In 1850 the Superb, in common with the rest of the Mediterranean squadron, was at sea for nearly six months; during the greater part of the time she had cholera on board. On putting to sea the flies were in great force, but after a time the Hies graclually disappearerl and the epirlemic slowly subsided. On going into Malta harbour, but withont communicating with the shore, the flies returned in greater force, and the cholera also with increased violence. After more cruising at sea the flies disapprared gradually, with the subsidence of the disease. In the yoars of 1854 and 1866 in this conntry the periods of oceurrence and disappearance of the epidemics were co-incident with the fly season." In 18s6, Flugge, accosding to Nuttall and Jepson (l.c.), observed that Hics 
may infect food during cholera times and that they must play an important part in the dissemination of the disease when they are numerous. He also draws attention to the fact that the worst cholera months are those in which insects abound.

Buchanan (1897), in at description of a gaol epidemic of cholera which occured at Burdwan in June, 1896, states that swarms of thies occurred about the prison, outside which there were a number of huts containing cholera cases. Numbers of Hies were blown from the sides where the huts lay into the prison enclosure, where they settled on the fond of prisoners. Only those prisoners which were ferl in the gaol enclosure nearest the huts acquired cholera, the others remaining lacalthy.

Tsuzuki (1904), reporting upon the cholera outbreak in Northern China in 1902 , states that "flies in China are a terrible infliction to the stranger," and remarks that if they are capable of carrying about the cholera germ they inust play an important part in the spread of the diserse. His experiments, mentioned later, demonstrated that flies are able under natural conditions to carry the cholera spirillum.

\section{Bacteriological evidence.}

Maddox (1885) appears to have been the first to conduct experiments with a view to demonstrating the ability of the flies to carry cholera spirillum, or as it was then called, the "comma bacillus." He fed the Hies Culliphora vomitoria and Eristalis tencu (the "drone-fly") on pure and impure cultures of the spirillum, and appears to have found the motile spirillum in the faeces of the flies. He concludes that these insects may act as disseminator's of cholera. During a cholera epidemic Tizzoni and Cattani (1886), working in Bologna, showed experimentally that flies were able to carry the "comma bacillus" on their feet. They also obtained, in two of these experiments, the spirillum from cultures made with flies from one of the cholera wards. Sawtchenko (1892) made a number of careful experiments. Flies were fed on bovillon culture of the cholera spirillum, and to be certain that the subsequent results should not be vitiated by the presence of the spirillum on the exterior of the flies, he disinfected them

H. H, $-\mathrm{F}$. 
externally and then dissected out the alimentary canal, with which he made cultures. In the case of Hies which had lived for fortyeight hours after feeding, the second and third cultures represented pure cultures of the cholera spirillum.

Simmonds (1892) in Hamburg placed flies on a fresh cholera intestine, and afterwards confined them from five to forty-five minutes in a vessel in which they could tly about. Roll cultures were then made and colonies of the cholera spirillum were obtained after forty-eight hours. Colonies were also obtained fiom a $\mathrm{Hy}$ one and a half hours after having access to a cholera intestine, and also from Hies caught in a cholera post-mortem room. Uffehmann (1892) fed two thes on liquefied cultures of the cholera spirillum, and after keeping one of them for an hour in a glass he obtained 10,500 colonies from it by means of a roll culture; from the other, which was kept two hours under the glass, he obtained twenty-five colonies. In a further experiment he placed one of the two flies, similarly infected with the spirillum, in a glass of sterilised milk, which it was allowed to drink. The milk was then kept for sixteen hours at a temperature of $20-21^{\circ} \mathrm{C}$., after which it was shaken, and cultures were made from it: one drop of milk yielded over one hundred colonies of the spirillum. The other fly was allowed to touch with its proboscis and feed upon a juicy piece of meat that was subsequently scraped. From one half of the surface twenty colonies, and from the other half one hundred colonies, of the spirillum were obtained. These experiments show the danger which may result if flies having access to a cholera patient, and bearing the spirillum, have access also to food. Macrae (1894) records experiments in which boiled milk was exposed in different parts of the gaol at Gaya in India, where cholera and flies were prevalent. Not only did this milk become infected, but the milk placed in the cowsheds also because infected. The flies harl access both to the cholera stools and to such food as rice and milk.

Tsuznki (l.c.) caught flies in a cholera honse in Tientsin and isolated the cholera vibrios from them by incubating the flies in bouillon and making plate cultures from the bouillon. Flies confined in a cage were also shown to transfer the cholera vibrios from a cholera culture to a culture plate of sterile agar.

Chantemesse (190.5) isolated cholera vibrios from the feet of 
flies serenteen hours after they had been contaninated. Ganon (1908) found that thies could trinsmit infection for at least twentyfour hours after feeding upon infected matter and that during such a period they may be carried long distances in railway carriages. He was mable to show that flies conld retain the power of infecting for more than four days, as the experimental flies did not live longer than that time.

Grahan-Smith (1910) has carried on a few experiments on the distribution of the cholera vibrios by flies. Flies were fed for an hour on a cholera culture emulsified in broth, afterwards they were trimsferred to a fiesh cage. At intervals specimens were canght and cultures were made of hearl, leg; wing, crop, and intestinal contents, the cultures being subsequently plated out and also eximined microscopically. The cholera vibrios were found on the legs up to thirty hours after infection but not later. They persisted in the intestine and crop for forty-eight hours but could not be found after that time. 'The freces passed thirty hours after' feeding were infected.

The foregoing experiments prove beyond doubt the ability of flies to carry the cholera organism both internally and externally, in a virulent condition and to infect food for a significant length of time after feeding upon or coming in contact with infected matter. Among those authors who have expressed their belief in the possibility of flies acting as agents in the dissemination of cholera, the names of Iarpmann (1897) and Geddings (1903) may be mentioned.

\section{Ophthalima.}

Flies are now generally recognised as active and important agents in the spread of ophthalnia, and although, so far as I have been able to discover, we have little bacteriological evidence at present to support this belief, the circumstantial evidence is sufficiently strong to warrant it. Nuttall and Jepson (l.c.) point out that Budd as early as $\mathbf{1 8 6 2}$ considered it was fully proven that flies serve as carrier's of Egyptian ophthalmia.

In speaking of its occurrence at Biskra, Laveran (1880) says that in the hot season the eyelids of the indigenous children are covered with flies, to the attentions of which they submit; in this 
way the infections discharge is carried on the legs and proboscirles of the flies to the healthy children.

Abel (1899) quotes the statements of Howe (1858) to the effect that the number of cases increases rapidly from the moment when flies are present in large numbers. Eye trouble oceurs in the same places when flies are numerous, e.g. the delta of the Nile; in the descrt where there are few flies there are also few calses of ilhess. Natives and especially children are remarkably indifferent to the attacks of flies, they allow the flies to settle in crowris about their eyes, sucking the secretions, and never think of driving them away. It is of interest to note that Howe states that an examination of the flies captured on diseased eyes revealed bacteria on their feet which were similar to those found in the conjunctival secretion. Howard (1911), whose attention was called by Howe to these facts, sent to Egypt for specimens of the flies commonly swaming about the eyes of ophthalmic patients which on examination proved to be 1. . domestica. I have also receired specimens from Egypt.

Dr Andrew Balfour, formerly of the Gordon College, Khartoum, in a letter to me, says that the Koch- Wreeks bacillus is generally recognised as being the exciting cause of Egyptian ophthalmia. He says, "Ophthalmia is not nearly so common in the Suclan as in Egypt, nor are flies so numerous: doubtless the two facts are assocrated." Dr MacCallan, of the Egyptian Department of Public Health, in answer to my inquiries, says that acute ophthalmias are more liable to transmission by flies than trachoma. In his opinion the spread of the latter is, to a compraratively small extent, through the agency of flies, but it is mainly effected by direct contact of the fingers, clothes, etc.

The Kuch-Weeks bacillus was first seen by Koch (1883) in Egypt in cases of acute catarhal ophthalmia. He found that two distinct discases were referred to under that name; in the severe purulent form he found diplococci, which he identified as very probably Gonococei: in the more catarrhal form he fomd snall bacilli in the pus corpuscles. He ascriber the propagation of the discase to flies, which were often seen covering the faces of children. Axenfeld (1908) states that "almost the only organisms occuring in acute "pidenics of catarhal conjunctivitis are the 
Koch-Weeks bacillus (perhaps also influenza bacillus), and the pneumococeus (in Egypt the gonococcus also, rarely subtilis). Other pathogenic conjunctivital organisms ${ }^{1}$ only exceptionally occur:" And, further, "Gonococei and Koch-Weeks bacilli evidently lose their power of causing a conjunctivitis very slowly indeed, and are very independent of any disposition." His statement that "on account of their great virulences and the marked susceptibility to them, a very small number suffices," is important in considering the relation of flies to the spread of the disease, although, as he remarks, cvery infection does not produce the disease. The fact that the Koch-Weeks bacillus cannot resist dryness cannot be urgert as an argunent against the spread of the infection by flies, or the same would apply to the typhoid bacillus, whose carriage by flies is proven. Axenfeld mentions L. Mialler and Lakah and Khouri as adrocating the view that flies may spread the infection more readily. In view of the fact that, as the same author states, "Koch-Weeks conjunctivitis is to be classed with the most contagious infections disease which we know of," it is important that the role of flies should be recognised.

Notwithstanding the occurrence in temperate climates of flies in less numbers than in such comtries as Egypt, it would be well to bear in mind the probable influence of Hies in cases of acute conjunctivitis, such as those described by Stephenson (1897) in England. The sole difference between the disease in Egypt and in England is, as Dr Bishop Harman points out to me in a letter, that "the symptoms produced (in Egypt) are, from climate and dirtiness of the subjects, more severe, and that there is found a greater number of cases of gonorhoeal disease than in England"; and, I would add, a far greater number of thies. This clisease is eminently suited for dissemination by flies, both on account of the accessibility of the infectious matter in the form of a purulent discharge from the eyes and on acount of the flies' habit of frequenting the eyes.

A number of writers, among whom are Braum (188.2), Demetriades (1894) and German (1896), refer to the agency of flies in communicating gonorhoeal and similar infections of the eye.

1 In this comnection he states (p. 236): "We can make the general statement that the Staphylococeus in the conjunctiva is not contagious." 
Abel cites Welander (1896) who describes the infection of a woman in a hospital. This patient's berl was next to that of another patient suffering from blennorrhoea, but a screen which did not reach to the eciling separated the two beds. All means of infection, except through the agency of flies, appeared to be excluclerl. Welander found that flies bore living gonococci upon their feet three hours after they had been contaminated with secretion.

\section{Plague.}

Although fleas are considered to be the chief agents in the dissemination of the plagne bacillus, in spite of the fact that the proof is not as yet considered by all to be absolutely convincing, it is nevertheless interesting from an historical point of view to refer to the ideas that have prevailed and the experiments which have been carried ont in reference to the relation of Hies to plagne. Nuttall and Jepson (1909) refer to the earlier writings on this subject. The prevalence of large numbers of flies during outbreaks of plague has been referred to by Knud as early as 1498 and by Varwich in 1577 . Mercurialis (1577) referred to the contamination of food by flies which had been frequenting plagne patients. The infection of healthy persons by contaminated flies was also suggested by Lange (1791). Haesar (1882) is cited by the abrve authors as referring to Bengasi, Tripolis, where an epidemic of plague occurred in 1858, being known to the Turks by the name of the "Kingdom of Flies."

Yersin (1894) observed the presence of dead flies in the laboratory in which antopsies on plagne animals were made. $\mathrm{He}$ demonstrated the presence of virulent plague bacilli in such dead flies by inoculation experiments. Nuttall (1897) conclusively proved that flies were able to carry the plague bacillus and that they subsequently died of the disease. The flies were fud on organs of animals which had died of plague. He found that such flies might survive eight days at $12-14^{\circ} \mathrm{C}$. and that they still contained the virulent bacilli for forty-eight hours or more after they were transferred to clean vessels. At temperatures of $14^{\circ} \mathrm{C}$. and higher, the infected flies died more quickly than did the control flies which had been fed on the organs of healthy animals. 
In two of the experiments the infected flies were all dear on the seventh and eighth days respectively at temperatures of $14^{\circ} \mathrm{C}$. These facts indicate that flies should not be allowed to have access to the bodies or excreta of cases of plague or to the food.

\section{SMALLPOA.}

Nuttall and Jepson (l.c.) give one reference only to flies in relation to small-pox. Hervieux (190t) states that laforgue at Tamorna-Djedida, Province of Constantine, observed that during an epidemic of small-pox at that place all the children who were attacked lived in the south-west of the village and there was no small-pox in the northern part of the village. This distribution of the disease was attributed to the direction of the prevailing winds, and observations indicated that flies and mosquitoes were distributed with the wind. Laforgue believed that flies played an important part in spreading the virus of small-pox.

\section{DiphTHERIA.}

While it is hardly likely, as Nuttall and Jepson have pointed ont, that under natural conditions flies would play any part in the dissemination of diphtheria, it is conceivable that, if the necessary conditions of infection occurred they would carry the infection. Dickenson (1907) cites Smith (1898) who carried out the usual and hardly valuable experiment of allowing flies to walk over infected matter and afterwards over culture media, with the natural positive results. The unreliable character of such experiments is indicated by the results of the experiments which GrahamSmith (1910) carried out with Bucillus diphtheriue. Two series of experiments were made. In the first flies were allowed to feed for thirty minutes on an emulsion of $B$. diphtheriue in saliva and then transferred to a fresh cage. At intervals from one hour up to seventy-two hours after feeding flies were killed and cultures were made on transparent serum medium from their legs, wings, heads, crops and intestinal contents. In the second series of experiments the flies were allowed to feed for one hour on an emulsion of $B$. diphtherice in broth and afterwards they were treated similarly to the flies in the first series. From the 
tabulated results it wonld appear that $B$. diphtherice seldom remains alive on the legs and wings for more than a few hours. In the crop and intestine they may live for twenty-four hours or occasionally longer. The faeces passed during the first few days after infection are frequently infected. These experiments would indicate, therefore, the ability of the house-fly to carry infection if suitable conditions occur.

\section{Yaws (Framboesia tropica).}

This disease which is widely distributed throughout the tropics and is especially common on the west coast of Africa is extremely contagious. It is characterised by ulcerous papules which develop into fungus-like incrustations of a spreading and intensely disagreeable nature. Gudger (1910) has called attention to a very early suggestion that flies carry the infection of this disease. This is contained in Bancroft's Essay on the Nutural History of Guiuna in South America which volume was published in 1769. The author states: "The yaws are spungey, fungous, yellowish, circular protuberances, not rising very high, but of different magnitules, usually between one and three inches in circumference. These infest the whole surface of the body, and are commonly so contiguous that the end of the fingers cannot be inserted between them; and a small quantity of yellowish pus is usually seen adhering to their surface, which is commonly covered with thies through the indolence of the Negroes. This is a most troublesome, disagreeable disorder, though it is seldom fatal. Almost all the negroes once only in their lives, are infecter with it, and sometimes the whites also, on whom its effects are much more violent. It is usually believed that this disorder is communicated by the flies that have been feasting on a cliseased object, to those persons who have sores, or scratches, which are uncovered, and from many observations, I think that this is not improbable, as none ever receive this disorder whose skins are whole: for which reason the Whites are rarely infected, but the backs of the Negroes being often raw with whipping and suffered to remain naked, they scarce ever escape it."

Gudger (l.c.) also calls attention to Koster's Trurels in Brazil 
in the yeurs from 1809-1815, published in Philadelphia in 1911 in which this anthor says, in reference to yaws: "This horrible disorder is contracted by inhabiting the same room with a patient and by inoculation; this is effecter by means of a small fly, from which every precaution is often of no avail. Great numbers of the insects of this species appear in the morning, but they are not so much seen when the sun is powerful. If one of them chances to settle upon the corner of the eye or month, or upon the most trifling scratch, it is enough to inoculate the bobus, if the insect comes from a person who labours with the disease." In reference to these two statements, as in many others where the worl "flies" is nsed, it may not be $M$. domestica to which the authors refer, in firct the statement that the Hies "are not so much seen when the sun is powerful" militates against the idea, although it does not in the least diminish the possibility of their being active agents in the dissemination of infected matter.

Other observers adduce similar evidence. Wilson (1868) states that in the West Indies there is a prevalent belief that Hies conver the disease from one person to another. Two cases are reported by Hirsch (1896) for which he believed thies were responsible. Both patients were living among Fijian children who were affected with the disease. The necessary raw places for the reception of the infection were present, one patient having an uncovered ulcer and the other sores on his feet, both of which exposed surfaces would attract flies. Cadet (1897) also points ont that skin lesions such as ulcers, the bites of insects or other animals, scratches, etc., are necessary for infection which may take place and through direct contact of infected clothes or by means of flies carrying the diseased secretions on their legs.

Experimental evidence is brought forward by Castellani (1907). He allowed M. domestica to feed mpon infected matter obtained by scraping slightly ulcerated papules. They were also fed upon the semi-nlcerated papules on the skin of three yaw patients. In both cases Spirochaeta pertenuis, the causative organism of this clisease, was found in microscopic preparations made from the mouth parts and legs of the flies. Monkeys were also infected with the disease by allowing specimens of $M$. domestica which had been fed as in the previous cases to come in contact with lesions made on the 
eyebrows of the monkeys. Castellani is of the opinion that yaws is generally transmitted from person to person by direct contact but under certain circunstances it may be conveyed by flies and posibly by other insects.

Robertson (1908) took about 200 flies which had been captured on yaws lesions and shook them up in sterile water. After standing for twenty-fom hours the water was centrifugalized and smears were made from the precipitate. In fom slides the organism Spirochaetu pertenuis were found.

In St Lucia, Windward Islands, Nicholls (1912) after studying the disease concluded that the majority of cases of yaw in the West Indies were cansed by the inoculation of surface injuries by the fly Oscinis pallipes. This insect feeds on the skin discharges of man and other animals. The flies are very persistont and engorge themselves with pus, blood, serum or sebaceous secretion.

\section{LEProsy.}

Experiments with flies and human and rat lepra are recorded by Wherry (1908). It was found that such flies as $M$. domestica, C. vomitoria and Lucilia caesur take up enomoms quantities of lepra bacilli from the carcase of a leper rat and deposit them with their faeces; but the bacilli apparently do not multiply in the intestinal tracts of the flies, as the latter are clear of bacilli in less than firty-eight hours. Larvae which have hatched out in the carcase of a leper rat become heavily infected with lepra bacilli. When they are removed and fed upon uninfected meat they pass out most of the lepra bacilli and the flies hatching out from the pupae of these larvae are generally uninfected. If the larvae of C. vomitoria be fed almost continnonsly on the carcase of a leper rat they remain hearily infested with lepra bacilli and on pupating such heavily infested specimens appear to be incapable of further development.

A house-fly, $M$. domestica, caught on the face of a human leper was found to be infected with lepra bacilli. At the beginning of the observation these were few in number but on the third day more than 1115 lepra-like bacilli were present in each speck deposited. However, only one bacillus was found in the specks 
deposited between the third and sixth days. The acil-prosf bacilli in the fly were not infective when injected into the sul)cutaneous tissue of the guinea-pig.

Ixthenf (1912) has studied the rlissemination of the leprous bacillus by the honse-fly. Flies (M. domestica) fierpuently settle on leprous ulcers loft exposed. Of twenty-three flies caught on such ulcers known to contain many bacilli, nineteen were fombl to contain the leprous bacillus in their intestines. The bacilli were sometimes present in very large numbers and were excretied in the faeces of the flies and showed no signs of degeneration even after a day or more in the intestine of the fly. Bacilli were fomm in flies eanght in the room and not directly on the ulcers but they occurred less frequently in such cases. The author examined twenty-three flies canght in his own house which was situated about one hunclied and fifty yards from the hospital reserved for very advanced cases of leprosy, but in no case did he fincl the leprous bacillus, which he takes as indicating that the range of dissemination is not very great. While the foregoing experiments wonld indicate that $M$. domestica is capable of disseminating the bacillus, it apparently can be infected only from patients who present open lesions or from infected discharges. B. leprae was not found in twenty-nine flies caught in rooms of patients with only nervous symptoms or with unbroken skin lesions. Lebceuf concludes: (1) that $M$. domestica is capable of absorbing enormous quantities of the leprous bacillus; (2) that the bacillus is found in large quantities, apparently in perfect condition, in the excrement of infected flies; (3) that there does not appear to be any multiplication of the bacillus within the fly, but the organism does not seem to be degenerate: (4) that it is possible that flies passing from a leprous patient and depositing their excrenent on the nasal orifices, perhaps during sleep, or upon raw cutaneous wounds of otherwise healthy persons living in the immerliate neighbourhood of leper patients, may disseminate the bacilli in this way.

Minett (1911) has also discussed the question as to the dissemination of leprous bacilli by flies.

These experiments and observations, although conducted with a comparatively small number of flies are, I think, sufficiently 
conclusive to warrant the conclusion that, under the conditions indicated by Lebunf, namely, abundance of Hies, proximity of leprons ulcers or infected diseharges and exposed places for infection on healthy persons, house-flies are able to transmit the leprons baeillus.

\section{DYSENTERY.}

It would appear to be not improbable that flies, in view of their relation to typhoid fever, should sometimes be agents in the spread of dysentery. The etiology of this disease has been a matter of considerable controversy but it is generally accepted now that in the bacillary type of the clisease one of the eausative organisms is $B$. dysenteriae, these organisms being regarded as the canse of epidemic drsentery, while in the sporadic or endemic dysentery, usually known as amoebic dysentery, the causative organism belongs to the Amoebu group of protozoa, of which there are probably several species. The possibility of flies carrying the infeetion of both types of disease appears to me to be highly proballe, especially in the amoebic type of the disease. The amoebae multiply on the intestine by fission and are passed ont with the faeces. When the faeees become hard the amoebae encyst. It is not unreasonable to suggest in view of positive evidence in other cases of a similar nature, that flies bred in or feeding upon infected faeces, might ingest the amoebic cysts and with these infeet food.

Unfortunately we have no exact evidence as to flies carrying dysenteric infection. Sinith (1903) states: "An old idea of some Anglo-Indian surgeons was that dysentery could be caught by using the same latrine as a dysentery patient. There may be something in this...the ubiquitous fly may, therefore, be a dysentery inoculator in open camp latrines." While such inoculation is not unlikely, the probability of flies infeeted in the latrine visiting food or patients in the hospital is greater. The pusibility of thies playing in dysentery a similar part to that which they do in typhoid and cholera is referred to by Bergey (1907). An epidemic of one hundred and thirty-six cases of drinentery which oceurred in an insane asylum at Woreester, 
Massachusetts, U.S.A., is describer by Orton (1910) who considererl that honse-flies were responsible fin the epirlenice In this paper which contains interesting olservations on the breeling of the thies in spent hops and malt barley, the anthor clescribes experiments which were carried ont with a view to testing his hypothesis. The possibility of infection being distributed in such an institution was appreciated to a greater extent owing to the difficulty of confining the intestinal discharges to the proper place. The clothing and bedding of the patients were brought to the laundry in which flies were abundant. In the experinents B. prodigiosus, being casily recognisable, was exposed in the laundry. This bacillus was recovered from flies subsequently at intervals in other rooms of the hospital. Such results would appeal to indicite a strong probability of the carriage of the dysenteric organism meler similar conditions which were known to exist.

I feel conficlent that firther investigations into the relation of house-tlies to the distribution of the causative organisms of dysentery of both types, batillary and amoebic, will give positive results'.

\section{OrIENTAL SORE.}

This skin disease which is characterised by a slowly spreading, ulcerating condition of the skin is endemic in certain tropical and sub-tropical regions such as Northern Africa, Sahara (Biskra), Egypt, Asia Minor, Mesopotamia (Bagdad) and India. Wright in 1903 discovered the so-called Leishman parasites in the granulation cells. Manson also discovered the same organism in cases of oriental sore and considered them, or a parasite morphologically identical, as the cansative organism of the sore and the latter investigator (1907) suggested that flies, bugs or other insects might be responsible for the indirect method of infection.

1 Frontowski (1913) infected the larvae of various flies including $M$. domestica with $B$. dysenteriae and allowed them to pupate. An examination of the faeces of the resulting flies gave negative results. The author elaborated Auche's experiments with adult flies and came to the conclusion that the bacteria can retain their virulence when on the feet or proboscis, or in the alimentary tract of the fly. whence they are eventually voided with the excreta. Wherever flies have free access to food and to infected human faeces the danger of dysentery and, according to Krontowski, epidemic typhus is great. 
Wenyon (1911) has recently made a very thorough study of oriental sore in Bagdad in which he investigated the possible relation of house-tlies to the disease. He found that house-flies appearerl to diminish in numbers to some extent during the hottest part of the summer when the maximum shade temperature reached $110^{\circ} \mathrm{F}$. Flies swarm abont the faces of the children, especially those having the sore. Such Hies collected from the face of a child suffering from an ulcerating type of sore are found to have the intestine filled with the exndation of the sore in which the parasites (Leishmania tropica) were readily found. Such a $\mathrm{Hy}$ feerling immediately afterwards upon some fresh abrasion of the skin must certainly in a number of instances inoculate the sore parasite. The parasite could not be found in the intestines of Stomorys feeding on the faces of children with sores. In infection experments with house-flies no evidence of the development of the sore parasite could be found and they seemed to disappear quickly. Wenyon conchdes that the limited distribution of the disease and the widespread prevalence of the house-fly would not appear to confirm the view held by some authorities that the house-fly is the normal carrier of the disease organism.

In discussing tropical sore Nuttall and Jepson (1910) record Seriziat's assertion that flies convey "Bouton de Biskra." In his study of the disease at Biskra, Laveran (1880) found that from September to October the slightest wound tends to become a sore. He has seen it develop from small pimples and pustules and from wounds cansed by burns or blisters. He believed that flies carried the virus on their feet and proboscides and thus ristributed infection.

There is no doubt that in tropical countries the organism of the various types of sore can be mechanically transferred by Hies from the granulated areas to new wounds and thereby inoculate the same. Its spread by Hies would be governed by their abundance, by the viability of the organism of the fly and the opportunities for obtaining and distributing infection. In this connection the observations of Patten ${ }^{1}$ (1912) are of interest. Referring to an idea entertained by some workers at one time 
that Hies inight act as one of the carriers of the tropical clisease Kala-Azar, a disease cansed by a species of Leishmuniu, he staterl that two years ago he had fed a large number of bred homse-flies (Musce rebulu, an Indian species) on fresh splenic juice and hat fomd that the parasites disalpearerl from the alimentary tract in a few hours. It was difficult, therefore, to understand how the parasite conld be transmitted in this way. Such an obscrvation was against the theory that flies feeding upon the discharge from an ulcerated sore might carry the infection. In another paper Patton (1912) gives further details and states that flies fed upon the discharge from the sores and afterwards on abrasions or scratches did not produce the sore although the experiment was carried out daily for about a month. The same investigator has since brought forward very conclusive evidence as to the organism being carried by the berl-bug.

\section{S'YPHILIS.}

I have been able to discover one reference only to the possibility of flies acting as agents in the spread of this disease by the mechanical transfer of the Spirochaeta, the syphilitic organism, from a patient to a healthy person. Dr. Kerr of Moroceo, in a paper on "Some Prevalent Diseases in Moroceo," read before the Glasgow Medico-chirurgical Society (Dec. 7th 1906), described epidemics of syphilis, where, according to the author, the disease was spread by flies which had been feeding upon the open sores of a syphilitic patient. 


\section{CHAPTER XXIV}

\section{MISCELLANEOUS EXPERIMENTS ON THE CARRIAGE OF MICRO-ORGANISMS BY FLIES, BY BOTH NATURAL AND ARTIFICIAL INFECTION}

Ix addition to the experimental evidence which has accumulated on the relation of thies to specific diseases, there are also on record a considerable number of experiments on the carriage of various micro-organisms, not in every case pathogenic, by flies. As these experiments have usually some particular interest I have bronght together such as seemed worthy of record.

I have previously recorded (1910) a very interesting series of experiments carried ont in 1908 by Giissow. Their particular interest lies in the fact that they clearly demonstrate the varied bacterial and fungal flora which the house-fly normally carries.

Giissow's experiments were as follows:

$$
\text { Experiment No. } 1 .
$$

A fly was caught in his living room (Norwood, London) at 10 a.m. on Nay 4 th and allowed to walk orer nutrient agar-agar in a Petri dish; the necessary precautions being taken to prevent extraneous infection of the inedium. The Petri dish was placed in an incubator and kept at $28-30^{\circ} \mathrm{C}$. At 6 p.m. on the same day there were plain indications of colonies forming, but they were too small to allow a separation count.

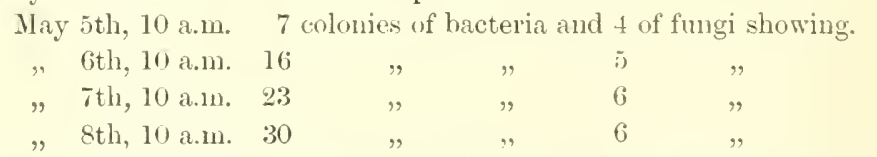

That is, in 96 hours, 30 colonies of bacteria and 6 colonies of fungi were observed.

The fungi were exanined and identified as follows:

$$
\begin{aligned}
& \because \text { colonies of Succharomyes sp. } \\
& 2 \text { Penicillium glaucum } \\
& 1 \text { colony of Aspergillus nigur } \\
& 1 \text { Cludosporium herburnm }
\end{aligned}
$$


The bacteria were removed in the ordinary manner and were sul-cultured, plated out and identified as follows:

$\begin{array}{lcccc}\text { Micrococcus ureat } & \ldots & \ldots & 2 & \text { colonies } \\ \text { Bacillus subtilis ... } & \ldots & \ldots & 7 & , \\ \text { Bacillus coli commune } & . . & \ldots & 11 & , \\ \text { Sarcinu luted } \ldots & \ldots & \ldots & 2 & " \\ \text { Bacilli stained by Gran } & \ldots & 3 & " \\ \text { Bacilli not stained by Grim ... } & 5 & ,\end{array}$

Experiment No. 2.

A fly was canght at 11.30 a.m. on May thl out of doors on Central Hill, Norwood, London, and was allowed to walk over nutrient agar-agar at 12 o'clock noon.

May 4th, 6 p.m. Colonies were plainly fonning.

$" 5$ th, 10 a.m. 13 colonies of bacteria and 6 colonies of fungi.

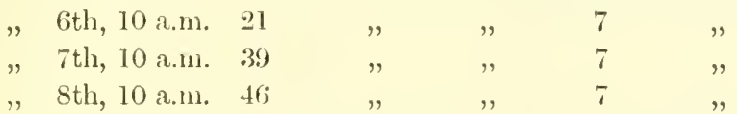

That is, in 94 hours, 46 colonies of bacteria and 7 colonies of fungi were obtained from this fly No. 2. The fungi were identified as follows:

$$
\begin{aligned}
& 2 \text { colonies of Macrosporium sp. } \\
& 3 \text { M'nicillium gluncum } \\
& 1 \text { colong of Cladosporium herbarum } \\
& 1 \text { "Musarium roseum }
\end{aligned}
$$

\begin{tabular}{|c|c|c|c|}
\hline Bucillus tumescens & $\ldots$ & .. & 18 colonies \\
\hline Mierococcus pyogenes & cureus & ... & 9 \\
\hline Surcinu lutes ... & $\ldots$ & & 2 \\
\hline Surcine ventriculi & $\ldots$ & & 1 colony \\
\hline Bucillus amylobacter & $\cdots$ & . & 4 colonies \\
\hline Acid-fast bacillus & $\ldots$ & $\cdots$ & 1 colony \\
\hline Bacilli stained by $\mathrm{G}$ & ram & $\ldots$ & 4 colonies \\
\hline Bacilli not stained $k$ & y Gra & & 7 \\
\hline
\end{tabular}

The bacteria after being sub-cultured and plated out were identified as:

\section{Experiment Ho. 3.}

This experimeut was perhaps the most interesting of the three as the fly was eaptured at 10.30 a.m. On May 4th on a dust-bin (Norwood, London), a situation in which flies are frequently found. It was allowed to walk over the surface of nutrient agar-agar.

May 4th, 6 p.m. Signs of colonies observed.

" 5th, 10 a.m. 18 colonies of bacteria and 7 colonies of fungi.

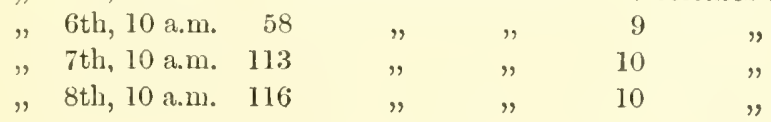

H. H,-F. 
That is, after $95 \frac{1}{3}$ hours, 116 colonies of bacteria and 10 colonies of fungi were obtained from this single fly. The fungi were itlentified as:

$$
\begin{aligned}
& \text { Penicillium glaucum } \quad . . \quad \ldots \quad+\ldots \text { colonies } \\
& \begin{array}{llllll}
\text { Eurotium sp). } & \ldots & \ldots & \ldots & 1 & \text { colony }
\end{array} \\
& \text { Sucharomyces sil. } \quad \text {.. } \quad \ldots \quad 2 \text { colonies } \\
& \text { Fusurium roseum } \quad \text {... } \quad \text {.. } 1 \text { colony } \\
& \text { Aspergillus niger } \quad \ldots \quad \ldots \quad 1 \quad, \\
& \begin{array}{lllll}
\text { 1/ucor rucemosi } & . . & \ldots & \ldots & 1
\end{array}
\end{aligned}
$$

\begin{tabular}{|c|c|c|c|c|}
\hline Bucillus coli comm & $e \ldots$ & . & 34 & 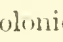 \\
\hline Bucillus subtilis... & $\ldots$ & $\ldots$ & 16 & " \\
\hline Bucillus tumescens & $\ldots$ & .. & 8 & $"$ \\
\hline Brecilliss lactis acidi & $\cdots$ & $\ldots$ & 4 & " \\
\hline Surcina latea $\quad \ldots$ & $\ldots$ & $\ldots$ & 12 & " \\
\hline Sarcina ventriculi & & $\ldots$ & 2 & " \\
\hline Wierococcus pyogenes & uureus & $\ldots$ & 21 & , \\
\hline Mierococcus ureue & $\ldots$ & $\ldots$ & 11 & , \\
\hline Acil-fast bacilli... & ... & $\ldots$ & 2 & $"$ \\
\hline Bacilli stained by $\mathrm{G}_{1}$ & ram & $\ldots$ & 4 & $"$ \\
\hline Bacilli not stained b & $\mathrm{Gr}$ & $\ldots$ & 2 & , \\
\hline
\end{tabular}

The bacteria after having been sub-cultured and plated out were identitied as :

The extremely large number and preponderance of bacilli carried by this Hy No. 3 shows very strikingly the infection which a fly frequenting such miscellaneous household refuse as is contained in the average household dust-bin or garbage may carry, and the results of such careful experiments as those which are recorded above demonstrate clearly not only that flies normally carry about the spores of fungi and bacteria and the extra infection which they obtain by frequenting refuse, but also their liability to carry and disseminate such bacteria, pathogenic and non-pathogenic, with which they may come into contact in their wanderings.

Manning (1902) obtained cultures of the following bacteria from infected flies: B. pyocyaneus, Stuphylococcus pyogenes aureus, B. typhi-abdominulis, and B. coli commune.

If flies have access to wounds of an inflammatory and suppurative nature they are liable to transport the Stuphylococci to other spots. Buchanan (1907) allowed M. domestica to walk over a film of Staphylococcus pyogenes aureus from an abscess, and afterwards over agar; a mixed growth resulted, in which $S$. pyogenes aureus predominated. Buchanan (l.c.) also experimented with the bacillus of swine fever. Nine blow-flies (C. vomitoria) were caught 
on the carcases of pigs which had dierl from swine ferer during an epidemic in 1905. Each fly was allowed to walli orer an agar culture plate for abont one minute. From one of the plates the bacillus of swine fever wats isolaterl. The flies were swarming on the carcases of the dead animals and were froguently seen to pass directly from each somce of infection to the fecding troughs of the pigs.

Strphylococci were found by Joly (189S) on a house-fly canght in the laboratory. Celli (l.c.) also records experiments which indicated that $S$. pyogenes aureus retains its virulence after passing through the intestine of the fly.

Reference has been previously made to experiments with Bucillus prodigiosus which was used on account of its suitability in the case of experiments with flies, being non-pathogenie, nonspore-bearing and easily recognisable. There are a number of records of other experiments on the carriage of the bacillus by Hies.

Abel (1899, eited by Nuttall and Jepson) refers to an experiment of Otto Helm in 1875 who stated that the slimy masses containing the bacillus "Monus prodigiosus" are easily convered from one food substance to another. Abel placed cultures of B. prodirgiosus and clean potatoes in different parts of a room. Tho the potatoes he added putrid meat so that the odour would attract the Hies. After $2-3$ days colonies of $B$. prodigiosus appeared in all the potatoes. Negative results were obtained when the room was rid of thies. Similar experiments by Burgess are mentioned by Hart and Smith (1898). Flies were fed on material containing B. prodigiosus and then aliowed to fly in a large room. After a few hours the Hies were recaptured and allowed to walk over slices of sterilised potato on which colonies of the bacillus subsequently developed. Abel records two instances in which he observed spontaneous infection of food by thies in houses where they were abundant. Flies were captured in these houses and placed singly in tubes containing sterilised potato. Seven of twenty-eight flies so captured in one house gave $B$. prodigiosus and a similar positive result was given by three out of thirty-three flies canght in the other house. Abel accordingly points out the possibility of thies carrying the bacilli of typhoid and cholera in a similar manner. 


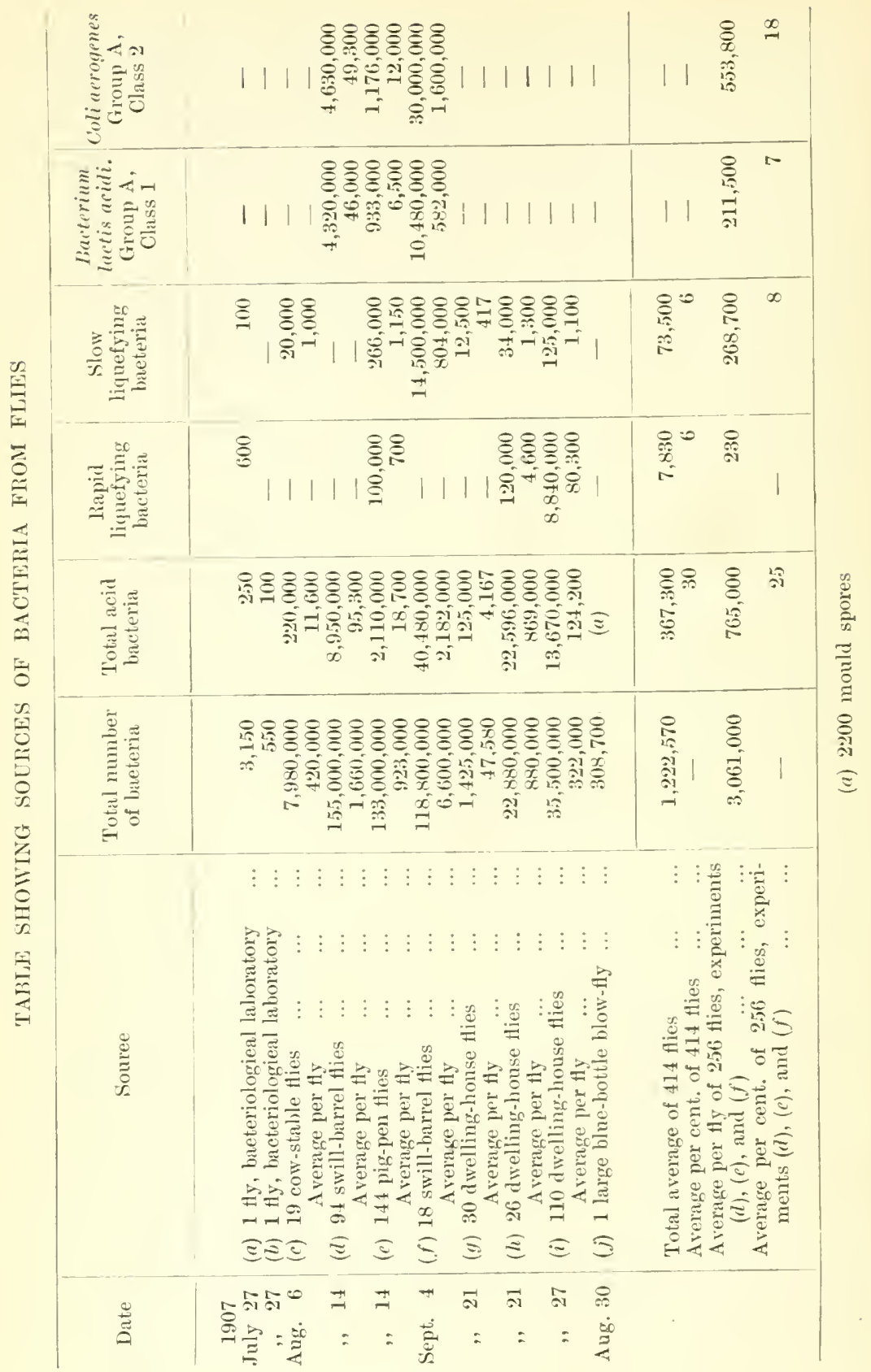


In 1907 experiments were carried ont by 1)r. M. B. Armold and inyself with B. prodigiosus. Flies which had just energed from the pupae, and therefore not alrearly contaminated with an extensive bacterial flora, were allowed to walk orel a film of the bacillus, after which they were confined to sterile glass tubes. At varying perjods they were taken ont and allowed to walk over the enlture plates. Those eontained for over twelve hours retained the bacillus on their appendages and transferred them subsequently to the eulture media, but they were not recovered from those Hies which were kept in confinement for twenty-four hours; a large number of Hies, however, were not used.

In diseussing the relation of thies to typhoid ferer reference was made to the infeetion of milk. In this connection an interesting investigation was made by Esten and Mason (1908) on the rôle which flies play in the carriage of bacteria to milk.

The thies were caught by means of a sterile net; they were then introduced into a sterile bottle and shaken up in a known quantity of sterilised water to wash the bacteria from their borlies and to simulate the number of organisms that would come from a fly falling into a quantity of milk. 'They summarised their results in the table given on the opposite page.

While the counts of the bacteria ean only be considered as comparative the results indicate clearly the nature of the source of infection. Commenting on these results the authors state that " early in the fly season the numbers of bacteria are comparatively large. The place where flies live also determine largely the numbers they earry."

\section{Poliomyelitis.}

Experiments have been carried on and are being continued by Flexner and Clarke (1911) on the contamination of the house-fly with the virus of poliomyelitis, more generally known as infantile paralysis or spinal meningitis. It was found that flies contaminated with the virus of poliomyelitis harboured the virus in a living and infectious state for at least forty-eight hours. It was not shown that this is the limit of the period of survival and the experiments threw no light on the question as to whether the virus is retained merely as a superficial contamination or whether it could survive 
in the Hy's gut. Further experiments recorded by Howard and Clarke (1912) demonstrated that $M$. domestica retained the rirus either in or on their bodies for at least twenty-four and forty-eight hours respectively. They also showed that the virus may remain in a viable condition in the alimentary tract of the fiy for at least six hours. The possibility of Hies obtaining infection from the infected discharges from the nose and throat or intestine is indicated. Further reference to the transmission of this disease is made under Stomoxys calcitrans.

\section{Trypunosomes.}

On account of its non-blood-sucking habits, few experiments have been carried out with a view to demonstrating the possibility of $M$. domestict carrying Trypanosomes. Referenee has aheady been made to investigations on the relation of flies to the allied organisms causing Tropical Sore. Experiments are recorded ${ }^{2}$ in which 1. . domestica was fed for 3-4 minutes on blood fiom a guinea-pig infected with Trypunosoma hippicum; after an interval of about 30 seconds the flies were placed orer the scratched skins of mules for about five minutes and it was demonstrated that this trypanosome may be transmitted by the flies ${ }^{2}$.

surete.

Mitzmain (1913) states that in experiments with Stomorys culcitrens and live stock, Sura organisms have been demonstrated in the mouth parts and stomachs of house-flies.

\section{Dunysz rims.}

An interesting experiment on the carriage of Danysz rat virus was carried out by Graham-Smith (1910). Flies artificially infected with the virus by feeding were allowed to settle and feed on a piece of bread soaked in milk. After one hour the bread was given to a mouse. A mouse which had fed upon bread given to flies forty-eight hours after infection died in two days and the virus was isolated from the spleen; another nouse ferd on bread given to the flies four days after infection died in two days. In

1 Report Thept. Sanit. Isthmian Canal Comm., Dec. 1911, pp. 42, 43.

2 The possibility of $M$. domestica acting as a vector of $T$. hippicum is convincingly treated by Darling (1913) who suggests that more attention be paid to the possible relation of $M$. domestica to trypanosome diseases. 
another experiment a mouse was ferl on breat soaked in an emulsion of the Hlies' fieces passerl about forty-eight hours after infection and scraperl from the walls of the cage. 'The mouse died in two days and the organisn was isolated from it. 'These experiments showed that flics which have fed on the virus are capable of infecting to so great an extent fool on which they settle and feed that mice fed on it became infected.

\section{Rubies.}

Experiments with a view to discovering whether flics would carry the virus of rabies obtained during the larval state have been carried nut by Fermi (1911). In the first series of experiments the author fed Hy larvae on the brains of rabies cases and then tested their virulence by emulsifying and injecting subcutaneonsly. In a second series a fixed virus and fly larvate were rubbed into an emulsion and likewise injected subcutaneonsly. The results inclicate that rabies virus cannot be transmitted through fly larvae. It appears that the fly emulsion has an attenuating effect upon a fixed virus, either through its direct action upon the virus or through its iudirect action upon the organism. It possesses no absolute lyssicirlal power since a virus mixed with fly larvae emulsion is found to be virulent when administered subclurally.

\section{Fungul spores.}

In the experiments of Guissow, already mentioned, it was shown that flies normally carry the spores of monlds such as Penicillium, Eurotium, Mucor, yeasts, etc. Consequently their frequent infection of food materials, which may be observed if attention is given to the matter, is readily understood. Gayon (1903) also cultivated several species of moulds from flies which he canght and dropped into nutrient gelatin. Experimenting with yeasts, Graham-Smith (1910) found that the yeast organisms did not appear to survive for more than a few hours on the legs and wings, but that they could be found in cultures of the crop and intestine for at least three days, and were present in the faeces 48 hours after the Hy had been infected.

Cobb (1906) made studies of the extent to which flies transported the spores of a fungus attacking sugar cane. The feet of 
a Hy which had been feeding upon the spores of this fungus left tracks of fungal spores on the sides of the glass vessel in which it had been eontained. The spores fron five of the tracks were calculated and the number of spres per track was estimated to be 860,000 . The possibility of the spores being carried by flies in this way was inclicated by the fact that such spores germinated uncler suitable conditions.

Bacteria on flies coptured under nutural conditions.

In addition to the investigation of Giissow, which I have recorled at the beginning of this chapter, a series of earefully conducted experiments has been carried out by Cox, Lewis and Glym (1912) with a view to ascertaining the number and varieties of bacteria carried by flies infeeted under natural conditions in sanitary and unsanitary city districts in Liverpool. The flies were eaptured in sterilised wire traps which were exposed for twentyfour hours. Flies from various districts were allowed to swim in measured quantities of sterile water to simulate the pollution of liquids when flies fall into them and to estimate the rate at which the bateria are given off. This experiment also served to indicate the comparative number of bacteria set free from the bodies of flies from dirty or more cleanly areas. The same flies were afterwards ground $u p$ in a sterile mortar with a sterile pestle to find the gross number of bacteria earried on and in a $\mathrm{Hy}$ and to ascertain whether the number carried inside a Hy is always greater or less than the number set free even after struggling in a liquid for 30 minutes. Over 450 naturally infected Hies were caught during September and the early part of October 1911 in different parts of the eity of Liverpool and the number and kinds of bacteria earried and contained by them were investigated. Their experiments showed that:

1. The number of bacteria derived from flies while struggling in a liquid may be very large and increase with the time they remain in the liquid. The number of bacteria varies from 2000 , the lowest figure for five minutes, to 350,000 , the highest figure for 30 minutes. This number may be taken as a measure of their capacity to pollute liquid with their vomit, excreta or bodies. The number of 
bacteria carried inside the Hy is very mueh greater than those carried externally.

2. Flies caught in insanitary or congesterl aneas of the city earried and contained far more bacteria (aerobic), including those of the intestinal group, than flies from the more sanitary, that is, cleaner, liss congested or suburban districts. The number of aerobic bacteria obtainer from flies eaught in insanitury districts varied from $\$ 00,000$ to $500,000,000$ per Hy; Hies from the eleaner or less congrested areas gave from 21,000 to 100,000 bacteria per fly.

3. Flies caught in the dwelling rooms of different corporation houses forming two sides of a street abont 400 yards long which constituted a sanitary "oasis" in the middle of a slum district earried and contained less bacteria of all kinds than those from the dwelling rooms of a street with insanitary property on each side.

4. The number of intestinal bacteria as indicated by glucose bile salt fermenters is greater in insanitary or congested areas, where they vary in number from 10,000 to $333,000,000$ than in the more sanitary areas where from 100 to 10,000 are carried per fly.

5. Pathogenic bacteria and those allied to the foodpoisoning group were only obtained from the congested or moderately congested areas and never from the suburban districts.

6. Flies caught in milk shops apparently carry and contain more bacteria than those from shops with exposed food in a similar neighbourhood. The authors attribute this faet to the milk being a suitable eulture medium for bacteria after having been inoeulated by the flies, later they re-inoculate themselves.

7. A comparison of the number of bacteria earried by flies and blue-bottles eaught in an eating-house opposite to slaughter-houses showed that the latter earried a mueh greater number. 
The morphological characters and cultural reactions of 123 strains of baeteria were examined by the authors. Among those identified were two streptococci and several Stuphylococci and stecince. One hundred and six were small gram-negative nonspore-bearing bacilli; these were grouped as follows:

Chromogenic group: two strains of $b$. pyocyunens were isolated from thies from a knackers' yart.

Colon group: 41 colonies of this group were picked off haphazard and elassified aceording to McConkey as follows:

B. acidi lactici type _.. 1995 per cent.

B. coli conmunis type ... 12.2," "

B. neupolitanus type ... $195 \%$ " "

B. lactis aerogenes type ... 46.4 ", ",

Sulmonella group: one bacillus gave identical reactions to $B$. enteritidis Gaertner, except that the serologieal tests were negative.

Horgun's Infuntile Diumhoeu group: one identical to Horgan's No. 1, and many other's closely resembling it and Morgan's Nos. 2 and 3 were obtained.

Others were included in the proteolytic, acid lactosesucrose (saecharose), and miseellaneons groups.

The anthors conclude: "It is clear that Hies from the suburbs where infantile diarrhoa is rare earry far less bacteria than those in the city where it is common. It was, nevertheless, impossible in the time at our disposal to correlate exactly the number or varieties of bacteria carried by flies in the city with the number of cases and deaths from infantile diarrhœa in indiridual streets.

"As the amomnt of dirt carried by flies in any particular locality, measured in terms of bacteria, bears a definite relation to the habits of the people and the state of the streets it demonstrates the neessity of efficient municipal and domestic cleanliness if the food of the inhabitants is to escape pollution, not only with harmless but also with occasional pathugenic bacteria."

In his study of the micro-organisms carried by flies under normal conditions to which reference has already been made (p. 245), Graham-Smith found that more than one-third of all the flies examined were infeeted with lactose-fermenting bacilli of the colon type. 


\begin{tabular}{|c|c|c|c|c|c|c|c|c|c|c|c|c|}
\hline \multirow{6}{*}{\multicolumn{2}{|c|}{ है }} & 怤 & $\stackrel{3}{=}$ & 0 & $\stackrel{2}{2}$ & $\therefore$ & $\therefore$ & $=$ & $=$ & $\stackrel{\infty}{\Xi}$ & $=$ & $\begin{array}{l}: \\
\stackrel{2}{9}\end{array}$ \\
\hline & & $\overrightarrow{\widetilde{J}}$ & $\stackrel{5}{3}$ & is & 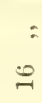 & $=$ & $=$ & $=$ & $=$ & $=$ & $\stackrel{2}{=}$ & : \\
\hline & & $\hat{0}$ & & $\stackrel{\infty}{\Xi}$ & $=$ & 1 & $\underset{: 1}{2}$ & $=$ & : & : & : & 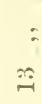 \\
\hline & & 芯 & & $\stackrel{2}{\tilde{E}}$ & & | & $\underset{\cong}{\Xi}$ & 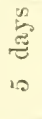 & $=$ & $\stackrel{\dot{D}}{\Xi}$ & $\begin{array}{l}\stackrel{n}{\mathrm{E}} \\
=\end{array}$ & Si \\
\hline & & $\begin{array}{l}气 0 \\
\Xi \\
\Xi\end{array}$ & & 1 & & | & $\underset{\text { aी }}{\stackrel{\infty}{\Xi}}$ & $=$ & : & $=$ & : & 胥 \\
\hline & & $\stackrel{0}{g}$ & & $\overbrace{n}^{\infty}$ & & 1 & 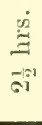 & 10 & $\underset{\sim}{\stackrel{\infty}{*}}$ & $\begin{array}{l}\dot{y} \\
\stackrel{y}{\Xi} \\
\stackrel{0}{0}\end{array}$ & $\stackrel{\sigma}{\omega}$ & : \\
\hline $\begin{array}{l}20=1 \\
=0 \\
=1\end{array}$ & & 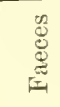 & $\underset{0}{\frac{n}{3}}$ & 0 & $\stackrel{n}{\infty}$ & $=$ & $=$ & $\stackrel{\dot{D}}{\Xi}$ & $\stackrel{n}{\frac{n}{E}}$ & $\frac{\dot{\infty}}{\Xi}$ & $\stackrel{0}{\frac{0}{2}}$ & $=$ \\
\hline 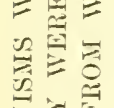 & 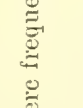 & $\underset{\tilde{J}}{\stackrel{5}{*}}$ & $\underset{\sigma}{\stackrel{n}{*}}$ & 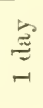 & 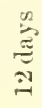 & $=$ & $=$ & $\frac{\infty}{\Xi}$ & 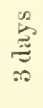 & $\begin{array}{l}= \\
\Delta\end{array}$ & $\therefore$ & : \\
\hline 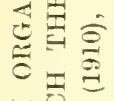 & 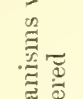 & $\widehat{\widehat{ٌ}}$ & | & $\mid$ & $\underset{\infty}{\stackrel{\infty}{E}}$ & 1 & 0 & $\frac{\dot{D}}{\Xi}$ & 旁 & $\frac{\dot{D}}{\rightleftarrows}$ & $\frac{2}{3}$ & $=$ \\
\hline $\begin{array}{l}\bar{z} \bar{z} \\
\bar{z} \\
\bar{z}\end{array}$ & 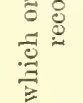 & 䔍 & 1 & 1 & & 1 & 0 & $\underset{⿱ ㇒}{\Xi}$ & $\vec{\overbrace{}}_{01}^{2}$ & $\frac{\dot{D}}{\Xi}$ & 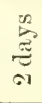 & : \\
\hline 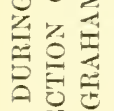 & 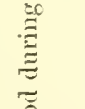 & $\stackrel{80}{3}$ & 1 & 1 & | & 1 & 0 & 0 & 0 & $\underset{20}{\stackrel{x}{\Xi}}$ & : & $\stackrel{n}{\stackrel{n}{E}}$ \\
\hline 空 & 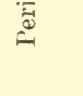 & 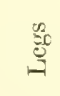 & $\mid$ & | & 1 & 1 & 0 & 0 & 0 & $\underset{20}{\stackrel{\infty}{0}}$ & $\underset{-1}{\mathrm{E}}$ & $\stackrel{0}{0}$ \\
\hline 营 & & & 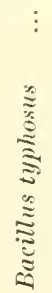 & 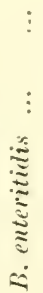 & 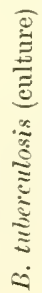 & 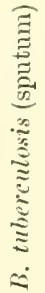 & 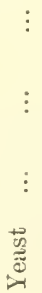 & 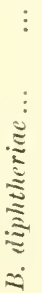 & 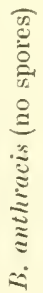 & 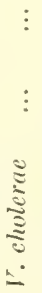 & 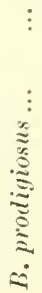 & 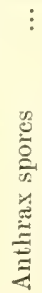 \\
\hline
\end{tabular}




\section{Intestinal Protozoa.}

Stiles (1913) in an interesting note refers to the possibility of Hies transferring intestinal protozoa such as Entumoebu coli, Lumbliu duodenalis or Trichomonas intestinulis from faecal material to food supplies. He suggests that the presence of such protozoa in food supplies might be taken as an indication of contamination ${ }^{1}$. The possibility of thies becoming infected, owing to their habits, with intestinal amoebae has also been discussed by Converse (1910) and others.

In considering experiments on artificially infected flies it should be remembered that the flies are enabled to obtain, in most eases, a much grosser infection than they might be able to obtain under natural conditions. Further, many factors which might possibly affect the degree of infectivity under natural conditions have not exercised possible adverse influences. Pending the results of further investigations therefore, experiments which have been carried out under unusually favourable artificial conditions must be considered in conjunction with those performed under natural conditions, which are chiefly recorded in the accounts given of the various specific diseases. The experiments of Giissow and of Cox, Lewis and Glynn which have been described in this section admirably demonstrate the nature and extent of natural infection.

1 Stiles and Keister (1913) have investigated this matter further with the result that they have arrived at the conclusion that the evidence that flies commonly act as carriers of the spores of intestinal protozoa is not very conclusive. 


\title{
CHAP'TER XXY
}

\author{
THE RELATION OF FIIES TO MYIASIS AND TO THE \\ SPREAD OF INTESTINAL WORMS
}

\section{Mriasis.}

THE occurrence of the larvae or maggots of Hies of different species in the human borly, where they most commonly are found in the intestinal tract and less frequently in the urinary passages, usually leads to a diseased condition to which the term Myiasis is applied. For many years cases of myiasis have been recorded and references to such cases are wiclely scattered through medical and scientific literature. In a large number of instances, especially in the cases of the earlier records, the identity of the species of larva was not determined and in fact, until recently, the determination of dipterous larvae was a matter of considerable difficulty owing to our lack of knowledge of the developmental histories of even the commoner species.

In a recent brief review of our knowledge (1912) I have collected a number of the more important and typical cases of myiasis of the intestinal and urinary tracts. Austen (1912) has also recorded in a very complete and excellent account instances of British Hies which have been found in cases of myiasis in man, to which account I am indebted for many of the cases to which reference will be made.

The species whose larvae have been recorded as causing myiasis in man are as follows:

The House-fly, Irusca domestica.

The Lesser House-fly, Fannia canicularis.

The Latrine fly, Funnia scalaris. 
The Blow-flies and Blue- or Green-bottle flies, Culliphora spp., Inciliu spp. and Sarcophaga spp.

Huscince stubuluns.

The Root Maggot fly, Anthomyia radicum.

The Cheese Maggot fly, Piophila casei.

The Drone fly, Eristalis tenctr.

Therew sp.

The House-fly, Musea domestiea.

In view of the abundance of this species and its habits it is somewhat remarkable that it has not been more frequently recorded in eases of intestinal myiasis. Austen states that only two cases have been brought to his notice; in both cases the larvae occurred in infants. In one case, the larvae of Musca domestica were "voided from the alimentary canal of a male infant aged seven months" together with the larvae of Fumiu caniculuris. The larvae were of difterent ages. Larvae of M. domesticu have been found by me (1909) in the stools of a child. Coln (1898) also records the occurence of the eggs in like material. Nicholson (1910) records three cases of intestinal rectal myiasis ${ }^{1}$.

The Lesser House-fly, Fannia canicularis, and the Latrine fly, F. scalaris.

These two species woukl appear to be most common in cases of myiasis of the intestinal and urinary tracts. As long ago as 1839 Jenyns recorded the case of a clergyman about 70 years of age, who complained of general feebleness, loss of appetite and a disagreeable epigastric feeling of a tremulons character. These symptoms began in the spring of 1836 and it was not until the autumn that the larvae were observed. They were expelled repeaterlly in large numbers and their expulsion in this manner continued for severnl months. The larvae were about equal in size and extremely active on their appearance. The malady did

1 Felt (1913) records a case of myiasis caused by the larvae of $M$. domestica. The infestation presumably arose from canned sardines which had probably been left exposed, as eggs and larvae were found in the fish of four out of six boxes examined.

Jones (1913) describes the occurrence of twenty to thirty living larvac of $M$. domestica in the stomach of a fatal case of hepatic abscess. The discase and the occurrence of the larvae was no doubt a coincidence. 
not recur and the evacuation of the larvae ceaserl shortly; the patient's health grachally improved but not completely. The author calls attention to the fact that the symptoms marle their appearance in the spring, but the larvae rere not expelled until the summer and antum following. It would appear, threfore, that they entered the stomach in the egg state and after hatching passed into the intestine where they completer their growth. From the description and figures which the author gives of these larvae they would appear to be $F$. scaluris and not $F$. cuniculuris as was supposerl.

In 1876 . Jurld describert the discharge of the larvae of $F$. sculeris from the intestine by a boy in Kentucky, U.S.A.

Stephens (1905) records the passage of two larvae per rectum, one of which was described as $F$. coniculuris and the other as Muscu corvinu, but from the author's description I am inclined to believe that the latter was $\boldsymbol{M}$. domestica.

The occurrence in the intestine of a youth of what would appear to be the larvae of one of these species of Fannia is recorded by Cattle (1906). This patient consulted the author in September 1905 and stated that he had passed the larvae a basinful at a time per unum. For some weeks he had not been feeling well and now complained of abdominal discomfort. The chief trouble was apparently an imaginative one, induced no doubt by the sight of the living larvae in his faeces. He had no vomiting or other gastric or intestinal symptoms. The larvae gradually left the patient although so late as March 1906 one or two at a time were occasionally seen.

Tulpius (1672) records the passage of 21 small larvae from the urethra. From the figure which is given it would appear that these are $F$. caniculuris. In 1792 Veau de Launay recorded the occurrence of and figured a larra which resembles $F$. cuniculuris.

Chrevil (1909), in an admirable and complete summary of previously recorder cases of myiasis of the minary tract of which a critical examination is made, gives an additional case of the occurrence of the larva of $F$. canicularis in a woman of fifty-five who suffered from albuminuria and urinated with much difficulty. On May 26th thirty or forty larvae of $F$. canicularis of different sizes were passed. 
In a case of the occurrence of $F$. canicularis in the United States reported by Blankmeyer (1907) it is stated that "the symptoms consisted of abdominal pains and distention and bloody diarrhoea followed by constipation." A saline purgative resulted in the passing of a bulky stool which was found alive with the larvae numbering from 1000 to 1500 . A few larvae continued to be passed for a few weeks.

Austen refers to the only case of urethral myiasis known to him in England. In this case which was reported by Dr J. F. Palmer to the Chelsea Clinical Society in 1901 a single larva identified by Austen as $F$. scularis was passed per urethram by a male patient.

A case of vaginal myiasis in an old beggar woman is described by Pieter (1912).

Laboulbene (1856) records the rearing of the larvae belonging to this genus from the intestine of a woman who had suffered for some time from stomachic pains with loss of sleep and appetite. On October 12th she took castor oil and after violent efforts and a further dose of an emetic she romited altogether about seventy larvae. The expulsion of the larvae was followed by a regaining of the appetite and sleep. In 1909 I recorded the occurrence of the larvae of $F$. cunicularis in the stools of patients suffering from intestinal disorders. Soltan (1910) has recorded the occurrence at Plymouth on May 28th of the larva of $F$. canicularis in the stools of a man who had not previonsly had intestinal pains. The occurrence in September 1909 in the faeces of a boy aged 12 of the larvae of a species of Fumia has been described by Garrood (1910).

The occurrence of dipterous larvae in the intestine is recorded by Hope in 1840, but in these earlier records it is frequently impossible to determine the species.

The Blow-fies and Blue-or Green-bottle flies, Calliphora spp., Lucilia spp. und Sarcophaga spp.

The larvae of these species of flies are chiefly sarcophagous feeding upon wounded and ulcerated surfaces in various mammals including man. Cleland (1912) records the occurrence of the larvae of Culliphor in an ulcer from a leper. In 1905 some eggs 
were taken from the stool of a patient suffering from diarthoea in the Manchester General Infirmary and were sent to me for examination; they proved to be the eggs of $C$. erythrocephalu. I am unaware of any other records of the nccurrence of the larvate of these flies in the intestinal or urinary tracts.

\section{Muscina stabulans.}

Portchinsky (1913) mentions the case of a Russian peasant which was brought to his notice in which, accorling to the physician's report, the larvae were in the man's body from about November 1909 to Larch 1910, causing during the whole period great pain and sickness with vomiting. From January 1910 onwards his faeces contained blood. Finally, during the two days following the injection of tamnin, about 50 larvae of $1 \%$. stabulans were passed. From Portchinsky's account it would appear that this species is not infrequently the cause of intestinal myiasis.

\section{The Root Maggot Fly, Anthomyia radicum.}

The breeding habits of this ty have already been discussed (p. 214). Austen (l.c.) mentions a single record of the occurrence of the larvae of this species in the faeces of a child which did not display any symptoms of ill health. The larvae which were passed in the faeces for some days soon disappeared after the administration of castor oil.

\section{The Cheese Maggot Fly, Piophila casei.}

Austen (l.c.) records three cases of the occurrence in the human body of this Hy. These larvae are the well known maggots or "skippers" which are found in cheese. In 1896 a case was reported in London of a woman of forty-nine years of age who had been attending the throat hospital for eighteen months for chronic pharyngitis, etc. For three weeks she noticed a profuse watery discharge from the nose and experienced sharp pains in the left frontal region. The discharge was never purulent. Tarious lotions were used without success until dilute Mandl solution was employed when four larvae of $P$. casei were discharged. Austen has examined adult flies bred from a case of intestinal myiasis in London, and Rondani records the expectoration of the larvae of 
this species in Italy by a patient suffering from an affection of the ehest.

Paris (1913) records the discharge of lirvae of Piophila together with those of Anthomyia from a young man (20) of Dijon suffering from intestinal haemorrhage and complaining of pains in the anal region. A decoction of absinthe leares successfully cansed the discharge of the larvae, numerous larvae alpearing subsequently at regular intervals. A cure was effected by a few weeks' treatment with ehloroform enematia and strong doses of thymol.

\section{Wode of Infection.}

In the majority of cases of intestinal and urinary myiasis the larvae of the two species of Famia have been found. Less frequently the larvae of $\mu$. domestica have oceurred. The larvae of these species and also of A. radicum breed in excrement and decaying vegetable prorlucts, and the female thies guided by their sense of smell and impelled by their natural instincts seek such substances. Owing to the fact that these flies are attracted to excrement, rlecaying, putrefying or purulent substances or matter several methods of infection are rendered possible.

In the case of intestinal myiasis, the flies may have deposited their eggs in or upon rotting or decaying fruit, vegetables or other fuod which may be eaten in a raw state, and thus the eggs or young larvae will be taken into the digestive tract. Or, the flies which are generally to be found depositing their eggs in the old style privies, may deposit their eggs in or near the anus, especially if the person is somewhat costive. The larvate on hatching, make their way into the rectum and thence into the intestine. This latter mode of infection is probably the common one in the case of infants belonging to careless mothers. Such infants are sometimes left about in an exposed and not very clean condition, in consequence of which flies are readily attracterl to them and deposit their eggrs.

The infection of the urinary tract is more difficult to understand. The flies are no doubt attracted to the genital apertures by the different albuminons secretions, spermatic, menstrual, gonorrheal or leneorthoeal. The larvae would feer upon the mueo-purulent secretions. It is easier to molerstand the infection 
of the urimary tract of a woman rather than that of a man. 'The case recorderl by Cherril indicates fairly clearly how the female urinary tract may be infected by the continued or prolonged exposure of the organ. As the thes are frequently found in herrooms the infection of both sexes dluring hot weather is sometimes rendered possible. Infection is chietly facilitated by uncleanliness and carelessness.

The whole subject of the relation of these thes to myiasis of the intestinal and urinary tracts is one which has received comparatively little attention. Certainly not the attention it deserves on account of the complications incident to such infections that may arise.

\section{Miscellaneous Cases of Myiasis.}

In arldition to the aforementioned cases of myiasis, which have been ascribed in most cases to definite species of dipterons larvae, medical and other literature contains numerous references to the occurrence of living dipterous larvae, or maggots in human beings ${ }^{1}$.

The remarkable occurrence of dipterons larvae in the anterior chamber of the human eye has been recorded by Ewetzky and Kennel (1904) and also by Thomas and Parsons (1908). I was enabled, through the kindness of my friend Dr Shipley, to examine sections of the latter case which showed the larvae in situ. Portchinsky (1913) has described and figured the occurrence of the larva of Hypoderma bovis, the ox warble, in the anterior chamber of the eye which it would appear to have reached by way of the nasal sinus. The occurrence of dipterous larvae in the orbit is also recorded by Keyt (1900) and Gann (1902).

Cleland (1912) has given a number of Austratian records. Two cases are given of the occurrence of dipterous larvae in the ear: in 1865 twenty maggots were removed from the ear of a small boy at Castlemaine, Victoria (Austr. Med. Journ. Vol. x. p. 95). Dr G. H. Salter of Ballan, Victoria, described (Austr.

1 Since the above was written Graham-Smith (1913) has given an excellent review of Myjasis caused by non-blood-sucking flies. In addition, the following authors have cited cases: Francaviglia (1912), Balzer, Dantin and Landesmann (1913), Surcouff (1913), Zepeda (1913), Neiva and Gomes de Faria (1913), de Moura (1913), Heckenroth and Blanchard (1913), Sergent (1913), Edgar (1913), Field (1913), Hall and Muir (1913), Candido (1913), Miller (1910). 
Med. Gaz. Mar. 1895) four cases of myiasis. An alcoholic woman complained of pain in the eye and a feeling as though pebbles were rolling over the eye-ball. The eve was red and much swollen and the lids more or less glued together with jus and blood. On separating them the space between the lower eyelid and the globe was teeming with maggots, about twenty or thirty in number, from their size apparently two or three days old. The cornea was chondy and nlceraterl in two or three spots and vision was materially impaired two months later. In Gisborne, a few months previously, Salter removed a number of full-grown maggots from the nose of a child aged seven months, the subject of hereditary syphilis. On another occasion the presence of the maggots accounted for a discharge from a child's navel. In a woman with epithelioma of the left temporal region a large number of full-grown maggots were removed which had almost demolished the growth as well as the left lower eve-lid and hacl found their way into the left orbit. In the same publication Russell of Adelaide, as cited by Cleland, rescribed a case in which twenty-three maggots were removed from between the eye-lids, and a case in which five maggots were extracted from a boy's ear, from which there was a foetid discharge. In describing the case of the maggots from the eye-lids he says: "There was a rounded open ulcer the size of a sixpenny piece at the inner comer of the eye, which had not nlcerated through the whole thickness of the lid. There was much conjunctivitis but no ulceration."

These cases may readily be explained in the light of our knowledge of the feeding and breeding habits of M. domestica and its allies responsible for myiasis in man and other animals.

\section{The Rôle played by Flies ix the Spread of INTESTINAL WORMS.}

It appears to have been an early surmise that honse-flies might, owing to their habits of seeking and frequenting excrement, serve as a means of disseminating parasitic worms by either infecting by contact the exterior of their bodies with the eggs of the worms or by ingestion of the eggs in feeding. The human excreta when moist are attractive to flies and the comparatively 
large size of the eggs of the parasitic worms does not preclude their dispersal by Hies as experiments have indicated.

Grassi (188:3) appears to have been the first to demonstrate the ability of thies to ingest the eggs. He broke 11) segments of the common tape-worm (I'cenic solime) in water; they hat previonsly been preserver in alcohol for some time. Flies sucked up the eggs in the water and he fomm them mnaltered in the faeces of the flics. The eggs of $T$. solium ineasure, aceording to Nicoll (1911), $035 \mathrm{~mm}$. in length and $025 \mathrm{~mm}$. in brealth. Eggrs of Oxyuris were also passed maltered. In another experiment Hies were allowed to feed on the eggs of Trichocephalus and he found the eggs some hours afterwards in the flies' faeces which had been deposited in the room beneath the laboratory; he also canght thies in the kitchen with their intestines full of eggs.

Nuttall (18!99) records a personal communication from Stiles who placed the larvae of Musca with female Ascaris lumbricoides which they devoured together with the eggs which these large nematorles contained. The larvae and adult flies contained the eggs of the Ascuris and as the weather at the time the experiment was curried ont was very hot the Ascuris eggs developed rapidly and were found in different stages of development in the insect, thus proving, as Nuttall points out, that $M$. domestica may serve ats a rlisseminator of this parasite.

Callandruceio (1906) examined flies which had settled upon faces containing the ova of the tape-worm Hymenolepis noma and the ova were found in the Hies' intestines. Flies which harl fed upon material containing the eggs of $H$. nana deposited excrement containing these eggs on sugar. Twenty-seven days later the eggs of this talpe-worm were found in the stools of a girl who harl eaten some of this sugar; as other possible sources of infection were carefully excluded this experinent clearly demonstrates a method of infection by flies.

Galli- Talerio (1905) found that flies conld carry not only the eggrs but also the larve of the American hook-worm Necutor americumus. He was mable to find either eggs or larvae in the intestines of the Hies. Leon (1908) recorered the eggs of the tape-worm Dibothriocephalus latus from the excrement of Hies 
which had been fed upon honey with which the eggs of the tapeworm had been mixed.

The most complete and raluable series of experiments on the dispersal of the eggs of parasitic worms of thes has been carried out by Nicoll (1911) in comnection with the Local Goremment Board enquiry. He recognised the isolated natme of the work of previous investigators, and while the account of his experiments is describer as being of a preliminary character it contains many results and observations of considerable value. 'T'en species of parasitic worms were experimented with, namely, the tape-worns, Terenia serrata, T. marginate and Dipylidium caninum from the dog, Hymenolepis diminute from the rat, Moniezia expansa from the ox, and the nematorles Trichuris trichiuris from man, Toxascuris limbata and Ankylostoma canimum from the dog, and Sclerostomm equimm and Ascuris megalocephala from the horse. Of these the following only are human parasites: T. trichimis, D. coninum, H. diminute, and T. limbuta. The main object of Nicoll's experiments was to ascertain, first, to what extent, and second, for how long a perioxl thies conlel carry egge by actually ingesting them and retaining them within their intestines, and, third, how great was the partiality they risplayed towards feeding on infective material. He points sut that the only parasites with which it is pussible that Hies can clirectly affect man are Taenia echirococcus and $T$. solium together with the following species which to not require an intemerliate lost:

Class $a$. Those in which the larval worm remains within the egg-shell.

\begin{tabular}{|c|c|c|c|c|c|c|c|c|}
\hline Ascuris lumbricoudes, & size & egg & $\cdot 060$ & min. & long, & $\cdot 045$ & mm. & liro \\
\hline Toxascuris limbatu & , & & $.0<0$ & , & . & $(0-0)$ & ., & " \\
\hline Belascuris mystux & , & , & 075 & , & "1 & 070 & , & . \\
\hline oxyuris vermicularis & , & , & 0.50 & $"$ & & 020 & " & \\
\hline Trivheris trichiuris & & & 0.50 & , & & $\cdot 025$ & , & \\
\hline Hymenolepis nareu & & & $\cdot 040$ & , & & $\cdot 0+1)$ & $\because$ & \\
\hline
\end{tabular}

Class b. Those in which the larva is liberated from the eggshell and spends its life in water.

Aukylostonce develemule, size of egg

Vecutor americusus

Schistosomem haenutobium..

stristosomm japonicum,

$\begin{array}{llll}50 & 0(1,5 & , & , \\ " & 115 & , & , \\ " & 07.5 & , & ,\end{array}$

. $40 \mathrm{~mm}$. broad (1)

045

$040,$, 
'The feeding habits of the house-tly hatre alpraty been describerl in an earlier chapter, but on aceount of its particular interest in connection with the possibility of the dissemination of parasitic worms by flies frequenting excrement, I have reservesl a quotation of Nicoll's own observations on this point for the present soction; these observations have been repeatedly confirmed by myself and doubtlessly by other investigator's. Ho says: "It is a matter of common observation that fresh and moist fineces attract thies much more readily than old dried fateces. Flies fered on warm fresh faces with considerable avidity, and they will do so even althongh they have been previonsly feeding on wther matrial. 'T', Hies which have not ferl for some time the prestence of fresh human faeces acts as an immediate source of attraction, and in some of ny experiments the eagerness with which they attacked it was nost striking. When the portion of faeces was so small that the flies conld not find standing room upon it or aromel it, they struggled together and pusherl each other aside, and more than once I have seen them so closely packerl together that each fly condel find rom only for the tip of its proboscis, the flies on the top practically standing on their heark, supporter by the borlies of those aromm. Their behaviour towarks older faeces, however, is very different. When the material has become cold it rloes not attract flies nearly so readly. So long as it romains moist it contimues to attract and does so quite as much as moist brearl, although very much less so than moist sugar. When it has become dry it possesses little or no attraction, but this is increaserl when it is moistened again. It is evident, therefore, that the presence of moisture plays an important part in a fy's attiture towards faeces as an article of food.

"When the altematives of fresh faeces, sugar and bread were offererl, the flies dich not confine their attention to any one of these articles but made repeated excursions from one to the other."

He proceeds to describe some interesting observations in regard to flies feeding on segments of tape-worms. Such tape-worm segments may be deposited together with the faeces or independently and in the case of some species of parasitic worms the eggs are conveyed to the exterior in the detached segments instead of being sherl singly into the gut. It was foumd that such detached 
tape-worm segments possessed a great attraction for flies. When an intact segment of a tape-Worm such as Taenia serrata, T. marginutre or Dipylidium cunimum mixed with moderately fresh faeces was presented to some flies they appeared to select the tape-worm and feed upon it in preference to the faeces. This observation was repeated on several occasions. Further, when an isolated tapeworm segment, some fatees and some sugar were separately introduced into the fly cage, the Hies showed a decided preference for the tape-worn, which they attacked with much assidnity. This preference was shown not only when the tape-rorm segnent was fresh but eren when it had lain a day or two.

Flies, it was found, are able gratually to pierce the fairly tough external covering of the tape-worm segments and to extract the internal contents containing the eggs. When flies had been feeding on a tape-worm segment for $5-10$ hours their crops were found greatly distended with the white milky juice of the tapeworm and tape-worm eggs were found in the Hies' intestines.

Special observations were made on the feeding of the fly larvate on parasitic worms. IThile it was found that even after a lapse of three or four days, the adult flies were unable to penetrate the thick cuticular investment of round worms such as Ascaris megalocephala and Touascaris limbata, such difficulties did not exist in the case of the larvae. Frosh round worms when offered to the larvae were at once attacked, but although they swarmed over the worms, unless the euticle of the worms was torm or ruptured in some way, they were unable to penetrate them and in the absence of other food they died. On the other hand, if the round worms were cut up or broken before being given to the larvae, the latter devoured the internal parts with great rapidity. Commencing at one end of a broken piece they would eat their. way through the soft tissues leaving nothing but the cuticular tube. It was found that within two or three days half a dozen larvae would devour a large worm 20 or 30 times their own bulk. When larvae had fed upon female egg-bearing worms large numbers of eggs were found surromnding then but not actually adhering to them and in the intestines of such larvae no intact eggs were found, but fragments of shells were always visible. No embryonic worms in any stage were found. Nicoll is of the 
opinion that even full-grown larvae are nuable to swallow unruptured eggs as large as those of the worms used, nanely $07 \mathrm{~mm}$.

Details are given by Nicoll of the most important of his experinents on the feeding of infective material to flies. The material was offered to the Hies in fonr clifferent ways. 1. Fateces contining ora. 2. Complete worms, or intact parts of them. 3. Broken or damaged segments of worms. 4. Suspensions of ova in water: After feeding thies were examined at varying intervals; the borlies and appendages were first examined; afterwards the alimentary tract was discected out and examined. The results of his experiments were as follows:

(a) Hymenolepis diminutu (ova 07 by $065 \mathrm{~mm}$.).

1. 11 flies were fed on contents of caecum of rat containing numerous eggs. Negative results were obtained.

2. 12 flies fer on rat faeces containing numerous ora. Negative results obtained.

3. (i flies fed on ripe segments of Hymenolepis diminuta containing numerous ora. Negative results.

t. 6 flies ferl on emulsion of tape-worm in water, containing numerous ora. Negative results.

These experiments demonstrated the inability of Musct domesticu to ingest eggs as large as those of Hymenolepis diminutu.

(b) Touescuris limbuta (ova 08 by $07 \mathrm{~mm}$.).

1. 8 thies fed on dog faeces containing numerous eggs. Negative results.

2 and 3. Two lots of 6 flies each fed on intact and broken female worms respectively. Negative results in each case.

(c) Ankylostoma caninum (ova 06 by $04 \mathrm{~mm}$.).

Negative results were obtained after feeding thies on dog faeces containing ova.

(d) Trichuris trichiuris (ova 05 by $025 \mathrm{~mm}$.).

From 12 flies which had been fed on human faeces containing a few ova, the ova of this tape-worm were recovered from one Hy and from the faeces of another fly. 
(e) Dipylidium caninum (ora 04 by $\cdot 0+\mathrm{mm}$.).

1. 4 II usca and 1 Fammiu were fed on unbroken ripe segments of the worm. The eggs were recorered from 2 Hies (Muscu) 26 hours after the infected faeces had been removed, demonstrating the ability of the flies to suck the eggs of the tape-worm and to carry them for a considerable time.

2. 6 Hies were fed on $\log$ faeces containing ova. The ora were found in 4 of these flies: in the case of 2 of the flies 43 hours after the infected faeces had been remored, showing that the flies can carry the eggs in their intestines for at least that length of time.

(f) Tuenia marginata (ova 035 by $035 \mathrm{~mm}$.).

1. The eggs of this species were removed from a blow-fly (Culliphora) on the second day after it had been fed on mashed up segments containing ora.

2. Eggs were recovered from Musca and Famia nearly three days after they had fed on ruptured segments containing numerous ora.

3. Eggs were recovered from Musca the day after it harl fed on an emulsion of ripe segments.

(g) Taenia serrata (ova 035 by $035 \mathrm{~mm}$.).

1 and 2. Eggs were found in flies in very large numbers, 500 in 3 flies and 400 in 2 flies, 2 hours after feeding on ripe segments in water, and on ruptured segments.

3. Eggs were found in a fly 21 hours after feeding on intact segments containing numerous ora.

4. Negative results were obtained from 4 flies fed on dried segments.

5. A single egg was recovered from one of 7 flies 8 hours after they were fed on intact segments containing numerous ova and one egg was found in the Hies' faeces about 20 hours after the segments had been removed.

6. From 3 flies which had fed on an emulsion of segments containing numerons ova, $1,2 \cdot 2$ and 312 eggs respectively were recorded up to $T$ hours after the emulsion had been remored. 
200 eggs were recovered from fineces of other thes. 171 eggrs were recovered from a fly $2+$ hours after feeding: these eggrs were ferl to a rabbit in which 2:3 Cysticerci were afterwards fomd, showing that the eggs remained capable of infecting for at least one day. Eggs were also recovered from a tly and from faeces 45 hours after feeding.

7. 10 Hies were fed on farees containing ruptured mature segments; a piece of sugar was also introdnced and the fileces were kept moist. The results demonstrated the important fact that farees containing tape-worm segments may continue to be a source of infection from which food, such as sugar, may be contaminated for as long as a fortnight.

A series of experiments was carried ont in which Hy larrate were fed upon faeces containing tape-worms or ripe segments.

Tuenia serratu. 5 eggs were recovered from three larvae two days after they had been placed on dog fineces containing ripe segments but no eggs were recovered from pupae or thies developing from larvae which had been fed on infected faeces.

Torascaris limbata. Larvae were placed on dog faeces containing mature female worms but no embryos or larval tape-worms were recovered from the fly larvae, pupae or adult Hies.

Ascuris meyulocephala. Several larvae were put in horse faeces containing female worus with numerous eggs. Negative results were obtained from an examination of the fly larve, pupae and adult thies. Nicoll points out that these results are at variance with the result of Stiles alrearly quoted, but, as he shows, the eggs of Ascuris lumbricoides, which Stiles used, are smaller than those of A. megalocephala.

Nicoll also experimentally shows that the well-known habit which thies have of cleaning their proboscides, appendages and bodies after feeding militates very materially against their carrying eggs on the exterior of their bodies. The longest period after which eggs of Hymenolepis diminuta, for example, were found adhering to tlies was about three hours. During this time, however, they may travel some distance from the source of infection. It was demonstrated that the eggs of this species of tape-worm, 
which are too large to be ingested by the flies, could be carried externally by the flies and that food (sugar) could be infeeted.

The eareful experiments of this investigator show that, under experimental conditions, the eggs of the following parasitic worms may be carried by Husca domesticu: Tueniu solium, T. serrutu, T. marginate, Dipylidium conimum, Dibothriocephulus latus(?). O.ryuris vermiculuris, Trichuris (Trichocephalus) trichiuris, both intemally and externally: Necator americamus, Ankylostomu caninum, Sclerostomum equimum, A scaris megalocephala, Torascaris limbata (= Ascaris canis e.p.), Hymenolepis diminuta externally only.

The practical significance of the results of the aforementioned studies of the relation of Musca domestica and such of its allies as have similar coprophagons or coprophilous habits is great. The necessity of preventing flies from gaining access to faeces or tapeworm segments is most clearly demonstrated and the possibility of flies infecting food with tape-worm eggs will undoubtedly furnish an explanation in many otherwise obscure cases of infection. 


\section{PART TI \\ CONTROL MEASURES}

\section{C'HAP'TER XXVI}

PREVENTIYE ANI) REMEUIAL MEASURES

THE significance of the house-fly as a carrier of the causative organisms of certain of our nost common diseases render's its control fundamentally necessary in any effort towards sanitary reform or in any system of preventive medicine. The disgust which its filthy habits call forth shorld be a sufficient impulse in the direction of its control; the fact that it can be no less dangerous than the mosquito or the tse-tse fly, should opportunity occur, should merit and demand the attention of all charged with or interested in the care of the people's health. The eviclence which has been adduced is more than sufficient to demonstrate that the prevention of many diseases cannot be undertaken with any hope of success so long as this factor in their dissemination is ignored.

\section{Prevention of Breeding.}

Of all control measures this is by far the most important. It is the key of the whole situation. The fly and mosquito problems are essentially similar. Malarial and yellow fever are eradicated by the abolition and protection of the breeding places of the mosquito. Similarly, by the abolition, and protection or treatment of the breeding places of the house-fly its control could be effected and its significance as a disease-carrier nullified.

The study of the breeding habits of the house-fly has indicated the places and materials in which it breeds. The chief breeding 
places are colluetions of horse-manure or stable refuse. Flies must not be allowerl to have access to such stable refuse. In order to attain this end it must be kejt in covered Hy-proof receptacles and regularly removed or it must be treated with some insecticidal substance. An increasing number of cities and towns are recognising the importance of the firmer of these requirements and are passing and, what is more important, enforcing bye-laws regarding

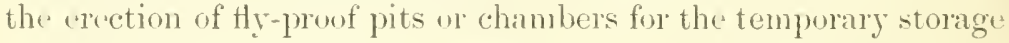
of manure. It is further necessary to have the floor and interior of the stable well constructed; the Hoor shonld be of solid masonry or concrete to permit goorl rlrainage and thorough cleansing.

Many municipalities have the necessary bye-laws on their statute books but lack the incentive or courage to enforce them. The plain facts already set forth shonld convince such inmicipalities of the grave danger to the health of the people they are elected to serve that the presence of breeding places of house-flies constitntes.

A necessary adjunct to the construction of sanitary stables and the storage of the horse-manure in Hy-proof receptacles is the regular removal of the manure. It was observed that Hies prefer to oriposit in the warm excreta and on this account eggs are often deposited in the manure before it is thrown into the storage receptacle. From such infested manure thies would emerge if it were not remored well within the shortest time that is occupied in the completion of the life-cycle of the fly. This time is shorter in the summer than in the winter. Therefore, during the summer and antunm months, from June to ()ctober, the manure should be removed regularly at intervals not exceeling seven days. A large number of towns and cities require its removal twice a week during this period and this is a wise precantion. During the remainter of the year the period may be extended to nine clays or three times each month ${ }^{2}$.

1 Levy and Tuck (1913) and Hutchison (1914) propose that advantage should be taken of the habit which the larrae of 11 . domestica have of migrating from the manure to pupate in the soil or in a drier situation. By placing the manure in receptacles from which the larvac can escape through wire gauze sides and bottoms, the larvae can be caught and killed in pans placed beneath such receptacles. By the use of such "maggot-tiaps" Hutchinson was able to show that 98 or 99 per cent. of the total number of larvae can be made to leave the manure, provided it is kept moist. 
While the advent of the intmmbilu hats molombtedly decreased the breceling places of the house-tly very materially and will continue to do so, there remains still mush to be done in the way of segregating or localising livery stables in addition to the enforcerment of the aforementioned sunitary regulations. This prineiple? is being adopted in eertain plates and its mor" general pratetice would have an appreciable effect on the problem of fly control. One great advantage of such segregation wonk be the increased opportunities afforded to sanitary inspectors of supervising the proper care and treatment of the stables and of the stable refine.

.Too much stress cannot be laid upon the necessity of prohibiting the storage of stable refuse and other breeting materials of the house-fly (see p. 94) in such places as railway depots, canal whares and sinilar places pending its removal. In the majority of cases outbreaks of thies have been traced to the adoption of such practices and such an abundance of thies may have dangerous consequences.

As an altemative to, but preferably in conjunction with the storage of horse-manure in Hy-proof receptacles, the treatment of the manure with an insecticidal substance with a view to destroying any house-fly larvat can be adopted with very marked success.

In 1897 Howarl conducted a series of experiments with a riew to discovering an insecticiclal substance which could be used for the destruction of the larvae in the heaps of manure in which they were breeding. He found that both lime and gas lime were not efticacious. In an experiment in which 8 lbs. of horse-manure containing larvae were treated with a pint of kerosene, which was washed down into the manure with water, it was found that all the larvae were killed. He also found that by treating 8 lbs. of well-infested horse-manure with one pound of chloride of lime all the larvae were killed, but the results were not satisfactory when a quarter of the quantity of chloride of lime was used. On experimenting with the kerosene treatment on a large scale he found that it was not only laborious but also not entirely successful, as is sometimes the case in the practical application on a large seale of successful experimental methods. He, therefore, devised another method of treating the horse-manure of stables. A chamber six feet by eight feet was built in the corner of the stable with which 
it communicated by means of a door: it was providerl also with a window furnished with a large screen. The manure was thrown into the chamber every morning and a small shorelful of chloricle of lime scattered over it. At the end of ten days or a fortnight the manure was removed through an open door and carted away. The experiment was carried ont in the stable of the U.S. Department of Agriculture and a marked decrease in the number of Hies was observed.

That chloride of lime can be used with beneficial results and on a large scale has been demonstrated by one of ny correspondents, Messrs McLaughlin, Bros, lumber manufacturers of Armprior, Ontario, Canada. In response to my request for a brief statement of their experience they write (April, 191:3) as follows:

"Four" years ago we hegan using chloride of lime in our stalles here to keep down house-flies. There are about 1:20 horses in the stables at night and most of them are brought in to feed at noon. The manure is removed every morning and again in the afternon when the nid-day feed is over. After each cleaning-ul, elloride of line is taken in in a shorel and seattered lightly just outside each stall. It must nut be put ton elose in, for if the horse lies on it it will burn the hair off him. The risk of this accident is, however, very slight, as during the four rears we have used the lime. it oceurred only once to one horse and a rery little eare will obviate it entirely. The smell of the chlorine given off by the lime while it is scattered in the stables donbtless tends to drive away the flies, and as the manure and line are swept up together, they are well mixed, and the chlorine having thus a good ehanee to exereise its germicidal properties, a large proportion of the flies' eggs and larvae are no doubt destroyed by it.

"It is, of conrse, inpossihle to determine with accuracy the decrease in the number of flies due to the use of the chloride of lime, but our men are satisfied that the reduction must he about 75 per cent. One striking evidence of the diminution is the comparative quietness of the horses now at night. A few years ago, when passing the stalles on a warm summer night, one was astunished at the noise caused by the never-ceasing tramping of the flypestered animals. Since we began to nise chloride of lime, this noise has practically ceased.

"We use about eight or ten pounds of the lime a day, or about $1000 \mathrm{lb}$. during the fly season. Bought by the larrel of some $300 \mathrm{lbs}$. it costs 2 cents per lb. in Montreal."

The above statement has been given in full as it affords striking evidence of the practical use of chloride of lime and its effect, not only fiom an insecticidal standpoint but as a means of 
securing for the horses the rest they need and nsually deserve, the value of which rest is evident.

I am informed by chemists that it is doubtful whether the admixture of a small quantity of chloride of lime would seriously affect the manurial properties of the stable-manure. Exact information on this point, however, has not yet been secured.

Howard (1911) records the results of experiments with kerosene as an insecticile. While it was found that on a small scale if eight quarts of horse-manure were sprayed with one pint of kerosene which was afterwards washed down with a quart of water all the larvae were killed; on a larger seale it was not wholly successful: "a considerabie proportion of the larvae escaped injury." Even had all the larvate been destroyed the cost of the treatment would be prohibitive.

Herms (1911) suggests that "when the manure pile can be spread ont to a depth of about half a foot it may be drenched with a distillate petrolemu, which possesses a high flash point, i.e. does not ignite asily, and has the necessary insecticidal property. The petrolemm oils, solel as proprietary compounds on the market as 'miscible oils,' 'spray emulsions,' and the like, should be applied at the rate of one part of the oil to ten parts of water. If kerosere oils of a low tlash point are used about stables and ont-buildings the elanger from fire must be considered."

On account of the danger incident to its use and the cost of the treatment, apart from the fact that its employment is not supporter by our experimental results, one is compelled to hesitate in recommending the general use of kerosene or paraffin oil for the destruction of thy larvate.

Forbes had a series of experiments carried ont in Illinois, U.S.A., on the destruction of the larvae in manure heaps. These are recorded by Howard (1911). In one series hydrated high calcium lime was used. When three pounds of this lime were mixed with fifteen pounds of horse-manure, ninety-fom per cent. of the larvac were killed; two pounds of lime mixed with twelve pounds of manure killed sixty-nine and one-tenth jer cent, of the larvate: four pounds mixed with twelve pounds of the manure killed sixtyone and three-tenths per cent. The climinished percentage in the last two experiments was accounted for by the fiact that the larvate

H. II. $-\mathrm{F}$. 
were nearly full-grown. The most successful results were obtained by the use of iron sulphate. It was found that the breeding of the house-fly in horse-manure conkl be effectively controlled by spraying the manure with a solution of iron sulphate. A solution of two pounds of iron sulphate in one gallon of water for each horse per day was userl. It was ealenlated that the arorage city horse produces about fifteen pomnds of manure per day and the heavier draught horses prorluce twenty to thirty pounds per day. The amount to be treated is, of conrse, much less than this as the horses are out of the stables a large preportion of the lay. The average cost of treatment in Illinois would work out at less than one penny (one and one-half to two cent.s) per horse per day. Not only is the iron sulphate stated to deodorize the nuanure but it does not injure its manurial properties. In fact, it is extremely probable that it increases the fertilising properties of the manure. Unfortunately, at the time of writing we have no exporimental evidence as to the effect of this and other insecticides on the fertilising value of the manure. It is anticipated that investigations on this aspect of the question will be carried on ${ }^{2}$.

It is claimed that the treatment of the manure with equal parts of acid phosphate and kainit will repel the flies and prevent their oviposition. Such treatment wonld certainly increase the fertilising ralue of the manure.

One is frequently asked how the farmer is to undertake the control of the house-fly abont his premises when he is compelled to

1 Since the above was written I have carried out a series of experiments in August and September, 1913 (see Journ. Econ. Ent, vol. 7, p. 281), with a riew to obtaining information on this aspect of the problem. It was found that the greatest mortalits was produced by chloride of lime scattered on the manure as it was piled; this was more fatal than iron sulphate solution.

Dr L. O. Howard has kindly permitted me to secure the results of a series of experiments carried out by the Bureau of Entomology, assisted by the Bureatu of Chemistry, of the U.S. Department of Agriculture, Washington, D.C., during the summer and fall of 1913 to discover an insecticide which wits not only cheap enough for the fimmer to use but which also did not injure the fertilising properties of the manure. It appears that borax (solium borate in the crude form) used either in the powdered form ( $2 \mathrm{lbs}$. to is bushels of manure) or in solution (oneeighth of a pounl to one gallon of water, using 40 quarts of the solution to s bushels of manure) gives the best results. The full report of this investigation will be publisher shortly ly the C.S. Department of Agriculture, to which important report the realer should refer. 
store large plantities of mamme in the stable yards. The difficultien of the farmer's case have been sonewhat unnecessarily magnified owing largely to a failure to appreciate the facts incident to the storage of manmre. Experiments which my colleague, 1)r F. T. Shutt, Dommion Chemist of the Canadian Department of Agriculture, has carried out have conclusively shown that from a fertilising standpoint it is a greater advantige to haml the mamme? directly on to the soril than to store it in the stable yard where a considerable proportion of its value is lost by leaching and other processes. In the control of the hense-fly on the firm the most effective measme which can be adopted is the immerliate hauling of the manne on to the land. It this is done flies will not breed in the manure as scattered manure, owing to its desiceated state, does not rearlity permit their breeding. The increase in the fertilising value of the manure thus treated serves as an additional reason for the more general adoption of the practice. If it cammot be scattered on the land at onee it is an advantage to compost it in heaps and cover the same with a layer of soil. Flies are attracted to and deposit their eggs in fresh manme. Rotted and coll manure does not attract and only in exceptional cases have I ever found Hies breeding in such manme either under natural or experimental conditions ${ }^{1}$.

The insanitary privy is the greatest menace to the public health. Not only does this mediaeval institution, when not properly cared for, serve as a favourite breeding place for Hies but it is the commonest source of infection. Fortunately, it cannot remain long: medical officers of health are manimous in its condemmation and the more general institution of water-carriage systems is having a pronounced effect on its abolition. The majority of people have no conception of the state of affairs in regard to the occurrence and conditions of insanitary privies. Excellent testimony on the subject in relation to infantile mortality is given by Newsholme (1910), to whose valuable report the reader desiring further information is referred. In his general summary

1 Washbum (1912) suggests the spraying of piles of horse manure with it solution of $i$ ounces of sodium arsenite in about 20 gallons of water to which about half-a-pint of treacle has been added. A similar solution used to kill grisshoppers was found very attractive to flies. 
Newsholme states "Infant mortality is highest in those counties where, under urban conditions of life, filthy privies are permitted, where streets and yards are to a large extent not 'made up' or paved." In his recommendations he says "Sanitary authorities in compactly populated districts should decide to remore all dry closets if a water-carriage system is practicable."

For the dry closet to be maintained in a sanitary condition great care and attention is required. It cannot be rendered Hyproof, however, owing to the ability of flies to emerge through the soil after having developed from eggs deposited on the faeces before they were covered.

\section{Destruction of Refuse.}

It is a remarkable fact that in many of our towns and cities, professedly progressive in sanitary measures, public "dumps," "tips" and garbage heaps are maintained. Frequently, they are located on a vacant piece of land surrounded by thickly populated districts in which there is almost invariably a plagne of flies during the summer months. On many occasions during my investigations I have examined such accumulations of organic and other rubbish and have found flies breeding in vast numbers. While such heaps contain a large proportion of mineral matter, such as clinkers, cinder's and ashes, etc., they invariably include (art-loads of organic rubbish of various kinds, especially domestic refuse, in which flies can breed (see p. 94). Not only do they breed but they also infect themselves with putrefactive and sometimes pathogenic bacteria. The greatest danger of such heaps, however, lies in their fly-productive rather than infective character. Cities and towns can no longer afford to permit these methods of disposing of organic refuse. Its prompt destruction by means of an incinerator is the only measure which will prevent its being a public nuisance and a serious breeding ground for flies. Further, the storage of the domestic organic refuse by the householder in Hy-proof receptacles frequently and regularly emptied or remored by the civic authorities must necessarily form :n integral part of any sanitary system of refuse disposal. 


\section{The Protection af INFants axp the Sick.}

By their helpless nature and by the force of circumstances infants are peeuliarly subject to the attentions of Hies. One has only to visit the populous districts of our towns and cities, where the poorer classes are compelled to live, to observe thr advantageous conditions under which thies are able to disseminate infection. All too insufficient attention is paid to the eareful disposal of human excreta which oceur in alleys and odd corners; privies are largely unprotecterl and the children lie and craw abont. One is impressed by the possibility of the fly-carriage hypothesis of summer diarrhoea and the frequent occurrence of intestinal myiasis becomes no longer surprising. 'The protection of such infants from the attentions of thies is absolutely essential under such conditions. Nor is it much less essential under most cireminstances in the summer when infants are wheeled arouncl in their carriages, subject to the attentions of flies whose previous visitations may have been of the foulest description.

The protection of sick persons, the exclusion of flies from the sickroom or the hospital, are precautions of so obvioms a nature in the light of our knowledge of the langers incurred by the presence of Hies, that it should be unnecessary to do more than indicate the necessity for such protective measmes.

\section{Protection of Fool).}

In the home, and where it is exposed for or preparatory to sale, food which is liable to become infected by virtue of its being attractive to Hies should be protected. Certain foods such as milk, cooked meats, etc, furnish excellent media for the transference of micro-organisms. Not infrequently one is filled with disgust at the sight of such eatables as cakes, confectionery and fruit liberally fonled with fly specks, the signifieance of which I have already discnssed in a former chapter. The exposing of foor on the strcet, in the dairy or cowshed, and in the shop should be prohibited, and it is an encouraging sign to find that sanitary authorities in many of our towns and cities both in Europe and America are not only passing bye-laws to this effect but are enforcing such requirements by fining the offenders. 


\section{The Destrection of Adult Flies.}

Many means have been devised whereby the adult flies may be destroved and, while the prevention of their breeding constitutes the fundamental principle of their control, the destruction of the flies must naturally form a part of any system of eradication.

The methods of destruction may be divided into two classes: trapping and poisoning.

\section{Trapping.}

There are on the market and in use a great variety of fly-traps the majority of which have proved successful. Such forms as the glass fly-traps baited with beer and the balloon wire trap baited with any attractive bait are well-known. The sticky Hy papers, ribbons and wires need no description.
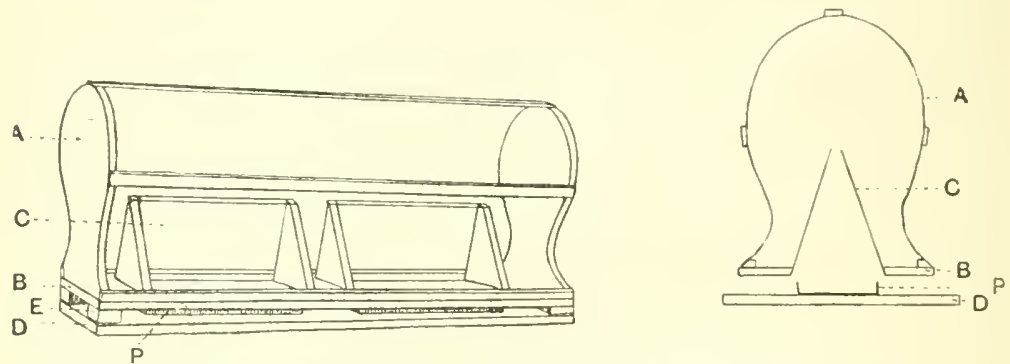

Fia. 101. The Minnesota Fly Trap. General view and cross section. (After photograph by Washburn.)

Parrott has devised a trap which consists of a shallow tin box having sides about three-quarter's of an inch deep: it is made long enough to fit in the bottom of the window pane. After these shallow boxes have been fitted they are filled about twothirds full of some insecticidal substance such as paraffin or kerosene, or an emulsion of the same, or a sticky mixture of equal parts of castor oil and resin made by boiling the two constituents together.

The "Minnesota Fly Trap" which has been devised by Washburn (1912) has proved successful in the trapping of flies in large numbers. On the back porch of a dwelling, not far from 
a stable where a few horses are kept, 8700 Hies were canght in two days, 12,000 in one day and 1s,000 in one and a half days. The trap is illustrated in fig. 101, and the following is a description of its construction: It measures twenty-four inches long, twelve inches high anrl eight inches wille. The sereen nsed for the large receptacle $A$ and the roof-shaped entrauces $\mathrm{C}$ is ordinary wire fly or mosquito sereen. The upper portion $A$ serves as a receptacle for the captmed flies; it rests on a board $B$ which carries two roof-shaped entrances $C$ open at the top to permit the entry of the flies into $A$. The middle board $B$ rests on a base board I) from which it is separated by means of small pieces of woorl E about half an inch in thickness fastened at the corner's as shown. (Tyon the base board I) rest two tin bait-pans P, separated by about one-quarter of an inch from the middle board B. The trap may be baited with any attractive substance such as meat scraps, raw fish seraps, brearl and milk, etc. The captured Hits may be killed by immersing the trap in hot water or by pouring boiling water orer it.

Hodge (1911) has taken advantage of the attractive power which the garbage or refuse can has for flies and has devised a trap which can be attached to the lid of the garbage can ; the licl is so arranged that it does not fit tightly on to the can but a quarter of an inch space permits the flies to enter and on leaving they naturally fly upwards and enter the trap which consists of an ordinary balloon wire fly-trap. In such a trap baited with attraetive food such as fish heads, etc., he has eaught as many as 2500 flies in fifty minutes. He has also made another device consisting of overlapping sereens of wire-gauze (see Hodge, 191:3) which ean be fitted to the window of the stable or cowshed and catches the flies as they leave the sime.

\section{Poisoning.}

The arsenical fly-papers or parls were among the earliest fly poisons.

Furmalin or formaldehyde has been employed in reeent years with marked suceess in most cases. Sometimes complete failure has been reporter, but in such eases I have often found that it 
was not correctly userl. R. J. Smith (1911) has demonstrated, and it has been subsequently confirmerl, that if sweet milk is added to the formalin it proves very attractive to flies and the mixture makes an excellent and fatal bait. The solution is made as follows: one ounce or two tablespoonfuls of forty per cent. formalin is mixed with sixteen ounces, that is, one pint of equal parts of milk and water. If this mixture is exposed in shallow plates in the middle of each of which a piece of bread is placed for the flies to alight upon, the flies will be attracted to the solution and poisonerl. The formalin has also the arlvantage of being a disinfectant. Houston (1913) has used the following method of application in the jail kitchen at Rajkot, India, with great success. Instear of exposing the mixture in shallow plates it is sprinkled about the room in tiny pools of one quarter to one inch in diameter from which pools the flies readily drink it. The substitution of buttermilk for the ordinary milk has also been suggested.

Berlese (1913) has for two years carried out observations and experiments on the control of Hies at S. Tincenzo (Pisa) by means of poisoned baits, deriving the idea from his work on the control of the olive fruit-fly by means of sweetened arsenical solutions. He rightly emphasizes the importance of destroying the flies outside the houses and near the breeding places where they congregate. He sprayed plants in the gardens and orchards near dwellings, and also heaps of manure and other likely breeding places with the following mixture: 10 parts of treacle, 2 parts of arsenite of potash or soda and 100 parts of water. The operation was performed every ten days and repeated after rain, and the manure heaps were sprayed when a fresh surface was exposed. In 1912 he experimented with small bunches of straw suspended for protection from the weather under conical zine covers. 'The straw was dipped in the following mixture: honey, l part; treacle, 1 part; sodium arsenite, $\frac{1}{2}$ part; water, 10 parts. These baits were hung round the houses in such places as the porches and verandas. Berlese states that by the use of these methods he succeeded in totally destroying the flies in each of the two years during the period of his residence in the village. By the perfection of this method, which enabled him to enjoy a flyless 
meal, he beheres that it would prove to be a thoronghly practical methor of dealing with the Hy nuisunce in larger places.

The burning of pure and fresh pyrethrum powder and also the dropping of twenty to thirty drops of carbolic acil on a hot iron plate or shovel have been recommenderl as means of richling rooms of flies. As the fumes do not always kill all the flies but only stupefy a certain proportion, it is important that the flies should be swept up and burnt before they have an opportunity to recover?

1 In a paper on "Experiments with House-fly Baits and Poisons," read by A. Wr. Morrill of Phoenix, Arizona, before the Amer. Ass. of Eeonomic Entomologists at Atlanta, Ga., U.S.A., on 2nd Jan., 1914, the author described the results of tests of various chemical and fruit baits. He found that the altractiveness of formalin raried from day to day, that formalin with vinegar, and vincgar alone, were cxcellent baits, and that potassium bichromate, which is sometimes recommended, has little ralue as an insecticide. The discussion on this paper elicited varions experiences among which were: that the formalin bait is more successful if water is absent from the room and that a mixture of sour milk and formalin sometimes gives good results. 


\section{CHAPTER XXVII}

\section{(IROANISED EFFORT IN CONTROL MEASTRES}

Wurte individual effort and example will materially alleviate the Hy nuisance and minimize the danger, the problem can only be attacked by corporate and coordinaterl action. In the previons chapter I have endeavoured to show that the problem of $\mathrm{Hy}$ control is fundamentally one of good sanitation. Where cities or towns have adopted the necessary standards of sanitation which the health of the community demands, the fly problem hardly exists. In support of this fact I will yrote one of many examples which might be given, natnely, the report of G. $\mathrm{N}$. Ifft, United States Consul at Nuremburg, Germany. He states" : There are so few Hies in Bavaria that they can in no way be regarded as a pest. This is perhaps due to the extreme cleanliness of Bavarian cities. Courtyards, alleys, vacant lots, \&c., are kept clean and the hallways and entrances to houses are as fresh as soap and water can make then. There are no quarters that conld be justly designated as slums, not even in districts where buildings hundreds of years old are the rule. Garbage is collected in closed tin or zinc cans and regularly removed in closed waggons in such a manner as to be inotfensive to either sight or smell." Of how many cities in other parts of the world could the same be sairl? Nevertheless, the last few years have witnessed an honest effort in the right direetion on the part of local anthorities, in spite of opposition from those who are interested in maintaining stables in thickly populated sections of cities and towns. It is a singular fact that prominent among snch opponents to reforms relating to

1 Derily Consular and Trade lieports, Bur. of Hamuactures, U.S. Hept. Commerce amd Labour, Hashington. 12th March, 1912. 15th year, No.60. p. 1031. 


\section{HOW TO DEAL WITH THE FLY NUISANCE.}

House flies are now recognized as MOST SERIOUS CARRIERS OF THE GERMS OF CERTAIN DISEASES such as typhoid fever, tuberculosis, infantile diarrhoea, etc.

They infect themselves in filth and decaying substances, and by carrying the germs on their legs and bodies they pollute food, especially milk, with the germs of these and other diseases and of decay.

\section{NO FLY IS FREE FROM GERMS.}

\section{THE BEST METHOD IS TO PREVENT THEIR BREEDIHG.}

House flies breed in dccaying or decomposing vegetable and animal matter and excrement. THEY BREED CHIEFLY IN STABLE REFUSE. In cities this should be stored in dark fly-proof chambers or receptacles, and it should be REGULARLY REMOVED WITHIN SIX DAYS in the summer. Farm-yard manure should be regularly removed within the same time and either spread on the fields or stored at a distance of nut less than a quarter of a mile, the further the better, from a house or dwelling.

House flies breed in such decaying and fermenting matter as kitchen refuse and garbage. Garbage receptacles should be kept tightly covered.

ALL SUCH REFUSE SHOULD BE BURNT OR BURIED within a few days BUT AT ONCE IF POSSIBLE. NO REFUSE SHOULD BE LEFT EXPOSED II fi cannol be disposed of at once it should be sprinkled wi:h chloride of lime.

\section{FLIES IN HOUSES.}

IVindows and doors should be properly screened, especially those of the dining room and kitchen. Milk and other food should be screened in the summer by covering it with muslin; frust should be covered also.

Where they are used, e-pecially in public places as hotels, etc., spittoons should be kept clean, as there is very great danger of flies carrying the germs of consumption from unclean spittoons.

Flies should not be allowed to have access to the sick room, especially in the case of infectious dicease.

The faces of babies should be carefully screened with muslin.

\section{TO KILL FLIES IN HOUSES.}

Mlix two tablespoonfuls (one ounce) of 40 per cent. Formalin, (a solution which may be obtained from any drug store at about 40 cents per pound bottle) (20 ounce), with one pint (sixteen ounces) of equal parts of milk and watcr. This mixture should be exposed in shallow plates, and a piece of bread placed in the middle of each plate will enable the flies to alight and feed. All dead flies should be swept up and burnt. The burning of pyrethrum in a room, preferably at night, is sometimes effective : the flies should be swept up and burnt, as many are only stupefied
by this substance.

\section{HOUSE FLIES INDICATE THE PRESENCE OF FILTH IN THE NEIGHBOURHOOD OR INSANITARY CONDITIONS.} to the

Copies of this circular, printed on paper or card, may be had on application

\section{Dominion Entomologist, Central Experimental farm, Ottawa. Department of AgRiculture, Canada. \\ (l'ublished by direction of the Hon. Martin Burrell. Minister of Agriculture.) IRerined edition, sood April 1992,}

Fig. 102. Reproduction of card prepared by the author and widely distributed !by the Canadian Department of Agrieulture. (Actual size 12 in. $\times 8 \frac{1}{2}$ in.) 
the control of the Hy pest should be the rendors of bread, milk and other articles of fool. Yet such has been the case in my experience. Their roices, however, are becoming less powerful in the conncil chambers where the stigma of insanitary conditions has so long been disregarded, and the increasing number of convictions for maintaining nnisances and exposing milk and food supplies to the attentions of Hies and the dust of the street are evidences of an awakening of the public conscience to its duty.

While inclividuals or small numbers of people acting in cooperation are seriously handicapped if they cannot look to the local health anthorities for assistance, the converse is cqually true, for withont the sympathy and the support of the people whom they serve the health anthorities cannot sncceed in their endeavours to ameliorate the sanitary conditions of the people. The zealous efforts of both individuals and of those in authority are essential to success.

It cannot be denied, however, in the light of what we now know in regard to the habits of the house-fly and the effect of its presence in numbers on the health of the community, that health authorities shonld not only enact the necessary bye-laws that will enable them to deal satisfactorily with the breeding places of the house-fly such as stable refuse, insanitary privies, collections of organic refuse and the protection of food sipplies, but that they should enforce the same. There are signs that the time is slowly approaching when one's senses will cease to be so distracted with the reiterated statement that the nation's greatest asset is the health of the people ringing in one's ears while filthy fly breeding spots meet one's gaze and foul odours greet one's sense of smell. The conscientious health officer is becoming more powerful than the vote-seeking " representative of the people."

Educational work is the most potent factor in deiling with this question. This should begin in the schools. It is unnecessary to change the curriculum but it is necessary that the teachers should know the facts and know them eorrectly. The lessons can be given as nature study or hygiene or both, and experience has shown that children not only quickly appreciate the significance of the Hy but are singularly active in making practical use of their knowledge. Such an organisation as the Boy Scouts can be 


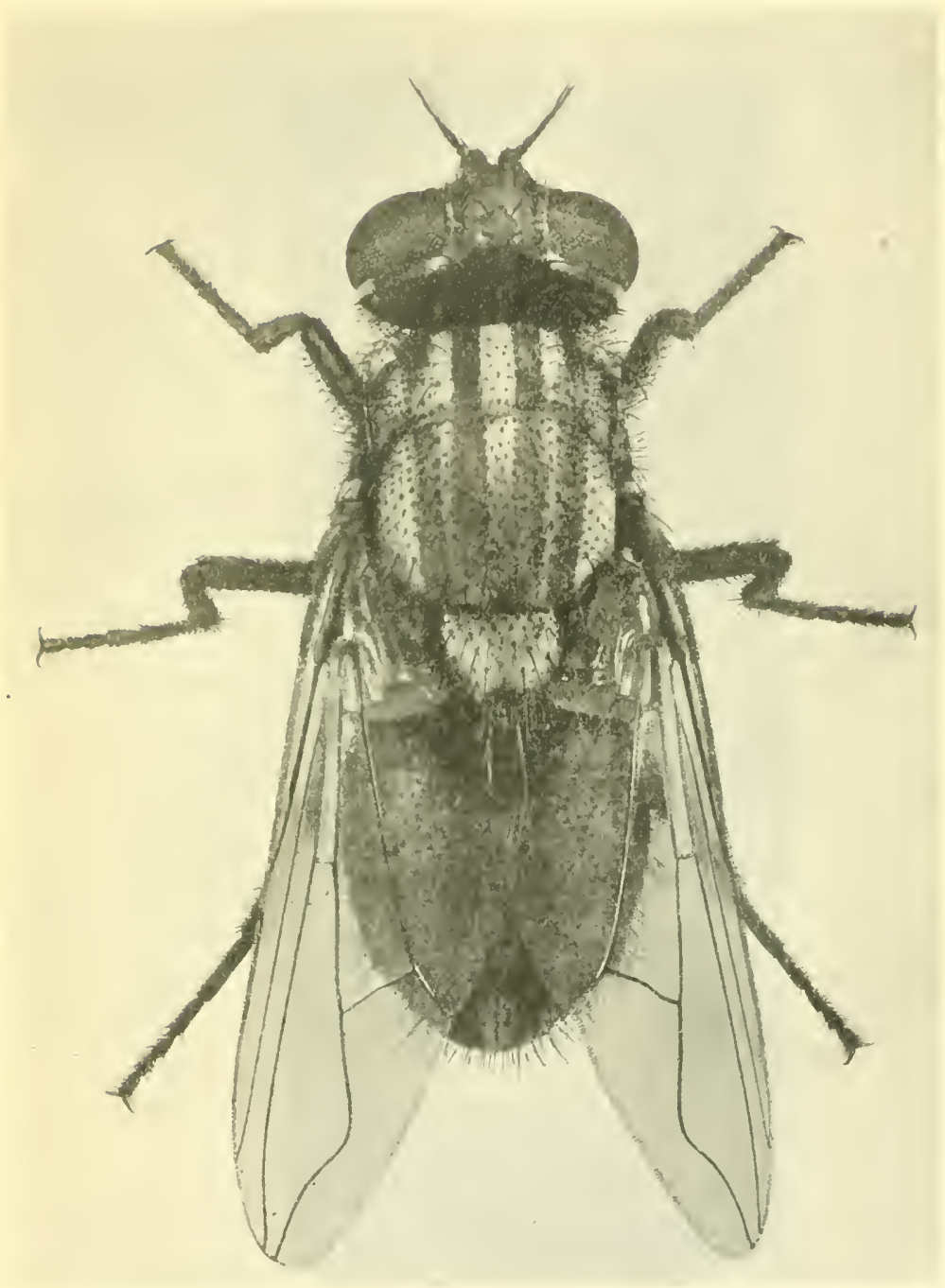

Fig. 103. Photograph of enlarged model of the House-fly, Huscu domestica, in the Anerican Museum of Natural History, New York.

(Reproduced by kind permission of the Museum authorities.) 
made a powerful adjunct to an anti-fly campaign, as I have found in Canada and as others have found elsewhere. They can assist

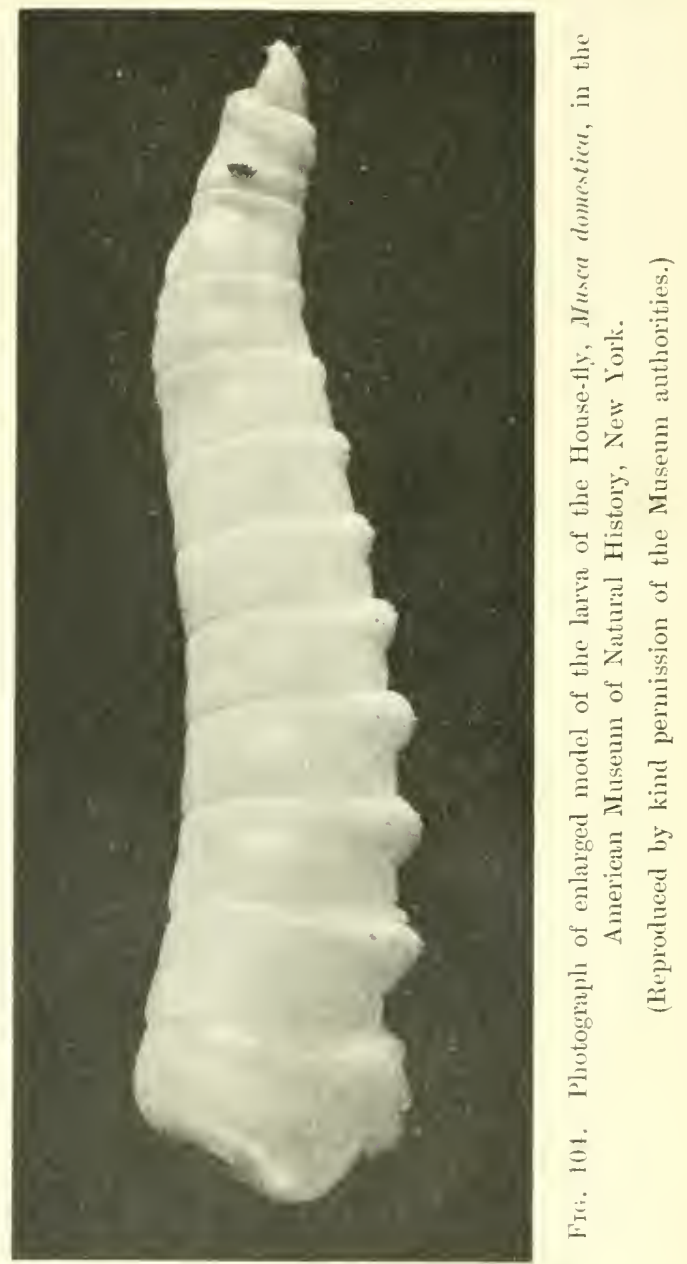

the sanitary anthorities in locating the breeding grounds and in their own listricts they can abolish the same.

Not less important is the work that ean be accomplished by women's organisations. The women of the community suffer most 
from the Hy pest. It is women who have to wage a constant war to protect the food in the home and the infints in the cradles. Women's organisations can do much to secure the adoption of anti-fly and sanitary measures and in many places they are succeeding in making the community more healthy. The boycotting of shopkeepers who do not protect the food they sell or of milk vendors whose premises are breeding grounds for flies is a cogent method of securing reform.

Citizens' organisations should begin cimnpaigns for clean cities. Such organisations are able to render invaluable service to the health ofticers by cooperating with then in the locating and suppression of the breeding grounds. By lectures, by the distribution of circulars such as the one illustrated herewith (fig. 102) which I prepared four years ago, and of other literature, much good can be done. The press has shown its willingness to assist, and the aid of local newspapers should be enlister. An excellent and educative cinematograph film illustrating the life-history of the house-fly and its method of spreading disease has been prepared and in my own experience has accomplished splendid work.

The statement camnot be too often repeated that flies and filth are synonymous terms. In a clean and sanitary community flies will be unable to exist in dangerous numbers and their absence may be taken as a measure of cleanliness. The time is coming when men will realise that it is easier to prevent disease than to cure it and less costly in terms of human lives. 


\section{BIBLIOGRAPHY}

AbeL, R. "Einige Ergainzungen zu der in No. 5-12 dieser Zeitschrift erschienenen Abhandlung von Nuttall ïber die Rolle der Insekten bei der Verbreitung von Infektionskrankheiten des Menschen und der Thiere." Hygienische Rundschan, Berlin, vol. 9, pp. 1065-1070, 1899.

Aissworth, R, B. "The House-fly as a Disease Carrier." Journ. Roy. Army Med. C'orps, vol. 12, 11). 485-498, 1909.

Albert, H. "Rôle of insects in transmission of disease." New York Med. Jomrn., vol. 81, 1). 22-20-225, 1905.

Alcock, A. Entomology for Medical Officers. (London: Gurney and Jackion), 347 PI', 136 figs., 1911.

Aldrich, J. M. A Catalogue of North American Diptera. Ninithsonian Misc. Coll., vol. 47, 680 JH., 1905.

Aldridse, A. R. "The Spreal of the Infection of Enteric Ferer by Flies." Jomn. Roy. Army Med. Corps, vol. 3, pp. 649-651, 1904.

"Homse-flies as Carriers of Enteric Fever Infection." Ibid., vol. 9, 1). $558-571,1907$.

Altamiraxo, F. "Inventigaciones sobre la putrefacción de los Zurrones de los moscos." Ann. J. Inst. Med. Nat., Mexico, rol, 2, pp. 99-101, 1896.

Anjersox, J. F. "The Differentiation of mutbreaks of Typhoid Fever due to infection by water, milk and contact." Medical Record (Nov. 28, 1908), vol. 74 , p. 909 ; also in Anerican Jomm. Pub. Health, vol. 19. 1\%. 251259.

Axderson, J. F. and Frost, II. H. Tramsmission of Polionyelitis by means of the Stable-fly, Stomoxys calcitrans. Public Health Reports, U.S. Public Health Service, vol. 27, P1. 1733-1735, 191‥

- Poliomyelitis. Further attempts to trumsmit the disease through the agency of the Stable-fly (Stomoxys culciturss). Public Health Reports, [T.A. Public Health Service, vol. 28, No. 18, 11). 833-837, 1913.

Axpour, $V$. "Recherches Anatomiques sur le thorax des Animanx Articulés et celui des Insectes Hexapoles en l'articulière." Ann. Sci. Nat. Zool., vol. 1,1824 .

ANDRE, C. Flies as agents in the dissemination of Kocli's bacillus. (Paper before Anti-Tuberulosis Congress, Washington, D.C.) 1908. 
Axthosy. "The suctorial (Mrgans of the Bhow-fly." Monthly Mierose. Journ., vol. 11, p. 24:2, 18:4.

Armstroxg, II. E. House-flies and Diserise; and the duties of Sanitary Authorities in relation thereto. Sprecial Rept. hy Mal. Officer of Health for Newcastle--иян-Tyue, 1908.

Arsistrosg, 1). P. Flies and Diarrhoeal I)isease. Publication X̃. 79, New York Ass. for Lmproving the Conclitions of the Pond Jur. Public Health and Hygiene of Dept. of Loeal Welfare, New York, 29 1pr., 3 pli., 1914.

"The House-fly and Diarrhoeil Disease among Children." Journ. Amer. Mel. Ass., rol. (i:2, H). 200-201, 1911.

A Ustex, E. E. "The House-fly and c'ertain Allied species as J bisseninator's of Enteric Ferer anong Troops in the Field," Jomrn. Ruy. Arny Med. Corps, vol. 2, pr. 6.5]-668, 2 pls., 1904.

Illustrations of British Bloud-sucking Flies, it plo, 34 col. plates. Brit. Mus. (Nat. Hist.), Lomlm, 1906.

Blond-sucking and other Hies known or likely to be concerned in the spread of clisease. In Allbutt's and Rolleston's System of Hedicine, vol. :1). $169-186,190$ \%.

"Notes on Hies examined during 1908. How to distinguish the more important species of flies found in houses." Reprort Locil (iovnt. Bd. on l’ul. Health aud Med. Subjects, N.S. No.5. Prelim. Repts. on Flies as Carrices of lnfection, lu). 3, 4, 1909.

_._ "Sone Dipterous Insects which canse Myiasis in Man." Trans. Sone. Trop. Med. and Hygiene, rol. 3, p1. 215-242, 1910.

"Menorandum on the result of examinations of flies, etc., from Postwich Tillage and refuse deposit ; with a note on the occurrence of the Lesser House-fly at Leeds." Repts. Local Fornt. Bd, on Publ. Health and Med. Subjects, N.S. No. 53; Futher Repts. (No. 4) on Flies as Carriers of Infection, 1). 11, 12,1911.

"British Flies which eause Myiasis in man." Repts. Local Gornt. Bd. Publ. Health and Med. Subjects, N.S. No. 60; Further Reports (No. j) on Flies as Carriers of Infeetion, 1"]. .5-15, 1912.

"The House-fly as a danger to Health. Its life-history and how to deal with it." Brit. Mus. (Nat. Hist.), Ecomom. Ser. No. 1, 11 l'p., 7 figs., 1913.

Axexfeld, T. The Bacteriology of the Eye. (Translated by A. MacNab.) Lomdon, 402 pl)., 87 figs., 3 pls, 1908.

AYlott, IV. R. "Do Flies spread Tubereulosis?" Virginia Med. SemiMonthly, Jume 26, 1896 ; also in Amer. Monthly Mieros. Journ., Aug., 1896.

ВАснмахx. "Ein Fall von lebenden Fliegenlarven in menschlichen Magen." Dentsche med. Wochenschr., fol. 24, pp. 193, 194.

Bachatetew, P. Experimentelle entomologische Studien. i. Temperaturrerhältuisse bei Insekten. Leipzig, 160 pI., 1901.

H. H. $-\mathrm{F}$. 
Васот, A. W. "On the persistence of Bacilli in the gut of an insect during metamorphosis." 'Trans. Ent. Soc., Lond., 1911, 1p. 497-500.

"The persistence of Barillus pyoryaneus in purpae and imagines of Musca domestica raised from larvae experimentally infected with the bacillus." Parasitology, vol. 4, ]']. 68-73. With addendum by J. C. G. Ledinghan, H. 73,74 , and an editorial note by G. H. F. Nuttall, 1) 73, 1911.

Balfour, A. Third Report of the Wellome Research Laboratories, Gordon College, Khartom, \}). 218, 219.

Balzer, F., Dantix and Landesmanx. "Un cas de Myiase ramprante clue à l'Hypoderma bozis." Bull. Soe. Françaice de Dermatol. et de Syphiligraphe, vol. 24, 1p. 219-226, 1913. Abstr. in Trop. Dis. Bull., vol. 2, (Nov. 15), 1'p. 526-527, 1913.

BAxks, N. "A Treatise on the Acarma or Mites." Proc. U.S. Nat. Mus., vol. 28, pl. 1-114, 201 figs., 1905.

__ "The Structure of Certain Dipterous larvae with particular reference to those in human Foods." Bull. No. 22, Techn. Series, Bur. Ent., U.S. Dept. Agric., 44 pp., 8 pls., 1912.

Barlow, J. "The House-fly or Typhoid Fly." Bull. Extension Dept., Rhode Island State Coll. No. 3, 12 11p., 1912.

Battersex, J. C. "Waterbome typhoid." Brit. Med. Joum., Part II, 10th Aug., 1895, 1. 393.

BAUWERkER. (A campraign against flies.) Zeitschrift fïr Gestïtkunde und Pferdezucht, vol. 8, pt. 6, 1). 121-129, Jume, 1913.

Becher. E. F. "Insects as carriers of disease." Cheltenham Proc. Nat. Sci. Soc., N.S. No. 1, P1. 73-92, 1908.

Becker, R. "Zur Kenntnis der Mundteile und des Kopfes des Dipterenlarven." Zool. Jahrb. (Anat.;, vol. 29, lp. 281-314, 3 lis., 5 figs., 1910.

Béclard, J. "Influence de la lumière sur les animaux." C. R. de YAcad. d. Sc., vol. 56, 11) $441-453,1858$.

Berg, C. "Sobre los enemigos pequenos de la langosta peregrina Schistocerca paranensis (Burm.)." C'om. Mus. Buenos Aires, vol. 1, Pl'. 25-30, 1898.

Berger, D. H. "The Relation of Insects to the dissemination of disease." New York Med. Jourm., vol. 85, pp. 1120-1125, 1907.

Berlese, A. "L' accopuramento della Mosca domestica." Rer. Patolog. vegetale, vol. 9, pl. 34.)-357, 12 figs., 1902.

— Gli Insetti. (Milan), rol. 2 (1. 18), 1912. "La distruzione della Mosca domestica." Redia, vol. 8, pp. $462-470$, 5 figs., 1912.

Bersisters, J. Summary of literature relating to the Bionomies of the parasitic fungus of Flies; Empusa muscue Cohn, with special reference to the economic aspect. Repts. Local (iovnt. Bel. on Pullic Health and Med. Subjects, N.s. No. 40, Further Repts. (No. 3) on Flies as Curricrs of Infection, 1) 1) 41-45, 1910. 
Berry. "Conjunctivitis set up ly Flies." Brit. Med. Journ. ]४y2, p. 1114.

Bertareld., E. " Terbreitung des Typlums dureh die Fliegen." Centralbl. Bakt. Palasitenk., rol. 53, pl. 4 46;-19.5.

Berer, H. G. "The Dissenination of Disease by the Fly:" New York Med. Jomrn., vol. 91, 111. 67-7-645, 1910.

Bezzi, M. and STers, P. Latalog der paläarktichen Dipteren (Bearbeitet ron Th. Becker, M. Bezzi, K. Kertes\% und P. Stein), rol. 3, 1. 828, Bulapest, 190\%.

Bigot, J. M. F. "Diptères nouvenux ou leu commus." Bull. Soc. Zoul. France, vol. 12, 1'l' 541--617, 189 .

Biflixgs. (Anthrix bacilli in flies cullected on infected steer.) Twentieth C'entmry Practice of Medicine, lags.

Bishopp, F. C: "The stable-fly (Stomoxys calcitrens L.), an inportant live stock pest." Jomrn. Econ. Ent., vol. 1; 111. 112-126, 2 pls., 1913.

The Stable Fly. Farmers Bull. No. 540, U.S. Dept. Agriculture, 28 pp., 10 figs., 1913.

Buaxchard, R. Traité Zoologie Médicale. Paris, 2 vols., 1890.

Blaskexiefer, H. C. "Infection with fly larvae, Anthomyin canicularis." Journ. Amer. Med. Asstn., vol. 45, 1. 1505, 1907.

Bogdarow; E. A. "Zehn Generationen der Fliegen (Muscu domestica) in veränderten Lebensbedingungen." Allg. Zeitschr. f. Entom., rol. 8, 1). $26,5-26 \%, 1903$.

Bollisger, O. "Experimentelle Untersuchungen iiber die Entstehung des Milzbrandes," 46 Versanml. d. D. Naturf. u. Aerzte zu Wiesbaden, September, 18:3; and "Milzbrand," in ron Ziemssen's Handl,. d. spec. Pathol. u. Therajie, rol. 3, pp. 282 and $457,1874$.

Booker, W. H. "A working plan for an anti-fly and anti-mosquito campaign." Bull. North Carolina State Bd. Health, Raleigh, X. C., rol. 27, No. 4, 1p. 126-133, July, 1912.

"Essential Facts about Flies," and "A Suggested anti-fly ordinance." Bull. Forth Carolina state Bd. Health, Raleigh, N. C., vol. 27, No. 4, pl) 1:33-141, 6 figs. (also issued as repriut), 1912.

Вогснє́, P. Fr. Naturgeschichte del Insckten besonders in Hinsicht ihrer ersten Zustande als Larven und Puppen. Berliu, 216 pp., 10 pls. (1). domestica, 1). 65-66, pl. 5, figs. 20-24), 1834.

Bras, C. K. Stomoxys calcitruns. Part I. Ann. Ent. Soc. Amer., rol. 5, pp. 421-430, 3 figs., 2 pls., 1912. Part II. Ibicl., vol. 6, pp. 197-202, 8 figs., 1913.

Bracer, F. "Die Zweiflügler des kaiserlichen Museums zu Wien: III. Srstematische Studien auf Grundlage der Dipterenlarven nebst einer Zusammenstellung ron Beispielen aus Literatur ïber dieselben und Beschreilung nener Formen." Denkschr. der Kais. Akad. der Wiss., math.-naturwiss. Classe, Wien, vol. $4 \overline{7}, 1$ 1p. 1-100. 5 pls., 1883.

Bracs. (Ophthalmia.) C'entralbl. f. prakt. Augenheilk., p. 5+5, 1882. (A review; cited by Abel, 1899. 
Braux, 11. The Animal Parasites of Man. (Lomdon: Bale, Sons and [Manielsson, 453 l'p., 294 figs., 1906.

BREFELD, O. "' Lntersuchungen iiber die Entwickelung der Émpusa muscce und E. radicans." Ahh. d. Naturf. Gesellsch. Halle, rol. 12, 11. 1-50, 1)l. $1-4,1871$.

Brewster, E. T. "The Fly, the J)isease of the House." McClure's Magazine, vol. :33, 1', if 1 -569, Sept., 1909.

Brittox, IT. E. "The Conmon Honse-fly ( $1 /$. domestica) in its relation to the public health." Yale Jled. Journ., vol. 12, p1). 750-757, 1906.

"The Honse-fly and its Relation to Tylhuid Fever." Proe. Sixth Conf. Health Officer's of Commecticnt, Hartforel, Comm., April, 1912, 18 pl. (reprint).

"The rôle of the house-fly and certain other insects in the spread of hmman diseases." P(p. Sci. Monthly, July, 191.2, 1'p. 36-49, 5 figs.

"The Howse-fly as a Disease-carrier and how controlled." 12 1p., 5 figs. (Publ. by Comneeticut State Bu, of Health), 1912.

Broes, (. T. "The Rulation of the Stable-fly (Stomoxys calcitrans) to the transmission of Infautile Paralysis." Jomm. Econ. Ent., vol. 6, pp. $101-$ 10:1, 1913.

Brtes, (. T. and Sheppard, P. A. E. "' The Possible Etiological Relation of Certain Biting Insects to the spread of Infantile Paralysis." Journ. Econ. Ent., vol.5, pp. 305-324, 1912. Alstracted previously in Monthly Bull. Mass. State Board of Health, Dec., 1911, p1. 337-3.0.

Bechaxux, R. M. "The (arriage of Infection by Flies." Lancet, rol. 173, 1). $216-218,5$ figs., 1907.

"Empusu muscue as a carrier of bacterial infection from the Housefly." Brit. Med. Journ., Nov. 22, 1913; Rejrint: 18 pp., 21 figs., 1913.

Buchдxм, W. J. "Choler" Diffusion and Flies." Indian Med. Gaz., lग. 86, 87, 1897 .

Bupd, W. "Uhservations on the veenrence (hitherte mnoticed) of malignant pustnle in England." Lancet, pl). 16-4, 165, 1862.

Brer, H. G. "Dissemination of Divease by the Fly." New York Med. Journ., April 2, 1910.

Cadet, (i. The Pian. Thìse, Borteanx, 1897.

Calaxdrcccio, s. "Clteriori ricerche sulla Taeniu nana." Boll. Accad. (iinenia, Catania, Fasc. 89, 11. 15-19, 1906.

Caldweld. Manual of Military Hygiene. Flies in trenches. 1). 237), 1905. Campbert, C. "Honse-flies and Disease." Brit. Med. Jomm., 1901 (:nd rol.), 1).989.

Caxpruo, (i. "Anchilustomoanemia associata a Miasi intestinale." Anm. Med. Navale e Colon, vol. 1, 1). 39t-407, 1 fig., 1913; Alistr. in Trop. Dis. Bull., vol. 2 (Nov. 15), 1. 533, 1913.

Cso, A. "Sul passagglo dei nicro-organismi attraverso l' intestino di alcui insetti." Estratto dall' [fficiale Sanitario, Rivista d' Igiene e di Medicina pratica. Anmo 11, 1. 98, 1898. 
C^o, G. "Sul passaggin dei germi attraverso le larve di alcuni insetti." Ann. d' Igiene sper., vol. 16, p. 64.5, 190m.

Cartir, H.J. "On a bi-sexual Nenatoid Worn which infests the f'mmmon House-fly (Jusca domestica) in bombay." Ann. Mng. Nat. Hist., ser. (3), vol. 7,1$)$ 1. $: 9$-333, 4 figs., 1861.

Carter, Hexre F. and Bracklock, B. "External Myiasis in a Monkey."

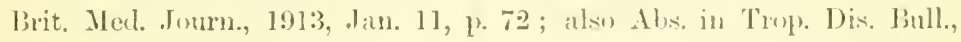
vol. 1, no. $8,1 \% .471,1913$.

Casteldaxi, A. "Experinental Investigation on Foumborin tropica (Iaws)."

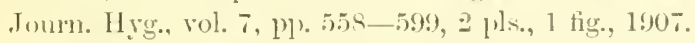

Catthe, C. H. "A case in which large quantities of dipterous larvae were passed prel" ammm." Brit. Med. Jomm., vol. 2, p. 1666. 1946;.

Céll, A. "Trasmissibilitì dei germi patogeni mediante le dejecione delle Musche." Bull. Soc. Lancisianin d. (nspedali di Roma, fasc. 1, pl. 1, 1888.

Chantemesse. (Cholma and Hies.) Report of Mecting of Acad. de Med., Paris, rer. in Met. Ree., vol. 6\$\$, 1). 949, 190\%.

Chapsax and Jomssos. "Hunse-Hies and Disease." Brit. Med. Jomm., 1901 (2nd rol.), 1) 126.

Chattos, E., and Lfger, M. "L'Antonomie des Trypanosomes propre anx Inseides démontrée par les élerages purs indéfinis." Comp. rend. soc. Biol., vol. 74, No. 10, 11). 54!-5.51, 19 !3.

Cherril, R. "Larres de monches dans la ressie de l'Homme." Rev. Sci., Paris, vol. 11, 1p. 6.21-624, 1909.

"Sur la myase des voies urinaires." Arch. de Parasitol., vol. 12, Pl. 369-450, 12 figs., 1909.

Chusmicek, J. F. "My ohservations on the typhoid epidemic in southern camps and its treatnent." New York Med. Journ., vol. 70, p1. 193-198, 1899.

Cleaver, EmM O. "The Rôle of Insects in the Transmission of Disease: a Résumé." Pennsylvania Med. Journ., vol. 4, 1).457, 1900.

Cleland, J. B. The Relitionship of Insects to Disease in Man in Australia. Second Rejt. Gort. Bur. Microbiulogy for 1910-11, py. 141-158, 1912.

Contes, B. H. "Medical note on the more familial flies." Trans. Coll. Phys. Phila., N. S., vol. 3, 1. 348, 1863.

Cовв, J. O. "Is the Common Honse-fly a factor in the spread of Tuberculosis?" Amer. Med., No. 9, 1905, pl. 475-47\%.

Coвв, N. A. "Fungus maladies of the sugar cane." Bull. No. 5. Expnt. Sta., Hawaiian Sugar Planters' Asstn. Div. Pathology, Honolulu, 1906.

"The House-fly." National Geographic Mag., May, 1910, 11), 371-380, 4 figs.

Cobbold, T.S. Parasites: A treatise on the entozoa of Man and Animals, including some account of the ectozoa. 508 pl., 85 figs., London, 1879.

Cochraxe, E. Wr. W. "A small epidemic of Typhoid Ferer" in connection with specifically infected Flies." Journ. Roy. Army Med. Cor'ss, vol. 18, 1). 271-276, March, 1912. 
Cockerill, J. W. "Report on the Prevalence of Enteric Fever in Bermuda," with Tahles and Diagrams. Ibid., wol. 4. 1p. 762-796, 1905.

Сонs, F. "Empusa muscue und die Krankheit der Stulenfliegen." Nova Acti Acaul. Caes. Leop. Carol. Crerm. Nat. Cur., vol. 25, 1) 301, 1855.

Сонs, .l. "Fliegeneier in den Eintleerungen eines Säuglings." Deutsche med. Wochensehr., Jahrg. 24, p1. 191-193, 1898.

Coker, W. C. "Necessity of water for flies." Nature Study Review, vol. 7, No. 9, Dec., 1911.

Coldinge, W. E. "House-flies and Public Health." Alsstract only, in Proc. Ass. Econ. Biol., Journ. Econ. Biol., vol. 6, 1). 153-154, 1911.

Compere, G. "A few facts conceming the Fruit-ties of the world, iii." Monthly Bull. State Bd. Hort., Calif., U.S.A., vol. 1, P1. 907-911, 1912.

Cosstock, J. H., and NeedhasI, J. G. "The Wings of Insects." Amer. Nat., vol. 32, p. 43, etc., and continued through the vol. into vol. 33, 1898.

Conradi, A. F. Controlling Flies. Cireular No. 23, South Carolina Agric. Exprort. Sta., Clemson Coll., S.C., 14 pp., 5 figs., 1913.

Covverse, G. II. "Amoebiasis." Bull. Cal. State Bd. of Health, October, 1910.

Copeman, S. M. Report to the Local Government Boird on the General Sanitary Circumstances and Administration of the County Borongh of Wigan, with special reference to Infantile Mortality and to Endemic Prevalence of Enteric Ferer and Diarrhoea, 22 pp., London; (Flies, 1. 18), 1906.

_ Memorandum on investigation into possible carriage of infection by Flies. Suggested "Plan of Campaign" in Lrban Vistricts. Repts. Loeal Gornt. Bd. on Pub. Health and Med. Subjects, N. S. No. 16; Further Prelim. Repts. on Flies as Carriers of Infection, pp. 1-4, 1909.

Note as to work in hand, but not yet pullished; and as to proposed further work in reference to Flies as Carriers of Infection. Repts. Local Govnt. Bd. Publ. Health and Ned. Subjects, N. S. No. 40 ; Firther Repts. (

Hibernation of House-flies (Prelinninary Note). Repts. Local Govnt. Bd. Pull. Health and Mel. Subjects, X. S. No. 85; Further Repts. (No. 6) on Flies as Carriers of Infection, 1.p. 14-19, 1913.

Copenax, S. M., Howlett, F. M., and Merrinax, G. An Experimental Investigation on the range of Flight of Flies. Repts. Local Gornt. Bd. on Publ. Health and Med. Subjects, N. S. No. 33 ; Further Repts. (No. 4) on Flies as Carriers of Infection, 1'1. 1-10, 1 mal, 1 tahle, 1911.

Coplix, W. II. S. "The Propagation of I)isease hy means of Insects, with special consideration of the common domestic types." Pennsylvania Med. Journ., vol. 3, p. 241, 1900.

Cox, (*. L., Lewis, F. C., and Glyex, E. E. "The number and varieties of Bateria carried by the Common House-fly in sanitary and insanitary city areas." Journ. Hygiene, vol. 12, 1)p. 290-319, 2 pls., 2 figs., 1912. 
CraIg, C. F. "The rôle of insects in the propragation of disease." Philadelphia Mel. Journ., vol. 3, 1\% 1381, 1899.

CRaWford, I. "Olservations on the seats and causes of discase." Baltinore Ned. and Physical Recorder, vol. 1, 117. 40, 81, 206; vol. 2, p. 31, $1808-$ $180 \%$.

Crichtox-Browxe, sir J. "Malaria in relation to sanitation." Reprint of ahleress before Sanit. Iusp). Asstu., 6 Aug. 1902, 28 "l.

DAxiels, C. II. Studies in laboratory work. London, 1907.

DarLIxg, S. T. "Experimental infection of the mule with Trypanosoma hippiam by meius of Muscu domesticu." Journ. Exp. Med., vol. 15, 1'1. $365-366,1912$.

The prurt played by flies and other insects in the spreat of infectious diseases in the tropies, with special reference to ants and to the transnission of T'r. hippicum by Muscu domesticu. 'Trums. Fifteenth Internat. Congress Hyg. and Denog., Sect. v, Washington, Reprint 4 1'p., 1913; Alstr. Rev. Appl. Ent., vol. 2, Ser. 13, 1p. 9-10, 1914.

Davane, ( $:$ "Etudes sur la contagion du charbon chez les animaux domestiques." Hull. Acacl. Méd. Paris, vol. 35, l'l. 215-235, 1870.

DedDrick, WT. II. "Notes on intestinal myiasis." Arch. f. Schiffs- und Tropen-Hygiene, rol. 12, 1p. 726-729), 1908.

DE GEer, CARL. "Mémoires pour servir à l'Histoire des Insectes." (Jf. domesticu, vol. 6, pp. 71--78, pl. iv, figs. 1-11). Stockholm, 1776.

Deli, J. A. "On the Strueture and Life-history of Psychodu sexpunctata." Trans. Ent. Soc. London, 11). 293-311, 1905.

Demetriades. (Ophthalmiu.) Centralbl. f. prakt. Augentreilk., p. 4l 2, 1894. Dickexsos, G. K. "The House-tiy and its comnection with disease dissemination." Med. Rec, vol. 71, P. 134-139, 1907.

Diesixg, K. I. "Kleine helminthologische Mittheilungen." Sitz. Kais. Akal. d. Wiss. Wien, vol. 43, pl). 269-282, 1861.

DOAxE, R. W. Insects and Diseave. A popular account of the way in which insects may spread or canse some of our common diseases. Amer. Nature Series (New York: Holt and Co.), 227 l11., 112 figs., 1910.

"An annotated list of the literature on Insects and Diseases for the year 1910." Journ. Econ. Ent., vol. 4, No. 4, p1. 386-398, 1911.

_ "An annotated list of the literature on Insects and Diseases for the year 1911." Ibid., vol. 5, No. 5, pp. 268-285, 1912.

Doxнoff. "Beiträge zur Physiologie, I : Ueber das Verhalten Kaltbliitiger Thiere gegen Frosttemperatur." Arch. f. Anat. und Phys. und Wiss. med. von Reichert und Du Bois-Reymond, 1) 724, 1872.

Joxoyax, E. Natural History of British Insects. Tol. 6, 1. 84, 1797.

Doxorax, H. L. ("Can Flies carry Cholera?") Indian Med. Journ., vol. 21, 1. $318,1886$.

Drew, H. V. "A case of invasion ly dipterous larvae." Brit. Meck. Journ., vol. 2, p. 1066, 1906.

Donkerly, J. S. "On Some Stages in the Life-history of Leptomonas 
muscue-domesticoe, with some remarks on the relationship of the Flagellate Parasites of Insects." Quart. Jomm. Micros. Sci., vol. 56, 1). $645-(5.5 .5,1911$

Duxxe, A. 3. "Typhoid Fever in South Africa ; its Cause and Prevention." Brit. Med. Jomm., March 8th, 1902, p. 620.2.

DutTox, W. F. "Insect carriers of Typhoid Fever." Joum. Amer. Med. Asstu., vol. 5:3, 111. 1248-1252, 7 figs., 1909.

"ilue-hottle flies as carriers of infection." Jonrn. Aner. Med. Asstn., vol. 5i3, 1). 1561, 1909.

EDGAR, ('. L. "A case of Screw-worm in the Nose." Texas State Journ. of Med., vol. 9, ]'. 21, 1913.

Ercolisi, G. B. "Snlla dimorfobiosi o diversi modi di vivere e riprodursi sotto duplice furma di ma stessa specie animali. Osservazioni fatte soln'n alcuni nematnelminti." Mem. Acarl. d. Ac. Ist. di Bologna, Ser. 3, vol. 4, 1']. 237-264, 2 pls.

Estex, W. M., and Mason, C. J. "Soumces of Bacteria in Milk." Bull. No. 51, Storr's Agric. Exp. Sta., Storrs, Comn., U.S.A., 1908.

Ewetzki, T., aud Kexsel, J. "Eine Fliegenlarve in der vorleren Augenkammer." 'Zeit. Augenheilk., Perlin, vol. 12, 1p. 337-351, 1 11., 1904.

Ewrag, H. E. "A new Parasite of the House-fly (Acarina, (tamasoidea)." Eut. News, vol. 24, 1). 4i.2-4.56, 1 pl., 1913.

FaIchat, $\mathrm{X}$. "Fly-borne enteric fever; the source of infection." Journ. Ruy, Army Merl. Cor [s, rol. 13, 1). 580-584, 1909.

"Bucillus typhosus in Flies." Ibid., pl. 672-675, Dec. 1909.

Farrar, R. Reports of Medical Inspectors of the Jocal Gorut. Board, No. 216, 3. 9, 1905. (Possible carriage of enteric fever by flies in Turkshire.)

Fent, E. P. "The Economic Status of the Honse-fly." Journ. Econ. Ent, sol. 2, 111. 39-44, 1909.

Typhoid or Honse-fly. Twenty-fifth Report State Entomologist, Bull. No. 475, New York State Ednc. Dept., PP. 12-17, 1910. Same observations also in Journ. Econ. Ent., vol. 3, J). 24-26, 1910.

"Methods of controlling the House-fly and thus preventing the dissenination of lisease." New York Med. Journ., April 2, 1910, No. 91, 11). $68.5-68 \%$.

"Control of Flies and other householil Insects." Bull. No. 465, New

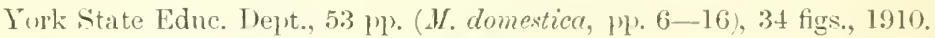

(Reports a case of Myiasis dne to M. domestica). Notes for the year. 'Twenty-eighth liejt. State Entomologist on Injurions and other insects of the state of New York. Museum Bull. No. 165, N.Y. State Museum, 1.. $93,19133$.

Fermi, 6. "Lyssicide action and vipus transmission by flies.") Centralbl. Bakt. 1 Aht. Orig., wol. 61, 1'. 93-97, 1911 .

Ficker, M. "Typhus und Fliegen." Arch. f. IIygiene, vol. 46, 1"1. 2-74-282. 1903. 
Fielo, F. E. "Myiasis; with special reference to some varieties treated at the (ieorgetown IIospital." Brit. Ciniana Med. Amm. for l!)11, Mp, for-fil, 1913.

Fintu, li. H., and Horrocks, II. II. "An Inquiry into the lufluence of suil, Fabries, and Flies in the dissemination of enteric infection." Brit. Mel. Jomm., rol. 2, p1). 9:36-94:3, 190.2.

Fletcher, J. Report of the Entonologist and Jutumist. Experimental Fams Report, Dept. Agric. Cinada, Ottawit, Pl. 22.5-2.26, 1900.

"Praetical Entomulugy:" (liev. of Howarl, 1900. Ins. Fauna of Humau

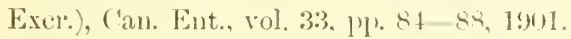

Flexier, S. "Some problems in infection and control." science, rol. :36, No. 934, 119. 68\%- $700,191: 2$.

Flexigr, S., and ('Larkf, P. F. "Contanination of the lunse-Hy with Polionyelitis virus." .Journ. Amer. Mel. Asitu., vol. so; pl\% 1717-1718, 1911.

FLC, P. C. "Studien iiber die im Dar'm der' Stubenfliege, Musce dumestica, rorkommenden protozöiren Gebilde." Centralbl. f. Balkt., rol. 57, 1). $52 \cdot 2-534,1911$.

Flëgre, C. (irundriss der Hygiene, pl). 473 and 532, 1891.

"Die Verbreitungsweise und Verhiitung her Cholera auf Grum der neneren cpideniologischen Erfahrmingen und experimentellen Forschungen." Zeitschr. f. Hygiene, vol. 14, p. 165, 1893.

Foxistorives. "Les momehes an puint de vue de l'hygiene." Gaz. hebdom.

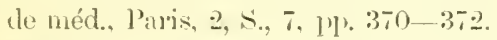

Formax, R. H. "Indian Enteric and Latrines." Jomn. Roy. Arny Med. Corps, vol. $7,11 \%$. 304-305, 1906.

Fraxcarigua, M. C. 'Altro easo di Myiasis nell' tomo per luma cuticulare d' Ilypoderma boris (De (ieer)." Policlinico, Sez. pratica, vol. 19, lp. 1593-1595, 1913; Abstr. in Trop. Dis. Bull.. vol. 2. (Nor. 15), 1. $526,1913$.

Fraxcis, C. F. "Cholera caused by a Fly (?)." Brit. Med. Jouru., 1, 2, P. $65,1893$.

Fraxklix, G. D. "Some Observations on the Breeding Fround of the Common House-fly:" Indian Med. Gaz., vol. 41, [11. 349-350, 3 pls., 1906.

Fraser. (Epidemic diarhuea in Portsmonth in relation to flies.) Hewlett (1905, p. 505) gives quotation from Friser's Report for 1902, 1. 47, eited by Nuttall and Jepson.

Frogfatt, W. W. "The House-fly and the diseases it spreads." Agric. Gazette, New South Wales, 1'l. 243-250, 1 fig., March, 1910; also issued separately as Miscellaneous Publication No. 1311.

Frost, I., and Tonhees, C. T. "The Honse-fly Nuisance." Country Life in America, May, 1908.

Fuchs. (Egyptian Ophthalmia.) Wien. klin. Wochenschr., No. 12, 1. 211, 1894. (ited by Abel, 1899.) 
Gadnie, D. W. "What shall we do with the house-Hy"?" Ky. Mel. Jumrn., Maly 1, 1911.

Galli-Talerio, B. "Les Insectes emme propagateurs des maladies." Ber. 14. Int. Congr. Hyg. u. Demogr., Berlin, $190 \%$.

"L'état actuel de nos comnaissances sur le rôle des mouches dans la dissemination des maladies parasitaires, et sur les morens de lutte à employer contre elles." Centralbl. f. Bakt. Alt. 1, vol. 54. 1'l. 193-209, 1910.

Gaxx, T. W. "Beef-worm in the orbital eavity." Lancet, vol. 1. pp. 19-21, 1902 .

Gryox, J. "Cholera and Flies." Geneesk. Tijdschr. v. Nederl. Indië, rol. 48, No. 2, pl. 227-233, 1908 ; abs. in Journ. Trop. Med. and Hyg. London, vol. 12, No. 10, p. $158,1909$.

Garrood, J. R. "Note on a case of intestinal myiasis." Parasitology, rol. 3, 1'p. 315-318, 1910.

GaYox, J. P. "A note concerning the transmission of Pathogenic fungus by flies and mosquitoes." Public Health, 'U.S.A.), vol. .2\&, 1'l. 116-117, 1903 .

Gedprisg, H. D. Précis on the Hy and mosquito as carriers of disease. Public Health Reports, L'.S. Pub. Health and Mar. Hosp. Service, vol. 17, No. 35, 1903.

Geserali, (. "Una larra di nematode della mosca commune." Atti Soc. d. Nat. di Mudena, Rendic., Ser. 3), vol. 2, pp. 8Q-89, 1856.

Geoffror, E. L. Histoire abrégée des Insectes, vol. 2, p. 624, 1764.

Gerhard, W. P. "Bibliography on Flies and Musquitoes as carriers of disease." Entom. News, Philadelphia, vol. 20, pp. 84-89, 1909.

"Additional Bibliography on Flies and Mosquitoes as carriers of disease." Ibid., P1). 207-211, 1909.

"Flies and Mosquitoes as carriers of disense." Author's Reprint from The Country Gentleman, Albauy, N.Y. Publ. New York, 14 pp., 1911.

Germax. Ophthalmiu.) (entralbl. f. prakt. Angenheilk. Supll., 1. 386, 1496. (Cited by Abel, 1899.)

Giard, A. "Deux espèces d'Entomophthora nouveaux pour la Hore française et la présence de la forme Turichium sur une Muscide." Bull. Scient. du Department du Nord, ser. 2, second year, No. 11, pp. 353-363, 1879.

Giles. C. II. "The anatomy of biting Hies of the genera stomoxys and Glosina." Jomm. Trop. Med., rol. 9, p. 99, 1906.

Girault, A. A., and Stxpers, G. E. "The Chalcidoid Parasites of the Common House or Typhoid Fly (Husca domestica, L.) and its allies." Pscche, vol. 16, pp. 119-132. 5 figs., 1909.

— "The Chalcidoid Parasites of the Common House or Trphoid Fly (Husca domestica, Linn.) and its allies." Il,ikl, rol. 17, 11).9-25, Feb. 1910.

vos Gleichex, F. Wilhels. Geschichte der gemeinen Stubenfliege. 32 pp., 4 1)ls., Nurnberg, 1790. 
Godfrer, R, "The False-scorpiuns of Scotland." Ann. Seot. Nat. llist, No. 69, January, 1909, 11. 22-2-26;.

Graham-sinth, G. s. Preliminary Note on Examinations of Flies for the presence of Colon Bacilli. Repts. Loeal Govnt. Bul, on l'nbl. Health and Med. Subjects, X. s. No. 16; Further Prelim. Repts. on Flies as Carriers of Infection, 1). 9-13, 1909.

Observations on the ways in which artificially infected Hies (Jusce (lomestica) carry and distribute pathugenic and other bacteria. Reprts. Local Gornt. Bu. on Publ. Health and Med. Subjects, N. S. No. 40; Further Repts. (No. 3) on Flies as Carriers of Infection, 11\% 1—41, 7 pls., 2.5 tables, 1910.

Further observations on the ways in which artificially infected flies (Musca domestica and C'ulliphora erythrocephelu) carry and distribute pathogenic and other bacteria. Repts. Local Gornt. 13d. Publ. Health and Med. Nubjects, N. S. No. 533 ; Further Rejorts (No.4) on Flies as Carriers of Infection, Pl. 31-48, 13 tables, 1911.

"Some observations on the anatomy and function of the oral sucker of the Blow-Hy (Calliphore erythrocephale)." Journ. Hygiene, rol. 11, No., 3, l'1. 390-408, 5 pls., Nov., 1911.

"House-Hies." Bedrock, No. 2, 1']' 205-223, 1912.

An Investigation of the incidence of the miero-organisms known as non-lactose fermenters in flies in normal surroundings and in surroundings associated with epidemic diarrhoea. In Ann. Rep. Locil Govnt. Bd., Sul. Rept. Med. Officer, $1911-1912$, p. 304-320, 1912.

An Investigation into the possibility of pathogenic micro-organisms being taken up by the larva and subsequently distributed by the fly. Iu Ann. Rept. Loeal Gornt. Bd., Supp. Rept. Mel. Officer, 1911-1912, 1’. 330-335, 1912 .

Flies and Disease: Non-blool sucking Flies. Camb. Pıl,. Health Ser., pp. xiv $+292,32$ text figs., 24 pls., Cambriclge, 1913.

Further observations on non-lactose fermenting Bacilli in Hies, and the sources from which they are derived with speeial reference to Morgan's bacillus. Repts. to the Local Gornt. Board on Publ. Health and Med. Subjects, X. S. No. 85; Further Rept. (No.6) on Flies as Carriers of Infeetion, 1'). 43-46, 1913.

Grassi, B. "Les méfaits des Mouches." Areh. ital. de Biologie, wil. 4, pp. 205-228, $188: 3$.

Griffith, A. "'The Life-history of House-flies." Public Health, vol. 21, 11) $122-127,1908$.

Griffith, F. "Description of a House-fly Parasite." Med. Brief, St Louis, vol. 35, 1). $59-63,1907$.

GrüxberG, K. Die Blutsangenden Dipteren. Leitfaden zur allgemeinen Orientierung, mit besonderer Beriicksichtigung der in den deutschen Kolonien lebenden Krankheitsiaberträger, 188 11', 127 figs. (Jena : (Elistav Fischer), 1907. 
Gudger, E. W. "An early unte on Flies as transmitter's of disease." Science, wh. :31, 11). $31-32,1910$.

"A second early snote on the transmission of yaws by Flies." Science, rol. $32,1 \mu .632-633,4 \mathrm{Nov} .1910$.

Güssow, 1I. 'T. Empusu muscue and the extermination of the Honse-fly. Repurts to the Local Govnt. Board on Public Health and Med. Subjects, N. S. No. 85; Further Rept. (No.6) on Flies as (arriers of Infection, l'1. 10-14, 1 11., 1913.

Gex́xot, E. "L'aplareil digestif et la digestion le quelques larves des monches." Bull. scient. de la France et de la Belgique, vol. 41, 1\%. 353$369,1907$.

(Gruaxi, E. "Ueher Ophthalmomyiasis." Klin. Monatsb]. Augenheilk., vol. 48, 11).625- (i27. Stuttgart, 1910.

Haeser. (Plague and tlies.) (ieschichte der med. u. epidem. Krankh. 3. Autl., vol. 3. (Cited by Nuttall, 1899.)

Hatiex, A. "On the larvae of insects discharged through the mrethra." Proe. Boston Soe. Nat. Hist., vol. 20, 11). 101-118, 1879.

HALL, M. C. and MUr, J. T. "A eritical study of a case of Myiasis due to Eristalis." Arch. Internat. Mfed., vol. 12, 11). 193-202, 1913; Abstr. in Trol. Dis. Bull., vol. 2, (Nor. 15), 1. 533, 1913.

Hamer, W. H. Nuisance from Flies. Rejort by the Nedical Officer presenting a report by Dr Hamer, Medical Officer General Purposes), on the extent to which the fly nuisance is produced in London by accumulations of offensive matter. 10 plo., 2 figs., 3 diagrams. Printed for the Loudon County Council (Public Health Committee), London, 1908.

_- Nuisance from Flies. Report of the Medical Officer of Health presenting a further leport by Dr Hamer, Medical Officer (General Purposes), on the extent to which the Hy nuisance is produced in London by aceumulations of offensive matter. 6 l'p., 4 diagrams. Printed for the London Comnty Council (Public Health Committee), London, 1908.

"The Breeding of Flies summarised." Am. Mell. No. 3, 1908, p. 431.

Flies and rermin. Report by the Medical Officer of Health presenting reports by Dr Hamer, Medical Officer (General Purposes, on Nuisance from Flies and on the seasonal prevalence of rermin in common lodginghomses. Rejort of the Public Health Committce of the London Connty Council for 1909. Appendix No. 4, 9 11), 5 charts, 1910.

HAMERToN, A. E. "Iutroduction to methods of study of the morbid listology of disease-carrying insects." .Journ. Rns. Army Med. Corls, vol. 11, 111. 243-249, 1908.

Hanntox, A. "The Fly as a Carrier of Typhoid; an inquiry into the part played by the common Homse-fly in the reent epidemic of typhoid ferer in (hicago." Journ. Amer. Merl. Ass, vol. 40, 1\% 567, 1903.

"The common House-fly as a carrier of typhoid fever." "Journ. Amer. Merl. Ass., vol. 12, p. 1034, I904.

- (Isolation of tuhercle bacilhs from thies canght in a privy.) lrit. 
Med. Jomrn., 1. 14!, 1903; also see Jomm. Aner. Med. Ass., anth Feb., $190 \%$.

Hamilios, A. "The rôle of the House-fly and other insects in the spread of infections aliseases." Illinois Med. Jomm., springlield, wh. !), l'p. is:3587,1906 .

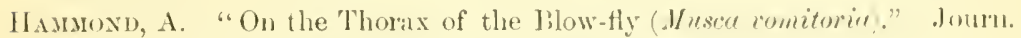
Limu. Soc. (Zool.), vis. 15, 11). 9-31, 2 pls., 1881.

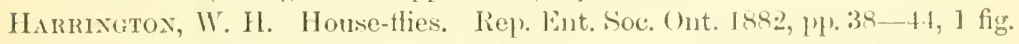
IARrison, J. H. H. "A cilse of Myiasis." Jomm. Trop. Med., vol. 11, p. 305, 1908.

H.tcu, E. "The Honse-fly as a Carrier of Disease." Ann. Aner. Acad. Pol. soc. Science, Mall. 1911, pr. $412-42: 3$.

Report of the ('haiman of the Fly-tighting Committee of the American Civic Assn., Am. (onvention, Baltinore, Md., 20th Nov. 1912. Separately issned, 16 ll'., 1913.

H.ictefecrle. "Les Diptères parasites des civités naturelles ehez l'homme." Amiens Bull. soc. lim., vol. 18, l'1. 81-90, 1907.

H.rW.rnd, E. H. "The Fly as a Carrier of Tuberculosis Infection." New Fork Med. Jomrn., vol. 80, 1). 643-644, 1904.

Heckexrotm, F. and Blaxchard, M. "Note sur la présence et l'endémicité d'une Myiase furonculeuse au ('ongo français." Bull. Soc. Path. Exot., rol. $6,113.350-351,1913$.

Hexcegur, L. F. Les Insectes. Paris, s04 l'l., 1904.

Hexsches. (The larrae of thies as the cause of chronic psendomembranons enteritis.) Wien. klin. Rundschau, No. 33, 1896. (Rer. in Aner. Jomm. Merl. Sci., vol. 11:3, 1. 73:- 1897.)

Hepworth, J. "On the structure of the Foot of the Fly." (quart. Journ. Micr. Sci., vol. 2, 1p. 158-160, 1854.

Herus, W. B. "Essentials of House-fly Control." IBull. Berkeley (Cal.) Bd. of Health, 29 .June, 9 11., 1909.

"The Honse-fly Problem." Pacific slope Asstn. Econ. Entomologists, Bull. Card No. 1, 1909.

"Medical Entomology, its scope and methods." Journ. Econ. Ent., rol. 2, 1'\%. 26.5-26\%, 1909 .

"The Berkeley House-fly Campaign." Calif. Journ. Techmol., vol. 14, No. 2, 11 ple., 3 figs., 1909.

"Insects as they relate to rural hygiene." Calif. Cultivator, rol. 34, No. 2, 1'p. 35, 38, 39 and 43, 1910.

Insect Pests as they relate to rural hygiene, with special reference to control. Proc. Thirty-sixth Convention Califomia State Fruit Growers, Pl. 160-167, 1910.

"How to control the Common House-Hy." Monthly Bull. Calif. State Bu. of Health, rol. 5, Мay, pl. 269-277, 5 figs., 1910.

"Fight the Fly,-Why,-When,-Why,-How?" Bull. Berkeley (Cal.)

Bd. of Health, 1910. 
Herss, II. B. "The House-fly in its relation to public health." Bull. 215, Calif. Agric. Exp. Sta., 11. 513-548, 15 figs., 1911.

Herviecx. (Report on carriage of smalpox by flies, read to Academy of Medicine, Paris, June 5th, 1904). Lancet, pt. 1, p. 1761, 16th June, 1904.

IIEsse, E. "The parasitic fungus of the House-fly." Shrewsbury Chronicle, 29) Nov. (Reprint), 1912.

"Parasitic Mould of the House-Hy." Brit. Med. Journ., Jan. 4th, $1913,1.41$.

HewitT, C. G. "A Preliminary Account of the Life-history of the Common House-fly (Musca domesticu, L.)." Manchester Mem., rol. 51, part i, 4 p., 1906 .

House-flies. Ann. Report and Trans. Manchester Micros. Soc., 1907, P). 8.2-92, 1 pl.

"On the life-history of the Root-maggot, Anthomyia radicum Meigen." Journ. Econ. Biol., vol. 2, pp. 56-63, 1 pl., 1907.

"On the Bionomics of certain calyptrate Muscidae and their Economic signiticance with especial reference to Flies inhabiting houses." Journ. Econ. Biol., vol. 2, 11. 79-88, 1907.

"The Proboscis of the House-fty." Brit. Med. Journ., Norember 23rd., $190 \overline{7}, 1.1558$.

"The Structure, Development, and Bionomics of the Honse-fly, Mresca domestica, Linn.: Part I. The Anatomy of the Fly." Quart. Jouru. Mier. Áci., vol. 51, pp. 395-448, pls. 22-26, 1907.

Idem, Part 1I. "The Breeding Hal,its, Development and the Anatomy of the Larva." Iloid., vol. 52, p1. 495-545, 4 pls., 1908.

"The Biology of House-flies in relation to Public Health." Journ. Roy. Inst. Public Health, vol. 16, pp. 596-608, 3 figs., 1908.

"The Structure, Development and Bionomies of the House-fly, Musca domesticu, Linn.: Part III. The Bionomics, Allies, Parasites and the Relations of $\%$. domestica to Disease." Quart. Journ. Micr. Sci., vol. 54, Pl. 347-414, 1 pl., 1 fig., 1909.

"House-tlies and Disease." Nature, vol. 84, 1p. 73-75, 3 figs., 1910.

House-flies and their Allies. Fortieth Ann. Rep., Ent. Soc. Ontario, lp. 30-36, \& figs., 1910.

"House-flies and the Public Health." Ottawa Naturalist, vol. 24, 11. $31-35,1910$.

The House-Hy, Musca domestica. A Study of its structure, Development, Bionomics and Economy. 195 pp., 10 pls., 1 fig. (Nlauchester, The University Press), 1910.

"The House-fly in Relation to Public Health." Public Health Joum. (Canada), vol. 2, p1). 259-261, 1911.

"The House-Hy." (Review.) Canadian Ent., vol. 43, pp. 294-295, 1911. Observations on the range of Hight of Fhes. Repts. Local Govnt. Bd. on 
Pulıl. Health and Med. Suljects, N. S. No. 60; Further Reports (No. 5) on Flies as Carriers of Infection, 11. 1-5, with map, 1912.

Hewit, ('. G. An Aeconnt of the Bionomies and the Larve of the Flies Fannie (Homalomyiu) canicularis L. and $F$. screlueris liab, and their relition to Myiasis of the intestinal and urinary tracts. Repts. Local Govnt. Bd. on Publ. Health and Med. Subjects, X. S. No. 60 ; Further Reports (No. 5 ) on Flies as Carriers of Infection, 11). 15-22, 3 figs., 1912.

"Fannia (Homelomina) cuniculeris Linn. and F". scularis Fab." Parasitology, vol. 5, 11\%. 161-174, 7 figs., 1 pl., 1912.

Homse-flies and how they spread disease. Cambridge University Press (in Cambridge Mamuls of science and Literature), 122 1)p., 19 figs., 1912. "On the predaceous hilbits of Scatophagu, a new enemy" of Musca domesticu." Can. Eut., vol. 46, 11. 2-3, 1914.

Hewlett. "lnsects as carriers of disease." Med. Press and Cire., N. S. vol. $76,111.439-442$. london, 1903.

Hewlett, H. T. "The etiology of epidemic diarrhoea." Journ. Prevent. Med., rol. 13, 11. 496-507, 1905.

Hicksos, S. J. "The Eye and Optic Tract of Insects." Quart. Joun. Micr. Sci., vol. 25, 11\%. 1 - 39, 3 1 1s., 1895.

"A Parasite of the House-Hy." Nature, October 26th, 1905.

Hixde, E. Note on the Colon Preference of Flies. Repts. Local Govnt. Bd. on Publ. Health aud Med. Subjects, N. S. No. 85; Further Reprorts (No. 6) on Flies as Carriers of Infection, lp. 41-43, 1913.

"The Flight of the Honse-tly." Proc. Camb. Phil. Soc., vol. 17, p1) 310$313,1914$.

Hirsch, C. T. W. "An accomnt of two cases of Coko or Framboesia." Lancet, pt. 2, pl. 173-175, 1896.

Hodie, C. F. "A practical point in the stuly of typhoid or filth fly." Nature Study Review, vol. 6, 1p. 195-199, 1910.

"A Plan to exterminate the Typhoid or Filth-Disease Fly." La Follette's Weekly Magazine, Madison, Wis., vol. 3, No. 15, pl). 7-8, (illus.), April 15, 1911.

"How you can make your home, town or city, flyless." Nature and Culture, Cincimati, Ohio, rol. 3, Tos. 2 and 3, pp. 9-23, 7 figs., JulyAllg., 1911.

"Exteminating the Fly." California Outlook, Sept. 30, 1911.

"A New Fly Traj." Joum. Econ. Ent., vol. 6, 11. 110-112, 1 pl., 1913. "The Distance House-Hlies, Blue-bottles and stable Flies may travel over water." science, N. S., vol. 38, pp. 512-513, 1913.

Hoffrann, E. "Ueber die Verbreitung der Tubereulose durch stubentliegen." Correspondenzbl. d. ärztl. Kreis- und Bezirksvereine in Königr. Sachsen, vol. 44, 111. 130-135, 1888.

Holjarex, X. "Zur Monphologie des Insektenkopfes: II. Einiges über die Reduktion des Kopfes (ler ])ipteren-larven." Zool. Anz., rol. 27, pl). 343355,12 figs., 1904. 
HuPE, F. "On the Insects and their larvae occasionally found in the luman

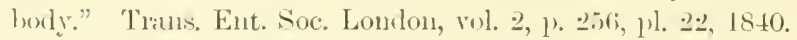

Hotstox, IV. II. "Folmalin against Flies." Indian Med. Gaz., Feb. 1913, 1. . it.

Howard, C. W' and Clarke. P. F. "Experiments on insect transmission of the virus of Polionyelitis." Jonm. Exp. Med., vol. 16, 1p. 850-859, 1912.

Howari, L. O. "Honse-flies" (in "The Principal Honselnold Insects of the Lnitel States, by L. O. Howard and C. L. Marlatt), United States of Anericar Dept. of Agriculture, Waslington, l)ivision of Entonology. Bull. No. 4, N. S. (revised el. 1902), M'. 43-47, ankl figs., 1896 .

"Further motes on the House-fly" in "some Miscellaneous Results of the work of the Division of Entomology." L.S. Dept. of Agriculture, Division of Entomology, Bull. No. 10, X. S., 11). (3:3-65., 1898.

"A c'ontribution to the study of the Insect Fama of Human Excrement "with expecial reference to the spread of Typhoid Fever ly Flies)." Proc. Wasl. Acad. ściences, vol. 2, 1\%. 511-604, figs. 17-38, pls. 30, 31, 1900. "On some Diptera reared from cow manure." Can. Ent., vol. 33, 11). $42-44,1901$.

"Flies and Typhoil." Pop. Science Monthly, Jan. 1901, 1p. 249-256.

"Honse-flies." Circular No. 35, 1)iv, of Ent., L.S. Dept. Agric., 8 pl., 6 figs., 1898; alsu revised ed. Circular No. 71, 10 1'p., 9 figs., 1906.

"How insects affect Health in Rural Districts." Farmers Bull. No. 155, U.S. Dept. Agric., 1'l. 1-19, 16 figs., 1908.

"Economic Loss to the People of the United states through Insects that carry Disease." Bull. No. 78, L.S. Dept. Agric., Burean of Entomology, 40 ple, 3 tables, 1909.

"Flics as carriers of infection." seience, $\mathrm{X}$. S., vol. 34. 11. 24-25, (Review), 1911.

"House-Hlies." Farmer's Bull. No. 459, U.S. Dept. Agric, Washington, $16111 ., 9$ figs., 1911.

The Honse-tly, disease-carrier. 312 11'., 39 figs. Stokes Co., New York; John Murray, Londen, 1911.

Howe, L. Egylutian Ophthalmia.) Seventh Internat. Congr. Ophthahmol., Wiesbaden, 1. 32:3.

Huber, J. B. Inseets and 1)isease. New York State Journ. Mled., Nov., 1908. Нrвев, J. ('. Bibliographie der klinischen Entomologie. Jena, 1899.

Hutchisox, R. H. "The Migratory Habit of House-Fly larrae as indicating a favourable remedial measure. An account of progress." Bull. No. 14, C.S. Jept. Agr., Washington, 11 ply, 1914.

Hutchisson, Woods. "How doth the little busy Fly?" Country Life, (U.S.A.), vol. o, 1). 31-3:3, Aug. 15, 1911.

"The story of the Hy that does not wipe its feet." Sat. Even. Post, T llarch, 1 sos.

Huxter, IT. Ocourrence of phagne bacilli in alimentary tract of flies that lial fed on infected material in Hong Kong.) ('unted in article wn "The 


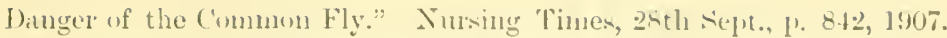
('ited hy Nuttall and Jepson, 19)9.)

Henter, W. 1). "Aneriean Interest in Medical Eutumology." Journ. Eum. Ent., rol. 6, pl. 27-39, 1913.

Isss, A. 1). "On the Larval and P'upal Stages of Anopheles muenlipenis, Meigen." Jnum. of Hygiene, vol. 7, 117. 291—31n, l fig., Hls. 4, 5, 1907 .

Jackos, 1). D. Pollution of New York Harbour ats a Menace to Health ly the Dissemination of Intestinal I)isease through the Ageney of the ('ommon House-Hy. A Report to the committee on Pollution of the llerchants' Association of New York, $2 \pm 1$ 1'p., 2 matps, 3 eliarts, 3 figs., 1907.

"Conveyance of Disease by Flies smmmarised." Buston Med. and sirg. Jomin. 1908, p. 451.

"The Disease-carrying Honse-fly." Review of Reviews, (U.S.A.), July, 1910.

Jexings, A. H. and King, W. V. "An Intensive Study of Insects as a possible Etiologic factor in Pellagri." Amer. "Journ. Med. Sici, vol. 46, (Sept.), p. 411, 1913.

Jexrss, L. Nutice of a case in which the larvae of a dipterums insect supposich to be the Anthomyia canicularis Meig. were expelled in large quantities from the human intestines. Trans. Ent. Soc. London, vol. 2, 1. $153,1839$.

Jepsox, J. P. Some observations on the breeding of Musca domestica during the winter months. Repts. Local Gornt. Bd. on Publ. Health and Med. Subjects, N. S. No. 3. Prelin. Repts. on Flies as Carriers of Infection, pp. 5-8, 1909 .

"The Breeding of the Common House-Hy (J/used domesticr) during the winter months." Journ. Eeon. Biol., vol. 4, 11. 78-82, 1909.

- Notes on experiments in colouring Flies for purposes of identification. Repts. Local Gornt. Bd. on Puhl. Health and Med. Suljects, N. S. No. 16, Further Preliminary Repts, on Flies as Carriers of Infection, 11. 4-9, 1909.

JoLx, P. R. Importance du rôle des insectes dans la transmission des maladies infectieuses et parasitaires. Du formol comme insecticide. Borleaux, 90 f'n., 'Thèse, 1898.

Joxes. "The Common House-fly as the cause of disease." Maritime Med. News, Halifax (Canada), rol. 18, 11). 28.5-294, 1906.

Joxes, F. W. C. "Notes on enteric fever prevention in India." Journ, Roy. Army Ned. Corps, vol. 8, 1p. 22-34, 1907.

Joxes, (r. I. "Hepatic Alscess (Non-Amebic) and Gastro-intestinal myiasis." Journ. Aner. Med. Ass., vol, 61, 1. 1457, 1913.

Joseph, G. "Leber Fliegen als Sehädlinge ind Parasiten des Menschen." Theil 4, Myiusis septica. Dentsehe Medicinal-Zeitung, No. 65, Pl. 725$728,1887$.

H, H, - F, 
JUDD, G. S. "Larvae discharged from the lower intestine of a boy." Amer. Nat., wol. 10, 1. 374, 1876.

Kanmener, P. "Regeneration des Dipterenftügels beim Imago." Arch. f. Entwick., rol. 25, 11\%. 349-360, + figs.. 1908.

Krinin, M. 1). "Sur le parasitisme de la larve de Pollenice rudis Fab. dans Allobophore chlorotice sar." Compt. rend. Sinc. Biol., vol. 6i, pp. 201203.

"Structure du pharyux en fonction du régime chez les larves le Diptères eyclorhaphes." Comptes-1endus Acad. Sci., Paris, vol. 155, 11\%. 1548 $1550,1912$.

Kellers, H. C. "A sanitary garbage can holder." U. S. Naval Med. Bull., vol. $5,1 \% 45,1911$.

Keliy, H. A. "A historical note upon Diptera as carrier's of diseases." ParéDéclat. Johns Hopkins Hosl. Bull., vol. 12, 7 pl. Aug., 1901.

Kest, W. S. A Manual of the Infusoria, vol. 1, 1. 245, pl. 13. figs, 29-34, $1880-1881$.

Kew, H. W. "Lincolnshire Psendo-scorpions: with an Account of the Association of sneh Animals with other Arthroporls." Naturalist, No. 534, July, 1901, [']' 19:3-215.

KEYT, F. T. "A case of 'Beef-worm' (Dermatobia noxialis) in the orbit." Brit. Med. Journ., vol. 2, p. 316, 1900.

Kirby and Spexce. Introduction to Entomolugy. Tol. 4, pl. 228-229, 1826.

Klen, E. "Flies as carriers of the Bacillus typhosus." Brit. Med. Journ. (Oct. 17, 1908), pl). 1150-1151.

Kobayashi, S. "Nipponsan kajo no hassei oyobi shusei ni tsuite." (The metamorphosis and bahits of the Japanese Honse-fiy). Dobuts Z. Tokyo, vol. 21, Pl. $335-341,1909$.

Koner, G. M. "The etiology and prevention of infections diseases." Virginia Med. Monthly (Reprint), April, 1892.

- Report on the prevalence of typhoid in the district of Columbia. Report, Health Officer, D. C. for year ending June 30, 1905, pp. 253-292.

Koсн, R. "Bericht ïber die Thätigkeit der dent.schen Cholera-Kommision in Aegypten und Ostindien." Wiener med. Wochenschr., No. 52, Pl. 1548$1551,1883$.

Kowalevski, A. "Beiträge zur Kenutuiss der nachembyonalen Entwickhung (ler Museiden." Zeit. f. wiss. Zool., vol. 45, 1p. 542-594, 1)ls. 26-30, $188 \%$.

Kraepelin, K. "Zur Anatomie unct Physiologie des Riïssels ron Musca." Zeit. f. wiss. Zool., vol. 39, pp. 683-719, 2 pls., 1883.

Krontowski, A. "Zur Frage iiber die Typhus- und Dysenterieverhreitung dureh Fliegen." Centralbl. f. Bakt. Parasitenk. und Infektionskrankheiten, Jena, vol. 68, lp. 586-590, 1913; Abs. in Rer. Ap]l. Ent., rol. 1, Ser. B., 1). 117-118, 1913.

Kuxckel d'Herculais, J. Récherches sur l'organisation et le développement 
des Volneelles, inscetes diptires de la famille des Syrphides. Paris, part i, 1875-81.

Laboulbène. (A case of intestinal myiasis caused by Funniu lantate) Comptes rendus Soe. Biol., p. 8, $1856^{\circ}$.

L.Allier, P. Tahleau des larves de Diptères évaeuces par l'urètlira. Thésis, Paris, 1897 .

Lambotte, U. "Insectes et maladies infectieuses." Ann. Soc. Méd.-chir. de Liège, vol. 44, pp. 371-389, 1905.

LAxGE, M. Rudimenta doctrinae de peste. 2nd edit., Offenbach, 111. 27-28, 1791. (Quoted by Abel.)

LAxgrield, M. "The rôle of insects in the transmission of disease." 'Trained Nurse, etc., New York, vol. 35, pp. 195, 2633 and 336, 1905.

Laverax, A. "Contribution d̀ l'étude du bouton de Biskra." Anll. d. Dermatologie, 2nd ser., vol. 1, 1'l. 173-197, 1880.

Lawrexce, S. II. "Dangerous dipterous larvae." Brit. Med. Journ., vol. 1, 1). $88,1909$.

Lebeer, A. "Dissemination du bacille de Hansen par la monche domestique." Bull. Soe. Path. Exot., vol. 5, No. 10, 11). 860-868, 1912.

Ledinghas, J. G. "On the survival of specific microorganisms in pupae and imagines of $\mathbf{H}$ usca domesticu raised from experimentally infected larvae. Experiments with Bacillus typhosus." Joum. Hygiene, (Camb.), vol. 11, No. 3, p1. 333-340, 1911.

LÉGER, L. "Sur la structure et le mode de multiplication des Flagelles du genre Herpetomonas, Kent." C. R. Ac. Sci., vol. 134, p. 781, 7 figs., 1902. "Sur quelques Cercomonadines nouvelles on pen connues parasites de l'intestin des insecter." Arch. f. Protistenk., vol. 2, [1). 180-189, 4 figs., 1903.

Leidy, J. "Flies as a means of communicating contagions diseases." Proc. Acad. Nat. Sc. of Philadelphia (Meeting of 21 st Nov., 1871), p. 297, 1872.

— "On a parasitic worm of the House-fly." Proc. Acad. Nat. Sci. Philadelphia, rol. 26, p. 139, 1874.

"Researches in Helminthology aud Parasitology." Smithsonian Miscell. Collectious, Washington, in rol. 46, 281 pp., 28 figs. (Reprint), 1904.

Leleax, P. S. "Notes on Myiasis." Brit. Med. Journ., vol. 1, 1"). 245-246, 1904.

Lecckart, R. "Die Fortpflanzung und Entwicklung der Pupiparen. Nach Beobachtungen an Kelophagus ovinus." Abhandl. Naturf.-Gesell., Halle, vol. 4, pp. 147-226, 3 pls., 1853.

Levr, E. C. and Freeman, A. E. "Certain conclusions conceming typhoid fever in the south, as deduced from a study of typhoid fever in Richmond, Va." Old Dominion Journ. Med. and Surg, vol. 8, (Reprint), 39 pp., 3 maps, 3 charts, 1908.

LEFY, E. C. and TuCk, W. T. "The maggot-trap-A new weapon in our warfare against the typhoid fly." Amer. Journ. Pub. Health, vol. 3, So. $†, ~ p p .657-660,1$ fig., 1913. 
Imagri, A. and Jexpixgs, E. Some Flagellate Forms found in the Intestinal Tracts of Diptera and other Genera. Loudon (Adlard and Son), 25 pl., 5 pls., 1906.

Lrxiets, C. De. Systema naturae (10th ed.), rol. 1, 1). 596, 1758, and Fanma sneciea, (ed. ii), Holmixe, 1761.

vox lixstow. "Beobachtungen an nenen und hekannten Helminthen." Arch. f. Naturgesch., pp. 18:3-2(17, 1875.

Lochsaxs, R. "Eine epidemische auftretende Krankheit der Stubenfliege verursicht durch Limpusa muscue." Pharm. Reformer, Wien, vol. 4, p. 127,1899 .

LoEb, J. Jer IIeliotropismus der Thiere und seine Uebereinstimmung mit dem Heliotropismus der Pflanzen. Wurzburg, 118 pl., 6 figs., 1890

Lond, F. T. "Flies and tulereulosis." Boston Med. and Surg. Journ., rol. 101, pp. 65) - 65.5, 15th Dec., 1904.

Lowre, B. T. The Anatomy and Physiology of the Plowfly (Nusca romitoria). 121 1'p., 10 pls., London, 1870.

"On the Compound Vision and the Morphology of the Eye in Insects." Trans. Linn. Soc. (Zool.), vol. 2, pt. 11, 1884.

— The Anatomy, Physiology, Morphology and Development of the Blowfly (crelliphorre erytlerocepleala). =2 vols., London, 1895.

Lumbock, J. Lord Aveburs). "The fly in its sanitary aspect." Lancet, pt. 2,1871, p. 270 .

Lumsers, L. L. and Axnersos, J. F. "The origin and prevalence of Typhoid Fever in the Distriet of Columbia (1909-1910)." Pub. Health and Marine IIosp. Service, Hyg. Lab. Bull. No. 78, Oct., 1911.

LUMsDex, L. L. Sanitation of Flood-stricken towns and eities, with special reference to conditions observed in river towns and cities of Kentucky. Public Health Repts., U.S. Public Health Service, rol. 28, No. 24, 1)1. $1195-12 \div 0,1913$.

Lyoset, I'. Tritité anatomique de la chenille qui ronge le boris de saule. 2nd éd., La Haye, 18 pls., 1762.

MCCAMpBelL, E. F. and Cooper, H. J. "Myiasis intestinulis due to infeetion with three species of dipterons larvae." Journ. Amer. Med. Assn., vol. 53, Oct. 9, 1). $1160-6=2,1909$.

MACDodgat, R. $s$. "Inseets and Arachnids in relation to the spread of disease." Pharm. Journ., Loudon, Ser. 4, vol. 22, p. 60, 1906.

"Shee], Maggot and related flies. Their classifucation, life-history and habits." Trans. Highland soc. Scot. (Rejrint), 42 pl), 1909.

McFarlaxi, J. "Relation of insects to the spread of disease." Nedicine, rol. 8, 15 Mr., 12 figss, 1902 .

MACK1хxох, 1). L. "Herpetomonads from the alimentary tract of certain Inng-flies." Paracitology, vol. 3, p1. 255-274, 1 pl., 1910.

Ilackoskit, G. "The Proboscis of the House-fly." Amer. Nat., vol. 5, l'p. 153-161, 1880. 
Macrae, R. "Flies and Clolem Diffusion." Indian Med. Gat., 1491, Pl. $407-412$.

Maddox, R. L. "Experiments in Feeling some Insects with the C'urved or" Comme Baccillus, and also with another liacillus (J). subtitis?)." .Journ. Roy. Hicros. Soc., ser. 2, vol. 5, pp. 602-(507, 941--9.5.2, 188.5.

MANEWARING, W. II. "Flies as earrier's of Bacteria." fomm. Applied Jicr. (Rochester, N. Y.), vol. 6, 1. 2402, 1903.

Maxsa, F. V. Bidrag til Folkesygdonmenes og Sundherlspleiens Historie i Damuark fra de aeldste Tider till Begyndelsen af det attende Aarhnmdrede. Copenhagen, 1872. (Cited by Nuttall, 1899, re plitgne and insects; see (1). 126, 212, 312.)

Maxsox, I'. 'Tropical Diseases. (4th ed.), 876 lly., 241 figs., 7 enl. plin., Lamdon, 1907.

Marpyaxx, G. "Die Verbreitming von Spaltpilzen durch Fliegen." Arch. f. Hygiene, vol. 2, 1). 560-5633, 1884.

Martin, A. W. "Flies in relation to typhoid ferer and smmmer liarrhoea." Public Health (London), vol. 15, p. 652, 1903.

Martix, C. J. Horace Dobell Lectures on Insect Porters of Bacterial Infeetions, delivered before the Roy. Coll. of Physicians. Brit. Met. Journ., Jan. 4th, 1). 1-8, and Jan. 11th, 1'1. 59-68, 1913. (19. domestica discnssed in the first lecture.)

Martini, E. "Insekten als Krankheitsüberträger." Moderne ärztliche Bibliothek, 39 pl., 27 tigs. (Reprint), 1904.

Mason, C. F. "The spread of disease by insects." Internat. Clin. Phila., Ser. 14, vol. 2, 1']. 1-24, 1904.

Mays, T. J. "The Fly and Tubereulosis." New York Med. Journ. and Plila. Yed. Journ., vol. 82, pp. 437-438, 1905.

MEGanix, J. P. "Du transport et de l'inoculation du virus charbonnenx et autres par les mouches." Compt, rend. de l'Acad. des Sci., Paris, vol. 69 p). $1338-1340,1874$.

"Memoire sur la question du transport et de l'inoculation du virus pal" les mouches." Joum. de l'anat. et de physiol. etc., Paris, vol. 11, pp. 121 133, 1 pl. Also in Journ. de méd. vétér. mil., Paris, vol. 12, pl. 461 $675,1875$.

Les parasites articulés (Paris: Masson), 2 vols., 210 1'p., 91 figs., 26 pls., 1895 .

Les insectes buveurs de sang et colporteurs de virus. Paris, 150 pp., 1906.

De Meijere, J. C. H. "Ceber die Prothorakalstigmen der Dipterenpupıen." Zonl. Jahrb. (Anat.), vol. 15, pp. 623-692, pls. 32-35, 1902.

Mercurialis. De pestilentia. Venice, 157\%. (Cited by Abel, 1899.)

Merk, A. "On the relation of $M$. domestica to vaccine." Hyg. Rundschau, vol. 20, pp. $233-235,1910$.

Mercis, A. A. C. E. "The Foot of the House-fly." Journ. Quekett Club (2), vol. 6, P. 318, 189 \%. 
Meris, A. A. C. E. "Supjlementary Note on the Foot of the House-fly." Journ. Quekett Club (2), vol. 9, pl). 167-165, 1905.

Minlen, R. T. "Myiasis dermatosa due to ox-warble flies." Journ. Amer. Med. Ass., vol. 55, 1》. 1978-1979, 1910.

Milikes, F. B. "Another Breeding-Place for the House-fly." Journ. Econ. Ent., vol. 4, 1). 275, 1911.

Mrschis, E. A. "Report on the Anatomy of the Tsetse-fly (Glossina morsitans)." Proe. Roy. Soc. (Ser. 13.), vol. 76, pp. 531-547 and figs., 1905.

Мrintt, E. P. "The Question of Flies as Leprony Carriers." Journ. Lond. School Trop. Med., vol. 1, 11. 31-35, 1911.

Mitzman, M. l3. "Stomoxys culcitruns Linn. A Note giving a summary of its Life-history." Public Health Rejorts, U.S. Pub. Health Service, rol. 28, No. 28, pp. 345-346, 1913.

"The Role of Stomoxys calcitrans in the transmission of Trypanosoma evansi." Philippine Journ. Science, Sect. B) (Philippine Joum. Trop. Med.), vol. 7, pl'. 475-518, with 5 pls., Dee. 1912. Abstr. in Trop. Dis. Bull., vol. 2, pp. 130-133, 1913.

"Experimental Insect Transmission of Anthrax." Public Health Repts., U.S. Pub. Health Service, vol. 29, (Jan. 9, 1914), Pl. 75-77, 1914.

Moxiez, R. "Apropos des publications récentes sur le faux parasitisme des Chernétides sur différents Arthropodes." Rev. Biol. du Nord de la France, vol. 6, pp. 47-54, 1874.

Moore, W. "Diseases probably caused by flies." Brit. Med. Journ., pt. 1, p. 1154, 3rd June, 1893; also in Med. Magaz., July, 1893.

Morgan, H. DE R. "Upon the Bacteriology of the Summer Diarrloea of Infants." Brit. Med. Journ., April 21, 1906, 12 pp., and July 6, 1906, 11 l').

Morgax, H. de R. and Ledragham, K. C. G. "The Baeteriology of Summer Diarrhoea." Proc. Roy. Soe. Med., Mar., 1909, 11). 1-17 (separate pagination in Reprint).

Moucheт, R. "Myase intestinale ehez l'homme." Bul. Soe. Path. Exot., vol. 5, 11p. 508-511, 1912 .

DE Moura, C. "Mriase do Seio." Revista Med. cle S. Paulo, vol. 16, p. I, 1913 ; Abstr. in Trop. Dis. Bull., vol. 2, (Nov. 15), 1. 530, 1913.

Muxsox, E. L. The theory and practice of Military Hygiene. (London: Ballière, Tindall and Cox), 1901.

Mifrray, A. Economic Entomology. London, p. 129, 1877.

NASH, J. C. T. "The Etiology of summer I)iarrhoea." Lancet, 1) 330, 1903. "The seasonal ineidence of typhoid ferer and of diarrhoea," cte. Trans. Epidemiol. Suc., London, N. S. vol. 22, 11). 110-138, 1903.

_ "Some points in the prevention of epidemie diarrhoea." Lancet, 1. 892, 1904.

"The waste of infant life." Journ. Roy. Sanit. Inst, vol. 26, Pl. 494$498,1905$. 
Nash, J. C. T. Annuml Reprort of the Merlical Othicer of Health, Borough of Southexul-on-šear. 1906.

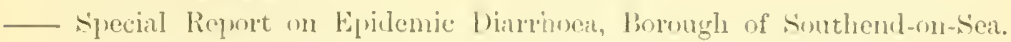
16 ply. 1 chert, 1906.

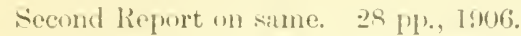

"The Prevention of summer or Epiclemic Diarhoea." The Practitioner, Mlay, 190; 12 plp.

"Honse-flies ats camiers of I)inease." Joum. of Hygiene, vol, 9, 111. 141169. 1909.

"Flies as a Nuisance and Flies ats a "Dingerous Nuisance." Lancet, 1908, p1). 131, 132.

"A note on the Bacterial contamination of Milk as illustrating the connection lotween Flies and epidemic diarrhoea." Lancet, part 2, 1'1. $1669-16699,1908$.

"Hone-tlier as earriers of disease." Norwich Rep. Mlus. Assn., vol. 2, ['p. $14-1$ 1 $1909-09$.

Nerva, A. and Goyes de FAbriA. "Jyiasis humama, verursacht durch Larven sou sascophaga pyopleite n. sp." Mem. Inst. Oswaklo Cruz, vol. 5, 1\%. 16-2.2, 1913 ; Ahste. in Trop. Dis. Bull., vol. 2, (No. 15), 1). $529-53(1,1913$.

Newport, G. "Insecta," in Todd's Cyclopaedia of Anatomy and Physiology, rol. 2, 11). 853-994, 1839.

Newsholse, A. Ammal Report on Health of Brighton (p. 21, infection of milk by Hies', 1903.

"Domestic infection in relation to epidemic diarrhoea." Joum. of Hygiene, vol. 6, 1'ए. 139-1 18, 1906;.

Enteric fever in Durham. Quntation of Newsholme's report in Times, Weekly Edition, Aurust ith, 1910.

A Report on infint and ehild mortality, heing a Supplement to the Report of the Medical Health Officer in the 39th Am. Rept, of the Local Government Board 1909-10, (separate, 110 11\%).

Newstead, R. "On the Life-histury of Stomorys calcitrans Limn." Journ. Econ. Biol., rol. 1, 1'p. 15\%-166; 1 1)l.. 1906.

Preliminary Report on the Habits, Life-Cycle and Breeding l'laces of the Common Honse-fly (.Musca domesticu Linn.) as observed in Liverpool, with suggestions as to the hest means of checking its increase. Liverpool, 23 ll., $1 \pm$ figs.. $190 \pi$.

- Second Interim Report on the House-fly as observed in the city of Liverpool, 4 pp., 1909.

Nicholas, G. E. "The Fly in its Sanitary Aspect." Lancet, 1873, vol. 2. p. 72t.

Iichol.s. L. St Licia Laboratory report for the half year ending Sept. 30th, 1911. Report to the Adrisory Committee of the Trop. Disease Roseareh Fund, APl. vi, No. 14, p. 199, 1911.

"The transmission of pathogenic micro-organisms by tlies in St Lucia." Bull. Ent. Research, vol. 3, 1\% 81, 1912. 
Nichol.sos, J. L. "Mriasis ; a report of three cases of primal rectal infection." Jomrn. Amer. Mel. Ass., May 21, 1910.

Nicoll, W. "On the rarieties of Brealles coli associated with the Honse-fly (Huscu domestime)." Journ. Ilygiene, vol. 11, No. 3, 11). 391_389, 1911.

- On the part played by Flies in the clispersal of the eggs of parasitic worns. Repts. Local Gornt. Bd. on P'ubl. Fealth and Med. Suljects, N.S. No. 53: Further Repts. (No. 4) on Flies as Carriers of Infection, 1). 13-30, 1911.

Niewexilowsin, G. H. "La Transmission des Maladies par les Monches." Niaturaliste Candien, vol. 40, 17). 33-38, 1913.

Nivex, J. Annual Reports on the Health of the City of Manchester, 19041912.

"The Houve-fly in relation to Summer Diarrhooa and Enteric Fever." Proc. Roy. Six. of Med., April, 1910. Reprint, 83 1p.)

Noen, P. "La linerre aux Mouches." Bull. d. lab. régional d'Ent. agric., Fonen, 191:, 1'1. 4-5.

Norr, F. G. "J)isease carriers." Seience, vol. 36, No. 914, p1. 1-9, 1912.

NuttalL, G. II. F. "Zur Aufklärung der Rolle, welche lnsekten bei der Terbreitung ler Pest spielen-Ueber die Empfindlichkeit verschiedener Thiere fur dieselbe." Centralbl. f. Bakteriol., vol. 222, Pl). 87-97, 1897.

On the Rôle of Insects, Araehnids, and Myriapods, as Carriers in the Spread of Bacterial and Parasitic Iniseases in Man and Animals: a Critical and Historical stuly. Johns Hopkins Hospital Reports, vol. 8, $15 t$ pp., 3 pls. (A very full bibliography is given.) 1899.

"The part played by Insects, Arachnids and Iyriapods in the propagation of infective disenses of Man and Animals." Brit. Med. Jonn., 9 Sept. (4 pp. rejurint), 1899.

"The rôle of Insects, Arachnids and Myriapods in the lropagation of infeetive disenses of Man and Animals." Journ. Trop. Hed., 1). 107110, Nor. 1893.

"Die Rolle der Insekten, Arachniden (Ixodes) und Myriapoden als Träger bei der Verbreitung ron durch Bakterien und thierische Parasiten verursachten krankheiten des Menschen und der Thiere." Hyg. Rundschau, vol. 9, (72 1). reprint), 1899.

"Insects as carriers of disease." Reprint from Bericht iiher den xiv. Intern. Kongress f. Hyg. u. Demographie, Berlin, $190 \%$.

Nuttali, G. H. F., and Jepsos, F. P. The prart played by Husca domestica and allied (non-biting) Flies in the spread of infective diseases. A summary of unr present knowledge. Repts. Local Govnt. Bd. on Publ. Health and Med. Nulijects, N.S. No. 16; Further Prelim. Repts. on Flies as Carriers of lnfection, pl. 13-41, 1909.

Nuttal, G. H. F., Hindel, E. and Merribax, G. The Range of Flight of Muscu domesticu. Repts. Local (iovnt. Bd. on Publ. Health and Med. Subjects, N.S. No. 85; Further Repts. No. 6) on Flies as Carriers of Infection, $\mu 2.0-41,11$ charts, 1!1:3. 
Odum, W. H. "Are flies the enuse of enteric ferer?" Journ. Roy. Army Mel. ('olps, vol. 10, 11). 528-530), 1909.

Oure, E. W". "Cytological stuclies on the Entomophthorea : i. 'The Morphology and Development of limpusu." But. (inz., vol. 41, 1. 19:2, 2 plls., 1904 ;

Olsex, A. P. "Ouly a Flyspeck." (Fourl Health, wol. 10, No. 7, 1'1. 195.200, 3 figs., July, 1912.

Osmexi, A. E. The Fly: an etiological factor in intestinal diseases. Cincinnati, 1909).

Ostex-SACkex, C. R. "On Mr Portchinski's puhtieations on the larvile of Muscidae, inchuding a detailed alsetract of his last payer : 'Comparative Biology of Necrophagous and Colrophagous Larvae." Perl. Ent. Zeit., vol. 31, 11). 1\%-28, 1887.

Packard, A.S. "On the Transfomations of the Common House-fly, with notes on alliel forms." Proc. Jonston Soc. Nat. Hist., vol. 16, 11). 136150,1 pl., 1874 .

Parxe, J. II. "The House-Hy in relation to city garbage." Psyche, vol. 19, 1 1. $156-159,1912$.

PALMER, J. W. "The relation the House-fly bears to typhoid and other infectious diseases." Atlantic Journ. Rec. of Med, Aug., 1910.

Paraxt, G. "Un procédé de destruction des mouches." Bull. Soc. Autun, vol. 17,1 p. $118-124,1905$.

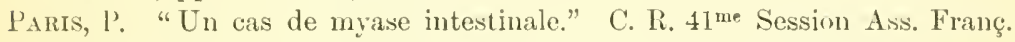
avancement d. Ściences (Nîmes, 1912). Paris, p. 447, 1913.

Parkes, L. C. "The Common House-Hy." Journ. Roy. Sanit. Inst, May, 1911.

Parrott, P. J. "To rid the house of Hies." Bull. No. 99, Kansas State Expnt. Sta., 1900.

Patton, W. S. "The Life-Cycle of a species of Crithidia parasitic in the intestinal tract of Gerris fossarum Fabr." Arch. f. Protistenk., vol. 12, pp. $131-146,1908$.

—_ "Herpetomonas lygari." Ibid., vol. 13, pl. 1-18, 1 pl., 1908.

"The Parasite of Kala-Azar and Allied Organisms." Lancet, January 30th. 1909, pl). 306-309, 2 figs., 1909.

"A critical review of our present knowledge of the Hamoflagellates and allied forms." Parasitology, vol. 2, pp. 91-139, 1909.

- Preliminary Report on an Investigation into the Oriental Sore in Cambay. Scientitic Mem. by Officers of the Med. and Sanit. Depts. of the Gornt, of India, N. S. No. 50, 21 1p., 1912. Abs. in Kala-Azar Bull. No. 3, pp. 163-167, Trop. Dis. Bur., London, 1912.

- Studies on the Flagellates of the Genera Herpetomonus, Crithidiu and Ryjichoidomones. No. 1. The Morphology and Life-history of Herpetomonus culicis, Novy, Macheal and Torrey. Scient. Mem. by Officer's of the Med. and Sanit. Wepts., Govnt. of India, N. S. No. 57, pp. 1-21, 1 pl., 2 figs. (Calcutta), 1912. 
Patton, W. S. and Stricklasd, C. "A critical review of the relation of llood-sucking invertebrates to the life-cycles of the Trypanosomes of the vertcbrates, with a note on the recurrence of a species of Cirthidiu, C. ctenophthalmi in the alimentary tract of Ctenophthalmus agyrtes, Heller." Parasitology, vol. 1, pp. 322-346, 12 figs., 1908.

Patton, W. S. and CragG, F. W. A Text-book of Medical Entomology. xxxiv +764 ll', 89 pls. (Madras and Calcutta), 1913.

Pesse, H. D. "Relation of flies to the transmission of infections disease." Long Island Med. Journ., Dec., 1910.

Pérez, C. (Metamorphosis of Blowfly.) Arch. \%ool. Expér., vol. 4, pp. 1-274, 1910 .

Perrix, W. S. "Note on the possihle transmission of Sarcocystis by the Blowty." Spol. Zeyl., Columbo, vol. 5, pp. 58-61, 1 pl., 1907 .

Peters. "Observations upon the natural history of Epidemic Diarrhoea." Joum. Hygiene, rol. 10, p. 602, 1910.

PIAxa, G. P. "Osserrazioni sul Disphurugus nasutus Rud. dei polli e sulle Nematolmintiche delle mosche e dei Porcellioni." Atti della Soc. Ital. d. Sci. Nat., vol, 36, 1'1). 239-262, 21 figs., 1896.

Pickard-Canbridge, $O$. "On the British species of False-Scorpions." Proc. Dorset Yat. Hist. and Antiq. Field Club, vol. 13, 1p. 199-231, $31,1 \mathrm{~s} ., 1892$.

Pieter, H. "Un Cas de Myase Vulvo-Vaginale." Rev. de Mćd. et d'hyg. Trop., vol. 9, p1). 176-177, 1912.

Pinkos, H. "The Life-History and habits of Spalangia muscidarum. A parasite of the Stable-fly." Psyche, vol. 20, 1p. 148-158, 1913.

Poore, (i. V. "Flies and the science of scavenging." Lancet. pt. 1, Il). 13891391, 18th May, 1901.

Portchixsky. J. A. "Recherches biologiques sur le stomoxys calcitrans L. et biologic complaréc des mouches coprophagues." (In Russian.) Publications of the Entomological Burean of the Russian Dept. of Land Administr. and Agriculture, vol. 8, No. \&, 91 1\%., 97 figs., 1910.

"IIydrotuea dentipes F. Sa biologie et la destruction par ses larves de celles de Musea domesticu, L." Publications Entomological Bureau, Russian Dept. of Land Administr. and Agriculture, vol. 9, No. 5, 30 pl., 25 figs., 1911.

"Muscince stubulans Fall., Mouche nuisible à l'humme ct à son ménage, etc., état larvaire destructeuse des larres de Husca domestica." Publications Entomological Bureau, Russian Dept. of Land Administr. and Agriculture, vol. 10, No. 1, 39 pp., 32 figs. Abstr. in Rev. Aprpl. Ent., Imp. Bur. Ent., vol. 1, Ser. B, I'1. 108-110, 1913.

"(Nestrus ovis, sa biologie et son rapport à l'homme." Publications of the Entomolingical Burean of the Russian Department of Land Administr. and Agriculture, vol. 10, No. 3, 63 Pl', 28 figs., 1913.

Porter, A. "The life-cycle of Herpetomonas jaculum (Léger, parasitic in 


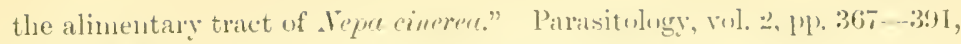
1 pl., 1909.

Porter, A. "The Structme and Life-histmy of Crithidiu pulicis n. sp., parasitic in the alimentary tract of the human Hea I'ule.r imiturs." P'arasitology, rol. 4, pl]. 237-254, 1 pl., 1911.

Pratt, F. C. "Insects bred from Cow-manure." Canadian Eut., vol. 44, l'l. $180-184,191 \%$.

Proto Gonez l. Deríx Borus, G. "Solre la causa de la menre de los moscas en Bogotá." Rer. Med., Logotá, vol. 1:2, pp. 6.j-74, 1849-9.

Prowazek, s. "Die Ëntwieklung ron Herpetomenes, einem nit den Trypanosomen verwandten Flagellaten." Arb. aus dem. Kaiserl. (iesundheitsamte, vol. :20, J1.440-4.52, T figs., 1904.

"Notiz zur IIerpetomonus-Morphologie sowie Penserkung zu der Arbeit von Wenyon." Arch. f. Protistenkunle, vol. 31, 11\%. 37-38; Abstr. in Trop. Discises Bull., vol. 2, No. 9, p. 465, 1913.

Prevot, C. Contribution à l'étude des larves de diptères trouvées dans le corps humain. Thèse No. 267. Faculté le médecine de Paris, 84 I'p, 2 pls., 19s.”.

PUrdr, J. A. "Flies and fieas as factor's in disease." Joum. Roy. Sanit. Inst., Trans. vol. 30, 1ए. 496-503, 1910.

"Flies and Heas as factors in dissemination of disease; effect of petrolem as an insecticile." Med. Press and (ircular, .Jau. 12, 1910.

QuilL, R. H. Report on an Gutbreak of Enteric Fever at Digatalawa Camp, Ceylon, anong the 2nd King's Royal Rifles. Army Med. Dept. Reprort, Apuendix 4, 1. 425, 1900.

Rambert, A. "Recherches expérinentales sur lat transwission th chartion jar les monches." C. R. Ac. Sci. Paris, vol. 69, pp. 805-812, 1869.

Ramirez, R. "The Diptera from a hygienic point of view." Public Health (U.A.A.), vol. 24, pp. $257-259,1894$.

Raxsou, B. A. "The life-history of a parasitic nematode Habronemu muscue)." sience, X. S., vol. 34, IN. 6990-69:2, 1911.

"The life-history of Habroneme macae (Carter). A parasite of the horse transmitted by the House-Hy." Bull. No. 163, Bur. Animal Indust., U.... Dept. Agric., 36 pl\%, 41 figs., 1913.

RéAludr, R. A. F. DE. Mémoires pour servir à l'Histoire des Insectes. Paris, vol. 4; M. domestica, p. 384, 1738.

ReEn, W. (Flies the cause of typhoid ontbreak in any in 1899.) War Dept. Ann. Rept. (Washington), pp. 627-6333, 1899.

Rees, W., Tatghax, V. C. and Shakespeare, E. O. Report on the origin and spread of typhoid fever in L.S. military camp during the Spunish war of 1899. Vol. 1, text, 720 pl, vol, 2, majs and charts, 1904.

Recri, II. "Der weisse Tod der Musca domesticu." Societas Entomologica, Zurich, vol. 29, Pl. 13-14, 1914.

Richardsox, C. H. "An undescribed Hymenupterous parasite of the House-fly." Psyche. vol. 20, P1. 38-39, 1 11., 1913. 
Richarnsos; C. H. "Studies on the habits and development of a hymenopterous par:asite, Simblengia muscidarem Richardson." Journ. Morphology, vol. 24, 1). 513 -5is, 16 figs., 1913.

RipLos, J. R. An investigation of the prevalence of typhoid fever at Charlestown, W. Vir. Public Ilealth Reports, Public Health and Marine Hospital Service, Washington, vol. 26, 11) 1789-1799, 1911.

Rilex, II. A. The Relation of Insects to Disease. 4 pl. Author's Reprint (surce not given), Ent. Labty., Cornell Univ., Ithaca, X. Y.

"Earlier references to the relation of flies to disease." Science, N. S. vol. $31,1 \mu .263-264,1910$.

Robertson, .J. Report of the Medical Officer of Health of the City of Birninglam for the vear $1909,144 \mathrm{pl}$.

Robertsox, A. "Flies as carriers of contagion in Yaws (Framboesia tropica)." .Jouru. Trop. Med, and Hyg., vol. 11, No. 14, p. 213, 1908.

Rogers, L. "The Conditions affecting the Development of Flagellated organisms from Leishman lwolies and their hearing on the probable mole of infection." Lancet, June 3rd, 1905, Pp. 1484-1487, 1905.

Rosexat, M. J. and BrCes, C. T. "Some experimental observations upon Monkeys concerning the transmission of Poliomyelitis through the ageney of stomoxys calcitrans." Bull. Mass. State Board of Health, Sept., 1912, 1). 314-317; also see Public Health Repts., U.S. Public Health Service, rol. 27, p. $1593,1912$.

Rosexau, M. J., Lemsnex and Kastee. Report No. 3 on Origin and Prevalence of typhoid ferer in the District of Columbia. Bull. No. 52, Hyg. Lakh. U.S. Pub. Health and Mar. Hosp. Service, Washington, p. 30, 1909 .

Roserbusch, F. "Teber eine neue Encystierung bei Crithidia muscaedomesticae." Centr. f. Bakt. 1. Alt. Orig. vol. 53, pl. 387-393, 1 pl., 1910 .

Ross, E. H. The Reduction of Domestic Flies. London, John Murray, 103 PI., illustr., 1913.

RudolphI, R. Entozoorum sive vermium intestinarum bistoria naturalis, p. $524,1808-1810$.

Ryder, J. A. "Cholera and Flies." Entom. News, rol. 3, p. 210, 1896.

SAJulelsox, J. and Hicks, J. B. "The Earthworm and the Common HouseHy." Humble Creatures, pt. 1, 79 pp., 8 pls., London, The House-fly, ㄹ. 26 - 79 , pls. $3-8,1860$.

Saxmiands, J. E. "Epidemic Diarrhoea and the bacterial content of Food." Journ. Hyg., vol. 6, pp. $7-92,1906$.

Saxpwith, F. If. "The Danger of the House-fly." Clinical Journ., vol. 39, No. 4, Nov. 1, 1911.

Saxgree, E. B. "Flies and Typhoid Fever." New York lled. Record, vol. 5.), 11). $88-89,4$ figs., 1899.

Saxtori, S. "La mosehe domestiche eome causa di diffusione delle malattie infettive intestinali." II Policlinico (Nez. pratica). 
Sawtchenko, J. (i. "Le rôle des monches dauss la plopangation de l'épidénie eholérique." Tratch, st Petersburg. Reviewed in Ann. de l'Institut

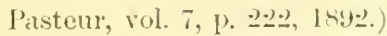

Sarari, W. G. "Recent work on typhoid ferer bacteriology." Pulilic Health (T.S.A.), Oct., 1907.

Schillixg, (". "Die Lebertragung vou Krankleiten durch Insekten und ihre Bekimpfung." Gesundh. Ingenieur, vol. 30, lpp. 300-303, 190\%.

Schiser, J. R. Fiuma Anstriaca: 1)ie Fliegen, 2 vols., Wien, $186 \%$.

Schleclex. "Geschichtliche und experimentelle Stulien iiber den Prodigiosirs." Areh. f. Hyg., vol. 26, Pi. 16-17, 1896.

Schlberg and Büxg. (Further inventigations of the transmission of pathogenic miero-organisms hy native hlood-sncking flies.) (entrall). lakkt. ] Albt., Ref., 5i, pl. 301-303, 1913.

Schlberg, A. and Kurx, 1'. (Dissemination of disease by stomexys calcitrans.) Arbeit. k. Gesumlheitsante, vol. 31, 113. 37--393, 1911.

Scotr, J. "The dangerous house-HF." Indian Public Health, rol. 5, lp. 292-298, 1909 .

SEDGWICK, W. T. and WIssLow, C. E. A. "Statistical studies on the seasonal prevalence of Typhoid Ferer in various comntries and its relation to seasunal temperature." Mem. Am. Acad. Sci., vol. 12, Nor., 11) $521-577$, 8 charts, 190.2 .

SExatrur. "Ueber lebende Fliegenlarven im Magen und in der Mundhühle." Berlin. klin. Woehenschr., No. 7, 1890.

SERgext, Eum. and Eт. "La 'Tamné, Myiase hmmaine des Montagnes Sihariennes Tonareg, identique à la 'Thimui' des Kabyles, due à (lestrus oits." Bull. Soc. Path. Exot., vol. 6, pp. 487-48t, 1913.

Seriziat. Etudes sur l'oasis de Biskra. Paris, 1875. (Cited by Laveran, 1880.)

SHarp, D. "Insects," part 2, Cambridge Nat. History, London, 1895.

SHARPE, W. S. "Intluence of dust aud flies in the contamination of food and the dissemination of disease." Lancet, pt. 1, 2nd June, 1900.

Shipley, A. E. Infinite toment of Flies. Camb. Univ. Press. (Printed privately.) $23111 ., 1905$.

"Insects as carriers of Disease." Nature, vol. 73, p1). 235-234, 4th Jan. (Abs. of address hefore Brit. Assn., Pretoria, S. A.), 1906.

Infinite Torment of Flies, and The Danger of Flies. In Pearls and Parasites. (London, John Murray), pl. 155-173 and 174-182, 1908.

"The Danger of Flies." Science Progress, vol. 1, 111. 723-729. April, $190 \%$.

Shoemaker, E. M. and WAggoner, A. "Flies as carriers of Bacteria." School Science, April, 1903.

sibthorpe, E. H. "Choleri and Flies." Brit. Med. Journ., Sept., 1896, p. 700 .

Simsoxds, M. "Fliegen und Choleraübertragen." Deutsch. med. Wochenschr., No. 41, p. 931,1892 . 
Simpsox, R. J. S. "Medical history of the South African War." Journ. Roy. Army Med. Corps, vol. 15, pl. 257 and 260-1, 1910.

Sisprox, II. J. R. The Principles of Hygiene as applied to Tropical and sulutropieal Climates. London, 1908.

Shixier, H. "The Relation of House-tlies to the spread of Disease." New Orleans Med. and Surgical Journ., vol. 61, 11. 9.50-959, 1909.

"How dues the House-fly pass the Winter?" Entom. New's, vol. 24, 1). 303-304, 1913.

SLATER, J. W. "On Diptern as spreater's of disease." Journ. of Science, London, ser. 3, pp. 53:3-539, 1881.

Surt, R. "Die Fliegenklankheit und ihre Behandlıng." D. med. Wochensehr., Leipzig, rol. 32, p1. 763-764, 1906.

Smrth, A. J. "Notes upon several larral insects occurring as parasites in Man." Med. News, vol. 81, p. 1060, 2 figs., 1902.

Sнгтн, F. "House-flies and their ways at Benares." Jonrn. Roy. Army Med. Corps, vol. 4, 1p. 150-155 and p. 447, 1907.

"Municipal Sewage." Journ. Trop. Med., vol. 6, pł. 285-291, 304 $308,330-3344,353-355,381-383,1903$.

Smrth, J. L. "An investigation into the conditions affecting the oceurence of typhoid ferer in Belfast." Journ. of Hyg, vol. 4, pp. 407 _433, 1904.

Simth, R. 1. "Formalin for poisoning house-flies proves rery attractive when used with sweet milk." Journ. Econ. Ent., rol. 4, pl, 417-419, 1911.

Surth, T. "The House-fly as an agent in Disisemination of infectious direases." Journ. Pub. Hyg., Aug., 1908, P1. 312-317.

Sxell. (Infantile diarrhoea and flies, 1906.) (ited by Ainsworth, 1909. 1. 487, no reference given.

Soltal, A. B. "Note on a case of intestinal infection of man, with the larva of Homalomyire canicularis." Parasitology, vol. 3, 13. 314, 1910.

Somms-Latbach, Graf de. "Über die liebstliche Pilzkrankheit der' Stubenfliege." Abl. d. Naturf.-Ges., Halle, 37. 1870.

Speiser, P. "Insekten als Krankheitsüberträger," in Krancher's Entomol. Jahrg., 7 pl'., 1904.

Spilladas and Haushalter. "Dissemination du bacille de la tubereulose par les monches." C. R. Ac. Sci., vol. 105, 1'1\% 352-353. 1887.

Stalluax, G. P. "Ants destroying the larvae of Flies." Military surgeon, vol. 31, No. :3, 11). 325-326, 1912.

Steix, F. R. Del Organismus des Infusionsthiere, m. Abtheilung-Die Naturgesehichte des Flagellaten oler Geisselinfusorien. 154 p1', 24 pls., Leiprig, 1878 .

Stephexs, J. W. W. Two Cases of Intestinal Iyiasis. Thompson Tates and Johnstone Taboratories Rejort, vol. 6, prirt 1, 1p, 119-121, 1905. "Transmission of disease by insects." Bart's. Hosp. Journ., rol. 12, 1'. 131-134, 1905.

Steprits, J. W. W. and Newstean, R. "The Anatomy of the P'roboseis of 
Biting Flies. Part 2. Stomoxys." Aun, "Trop. Mel. and Parasit., vol. 1, 1). $171-182,8$ pls., 1907.

Stephensos, S. Report on the prevalenee of Ophthalmia in the Metropolitan Poor Law Schools. Blue book, Octuber 2ud, 1897. (Revicwed in Lancet, October 16th, P. 1. 990-991, 7897.)

Stersibrg, G. Il. "Sanitary Lessons of the War." Philad. Med. Journ,, June 10th and 17th, 1899.

Strles, C. W. "Insects as disseminators of disease." Virginia Med. Semimonthly, vol. 6, pp. 53-58, 10th May, 1901.

"The Sanitary Privy : its purpose and construction." Public Health Bull. No. 37, U.S. Pnb. Health and Mar. Hosp. Service, 24 pl', 12 figs., 1910.

Contamination of Fool Supplies. Public Health Reports. U.S. P'ublic Health Service, vol. 28, Pp. 290-291, 1913.

Stiles, C. W. and Keister, WM s. "Flies as Carriers of Lamblia spores. The contanination of food with human excreta." U.S. P'ublic Health Rep., rol. 28, No. 48, 11). 2530-2534, 1913.

Stiles, C. II. and Lussoles, L. L. "The Sanitary Privy." Farmers Bull., No. 463, U.s. Dept. Agric., Washington, 9 figs., 1911.

Stiles, C. W. and McMIrLer, H. The ahility of fly larvae to crawl through sand. Public Health Reports, Public Health and Marine Hosp. Service, vol. 26, p. 127\%, 1911.

Strattox, C. H. "The prevention of enteric fever in India." Journ. Roy. Aruny Med. Corps, vol. 8, p. 224, 1907.

Surcouf, J. "La Transmission du ver macaque par un Houstique." Compte Rend. Ac. Sci., rol. 156, pl. 1406-1408, 2 figs., 1913.

SrdexнAн, T. Sydenham's Works. Syd. Soc. Ed., vol. 1, p. 271, 1666.

Srkes, G. F. The distribution of flies in Providence, R.I. Ann. Rept. Supt. Health, Providence, for 1909, pp. 7-15.

Thaschenberg, E. L. Praktische Insektenkunde, part IV; ( 1 . domestica, P1. 102-107, fig. 27), 1880.

TAYlor, T. "Mfusca domestica as a carrier of contagion." Proc. Am. Assoc. Adv. Sci., vol. 31, 1. 528, 1883.

Tebiutt, H. "On the influence of the netamorphosis of Musca domestica "1) which bacteria administered in the larval stage." Journ. of Hygiene, vol. 12, lp. 516-526, 1913.

Terry, C. E. "Extermination of the House-fly in cities; its necessity and possibility." Aner. Journ. Pub. Health, vol. 2, p1. 14_22, 1912.

Terry, C. E. Fly-borne typhoid fever and its control in Jacksonville (Florida, U.S.A.). Public Health Reports, U.S. Public Health Scrvice, vol. 28, pl. $68-73,1913$.

Thaxter, R. "The Entomophthoreae of the United States." Mem. Boston Soe. Nat. Hist., vol. 4, H') 133-201, pls. 14-21, 1888.

ThéBault. "Hémorrhagie intestinale et infection typhoïcle causée par des larves de Diptères." Arch. de Parasitol., vol. 4, 1). 353, 1901. 
Theonald, F. V. Swarms of Flies lued in house-refuse. Second Rept. on Economic Zool. Brit. Mus. Nat. Hist., pp. 125-126, 1904.

"Flies and ticks as agents in the distriluntion of disease." Proe. Ass. Econ. Biol., vol. 1, pt. I, pp. 17-26, 1905.

"Flies in distribution of disease." Nursing Times, London, rol. 1, 1. 461,1905 .

- The Honse-fly. Rept. on Eeonomic Zoology, S.E. Agric. Coll., Wye, 1). 109-111, 2 figs., 1905.

The Honse-fly Amnoyance. Rept. on Ecomomie Zoology, S.E. Agric. Coll., Nye, 1'p. 141-143, l fig., 1907.

IFouse-flies, their destruction and prevention. Rept. on Econonic Zoology, S.E. Agric. Coll., Wye, pp. 133-137, 1 fig., 1911.

Thomas, F. G. and Parsons, J. H. "Dipterous Larva in the anterior chituber of the eye." Lancet, 1908, Oct. 24, p1. 1217-1218.

Thomson, F. W. "The House-fly as a earrier of 'Typhoin infection." Journ. Trop. Med. and Hyg., vol. 15, pp. 273-277, 1912.

Thonson, J. A. Darwinism and Human Life. (London: Andrew Melrose), 245 lip., 1909.

Tizzoxi, (i. and Cattani, J. "Untersuehungen iiluer Cholera." Centralbl. f. d. med. Wissensch., Berlin, vol. 24, 1p. 769-771, 1886.

Tоотн, H. H. "Enteric Ferer in the Army in Sonth Africa." Brit. Med. Jomru., November 10th, 1900, (Reprint 5 1\%).

_ "Some personal Experiences of the Epidemic of Enteric Fever anong the "Tronss in South Africa, in the Orange River Colony." Trans. Clin. Soc., wol. 34, 64 1'l\% (Rẹrint), 1901.

Tooth, H. H. and Calverlex, J. E. G. A Civilian War Hospital. (London: John Murray), 1901.

Torrex, J. C. "Numbers and types of bacteria carried by eity flies." Journ. Infect. Discases, vol. 10, No. 2-, pl. 166-177, 1912.

Tsuzuki, J. "Bericht iiber meine epidemiologischen Beobaehtungen und Forschmgen wahrend der Choleraepidemie in Nordchina im Jahre 1902, etc." Arch. f. Schifts- u. Tropen-Hyg., vol. 8, pp. 71-81, 1904.

Tulloch, F. "The Internal Anatomy of Stomoxys." Proe. Roy. Soe. (Ser. B.), vol. 77, p1. 523-531, 5 figs., 1906.

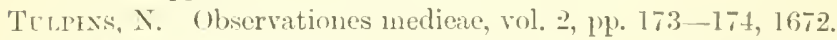

Uffelmaxi, J. "Beiträge zur lBiologie der Cholerabaeillıs." Berl. klin. Wochensehr, 1892, P. 1213-1214.

TXDERWoOD, W. L. House-fly as earrier of disease. liston, 1903.

VACHER, F. Report of County Medieal Officer of Health on "Some recent Investigations regarding the propagation of disease by thes." Cheshire Cinuty Couneil, 1909.

Tambari). "Au sujet hes mesures à prendre contre les monehes." Bull.

Mens. Office Internat. d'hyg. Publique, Paris, I1). 1313-1336, 1913.

VAxer, C. "Contributions à l'étude des Larves et des metamor'phoses des 
Diptères." Ann. de l'Univ. de Lyon, X. S., 1. Sciences méd., fince. 9,

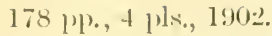

VARLLY, (' " Ilicroscopical olservations on a malady affecting the common

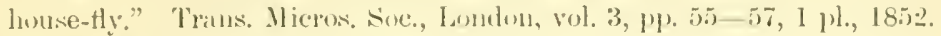

Veat be ladey. "Observations sur les vers rendus avec l'urine." Observ. de phys de Rozier, vol. 50, 1\% ]58, 1792.

Teeder, It. A. "Flies as Sipreader's of Disease in Camp." New York Med. Record, vol. 54, September 17th, 1. 42!), 1898.

"The spread of Typhoil and Dysenteric Diseases by Flies." Public Health (U.S.A.), vol. 24, pp. $260--262,1898$.

"The relative importance of Flies and water smply in spreading lisease." Mled. Record, rol. 55, 1'1. 10-12, 1899.

"Typhoid Fever from sources other than water suplly." Med. Record, vol. 622,1$) 121-124$, July 26,1902 .

Toglek, C. H. "Weitere Beitriige zur Kemntmis von Dipteren-larven." Hllust. Zeitsdur. f. Entom., vol. 5, 11). 273-276, 8 figs, 1900.

Vıgxox, P. "Recherches de Cytologie générale sur les Epithéliums, l'aplareil pariétal protecteur ou unoteur; le rôle de lin co-ordination biologique." Areh. Zool. Exp. et Gén., vol. 9, 1). 371-720, pls. 15-18, 1901.

Wran, B. "Ueber die Kopfbildung Cycloripher Dipterenlarven und die postembryonile Entwicklung des Fliegenkopfes." Arb. zool. Inst. Wien, rol. 20,114 1!n., 20 figs., 3 juls., 1914.

WAнlarkx, E. " [nsekten som sjukdomsspidare." Fauna och Flora Uplsala, rol. 3, pl. 12-22, 1908.

WaLLMax, E. "Contribution à la comnaissance du rôle des microbes dans les roies digestives." Anm. Inst. P'astenr, vol. 24, pl). 1-96, 1911.

WaLsh, B. 1). "Larvae in the lomnan lowels." Amer. Entom., rol. 2, l'p. $137-141$, I fig., $187 \%$.

WaLkeR, F. Insecta Saundersiana, i, Diptera, J. 345, 1856.

WAxHIL, C. F. "An investigation into the causes of the prevalence of enteric fever among the troops stationed in Bermuda, giving details of the measures adopted to combat the disease, and showing the results of these measures, during the years 1904-1906." Jouru. Roy. Army Med. Corps, rol. 12, 1). 28-45, 1909.

WARD, H. B. "The Relation of Animals to Disease." Science, N. S. vol. 22, Pl. 193-203, 1905 ; also Trans. Amer. Hicro. Soc., vol. 27, pp. 5-20, 1907.

Wasmbuns, F. L. The Typhoid Fly on the Minnesota Iron Range. Thirteenth Report of the State Entomologist of Minmesota, 1909-1910, pp. $135-1+1,6$ figs., 1910.

"Grasshopper work in Mimesota during 1911." Journ. Econ. Ent., vol. .), 11. 111-118, 1912. (M. domestica, suggested poison, 1. 114.)

"The Minnesota Fly Trap." Journ. Econ. Ent., vol. 5, pl). 400-402, 3 figs., 1912.

Weismans, A. "Die Entwickelung der Dipteren im Ei, nach Beobachtungen

H. H.-F. 
an Chironomus spec., Musca vomitoriu und Pulex canis." Zeit. f. wiss. Zool., vol. 13, pl'. 107-220, 1,1s. $7-13,1863$.

Weismaxx, A. "Die naehembryonalen Entwickelung der Musciden nach

Beobachtungen an Musca vomitoria und Sarcophagu "arnarire" Zeit.

f. wiss. Zool., vol. 14, 1) 18. 185-336, 11s. 21-27, 1864.

Welander. (Gonorhoeal ophthalmia conveyed by flies.) Wien. klin. Wochenschr., No. 52, 1896. (Cited by Aliel, 1899.)

" $\mathrm{ELCH}, \mathrm{P}$. S. "Observations on the life-history of a new species of I'sychoda." Amnals Ent. Soc. Amer., vol. 5, pp. $411-418,2$ pls., 1912.

Wrexrox, C. M. "Oriental sore in Bagdar, together with observations on a gregarine in Stegomyia fasciuta, the Haemogregarine of dogs and the Flagellates of House-flies." Parasitology, vol. 4, pl. 273-344, 5 pls., 1911.

"Observations on Ilerpetomonas muscue-domesticue and some allied Flagellates with special reference to the structure of their nuelei." Areh. f. Protistenkunde, vol. 31, pp. 1-36, 3 pls., 6 figs., 1 diagram; Abst. in Trop. Diseases Bull., vol. 2, No. 9, 1). 463-465, 1913.

Werner, H. "Ueber eine eigeisselige Flagellatenform in Darm der Stubenfliege." Arch. f. Protistenk., vol. 13, pp. 19-22, 2 pls., 1908.

WEsche, W. "The Genitalia of hoth Sexes in the Diptera, and their relation to the Armature of the Mouth." 'Trans. Linn. Nive., rol. 9, pp. 339-386, 8 pls., 1906.

Westcott, S. "Flies and Disease in the British Amry." Journ. State Med., rol. 21 , p1. $480-488,1913$.

Wheeler, W. M. Ants. Their structure, development and behaviour. Columbia Univ. Press, Biol. Ser. No. 9 (New Tork), 663 pp., 286 figs., 1910.

Wherry, W. B. "Insects and infection." Calif. State Journ. Med., Nor., 1907, 1]. 281-285.

- Notes on rat leprosy and on the fate of human and rat lepra baeilli in flies. Public Health Reports, Pub. Health and Marine Hosp. Service, Washington, U.S.A., vol. 23, No. 42, 8 pp. (Reprint), 1908.

"Further notes on the rat lejrosy and on the fate of the human and the rat leper bacillus in flies." Joum. Infect. Diseases, vol. 5, No. 5, 1908.

Whipple, G. C. Typhoid Fever, its Causation, Transmission and Prevention. (New York: Wiley and Sons, London: Clrapman and Hall). 1908.

Whiте, T. C. "On Empusa muscae." Journ. Quekett Micros. Club, London, vol. 4, pl). $211-213,1874-77$.

Wrucox, E. V. "Fighting the House-fly." ('ountry Life in Ameriea, May; 1908.

Milkerson. "Flies as carriers of disease." Mobile Med. and Surg. Journ., vol. 4 , pp. 125-141, 1904 .

Winter, G. "Zwei neue Entomophthoren." Bot. Ceutralbl., vol. 5, p. 62, 1881.

Wirsixg, E. "Ueber Myiasis intestinalis." Zeits. klin. Med., Berlin, vol. 60, l.l. 1-2-13:3, 1906. 
WISE, K. S. and MINNETT, E. I". "Experiments with crude cirbolic acid as a liarvichle in British (iniana." Ann. Trop. Merl, and l'arasitul., rol. 6, 111. $32 \%-330,1912$.

Woodiouse, T. P. "Notes on the causation and prevention of enterie fever in lndia." Jonrn. Roy. Army Med. ('orps, vol. 10, 1\%. 616, 1910.

Jersin. "La peste bubonique à Hongkong." Ann. Inst. Pasteur, vol. 8, 1'). (662-667, 1894.

Zepend, P. "Nouvelle note concernant les M[oustiques qui propragent les larves de Dermatobia aymientris et de Chrysomin macollaria et pentêtre celle de Lund, et de la Cordilobire anthropophergr." Rev. de Med. et d'Hyg. 'Trup, vol. 10, I']. 93-95, 1913.

Zетек, J. "Dispersal of Musen domestic" Linne." Ann. Ent. Sioc. Amer., vol. $7,11 \%$. $70-72,2$ figs., 1914.

ZwICk, K. G. "Jassnahmen gegen die Cebertragnng ron Infektionskrankheiten durch die Hausfliegen." Schweizerischen Rumdschan für Med., vol. 14; (Reprint, pp. 1-16). No. 13, 1914.

Axoxyous. "Gangrenous Fly." Laneet, pt. 2, 1) 114, 1863.

__ "The pestiferous fly." Lancet, pt. 1, 1. 156, 25th .Jan., 1873.

"Les mouches considérées comme agents de propagation des maladies contagieuses, des épidémies et des parasites." Bull. Soc. Linn. Nord France, No. 152, Pl). 215-217, 1884-5.

"The Fly Plague." Lancet, pt. 2, p. 418, Aug., 1903.

— Bulletin Chicago School of Sanitary Instruction. (1)ept. of Health, (hicago), 27th Jume, 1908.

"Flies and typhoid fever." Editorial in .Journ. Amer. Mled. Assm., Nov. 19, 1910.

— "Abating the Fly Nuisance." Comment in Joum. Aner. Med. Assn., Aug. 20, 1910.

__ "The Domestic Elies." Ed. in Brit. Mled. Journ., Aug. 26, 1. 449, 1911.

—_ "Literature on Flies." Journ. Amer. Med. Assn., June 24, 1911, 1. 1900.

— "Breeding Places for Flies as nuisances; disposal of wastes in a nonsewered town." Journ. Amer. Med. Assn., Sept. 23, 1911, 1. 1076.

"Dangerons Flies." E. P. W. Nature, vol. 29, pp. 482-483.

- Transmission of Trypanosoma hippicum by Wusca domestica. Report Dept. Sanit., Smithsonian Canal Com., Dec., 1911, p1. 12-13.

__ "A Campaign against Flies." Nature Study Review, Jan., 1911.

— "The Flyless City Campaign." Ed. in The Outlook, Aug. 19, 1912, pl. $857-858$.

_- "The Etiology of Kala-Azar." Nature, vol. 89, pp. 386-388, 1912.

_ "The House-fly." Monthly Iull. Indiana State Bd. Health, May, 1908.

— The House-fly at the Bar. Indietment Guilty or Not Giuilty? 48 1)., illustr. (Merchants' Asstı. of New York, Chairman Ed. Hatch, Jr.) April, 1909.

_ "Flies as Carriers of Disease." Good Health, wol. 5, No. 1-1, Pl. 424426,2 figs., July, 1907 . 
Axoxruous. "A purasitic mould of the House-fly." Brit. Med. Jouru., No. 2714 , Jan. 4, 1913, pp. 41-42.

"Deadly Typhoid Fly an old acquaintance in Disguise." Weekly News Letter, U.S. Dept. Agriculture, Washington, vol. 1, No. 30, Mar. 4, 1. 4, 1914 .

"Honse-flies and Disease: Flies in 1)elhi; Flies in Poona." Trop. Dis. Bull., wol. 3, No. 7 (sanitation No.), 1'p. 377-379, 1914. 


\section{AU'THORS' INDEX}

Abel, 276, 278, 291

Ainsworth, 23:, 254

Allirich, 208

Aldridge, 211, 235, 23×, 250

Amyot and McClenahan, 244

Anderson and Frost, 193, 201

Anthony, 12

Armstrong, $26 \pm$

Arnolil, 68, 249. 29:3

Andoin, 20

Austen, $7,90,187,213,237,311,302$, $30.4,305$

Arebury, 220

Axenfeld, 276

Bachmetjew, 83

Bacot, 27

Balfour, 212, 276

Balzer, Dantin and Landesmann, 307

Bancroft, 250

Banks, 155, 156, 205, 209

Becker, 116

Beclard, 101

Berg, 170

Bergey, 221, 284

Berlese, 10, 50, 56, 98, 158, 201, 328

Bernstein, 165

Bigot. 212

Bishop Harman, 277

Bishopp, 169, 199, 200, 201

Blankenmeyer, 304

Bogdanow, 82

Bollinger, 267

Bouchè, 88

Brain, 199

Brauser, 115

Braun, 277

Brefeld, 162, 164, 165

Brischke, 190

Brues, Sheppard and Rosenau, 198, 201

Buchanau (R. II.), 165, 166, 204, 249, $2177,270,290$

Budd, 27 .

Butschli, 177
Butterfield, $15 \%$

Burgess, 291

Cadet, 281

Callandruecio, 309

Candido, 307

Carter, 181

Carter and Blackloek, 190, 209

Castellani, 2×1, 28:2

Cattle, 303

Celli, 247, 270, 291

Chantemesse, 274

Chevril, 191, 303, 307

Chmelicek, 235

Cleland, 208, 212, 213, 304, 307, 308

Cobb, 271, 294

Cobbold, 221

Cochrane, 2.51

Cockerëll, 237

Cohn, 302

Compere, 171

Comstoek, 217

Comstock and Needham, 23, 2.5

Converse, 300

Copeman, 85, 241, 253

Copeman, Howlett and Merriman, 6s, 70,207

Coplin, 221

Cox, Lewis and Glynu, 219, 29t;

Crawtord, 220

Dall, 206

Dalla-Torre, 170

Darling, 294

Davaine, 267

Davis, 91

Delepine, 244

Dell, 145

Demetriades, 277

Diekenson, 279

Diesing, 182

Doerr, 83

Donhoff, 83

Donovan, 154

Drober and Hunner, 2:30 
Dunkerly, 177, 178, 179, 180

Dunne, 236

Dutton, 235

Dwyer, 211

Edgar, 307

Ercolani, 181

Esten and Mason, 293

Ewetzky and Kennel, 307

Ewing, 157

Fabre, 202

Fabricius, 5

Faichne, 96, 224

Felt, 95, :302

Fermi, 295

Ficker, 249

Field, 307

Firth and Horrocks, 247

Fletcher, 208

Flexner and Clarke, 293

Flugge, 272

Forbes, 68, 88, 91, 321

Förster, 170

Francaviglia, 307

Fraser, 252

Galli-Valerio, 83, 309

Gaun, 307

Ganon, 275

Garrood, 304

Gayon, 295

Gedüings, 275

Geer, de, 2, 87, 154

Generali, 182

Geoffroy, 154

German, 277

Giard, 164

Girault, 91

Giranlt and Sanders, 167

Gleichen, 2, 3, 87, 88, 96

Godfrey, 152

Graham-Smitl, 4, 12, 16, 36. 64, 75, $76,77,78,79,80,82,219,222,224$, $228,245,250,262,268,269,271,275$, $279,294,295,298,299$

Grassi, 221, 309

Griftith, 86. 96, 109, 110, 111

Gudser, 2\$0

Güissow, 164, 165, 288, 295

\section{Haesar, $27 \mathrm{~s}$}

Hall and Iluir, 307

Hamer, 65, 66, 98, 157, 1s8, 189, 197, $205,207,210,259,260$

Hamilton, 240

Hammond, 28

Harrington, 181

Hart and Sinith, 291

Hayward, 270

Heckeuroth and Blanchard, 307
Heeger, 189

Helm, 291

Henneguy, 115, 116

Herms, 96, 98, 110, 205, 321

Hervieux, 279

Hewson, 221

Hickson, 32, 153

Hindle, 84

Hine, 68, 207

Hirsch, 281

Hodge, 74, 327

Hoffmann, 270

Holmgren, 136

Holscher, 220

Hope, 304

Houston, 328

Howard (L. O.), 4, 66, 68, 57, 88, 91, $97,109,113,114,155,156,158,161$, $170,188,190,193,202,205,206,207$, $208,230,237,239,244,276,319,321$, 322

Howard (C. W.) and Clarke, 294

Howe, 276

Hutchinson, 318

Ifft, 330

Imms, 145

Jackson, 242, 246

Janet, 64

Jennings and King, 65

Jenyns, 302

Jepson, 85, 86, 90, 96

Joly, 291

Jones (F. W. C.), 239

(G. I.), 302 (P. L.), 171

Joseph, 269

Judd, 303

Kanmmerer, 86

Keilin, 136, 207

Kent, 173

Kerr, 2 $₫ 7$

Kew, 152, 15:3

Keyser, 2:31

Keyt, 307

Kieffer, 169, 191

Kirby and Spence, 154

Kircher, 22.

Klein, 240

Klinger, 231

Kinud, 278

Koher, 232

Koch, 276

Koster, 280

Kowalevshi, 138

Kraepelin, 12, 17, 36, 61

Krontorski, 285

Kunckel d'Herculais, 19, 2*, 145, 15s

Kutscher, 230 
Laboulbene, $209,221,304$

Laforgue, 279

Lakah and Khouri, 277

lange, 278

Latreille, 155

I a veran, 275,286

Lebeuf, 28:3, 284

Ledingham, 227

Léger, 173, 174, 175

Leidy, 1s1, 220

Lentz, 2:30

Leon, 30 !

Leuckart, 127

Levy and Kayser, 230

Levy and 'Tuck, 318

Lingard and Jennings, 174, 177, 178

Limnaeus, $5,7,154$

Linstow, 181

Loeb, 105, 13.

Lord, 271

Lowne, 9, 10, 12, 15, 17, 18, 19, 20, 21, $28,31,32,33,37,41,46,64,115,117$, $120,134,137,138,140,144,145,147$, 202

Lyonet, 120

MacCallan, 276

MacDougall, 205

Iackinnon, 173, 174, 177

McLaughlin, Bros., 320

Macloskie, 12

Macrae, 27t

Maddox, 27:3

Manning, 290

Manson, 285

Marpmann, 275

Martin, 262, 261

Martini, 221

Megrun, 221

Meijere, 140

Meinert, 205

Mercurialis, 220, 278

Metchnikoff, 261

Michael, 155, 156, 157

Miller, 307

Milliken, 93

Minchin, 34

Ninett, 283

Vitzmain, 199, 201, 29!

Iohles, 244

Moniez, 153

Noore, 221, 272

Morgan, 166, 261, 262

Morgan and Ledingham, 261

Morrill, 329

Moses, 233

Moura, 307

Müller, 277

Murray, $15 t$

Nash, 90, 252, 253, 261, 263
Neiter and liefmann, 230

Neiva and Gomes de Furia, 307

Newport. 115

Newsholme, 241, 25:3, 323, 321

Newstend, 4, 89, 109, 193, 199, 216;

Nicholas, 27.

Nicholls, 2*2

Nicholson, 302

Nicoll, 75, 223, 227, 245, 309, 310, 311, $312,313,314,315,316$

Niven, $155,66,188,250,251,254,259$, 263

Nuttall, 220, 239, 266, 267, 269, 278, 309

Nuttall and Jepson, 252, 272, 275, 278, $279,286,291$

Nuttall, Merriman and Hindle, 74

Olive, 165

Orton, 91, 285

Osten Sacken, 202

Oudemans, 156

Packard, 4, 87, 88, 109, 170

Paine, 93

Parker, 221

Paris, 306

Parrott, 326

Patton, 173, 174, 175, 177, 178, 179, 180,286

Perez, 106

Peters, 263

Piana, 182

Pickard-Cambridge, 151, 153

Pieter, 304

Pinkus, 169

Portchinsky, 171, 172, 199, 202, 205, $209,305,307$

Porter, 173, 174, 180

Pratt, 93

Prowazek, 173, 174, 175, 177

Quill, 238

Raimbert, 267

Ransom, 181, 182

Réaumur, '2, 98

Reed, 233, 234

Richardson, 168

Pidlon, 243

Riley (C. T.), 154, 155, 209

(WV. A.), 220

Robertson (A.), 282

- (J.), 67, 188

Robineau-Desvoidy, 207

Rogers, 178

Rondani, 305

Rosenbusch, 179

Russell, 308

Salter, 307, 308

Samuelson and Hicks, 4 
Sanders, 71,167

Sandilands, 253

Sangree, 249, 267

Sawtehenko, 273

Sawyer and Herms, 198, 201

Schiner, 6, 116, 190, 193

Schuberg and Boing, 201

Schuberg and Kinhn, 201

Scott, 221

Sellers, '250

Sergent, 307

Seriziat, 286

Shakespeare, 234

Sharp, 193

Shipley, 182, 307

Shutt, 323

Simmonds, 274

Skinner, 85, 221

Slater, 221

Smith (F.), 91, 110, 211, 212, 237, 2s4 - (R. J.), 328

Snell, 253 (T.), 279

Soltan, 304

Spillman and Haushalter, 270

Stallman, 171

Stein, 171

Stephens, 303

Stephenson, 277

Sternberg, 233, 234

Stiles, 300, 309

Stiles and Keister, 300

Stiles and McMiller, 108

Stratton, 239

Strickland, 179

Surcouf, 307

Sydenham, 220

Taschenberg, 4, 87, «४, 99, 190, 193, 209

Taylor, 182, 221, 242
Tebbutt, 228

Terry, 244

Thaxter, 161

Theobald, 91

Thomas and Parsons, 307

Thomson, 250

Tizzoni and Cattani, ㄴ73

Tooth, 236, 237

Torrey, 21!, 246

Townsend, 11, 135

Tsuzuki, 273,274

Tulloch, 34, 199

Tulpuis, 303

Vaney, 145

Varwich, 278

Vaughan, 232, 234

Veeder, 234

Vignon, 138

Walker, 211

Walsh, 196

Wanhill, 238

Washburn, 243, 323, 326

Weismann, 115, 144, 145

Welander, 278

Welch, 216

Wenyon, 173, 174, 177, 1s0, 286

Verner, 178

Wheeler, 170

Wherry, $2 \triangleleft 2$

White, 221

Wilson, 281

Winter, 164

Wright, 285

Yersin, 278

Zepeda, 307

Zetek, 74 


\section{SUBJECT INDEX}

Abdomen, external structure of, 26 nerves of, 34

terminal segments in male; see Gonapophyses

Abundance, in relation to breeding places, 96

Acrina: see Mites

Acarus muscarum, 154, 158

Accesiory glands, female genital, 50 copulatory resicles, 50,98

Air sacs; see Tracheal sacs

Alimentary system of $\mathrm{Hy}, 34$ larva, 132

Allobophora chlorotica, 207

Amoebic dysentery, 284

Ankylostoma caninum, 310, 313, 316 duodenale, 310

Anophcles maculipennis, 145

Antennae, 11

Antennal nerres, 34

Anthomyia radicum, 65, 213, 305 habits and life-history, 214 relation to myiasis, $30^{\circ}, 305,306$

Anthrax, 201, 228, 266; see also $B$. anthracis

bacteriological eridence, 266

ingestion of spores by larvae, 269

Ants, 170,171

Arachnids, 151

Arista, 11 .

Ascaris lumbricoides, 309, 315 megalocephalu, $310,312,315,316$

Arsenical poisons, 323, 328

Asilidae, 171

Aspergillus niger, 288, 290

Atherix, 116;

Atoma (Astoma) parasiticum, 155

Bacillus amylobncter, 289 anthracis, $228,266,2 ! 9$; see Anthrax coli, 240, 245, 249, 289, 290, 29s diphtheriac, 279,299

disenteriue, 228, 284 enteritilis, $222,22 \times, 299$ lactis acidi, 290, 298
Bacillus lactis acrogenes, 298

Morgan's, 228, 2!18

paratyphosus $\mathrm{A}, 225,226,245$

prodigiosus, 222, 22.3, 224, 228, 235, $291,293,299$

pyocyuneus, 223, 224, 227, 290, 298 subtilis, 289, 290

tuberculosis, 270 ; see Tnberculosis

tumescens, 289, 290

typhosus, 224, 225, 227, 228, 229, $240,244,299$; see Typhoid ferer

Bacteria, methods of spread by flies, 221 duration on flies, 299

Bavaria, flies in, 330

Lelascaris mystax, 310

/ Blow tlies, 202; see Calliphora spp.

Bodo muscue-domesticue, 173

Borax, as insecticide, 322

Breeding habits, 87

place, location of, 9:5 treatment of, 318 season, 95

Caeca, mesenteric, of larva, 138

Calliphora erythrocephala, 12, 93, 190 , $228,245,266,269$

comparative abundance, 66,67 life-history, 202, 203, 204, 205 myiasis, relation to, $302,30.1$ vomitoria, $115,162,202,245,266$, 273,282

Carabidae, 170

Centipedes, 158

Cephalic ganglion, 29

Cephalopharyngeal skeleton:

first instar, $10^{\circ}$

second instar, 103

mature larva, 116,134

Cephalopharyngeal muscles, 122

Cercomonas muscae-domesticae, 173

Cercopithecus callitrichus, 190

Cerebral lobes, of larva, 12s, 12,

Chalcidoid parasites, 167

Cheese Maggot $\mathrm{Fly}$; set Piophilu

Chelifers; see chernes 
Chernes nodosus, 151

Chironomus, 116

Chloride of lime; see lime

Cholera, 27:

bacteriological evidence, 273

I. cholerue, $299^{\circ}$

Chyle stomach of fly; see Ventriculus of larva; see Mesenteron

Circular, 331

('ladosporium herbarum, 288, 289

Clavicle, 19

Cluster Fly; see Pollenin

Clypeus, 10, 11

Colour preference, 83

Comma bacillus, 27:)

Conjunctivitis; see Ophthalmia

Copulation, 98

Costa, 21, 22

Coxa, 26

Crithidia gerridis, 179 muscae-domesticae, 178, 179

Crop, 36 function of, 77

Cynipidae, 169

Danysz virus, 294

Dentate sclerite, $\mathbf{1 3 4}$

Dermestid, 170

Description of $M$. domestica, 5, 6, 7

Desiccation, influence on Jarva, 111

Destruction of larvae; see Prevention of Breediny of adult flies, $: 266$

Development, duration of, $10 \mathrm{~s}$ factors governing, 110

Diarrhoea, summer or infantile, 2.52 criticism of bypothesis, 259 causal organisms of, '261 experiment on suppression, 264

Libothriocephalus latus, 309,316

Digestion of food, rate of, 78,81 .

Dinychella asperata, 157

Diphtheria, 279

Dipylidium caninum, 310, 312, 314, 316

Discal sclerites, 17

Disease, dissemination of organisms of, 218

Distribution, 7,8 local, (;);

Dysentery, 284

Earwigs, 171

Educational work, 32.2

Eggs, influence of light on, 101 number, 100 structure, 101

Ejaculatory duct of male, :2, 57 sac of male, 53 apodeme, $\mathbf{5 3}$

Enrergence from pupa, 108

Empusa americana, 162
Empusa muscae, 160 development, 162 practical value, 165

sphuero-spermu, 161

Eutamoeba roli, 300

Enteric fever; see Typhoid

Entomeohthora calliphora, 164, 165

Epicranium, 10

Epischnia canella, 189

Eristalis tena.r, 273, 302

Eurotium, 290, 295

External structure of $\mathrm{fly}, 4$

Eyes, 10, 32

Eye, myiasis of human, 307 infection of human; see Ophthalmia

Facialia, 10

Facio-peristomial sclerites, 10

Faecal spots, 82, 222

Faeces, infection from larvae bred in human, 224, 225, 226, 227

Fannia, 177

canicularis, $11,48,157,177,186$, $195,196,210,213,245,266$ breeding habits, 189

comparative abundance, 65,66 , 67,187

larva, 190

myiasis, relation to, 301, 302 , 303,314

scularis, 186,213

habits of, $1 ! 3$

larva, 195

myiasis, relation to, $301,302,303$

Fat-body of $\mathrm{fly}, 47$

larva, 145

Feeding habits, 74, 311

Femur, 26

Fermentation, effects of. 57, 112

Finites, 169,170

athomyiarum, 170

scutellarius, 170

striolatus, 170

Filaria bancrojti, 185

muscale; see Habronemu

stomoxeos, 181

Flagellum, 11

Flight of thies, range of, 67

Food, influence on larvae, 111

Formuldehyde as poison, 327, 328, 329

Frambosia tropica. 280

Frons, 10

Frontalia, 11

Frontal strije, 10, 11

Fronto-orbital bristles, 11

Fulerim, 17

detractor muscles of, 5!)

Fungal spores, tlies carrying, 288, 289, 290,295

Furca, 14

Fusarium roseum, 289, 290 
Gamasid mites, 156, 157, 210

Ganglion of larva, 127

Garbage, species of tlies breeding in, 93

Genae, 10

Generations, number of, 113

Gerris fossurum, 179

Glosina, 5, 34

Gonapophyses of male, 53

Gonococci, 271, 278

Gonorrhoeal disease, 277

Gulo-mental plate, 10

Gustatory papillae, 17, 62 bristles, 61

Habronema microstoma, 180 muscae, 181

life-history, 184

occurrence, 183

Haematobia serrata, 169 stimulans, 266

Halteres, 25

Hatching of larva, 101

Haustellum, 12, 14 inuscles of, 59,60

Head capsule, 9 internal structure of, 58

Heart of $\mathrm{fly}, 47$ of larva, 143

Herpetomonas jaculum, 174 lygaei, 174 muscae-domesticae, 173

Hibernation of flies, $8 \mathbf{i}$ pupae, 107

Histogenesis, $106^{\circ}$

Homalomyia; see Fanniu

Humeri, 20

Hymenolepis diminuta, 310, 313, 315, 316

Hypoderma bovis, 307

Hypopharynx, 14

Hypostomal sclerite, 135

Imaginal dises, 145

cephalic, 147

thoracic, 148

Infantile paralysis; see Poliomyelitis

Infected larrae, infection from, 224,225 , $226,227,228$

Infection, natural, of flies, 288,296

Insecticides for larvae, 319,320 adult flies, 327

Interclavicle, 18

Intestinal worms, spread of, by flies, 308

Intestine of $\mathrm{fly}, 38$ larva. 139

Iron sulphate, as insecticide, 322

Jowl, 10

Jugulares, 19

Jugum, 9
Kainit, as insecticide, 3220

Kala-azar, 17x, 20s7

Kerosene, as insecticile, 319, 321

Koch.Weeks bacillus, 276

Labial nerves, 31

Labium, 14

Labium-hypopharynx, 14, 15 muscles of, 60

Labrum-cpipharyux, 14 muscles of, 60,61

Lamblia duodenalis, 300

Lapleria canis, 171

Larva, 102

first stage, 102

second stage, 103

mature, 103

external features, 114

muscular system, 120

nervous system, 127

Latrine fly; see Fannia scalaris

Legs, 26

Leishmania tropica, 286

Leprosy, 282

Leptomonas muscne-domesticae, 177, 179, 180

Light, influence on flics, 83 larvae, 105

Lime, as insecticide, 319, 321

chloride of, $319,320,321,32 \cdot 2$

Locomotion of larvae, 127

Locomotory pads of larva, 11 s

Longevity. 86

Lucilia, 93, 302, 304

caesur, 162, 204, 266, 282

nobilis, 205

Lnnule, 11

Lyperosia irritans, 266

Hacrocheles muscae, 157

Macrosporium, 289

Malpighian tubes of $\mathrm{fly}, 40$ larva, 138, 139

Mandibular sclerite, 134

Muntis, 171

Manure, disposal of, 31s, 319

loss in storage, 323

Marking flies, 68, 69, 71

Maxillae, 12

Melanostomum scalare, $16 \mathrm{l}$

Melophagus orimus, 127

Mesenteron of larva, 138

IIesosternum, 22

Mesothorax, 20

Metafurca, 22

Netasternum, 220

Netathorax, 22

Micrococeus pyogenes aureus, 289, 290 ureue, 289,290

Migratory habit of larvae, 107, 308

Milk, infection of, by flies, $24 \cdot 2, \cdot 293,297$ 
Mites, 154

Moniezir expansa, 310

Moth Hies; see Psychoda

Houth of tiy ; see Oral aperture larva, 133

Hucor racemosa, 290, 295

Musca domestica, sub. sp. determinata, 211

enteriate, 212

neluula, 287

retustissima, 212, 213

Muscidifurax, 167 raptor, 168

Muscima stubulans, 157, 158, 190, 207 destroying 1 . domestica, 171,172 habits and life-history, 208 nyiasis, relation to, 305

Muscular system of $\mathrm{fly}, 28$ larva, 120

Museum models, 333, 334

Iyiasis, 301 mode of infection, 3116

Myrmica levinodis, 64

Nasonia, 167 brericormis, 167,168

Necator americanus, 309, 310, 316

Newatode parasite, 181

Nervous system of fly, 29 visceral, 37

larva, 127 visceral, 131

Nemroblast; see Ganglion

Nuisances and flies, 211, 242

Numbers in breeding places; see Abundance

Nymph, 105

Occipital foramen, 9 ring, 9,10

Ocellar nerve, 31 triangle, 10

Ocelli, 10

Oesophagus of $\mathrm{ty}, 36$ larva, 136

Olfactory pits, 11

Ophthalmia, 275 in children, 275

Oral aperture of $\mathrm{Hy}, 17$ lobes of tiy, external structure of, 15 internal structure of, 61 larva, 116

Organised control measures, 330

Oriental Sole, $2 \times 5$

Oscinis pallipes. 282

Ottawa Hight experiments, 71

Ovaries, 48

Oviduets, 48

Oviposition, y!

Ovipositor, 50

Oxyuris rermicularis, 310,316
Pachycrepoideus dubius, 168

Parafin oil; see Kerosene

Parapteron, 21, 2*2

Parasitic insects, 167 protozoa, 173

Penicillium claucum, 288, 289, 290, 295

l'enis, 53, 55, 56

Pericardium of $\mathrm{fly}, 18$ larva, 144

Peridromia sancia, 208

Petroleum, as insecticide, 321

Phalacrocera, 136

Pharyugeal nerve, 31 pump of $\mathrm{Hy}_{2}, 77$ sclerites, 135

Pharynx of $\mathrm{fly}, 36$ dilator museles of, 58 larva, 126,136 muscles of, 121

Phlebotomens, 216

Pigmeophorus, $\mathbf{1 5 6}$

Piophila casci, 21fi, 302, 30:

Plague, ‘278

Poisonerl baits, 328, 329

Poisoning tlies, 327, 320

Poliomyelitis, 195, 2983

Pollenia malis, 206, 207

P'ostscutellum, 20

Postwick experiments on Hight, 68

Predaceous insects, 170

Preoviposition period; see Sexual ma. turity

Prescutum, 20

Prevention of breeding, 317

Preventive measures, 317

Privy, danger of, 323

Proboscis, intlation of, 63 musculature of, 58 skeleton of, 12

Procerebrum, 31

Prosternum, 18

Protection of infants and sick, 325 food, 325

Prothorax, 18

Protocalliphow aroenlandicu, 205, 206 azurea, 205

Protozoa, intestinal, carried by flies, 300

Proventriculus of $\mathrm{fly}, 36$ larva, 137

Pseudocephalon, 116

Pseudoscorpionidea: see Chernes

Psendotracheae, 15, 16, 61 interbifil spaces of, 16

Psychoda spp., 216 albimaculuta, 216 punctatu, 145

Ptilinum, 11, 108

l'ulvilli, 26

Pupa, 105

l'upation, 105, 107 deptli of, 1118 
Pycrosoma chloropyga, 2237

Pyrethrum, 324

liabies, 29;

liectul valve, 30 glands, $: 39,41$

lieetum of $\mathrm{Hy}, 39$ larva, 140

liefuse heaps und tlies, 241, 324

liegeneration of lont parts, 86

liegurgitating habit, 78,80

lieproductive system of female, 48 male, 52

Respiratory system of $\mathrm{Hy}, 41$ larva, 140

Robber Flies; see Asilulae

lioot Maggot Fly: sce Anthomyin radi. cum

liostrum, 12

Saccharomyces, 288,290

Salivary glands of $\mathrm{fl} y$, lingual, 29 iabial, 63 larvu, 139,150

ducts of larva, 135, 139

Sialticus scenicus, $\mathbf{1 5 9}$

Sarcina lutea, 289, 290 ventriculi, 290

Surcophaga carnaria, 216, 302, 304

Seape, 11

Scatophaga, 177

Scenopinus, 217

Schistosomum haematobium, 310 juponicum, 310

Sciara, 165

Sclerostomum equinum, 310, 316

Seutellun, 20

Scutigera coleoptera, 158 forceps, ] smithix, 1 is

Seutum, 20

Seasonal prevalence, 67

Seusory organs of larva, 132

Sexes, distinction, 11 proportion of, $4 \varangle, 98$

Sexual maturity; 112

Sheep maggot; see Lucilia caesar

Simulium, 116

Small-pox, 279

Sodium arsenite, as insecticide, 323,328

Spalungia, 167 muscidarum, 168, 169

Solenopsis geminata, 170

Spermathecae, 49

Spiders, $15 !$

Spiracles of tiy, abdominal, 27, 47 thoracic, 20, 21, 41, 46 larra, 140 pupa, 105

Spirochueta pertenuis, 281

Stable Fly; see Stomoxys calcitrans
Staphylinidae, 170

Sitrpliylocoecus, 290, 291, 29k

Sitomorys: calcitrans, 5, 11, 34, s0, 107, $168,169,181,245,266,2 \times 6,29 \cdot 1$

comparutive abundance, (ji), (ifi, 197

life-history and habits, 19y

pharyngeal pump, 77

relation to disease, 201

Strutiomys, 116

Streptocucci, 201, 246, 298

Suboesophagreal ganglia, 31

Sirmner diarrhoea; see Diarlioea

Supraoesophageal ganglia, 29

Surra, 294

Syphilis, 287

Sympathetic nervous system of $\mathrm{tly}, 37$

Syrphids, Empuse on, 161

Taenia marginata, $310,312,314,316$ serratu, $310,312,314,315,316$ solium, 309, 316

Tapeworms, thies feeding on, 311 eggs, ingestion of, 75,308

Tarsus, 26

lemperature, influence on eggs, 101 Hies, 83. 260

larvae, 97, 110

Testes, 52

Theea, 14

Thereva, 302

Thoracic ganglion, 32 nerves, 33

Thorax, 18

Tibia, 26

Toxascuris limbuta, 310, 31:2, 313, 315 , 316

Tracheal sacs, of abdomen, 42 head, 44

thorax, 42

system; see liespiratory system

trunks, of larva, 140,142

Trap, Minnesota Fly, 326

Trapping flies, 326,327

Trichocephalus, 309

Tricholoma, 182

Trichomonas intestinalis, 300

Trichuris trichiuris, $310,313,316$

Trochanter, '26

Trombidium muscae, 156, 15x purasiticum, 154, 15.5, 156

Trox suberosus, 170

T'rypanosoma hippicum, 294

Tuberculosis, 269

experimental evidence, 270

Typhoid "carriers," 229, 230, 231

Typhoid fever, earriage by tlies, 22?

in cities and towns, 232, 239, 240, $241,242,243,244$

in military camps, 232, 233, 234, $235,237,235$

in military stations, 238, 239 
Typhoid fever in South African War, 236,237

in Spanish American War, 232, 234, 235

bacteriological evidence, 244

T'yroglyphus, 126

Ungues, 26

Vagina, 49

Vascular system of $\mathrm{fly}, 47$ larva, 143

Vas deferens, 52

Ventriculus of $11 \mathbf{y}, 37$ larva; see Mesenteron

Vertebrate enemies, 172
Vertex, 10

Vesiculae seminales; see Spermathecae

Tespa sp., 171

Volucella, 149

Vomit spots, 80,222

Wasps, 171

Wild tlies, infection of ; see Infection of flies

Wings, 23

Winter, flies breeding in; see Breeding season

Xylina, 189

Yaws, 280 


\section{CAMBRIDGE MANUALS SERIES}

Cloth, 1 s. net each; leather, $2 s$. 6d. net each

Among the volumes already published are the following:

House-Flies and How They Spread Disease. By (i. (i. HewitT.

"Dr Hewitt's little volmme is especially comprehensive and well arranged. The book contains a bibliograply and is sufticiently indexed and illustrated, making altogether, perhaps, as good a manual on the subject as could at the present state of our knowleige lue producer in similar compass." - Times

The Life-Story of Insects. By Prof. G. H. Carpexter.

Bees and Wasps. By O. H. JATTER, II.A., F.E.S.

Spiders. By Cecll Warbertor, M.A.

The Flea. By H. Russelt.

Earthworms and their Allies. By F. E. BEDDARD, M.A., F.R.S.

Life in the Sea. By James Johistone, D.Sc.

A list of the eighty-sir volumes now ready will be serit on application.

The Vertebrate Skeleton. By s. H. Rervolis, I.A., Professor of Geology in the University of Bristol. Second edition. Demy 8ro, 15s. net. Cambridge Zoological series.

Observations upon the Natural History of Epidemic Diarrhoea. By O. H. PETERs, M.D., D.P.H. J Jarge Royal 8vo. With 38 talles and 9 eharts. $7 s$. net.

The Journal of Hygiene. Elited by G. H. F. Nutrald, M.D., Pf..D., Sc.D., F.K.S., in conjunction with J. S. HaLdaxe, M.D.,

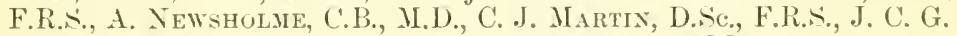
Ledrghas, M.B., D.Sc., and G. S. GrahaM-Simtr, M.D.

The Jourual is issued as material accumulates. A volume contaning about 500 pages, with plates and figures, is issued annually. The subscription price is ftl. 1s. net per volume (post free), payable in advance; single numbers, is. net,

Parasitology. Edited by G. H. F. NuTtall, F.R.S., and A. E. Shiplet, F.R.S.

Parusitology is published about four times a year. A rolune containing about 400 to 500 pages, with plates and figures, is issued annually. The subscription price is $\$ 1,10$ s. net per volume (post free), parable in adrance; single numbers, 10s, net. Subscribers to the .loumul of Hygiene may ol,tain single numbers of Purusitology at the reduced rate of is. tid. net, or may' become subscribers at the rednced rate of $\$ 1.1 s$.

Cambridge University Press

C. F. Clay, Manager: Fetter Lane, London 


\section{G. S. GRAHAN-SMITH, M.D., AND J. E. PURVIS, M.A.}

Flies in Relation to Disease. Non-Bloodsucking Flies. By G. S. GRAнам-SмIтн, M.D., Lecturer in Hygiene in the University of Cimbridge. Demy 8ro. Second edition, revised and enlarged. With 27 plates, 32 text-figures and 20 charts. $12 s .6 d$. net.

"The fact that the look is published at the Cambridge University Press is sufficient gmarantee of the excellence of the printing and binding.... We can only say that if the other volumes of this series...are as good as this one, a very high standard of excellence will have to be maintained. We consider tbat no one in the Public Health Service should be without this book." - Medical Times on the first edition

"This is just the book for students who either are, or are to be, occupied with questions of public health; it is careful, well-digested, precise and clear. Dr Graham-Smith has practical knowledge of the things that he writes abont, having already published numerous experinents on the transmission of bacteria by ties. His book is treely illustrated by excellent plates and text-tigures by Mr Edwin Wilson... We hope to see the facts deeply impressed on the public mind."-Nature on the first elition

Isolation Hospitals. By H. Franklin Parsons, II.D., D.P.H., formerly First Assistant Medical Officer of the Local (iovernment Board. Deiny 8ro. With 55 text-figures. 12s. 6d. net.

"Ewinently practical in character, it is at the same time complete in its information, so that the medical otficer may rely with confidence on finding accurate and impartial facts on matters connected with the isolation of infectious cases.... The volume should appeal very strongly to all medical officers of health, tubercnlosis ofticers, and sanitary anthorities, to whom it can be recommended with all heartiness." - Aberdeen Free Press

\section{The Bacteriological Examination of Food and Water.}

By Whlual G. SAvage, B.Se., M.D., D.P.H., County Medical Othicer of Health, Somerset. Demy 8vo. With 16 illustrations. $78.6 d$, net.

"A hearty" welcome will be accorded this compact guide, not only because it is eminently practical in its methods and directions, but also because it has beeu written by a man who has been accustomed to lo the work himself and to depend upon it as a basis for administrative action.... To all engaged in the administration of the public health...the book may be cordially commended."-Birmingham I)aily Post

\section{The Chemical Examination of Water, Sewage, Foods} and other substances. By J. E. Purvis, M.A., and T. R. Hodgson, II.A. Deny 8ro. 9s. net.

A prospectus of the series, giving a list of volumes in preparation. will be sent on application.

\section{Cambridge University Press}

C. F. Clay, Manager: Fetter Lane, London 




\section{PLEASE DO NOT REMOVE CARDS OR SLIPS FROM THIS POCKET}

\section{UNIVERSITY OF TORONTO LIBRARY}

QL

537

M7H6
Hewitt, Charles Gordon The house-fly, Musca domestica Linn

BioMed 
